\title{
IDA FORTINI
}

Neuropatias periféricas e alterações neuropsiquiátricas em pacientes portadores do vírus da Hepatite C: estudo observacional, caso-controle, retrospectivo e prospectivo

Tese apresentada à Faculdade de Medicina da Universidade de São Paulo para obtenção do título de Doutor em Ciências

Programa de Neurologia

Orientador: Prof. Dr. Ricardo Nitrini

(Versão corrigida. Resolução CoPGr 6018/11, de 13 de outubro de 2011. A versão original está disponível na Biblioteca da FMUSP)

São Paulo 


\section{Dados Internacionais de Catalogação na Publicação (CIP)}

Preparada pela Biblioteca da

Faculdade de Medicina da Universidade de São Paulo

Creprodução autorizada pelo autor

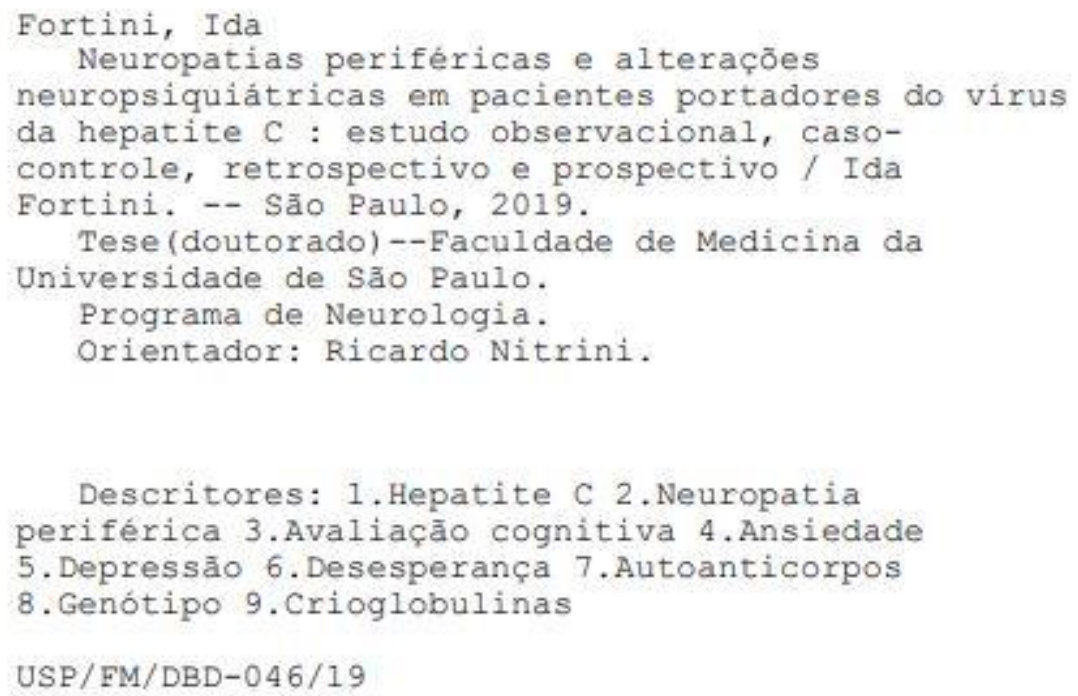

Responsável: Erinalva da Conceição Batista, CRB-8 6755 
Dedico este trabalho aos meus pais, Lidia e Ennio, que não mediram esforços para que eu pudesse ter oportunidades às quais eles não tiveram acesso, que me amaram, incentivaram e apoiaram incondicionalmente 


\section{Agradecimentos}

Ao meu orientador, Prof. Dr. Ricardo Nitrini que me estimulou e esteve sempre disposto a compartilhar seus conhecimentos e seu entusiasmo pelo trabalho científico, além de me honrar com sua amizade.

À Prof. Dra Fatima Mitiko Tengan, a verdadeira iniciadora deste projeto, minha amiga e colega de turma, por sua ajuda, colaboração, consideração e amizade.

Ao meu queridíssimo amigo de tantos anos Dr. Eustáquio Martins Gomes Arouca, neurologista e psicólogo, para o qual serei eternamente grata por toda ajuda na aplicação dos testes e inventários, companheirismo e incentivo.

À Caroline Manchiero, por sua generosidade em auxiliar o desenvolvimento do estudo, coleta de dados e amostras.

À Cleonice Bueno do Laboratório de Imunologia Humoral da Disciplina de Reumatologia da FMUSP, pela disposição de realizar a dosagem de crioglobulinas dos pacientes. 
À minha irmã, Giovana Fortini, que nunca mediu esforços para me auxiliar na compilação dos dados e resultados dos exames laboratoriais, revisão ortográfica e formatação.

Às funcionárias do Ambulatório de Moléstias Infecciosas do HC FMUSP, enfermeiras e auxiliares de enfermagem que me receberam com muita paciência e boa vontade, sempre prontas a me auxiliar.

À Alair Mariano, sempre disposta a me ajudar com a pesquisa bibliográfica e elaboração do trabalho.

Aos Professores Doutores Eduardo Genaro Mutarelli, Luis Henrique Martins Castro e Fatima Mitiko Tengan que participaram do exame de qualificação deste trabalho e que generosamente fizeram correções e preciosas sugestões.

À Thais Figueira, que se dispôs sempre a me orientar quanto ao andamento da pós-graduação, e que o fez com muita consideração.

Aos estatísticos José Demario e Regina Baratho pela colaboração na análise estatística dos dados e paciência em tentar sanar minhas dúvidas.

Aos meus companheiros de enfermaria Dra Márcia Rúbia Rodrigues Gonçalves e Prof. Dr. Luis Henrique Martins Castro, por sua compreensão e amizade, relevando minhas ausências para que eu pudesse finalizar este trabalho.

À minha família por me nutrir com seu amor e carinho. 
Aos pacientes, seus parentes e aos participantes do estudo, minha gratidão maior. 


\section{Normatização Adotada}

Esta tese está de acordo com as seguintes normas, em vigor no momento desta publicação:

Referências: adaptado de International Committee of Medical Journals Editors (ABNT).

Universidade de São Paulo. Faculdade de Medicina. Divisão de Biblioteca e Documentação. Guia de apresentação de dissertações, teses e monografias. Elaborado por Anneliese Carneiro da Cunha, Maria Julia de A. L. Freddi, Maria F. Crestana, Marinalva de Souza Aragão, Suely Campos Cardoso, Valéria Vilhena. 3a ed. São Paulo: Divisão de Biblioteca e Documentação; 2011.

Abreviaturas dos títulos dos periódicos de acordo com List of Journals Indexed in Index Medicus. 


\section{Sumário}

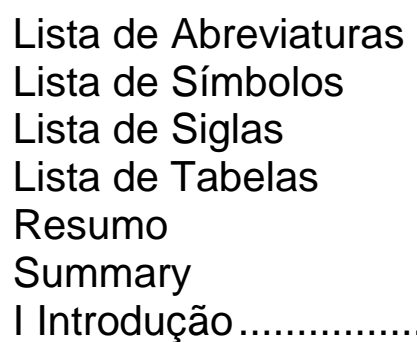

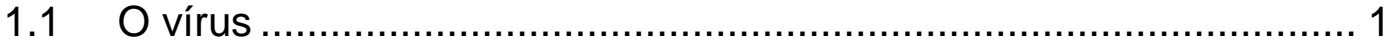

1.2 Dados epidemiológicos.............................................................. 4

1.3 Transmissão e Replicação viral .................................................. 7

1.4 Manifestações extra-hepáticas .................................................. 11

1.4.1 Crioglobulinemia............................................................ 15

1.4.2 Neuropatia Periférica......................................................... 19

1.4.3 Manifestações neuropsiquiátricas ......................................... 23

1.5 Instrumentos para avaliação da cognição ..................................... 30

1.5.1 Miniexame do Estado Mental .............................................. 30

1.5.2 Testes para avaliação de funções executivas ............................ 31

1.5.2.1 Teste do Desenho do Relógio .............................................. 32

1.5.2.2 Teste de Fluência Verbal..................................................... 34

1.5.2.3 Teste dos Dígitos em Ordem Direta e Indireta ....................... 35

1.5.3 Correlações entre o Miniexame do Estado Mental e o Teste do Desenho do Relógio .................................................................. 36

1.6 Avaliação de sintomas depressivos, ansiosos e de desesperança .... 37

1.6.1 Inventário de Depressão de Beck ...................................... 37

1.6.2 Inventário de Ansiedade de Beck .......................................... 38

1.6.3 Escala de Desesperança de Beck....................................... 38

1.7 Revisão da literatura......................................................... 39

1.7.1 Neuropatias periféricas nos pacientes com infecção crônica por HCV .................................................................................. 39

1.7.2 Alterações neuropsiquiátricas nos pacientes com hepatite $\mathrm{C}$

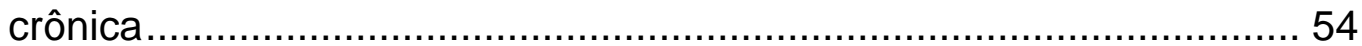

II Justificativa e Objetivos ............................................................ 85

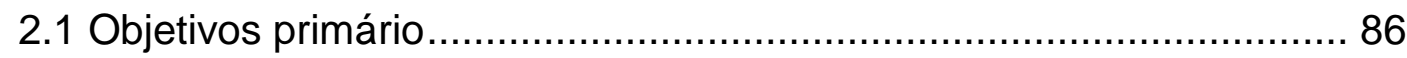




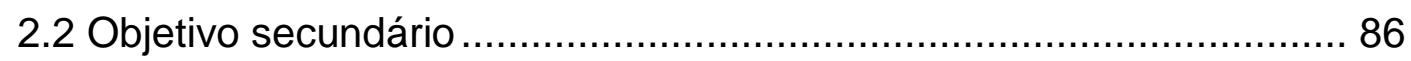

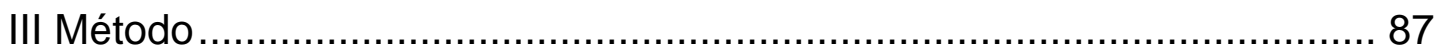

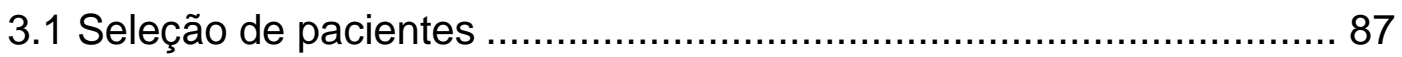

3.2 Seleção do grupo controle ................................................... 87

3.3 Avaliações e testes realizados pelos pacientes............................ 88

3.3.1 Miniexame do estado mental ........................................... 88

3.3.2 Teste do desenho do relógio ............................................... 89

3.3.3 Teste de fluência verbal na categoria semântica...................... 89

3.3.4 Teste dos dígitos ............................................................ 89

3.3.5 Inventário de Depressão de Beck, Inventário de Ansiedade de Beck,

Escala de Desesperança de Beck............................................. 90

3.4 Exames laboratoriais realizados pelos pacientes .......................... 90

3.5 Avaliações e testes realizados pelos indivíduos do grupo controle .... 91

3.6 Exames laboratoriais realizados pelos participantes do grupo controle 92

3.7 Metodologia de Análise de dados ............................................... 92

3.8 Desfecho primário............................................................ 93

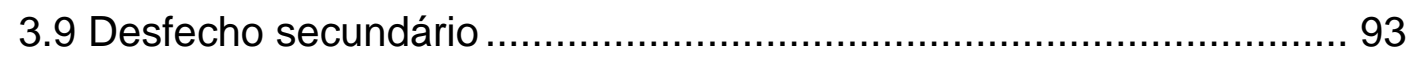

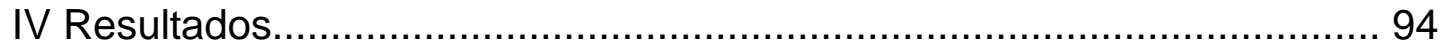

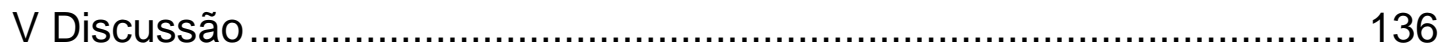

5.1 Comprometimento do sistema nervoso periférico........................... 136

5.1.1 Relação de neuropatia periférica e alterações do metabolismo da glicose nos pacientes com hepatite C ............................................ 146

5.1.2 Relação de neuropatias periféricas e presença de crioglobulinemia

5.1 .3 Autoanticorpos........................................................... 156

5.2 Alterações neuropsiquiátricas nos pacientes com hepatite C........... 166

5.2 .1 Depressão ............................................................... 166

5.2.2 Alterações de funções cognitivas ..................................... 171

VI Conclusões ........................................................................ 192

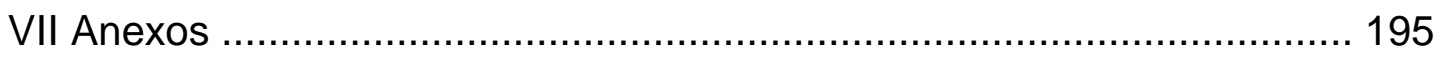

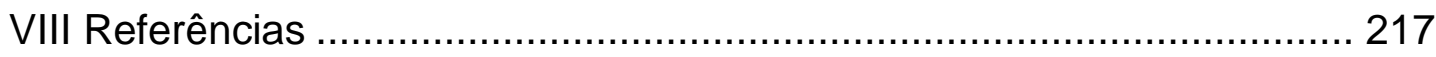




\section{Lista de Abreviaturas}

$\begin{array}{ll}\text { ALT } & \text { alanina aminotransferase } \\ \text { Anti-HCV } & \text { anticorpos anti-vírus da Hepatite C } \\ \text { AVC } & \text { acidente vascular cerebral } \\ \text { BAI } & \text { inventário de ansiedade de Beck } \\ \text { BDI } & \text { inventário de depressão de Beck } \\ \text { BHS } & \text { escala de desesperança de Beck } \\ \text { CGs } & \text { crioglobulinas } \\ \text { CM } & \text { Crioglobulinemia } \\ \text { Colab. } & \text { colaborador(es) } \\ \text { Díg OD } & \text { dígitos em ordem direta } \\ \text { Díg OI } & \text { dígitos em ordem inversa } \\ \text { DM } & \text { diabetes melito } \\ \text { ed. } & \text { Edição } \\ \text { EH } & \text { encefalopatia hepática } \\ \text { EHM } & \text { encefalopatia hepática mínima } \\ \text { EPEH } & \text { escala psicométrica de encefalopatia hepática } \\ \text { ENMG } & \text { eletroneuromiografia } \\ \text { ERM-1H } & \text { espectroscopia por ressonância magnética de próton único } \\ \text { et al. } & \text { e outros } \\ \text { FV } & \text { fluência verbal } \\ \text { FR } & \text { fator reumatoide } \\ \text { HBV } & \text { vírus da hepatite B } \\ \text { HCV } & \text { vírus da Hepatite C } \\ \text { HIV } & \text { vírus da imunodeficiência humana adquirida } \\ \text { HOMA } & \text { homeostasis method assessment } \\ \text { ICs } & \text { imunecomplexos } \\ \text { Ig } & \text { Imunoglobulina } \\ \text { IG } & \text { intolerância à glicose } \\ \text { IFN-a } & \text { interferon alfa } \\ \text { IL } & \text { interleucina } \\ \text { IMC } & \text { índice de massa corporal } \\ \text { LCR } & \text { líquido cefalorraquidiano } \\ \text { MEEM } & \text { Miniexame do estado mental } \\ \text { MNM } & \text { mononeuropatia múltipla } \\ \text { MN } & \text { mononeuropatia } \\ \text { NAA } & \text { n-acetil aspartato } \\ \text { NMO } & \text { neuromielite óptica } \\ \text { NP } & \text { neuropatia periférica } \\ \text { PAN } & \text { poliarterite nodosa } \\ \text { PERD } & \text { potenciais evocados relacionados à dor } \\ & \end{array}$




$\begin{array}{ll}\text { PNP } & \text { polineuropatia periférica } \\ \text { QVRS } & \text { qualidade de vida relacionada à saúde } \\ \text { RM } & \text { ressonância magnética } \\ \text { RNA-HCV } & \text { ácido ribonucleico do vírus da hepatite C } \\ \text { RVS } & \text { resposta virológica sustentada } \\ \text { SF-36 } & \text { short form } 36 \text { (avaliação de qualidade de vida) } \\ \text { SNC } & \text { sistema nervoso central } \\ \text { SNP } & \text { sistema nervoso periférico } \\ \text { STC } & \text { síndrome do túnel do carpo } \\ \text { TDR } & \text { teste do desenho do relógio } \\ \text { VS } & \text { versus }\end{array}$




\section{Lista de Símbolos}

$$
\begin{array}{ll}
> & \text { maior que } \\
< & \text { menor que } \\
= & \text { igual a } \\
\% & \text { por cento } \\
\geq & \text { maior ou igual } \\
\leq & \text { menor ou igual }
\end{array}
$$




\section{Lista de Siglas}

$\begin{array}{ll}\text { FMUSP } & \text { Faculdade de Medicina da Universidade de São Paulo } \\ \text { HC FMUSP } & \text { Hospital das Clínicas da Faculdade de Medicina da USP } \\ \text { OMS } & \text { Organização Mundial da Saúde } \\ \text { METAVIR } & \begin{array}{l}\text { Sistema METAVIR de avaliação de fibrose e inflamação } \\ \text { hepática }\end{array} \\ \text { SINAN } & \text { Sistema de Informação de Agravos de Notificação } \\ \text { SBP } & \text { Sociedade Brasileira de Patologia } \\ \text { USP } & \text { Universidade de São Paulo }\end{array}$




\section{Lista de Tabelas}

Tabela 1 Características demográficas dos participantes do estudo.

Tabela 2 Distribuição dos grupos por gênero e faixas de idade.

Tabela 3 Graus de Fibrose e inflamação hepática dos pacientes com hepatite $\mathrm{C}$ e genótipos virais.

Tabela 4 História de etilismo e uso de drogas dos pacientes com hepatite $\mathrm{C}$

Tabela $5 \quad$ Neuropatias periféricas nos pacientes com hepatite $\mathrm{C}$, crioglobulinas, metabolismo da glicose e genótipos

Tabela $6 \quad$ Neuropatias periféricas no grupo controle

Tabela 7 Neuropatias agrupadas no grupo dos pacientes e grupo controle.

Tabela 8 Comparação de pacientes e controles com NP em relação à presença de DM franco.

Tabela 9 Metabolismo da glicose, crioglobulinemia e genótipos HCV.

Tabela 10 Autoanticorpos nos pacientes com hepatite C.........

Tabela 11 Gamaglobulinas, frações do complemento, FANHEp2, FR e crioglobulinas nos pacientes com hepatite $\mathrm{C}$

Tabela 12 Autoanticorpos nos pacientes com hepatite $\mathrm{C}$, com e sem neuropatias periféricas.

Tabela 13 Gamaglobulinas, complemento, FAN-HEP2, FR e crioglobulinas nos pacientes com hepatite $C$, com e sem neuropatias periféricas. 
Tabela 14 Comparações entre as médias obtidas pelos participantes do estudo nos testes para avaliação de funções cognitivas.

Tabela 15 Escore obtidos por pacientes e controles no Miniexame do Estado Mental

Tabela 16 Subtestes do Miniexame do Estado Mental comparação entre pacientes e controles

Tabela 17 Fluência Verbal Semântica de pacientes e controles (categoria animais)

Tabela 18 Sujeitos com Fluência Verbal aquém da esperada para o grau de escolaridade.

Tabela 19 Pontuação de pacientes e controles no Teste do Desenho do Relógio (critérios Sunderland)

Tabela 20 Desempenho de pacientes e controles no Teste do Desenho do Relógio - critérios de Sunderland.....

Tabela 21 Pontuação no teste do Desenho do Relógio - critérios de Shulman.

Tabela 22 Teste dos dígitos em ordem direta e indireta de pacientes e participantes do grupo controle.

Tabela 23 Sujeitos com baixo desempenho nos testes dos dígitos em ordem direta e indireta.

Tabela 24 Comparação das médias obtidas pelos participantes do estudo no Inventário de Beck para Depressão, Ansiedade e Desesperança

Tabela 25 Graus de Depressão, Ansiedade e Desesperança dos pacientes e controles, segundo Beck.

Tabela 26 Depressão, Ansiedade e desesperança reestratificados

Tabela 27 Correlações positivas encontradas no grupo de 152 sujeitos.

Tabela 28 Correlações negativas encontradas no grupo de 152 sujeitos. 
Tabela 29 Correlações positivas entre as variáveis estudadas encontradas no grupo dos pacientes.

Tabela 30 Correlações negativas entre as variáveis estudadas encontradas no grupo dos pacientes.

Tabela 31 Correlações de Spearman - variáveis laboratoriais dos pacientes

Tabela 32 Correlações positivas entre as variáveis encontradas no grupo controle.

Tabela 33 Correlações negativas entre as variáveis encontradas no grupo controle. 


\section{Resumo}

Fortini I. Neuropatias periféricas e alterações neuropsiquiátricas em pacientes portadores do vírus da hepatite C: estudo observacional, caso-controle, retrospectivo e prospectivo [tese]. São Paulo: Faculdade de Medicina, Universidade de São Paulo, 2019.

Introdução: A infecção crônica pelo vírus da hepatite C (HCV) é considerada uma doença sistêmica com numerosas manifestações extra-hepáticas. Comprometimento do sistema nervoso periférico e alterações neuropsiquiátricas são relatadas em algumas séries, com certa heterogeneidade entre elas. Embora alterações cognitivas tenham sido descritas, alguns estudos não comprovaram esta associação. Poucos estudos sobre o tema foram realizados no Brasil. Objetivo: estudar alterações do sistema nervoso periférico e alterações neuropsiquiátricas nos pacientes com infecção pelo HCV e verificar se têm relação com genótipo viral, grau de fibrose hepática e presença de autoanticorpos. Método: 76 pacientes adultos (40 mulheres) com 18 anos ou mais de idade portadores de infecção crônica por HCV, virgens de tratamento, sem sinais de encefalopatia hepática franca, não portadores do vírus da Hepatite B (HBV), vírus da imunodeficiência adquirida (HIV) ou sífilis foram avaliados no período de agosto de 2009 a fevereiro de 2016 e comparados com grupo controle composto por 76 indivíduos não portadores de HCV, HBV, HIV ou sífilis (43 mulheres) com distribuição semelhante quanto ao gênero, faixas etárias e graus de escolaridade. Pacientes e controles foram submetidos a avaliação clínica, avaliação cognitiva breve [Miniexame do Estado Mental (MEEM), teste do desenho do relógio (TDR), teste de fluência verbal (FV) semântica, teste dos dígitos em ordem direta e indireta (WAIS-III)] e avaliação do humor, ansiedade e desesperança (Inventário de Beck). Os pacientes com hepatite C foram submetidos a extensa bateria de exames laboratoriais, determinação do genótipo, dosagem de insulina, gamaglobulinas, crioglobulinas (CGs), fator reumatoide (FR), frações do complemento e pesquisa de autoanticorpos. Resultados de biópsias hepáticas realizadas em menos de 18 meses da avaliação inicial no estudo foram considerados para análise. Além de exames para inclusão no estudo, os controles foram submetidos a avaliação laboratorial. O programa SPSS 20 (Statistical Package for the Social Sciences) foi utilizado para análise estatística. Resultados: Neuropatias periféricas (NP) foram encontradas em 29 pacientes $(38,1 \%)$ e 14 controles $(18,3 \%)[p=0,007]$. Dos pacientes portadores de HCV com NP, $12(41,4 \%)$ apresentavam mononeuropatias (MN) ou mononeuropatias múltiplas (MNM), 
$7(24,1 \%)$ polineuropatias (PNP) sensitivas ou sensitivomotoras, $5(17,2 \%)$ PNP com MN ou MNM sobrepostas, $4(13,8 \%)$ radiculopatias e $1(3,4 \%)$ neuropatia motora pura (1/29). Dos 14 portadores de NP no grupo controle, 8 $(57,1 \%)$ apresentavam neuropatia uni ou bilateral do nervo mediano, 4 $(28,6 \%)$ radiculopatias e $3(21,4 \%)$ PNP. Parestesias/dores neuropáticas nos membros sem sinais objetivos de NP foram relatadas por $26,3 \%$ dos pacientes e por $7,9 \%$ dos controles $(p<0,0001)$. Não houve diferença significativa na prevalência de diabetes melito (DM) entre pacientes e controles $(6,6 \%$ vs $9,2 \%)$. Dezessete pacientes $(22,4 \%)$ tinham intolerância à glicose. CGs foram detectadas no soro de $9,2 \%(6 / 65)$ dos pacientes e foram positivas no soro de $13,8 \%$ dos pacientes portadores de HCV com NP. Teor aumentado de gamaglobulinas séricas foi encontrado em 46,2\% (30/64) dos pacientes, positividade do FR em 26,7\% (16/60), níveis baixos de C4 em 19,3\% (16/60), anticorpos (AC) antimúsculo liso em 26,2\% (18/65), AC antitireoperoxidade em 22,9\% (8/35) e AC anticardiolipinas IgM em 20,7\% (12/58). Houve diferença estatística significativa entre pacientes com hepatite $C$ com e sem $\mathrm{NP}$ em relação à presença de $\mathrm{AC}$ anti-SSA/RO e antitirosina fosfatase $(p=0,028$ e $p=0,038$, respectivamente). Nos pacientes com hepatite $C, N P$ se correlacionou com idade $(p<0,05)$, grau de fibrose à biópsia hepática $(p<0,05)$ e alteração do metabolismo da glicose $(p<0,05)$ e no grupo controle com o diagnóstico de DM $(p<0,01)$. Não foram verificadas diferenças estatísticas significativas entre pacientes e controles em relação aos escores totais no MEEM, FV semântica, TDR e testes dos dígitos em ordem direta e indireta. A memória de evocação mostrou diferença significativa entre os grupos ( $p=$ $0,009)$. Mais pacientes que controles tinham escores $\leq 23$ no MEEM $(p=0,025)$. Resultados semelhantes foram obtidos na comparação entre sujeitos com escolaridade $>4$ anos. Não foi verificada diferença estatística entre pacientes e controles em relação ao grau de depressão, ansiedade e desesperança. Os genótipos do HCV não se correlacionaram com nenhuma variável estudada. Conclusão: $38,1 \%$ dos pacientes e $18,3 \%$ dos controles apresentavam NP. MN ou MNM representaram $41,3 \%$, as PNP $24,1 \%$ e as PNP com MN ou MNM sobrepostas $17,2 \%$. Nos pacientes com hepatite $C$ as NP mostraram correlação com AC anti-SSA/RO e antitirosina fosfatase. Foi verificada diferença significativa entre os grupos na memória de evocação e no número de sujeitos que obtiveram escores $\leq 23$ no MEEM, mas não quanto aos sintomas de depressão, ansiedade e desesperança.

Descritores: Hepatite C; Neuropatia periférica; Avaliação cognitiva; Ansiedade; Depressão; Desesperança; Autoanticorpos; Genótipos; Crioglobulinas 


\section{Summary}

Fortini I. Peripheral neuropathies and neuropsychiatric disorders in patients with hepatitis $C$ virus: an observational, case-control, retrospective and prospective study [thesis]. São Paulo: "Faculdade de Medicina, Universidade de São Paulo"; 2019.

Background: Chronic hepatitis $\mathrm{C}$ virus (HCV) infection is increasingly considered a systemic disease with numerous extrahepatic manifestations. Peripheral neuropathies (PN) and neuropsychiatric disorders are reported in some series of patients, with a certain heterogeneity between them. Although cognitive dysfunction has been described, some studies failed to prove this association. Few studies on the subject were conducted in Brazil. Objectives: identify disorders in peripheral nerve function and neuropsychiatric dysfunction in treatment-naïve patients with chronic HCV infection without overt hepatic encephalopathy and verify whether there is a relationship with viral genotype, liver fibrosis grade and presence of autoantibodies. Methods: a cohort of 76 adult patients with chronic HCV infection aged 18 years and older (40 women), treatment naïve, not coinfected with hepatitis B virus (HBV), acquired immunodeficiency virus (HIV) or syphilis was evaluated from August 2009 to February 2016 and compared with a control group of 76 individuals (43 women) with a negative screening for HCV, HBV, HIV or syphilis, with similar gender, age and educational level distribution. Patients and controls were clinically evaluated and submitted to a brief cognitive screening (Minimental State Examination (MMSE), clock drawing test (CDT), semantic verbal fluency test (VF) and digit span test (WAIS-III) in direct and inverse order and assessment of mood, anxiety and hopelessness through the Beck Inventory. Hepatitis $\mathrm{C}$ patients underwent extensive battery of laboratory tests, genotype determination, insulin dosage, and gammaglobulins, cryoglobulins (CGs), rheumatoid factor $(\mathrm{RF})$, complement fractions, and autoantibody screening. Anatomopathological studies of the liver performed within less than 18 months of the initial study interview were considered for analysis. The Statistical Package for the Social Sciences was used to carry out appropriate tests. Results: PN was found in 29 patients with $\mathrm{HCV}$ infection $(38.1 \%)$ and 14 controls (18.3\%) [ $p=0.007$ ]. Of the HCV patients with $\mathrm{PN}, 12(41.4 \%)$ presented MN or MNM, 7 (24.1\%) sensory or sensoriomotor PNP, 5 (17.2\%) PNP with MN or MNM overlap, 4 (13.8\%) radiculopathies and 1 (3.4\%) pure motor neuropathy. Of the 14 control subjects with PN, $8(57,1 \%)$ had uni or bilateral medial nerve neuropathy, 4 (28.6\%) radiculopathy and 3 (21.4\%) 
PNP. Paresthesias / neuropathic limb pain without objective signs of PN were reported by $26.3 \%$ of patients and $7.9 \%$ of controls $(p<0.0001)$. There was no significant difference in the prevalence of diabetes mellitus (DM) between patients and controls $(6,6 \%$ vs $9,2 \%)$. Glucose intolerance was found in 17 (22.4\%) HCV patients. Serum CGs were detected in 9.2\% (6/65) of the HCV patients and were positive in $13.8 \%$ of HCV patients with PN. High serum gamma globulins levels were found in $46.2 \%$ (30/64) of the patients, FR in $26.7 \%$ (16/60), low C4 levels in 19.3\% (16/60), smooth muscle antibodies in $26.2 \%(18 / 65)$, anti-thyroperoxidase antibodies in $22.9 \%(8 / 35)$ and $\operatorname{lgM}$ anticardiolipin antibodies in 20.7\% (12/58). Anti-SSA / RO and anti-tyrosine phosphatase antibodies were significantly different between HCV patients with and without PN ( $p=0.028$ and $p=0.038$, respectively). PN in HCV patients was correlated with age $(p<0.05)$, grade of liver fibrosis $(p<0.05)$ and altered glucose metabolism $(p<0.05)$ and in the control group with DM $(p<0.01)$. No statistically significant differences between patients and controls were found in the total scores of MMSE, semantic VF, TDR and digit tests in direct and indirect order. Recall memory showed a significant difference between the groups $(p=0.009)$. More patients than controls had scores $\leq 23$ in the MMSE $(p=0.025)$. Similar results were obtained in the comparison between subjects with $>4$ years of schooling. No statistical difference was found between patients and controls regarding the degree of depression, anxiety and hopelessness. HCV genotypes did not correlate with any of the studied variables. Conclusion: $38.1 \%$ of the patients and $18.3 \%$ of the controls had NP. In HCV patients with PN, MN or MMN represented $41.3 \%$, PNP $24.1 \%$ and PNP with $\mathrm{MN}$ or MMN superimposed $17.2 \%$. Anti-SSA/RO and antityrosine phosphatase antibodies showed a significant difference between HCV patients with and without PN. There was a significant difference between the groups in recall memory and in the number of subjects who obtained scores $\leq$ 23 in the MMSE, but not in the symptoms of depression, anxiety and hopelessness.

Descriptors: Hepatitis C; Peripheral neuropathy; Cognitive evaluation; Anxiety; Depression; Hopelessness; Autoantibodies; Genotypes; Cryoglobulins 


\section{Introdução}

\subsection{O vírus}

O vírus da hepatite $C$ (do inglês, Hepatitis $C$ Virus, HCV) é um RNA vírus de cadeia simples com polaridade positiva do gênero Hepacivirus, família Flaviviridae, identificado por Choo et al. em 1989.

Seu genoma tem cerca de 9.600 kb e codifica uma proteína única de cerca de 3000 aminoácidos a partir de um quadro de leitura aberto de mais de 9024 nucleotídeos. Esta poliproteína única é posteriormente clivada em várias proteínas estruturais e não estruturais. As proteínas estruturais são representadas pelo núcleo e duas proteínas do envelope (E1 e E2), a partir da extremidade. Seguem-se seis proteínas não estruturais (NS), a saber, NS2, NS3, NS4A, NS4B, NS5A e NS5B (Choo et al., 1991).

A poliproteína central do HCV é uma proteína multifuncional que modula a expressão gênica e viral, e é processada por proteases virais e do hospedeiro que produzem proteínas NS e a estrutura viral madura (Colpitts et al., 2015). Durante o estágio replicativo o RNA genômico do HCV é transcrito em uma cadeia de RNA complementar. Esta fita "negativa" constitui um modelo para nova síntese genômica e sua identificação representa uma prova de replicação ativa (Rosenberg, 2001). As partículas HCV formam um complexo de replicação 
associado à membrana; após a ampliação do genoma e expressão proteica, os vírions são montados e liberados (Heller et al., 2005; Piñero e Martinez-Salas, 2012). A montagem do HCV requer uma plataforma de gotículas lipídicas celulares e interações entre NS5A e a proteína do núcleo (Masaki et al., 2008). As partículas montadas brotam no retículo endoplasmático e são exportadas da célula em conjunto com a secreção de lipoproteínas. Uma marca registrada das partículas de HCV é sua conexão com lipoproteínas celulares e lipídios que determina a morfologia e propriedades biofísicas do vírion (Masaki et al., 2008). No sangue, as partículas de HCV são heterogêneas em tamanho e densidade dada sua associação com lipoproteínas séricas (Boyer et al., 2014; Colpitts et al., 2015). Proteínas da superfície celular têm afinidade por proteínas do envelope do HCV. São considerados como potenciais receptores de HCV o CD81, SR-BI, receptor de lipoproteína de baixa densidade (LDL-R), Claudinas, Ocludinas, L-Sign, D-SIGN e glicosaminoglicanos (Aktipi Aktipi; Yang et al., 2008).

O HCV exibe um alto nível de heterogeneidade genética que está associado principalmente ao erro natural da RNA-polimerase. Durante a replicação ocorrem mutações do genoma que levam a uma diversificação contínua e que resultam em populações de variantes virais conhecidas como quasispecies (Neumann et al., 1998). O grande conjunto de variantes fornecidas pelas quasispecies constitui um grande desafio para o controle da infecção pelo HCV e tem importantes implicações biológicas, como persistência viral, tropismo para as células hospedeiras, resistência aos fármacos antivirais e 0 desenvolvimento de vacina contra o HCV. 
Comparações de sequências de nucleotídeos de variantes recuperadas de indivíduos infectados em diferentes regiões geográficas revelaram a existência de pelo menos seis grandes grupos genéticos. Em todo o genoma estes diferem em 30 a 35\% nos sítios de nucleotídeos, com maior variabilidade em regiões como as glicoproteínas E1 e E2 (Okamoto et al., 1992). As sequências do gene central e alguns dos genes que codificam proteínas não estruturais são mais conservados. Considera-se existirem seis genótipos principais e mais de 50 subtipos (Choo et al., 1989; Zein, 2000; Lauer e Walker, 2001; Chen e Morgan, 2006). Cada genótipo é uma mistura de vírus relacionados de maneira muito próxima, quasispecies, que mostram diferentes graus de infectividade e patogenicidade (Zein, 2000).

Os principais genótipos associados à infecção pelo HCV predominam em diferentes localizações geográficas no mundo (Zein, 2000; Simmonds, 2004; Bowden e Berzsenyi, 2006). O genótipo 1 é predominante na América do Norte, América do Sul e Europa; o genótipo 2 predomina no Japão e na China; o genótipo 4, no Egito; o genótipo 5, na África austral e o genótipo 6, no sudeste da Ásia. De modo geral, os genótipos afetam a resposta ao tratamento antiviral, mas não influenciam significativamente a gravidade da doença ou sua progressão (Simmonds, 2004; Bowden e Berzsenyi, 2006).

Messina et al., 2015, revisaram estudos publicados entre 1989 e 2013 relatando prevalência de genótipos do HCV e combinaram estes dados com as prevalências estimadas pela Organização Mundial da Saúde (OMS) no projeto Global Burden of Disease. Desta forma, calcularam que o genótipo 1 é 
responsável por $46,2 \%$ dos casos de hepatite $C$, dos quais aproximadamente um terço estão no leste da Ásia. O genótipo 3 é o segundo mais prevalente (30.1\%); os genótipos 2, 4, e 6 são responsáveis por um total de $22.8 \%$ dos casos e o genótipo 5 por menos de $1 \%$.

O genótipo 1 do HCV é predominante no Brasil, identificado em 70\% da população infectada, seguido pelo genótipo 3, em 25\%, e genótipo 2 em aproximadamente 5\% (Cavalheiro et al., 2002; Campiotto et al., 2005).

Cada um dos seis principais genótipos do HCV contém uma série de subtipos mais intimamente relacionados que diferem entre si em 20 a $25 \%$ das sequências de nucleotídeos em comparação com a divergência de mais de 30\% entre os genótipos (Simmonds et al., 1993). Alguns genótipos se espalharam bastante em todo mundo, como os genótipos 1a, 1b e 3a, pela transmissão através de transfusões sanguíneas e compartilhamento de agulhas entre usuários de drogas nos países ocidentais.

\subsection{Dados epidemiológicos}

A OMS estimou que em 2015 aproximadamente 130 a 150 milhões de pessoas viviam com infecção pelo HCV em todo o mundo, representando $1 \%$ da população, e que aproximadamente 399.000 pessoas morrem a cada ano por hepatite C. A maioria destas mortes está relacionada ao desenvolvimento de complicações potencialmente fatais, como cirrose hepática (cerca de 280.000 mortes) e carcinoma hepatocelular (cerca de 120.000 mortes). 
Vários estudos mostraram que $90 \%$ dos doentes cronicamente infectados pelo HCV vivem em países com renda per capita baixa e média.

O HCV é endêmico em todo o mundo com grande variabilidade em sua distribuição (Shepard et al., 2005; Lavanchy, 2009). São consideradas áreas de alta prevalência no mundo (mais de 3,5\%) a Ásia central e oriental, o norte da África e o Oriente Médio. Áreas com prevalências moderadas (1,5 a 3,5\%) compreendem o sul e o sudeste asiático, a África subsaariana, as regiões andinas, o centro e o sul da América do Sul, o Caribe, a Oceania, a Australásia (Austrália, Nova Zelândia, Nova Guiné e ilhas vizinhas do Pacífico), a América Latina tropical e a América do Norte (Kretzer et al., 2014).

Segundo o Boletim Epidemiológico de Hepatite s Virais 2018 da Secretaria de Vigilância em Saúde do Ministério da Saúde do Brasil, de 1999 a 2017 foram notificados no Sistema de Informação de Agravos de Notificação (SINAN) 331.855 casos de Hepatite C com um dos marcadores - anticorpos contra o vírus da hepatite $\mathrm{C}$ (anti-HCV) ou RNA do vírus da hepatite C (RNA HCV) - reagente. $\mathrm{Na}$ análise da distribuição dos casos com anti-HCV e HCVRNA reagentes por regiões, $63,2 \%$ ocorreram no Sudeste, $25,2 \%$ no Sul, 5,9\% no Nordeste, 3,2\% no Centro-Oeste e 2,5\% no Norte. Em 2017, as maiores taxas de detecção foram observadas na faixa etária dos 55 a 59 anos, em ambos os sexos, chegando a uma taxa de detecção de 42,4 casos por 100 mil habitantes entre homens e 25,2 por 100.000 habitantes entre mulheres. A taxa de coinfecção com o vírus da deficiência imunológica humana adquirida (do inglês, Human Immunodeficiency Virus, HIV) foi 7,7\%. 
Estudo populacional transversal realizado em nosso meio por Pereira et al., 2013, com dados de indivíduos com idades de 10 a 69 anos de todas as cinco macrorregiões brasileiras nos quais foi realizada pesquisa de anticorpos contra o HCV por teste de Elisa de terceira geração coletados entre 2005 e 2009 mostrou que a prevalência geral de anticorpos contra o vírus da Hepatite C era de 1,38\%, maior nos grupos de indivíduos mais velhos, mas similar em ambos os sexos. De acordo com estes dados 1,3 milhões de pessoas têm anticorpos contra HCV no país.

No Brasil a seroprevalência de HCV varia por região. Segundo estudo de 2010 da Universidade de Pernambuco, a seroprevalência é de 0,7\% no Nordeste e $0,9 \%$ no Distrito Federal, aumentando para 1,2\% no Sul e 1,3\% no Sudeste e Centro-Oeste. A mais elevada taxa de prevalência é a da região Norte, $2,1 \%$.

O Ministério da Saúde do Brasil em parceria com a Faculdade de Medicina da Universidade de São Paulo (FMUSP) desenvolveu um modelo matemático para estimar o número de portadores de infecção crônica pelo HCV (Amaku et al., 2016). Este modelo utilizou dados de 12 anos de dois conjuntos de registros nacionais do Ministério da Saúde, o SINAN e o Sistema Nacional de Transplantes do Ministério da Saúde. O modelo estimou que 1,4 a 1,7 milhões de pessoas estavam infectadas pelo HCV no Brasil. 


\subsection{Transmissão e Replicação viral}

O HCV é transmitido por contato com sangue contaminado, transfusões de sangue, injecções contaminadas durante procedimentos médicos e uso de drogas injetáveis. A eficiência da transmissão sexual do HCV tem sido objeto de amplo debate e é geralmente considerada muito baixa (Tohme e Holmberg, 2010). Outras vias de transmissão são através de hemodiálise, transplante de órgãos de doadores infectados pelo HCV e transmissão vertical. Multiplicidade de parceiros sexuais, transfusões sanguíneas, uso de drogas intravenosas e baixo nível socioeconômico aumentam o risco de contrair infecção pelo HCV. Identifica-se pelo menos um fator de risco em $90 \%$ dos pacientes (Chen e Morgan, 2006; Alter, 2007; Lavanchy, 2009).

Existem evidências crescentes que o HCV pode atravessar a mucosa nasal e infectar cronicamente os indivíduos que usam drogas recreativas inalatórias como a cocaína, pelo compartilhamento de instrumentos inalatórios, dado o frequente sangramento da mucosa nasal que ocorre nesses indivíduos (Allison et al., 2012).

O risco de infecção pelo HCV após a exposição acidental a agulhas contaminadas é de $0,2 \%$ a $10 \%$ dependendo de vários fatores, incluindo exposição percutânea, alta carga viral do HCV ou coinfecção com HIV (Corey et al., 2009).

Durante os últimos 10 anos a taxa de hepatite $\mathrm{C}$ associada a transfusão, diminuiu significativamente no todo o mundo em consequência da introdução de 
restrições crescentes na elegibilidade dos doadores e da implementação de rastreio eficaz por anti-HCV ou RNA-HCV. A maioria dos milhões que estão cronicamente infectados pelo HCV estão agora na quarta ou quinta década de vida.

Segundo dados do Boletim de Hepatites Virais 2018 do Ministério da Saúde do Brasil, em 53,7\% dos casos notificados falta a informação sobre a provável fonte ou mecanismo de infecção. Nos casos onde esta informação foi fornecida verificou-se que o maior percentual de provável fonte de infecção foi referente ao uso de drogas $(13,2 \%)$, seguido de transfusão sanguínea $(11,4 \%)$ e de relação sexual desprotegida (8,9\%). Em 2017 a proporção de infecções por via sexual $(9,2 \%)$ foi superior ao percentual de infecções relacionadas ao uso de drogas $(8,1 \%)$ e à proporção de infecções por via transfusional, que foi de $6,8 \%$.

Apenas $20 \%$ a $30 \%$ dos pacientes com hepatite C aguda desenvolvem sintomas, geralmente 3 a 12 semanas após a exposição (Alter e Seeff, 2000). Em grande número de estudos foi relatado que alguns pacientes podem clarear espontaneamente o HCV, mas as taxas relatadas de eliminação espontânea do vírus variam muito. Em 2006, Micallef et al. realizaram uma revisão sistemática desses estudos e encontraram uma taxa média estimada de 0,26 (95\% IC, 0.220.29 ), isto é, $26 \%$ dos indivíduos infectados clareiam o vírus espontaneamente. Portanto, cerca de $75 \%$ a $85 \%$ dos pacientes contaminados pelo HCV desenvolvem hepatite C crônica, caracterizada pela persistência de RNA-HCV no sangue por pelo menos 6 meses. Nos $15 \%$ a $25 \%$ dos pacientes nos quais a 
infecção aguda pelo HCV é autolimitada, o RNA-HCV se torna indetectável (Chen e Morgan, 2006).

A maioria dos doentes com infecção crônica é assintomática ou tem apenas sintomas leves e inespecíficos e até $75 \%$ dos pacientes com infecção crônica permanecem inconscientes de seu estado até que problemas hepáticos desenvolvam-se em fases mais tardias de sua evolução (Maasoumy e Wedemeyer, 2012). Entre os que têm sintomas a queixa mais frequente é a fadiga; outras manifestações menos comuns incluem náuseas, anorexia, mialgia, artralgia, fraqueza e perda de peso (Chen e Morgan, 2006). Os sintomas raramente são incapacitantes e podem não ser atribuíveis apenas à doença hepática. Entretanto, podem causar prejuízo à qualidade de vida (Spiegel et al., 2005), o que pode ser parcialmente explicado pela consciência da infecção, segundo Rodger et al. (1999).

O diagnóstico tardio contribui para a transmissão da doença e para a alta taxa de mortalidade a ela associada.

Tanto a imunidade inata como primeira linha de defesa, como a subsequente ativação do sistema imunológico adaptativo são essenciais para o controle da infecção. No entanto, o HCV pode evadir as defesas do hospedeiro por resistência a anticorpos neutralizantes ou redução de imunogenicidade. Como resultado do desequilíbrio entre atividade do vírus e resposta imune insuficiente a maioria dos pacientes infectados desenvolverá hepatite crônica ativa (Horner e Gale, 2013). 
A persistência da infecção parece depender da rápida produção de vírus e da contínua disseminação célula a célula, juntamente com a falta de resposta vigorosa das células T aos antígenos do HCV (Bukh et al., 1995; Himoto e Masaki, 2012). A replicação varia entre $10^{10}$ a $10^{12}$ vírions por dia, com meiavida viral de 2 a 3 horas (Neumann et al., 1998). A rápida replicação viral e a falta de correção de erros pela RNA polimerase viral resultam em mutações frequentes no genoma do HCV (Bukh et al., 1995).

A infecção pelo HCV está associada a esteatose, fibrose e cirrose hepáticas e carcinoma hepatocelular (Bartenschlager et al., 2011). Segundo a OMS, para as pessoas portadoras de infecção crônica por HCV, o risco de cirrose hepática é de 15 a 30\% em 20 anos.

Embora os hepatócitos representem o alvo principal do HCV, a infecção por este vírus é considerada cada vez mais uma doença sistêmica, noção reforçada pelo acúmulo de evidências de entrada e replicação do HCV em todos os principais sistemas celulares do organismo (Revie e Salahuddin, 2011). O RNA-HCV foi detectado em células mononucleares do sangue periférico, líquido cefalorraquidiano e cérebro de pacientes cronicamente infectados (Radkowski et al., 2002; Dustin e Rice, 2007; Zignego e Craxí, 2008; Weissenborn et al., 2009).

Os efeitos variáveis da infecção crônica entre os indivíduos são devidos a diferenças de idade, gênero, nível de imunidade e cuidados de saúde ambiental (Alter et al., 1992). 


\subsection{Manifestações extra-hepáticas}

Numerosas manifestações extra-hepáticas (MEH) foram atribuídas ou são mais frequentes durante a infecção pelo $\mathrm{HCV}$, incluindo doenças linfoproliferativas e autoimunes (Cacoub et al., 2000; Zignego et al., 2007; Cacoub et al., 2016).

As MEH ocorrem durante a infecção crônica ou cirrose e podem resultar numa ampla variedade de manifestações clínicas capazes de agravar o espectro clínico da infecção hepática ou até mesmo dominar o quadro clínico (Chen e Morgan, 2006). O mecanismo comum subjacente à maioria das MEH é a autoimunidade e há muitos anos sabe-se que tiroidite, artropatias, sialadenite linfocítica com ou sem síndrome sicca, e diabetes melito são mais frequentes na infecção por HCV (Pawlotsky et al., 1995; Koike, 2005; Himoto e Masaki, 2012).

Estudos revelaram que 38 a $76 \%$ dos pacientes com infecção crônica pelo HCV desenvolvem pelo menos uma MEH (Cacoub et al., 2000; StefanovaPetrova et al., 2007).

Duas características imunológicas do HCV poderiam predispor a MEH de natureza autoimune. O vírus possui mecanismos eficientes de evasão imune que conduzem à infecção crônica, acúmulo de imunocomplexos (ICs) circulantes e fenômenos autoimunes. Outra característica importante é a estimulação da produção de fator reumatóide $(\mathrm{FR})$ monoclonal. A produção de $\mathrm{FR}$ causa a crioglobulinemia (CM) mista tipo II associada à infecção pelo HCV que é responsável pela maioria dos sintomas de vasculite, principal manifestação de doença extra-hepática relacionada ao HCV (McFarlane, 1992; Sansonno et al., 
2009; Himoto e Masaki, 2012). Muitas das MEH são desencadeadas pela proliferação de células $B$ e produção subsequente de autoanticorpos monoclonais e policlonais com atividade de fator reumatóide (FR) ou crioglobulinas (CGs).

A infecção persistente pelo HCV é responsável pela produção de uma variedade de autoanticorpos, incluindo autoanticorpos não órgão-específicos e autoanticorpos ógão-específicos, como um fenômeno autoimune induzido pelo vírus, tendo sido demonstrada grande diversidade de autoanticorpos no soro de pacientes com doença hepática crônica relacionada ao HCV (Clifford et al., 1995; Muratori et al., 2005; Palazzi et al., 2012; Himoto e Masaki, 2012). O espectro de autoanticorpos inclui anticorpos antinucleares, anti-SSA/RO, anti-SSB/LA, anticorpos antimúsculo liso, anticorpos anticitoplasma de neutrófilos (ANCA), antigangliosídeo GM1 e antisulfatídeo. Além disso, possíveis mecanismos envolvidos em uma série de MEH neurológicas incluem a ativação de células T autorreativas e respostas cruzadas induzidas pelo HCV contra polipeptídeos estruturais, neurais e não neurais (Cassani et al., 1997; Luo et al., 1998; Williams et al., 2009; Himoto e Masaki, 2012; Gilman et al., 2018).

Vários mecanismos de produção de autoanticorpos foram propostos, como mimetismo molecular entre um componente do vírus e uma proteína do hospedeiro (Bogdanos et al. 2001) e ativação de células B policlonais pela infecção persistente (Bianchi et al., 2007). A proliferação de células B é muito importante no desenvolvimento de doenças autoimunes como a síndrome de Sjögren e a CM. A predisposição genética também está fortemente relacionada 
com a presença de autoanticorpos na infecção crônica pelo HCV (Ferri et al., 2015).

A presença de autoanticorpos não órgão-específicos como anticorpos antinucleares e antimúsculo liso associa-se à gravidade da inflamação e fibrose hepática de pacientes com doença hepática crônica relacionada ao HCV (Cassani et al., 1997; Chrétien et al., 2009). Os títulos desses autoanticorpos parecem ser independentes de genótipos do HCV ou da carga viral (Williams et al., 2009; Chrétien et al., 2009; Himoto e Masaki, 2012; Ferri et al., 2015; Gilman et al., 2018).

Vários foram os mecanismos propostos pelos quais o HCV poderia causar MEH, como vasculite causada por CM (Lunel et al., 1994; Wong et al., 1996; Ragab e Hussein, 2017), vasculite tipo poliarterite nodosa (Cacoub et al., 2001; Saadoum et al., 2011), invasão direta do sistema nervoso pelo vírus, lesão do sistema nervoso por autoanticorpos e deposição de imunocomplexos circulantes (Himoto e Masaki, 2012; Ferri et al., 2015). Sabe-se também que a infecção crônica pelo HCV é caracterizada por inflamação hepática e sistêmica que leva à liberação de citocinas e aumento do estresse oxidativo (Zampino et al., 2013). Deste modo, o HCV pode causar manifestações sistêmicas através de numerosos mecanismos, tanto direta quanto indiretamente, via inflamação local ou sistêmica através de um processo imunomediado e/ou pela indução de um desarranjo metabólico (Weinman e Belalcazar, 2004; Alaei e Negro, 2008).

As MEH sistêmicas da hepatite $\mathrm{C}$ incluem a vasculite causada por CM (Authier et al., 1993; Lunel et al., 1994; Cacoub et al., 2000; Lauletta et al., 2012), 
doenças linfoproliferativas (King et al., 1998), doença renal (Johnson et al., 1993; Bandi, 2003), doença tireoidiana (Antonelli et al., 2004), resistência à insulina e diabetes melito tipo 2 (Allison et al., 1994; White et al., 2008). Além disso, o HCV pode causar comprometimento ocular, intestinal, cardiovascular e cerebrovascular e também induzir manifestações reumatológicas como a síndrome sicca e artrite reumatoide (Sawada et al., 1991; Hirohata et al.,1992; Cacoub et al., 2000), alterações dermatológicas (Nagao e Sata, 2004; Guerreiro et al., 2005) e neuropsiquiátricas, podendo afetar tanto o sistema nervoso periférico (SNP), quanto o sistema nervoso central [SNC] (Cacoub et al., 2000; Authier et al., 2003; Rosenthal e Cacoub, 2015; Ferri et al., 2015; Cacoub et al., 2016; Ragab e Hussein, 2017).

O fígado desempenha um papel importante no metabolismo de carboidratos, e assim, alterações do metabolismo da glicose, diminuição da tolerância à glicose e resistência à insulina (RI) são mais prevalentes nas doenças hepáticas crônicas (Weinman e Belalcazar, 2004; Bugianesi et al., 2005). A sugestão de que o HCV pode estar associado ao diabete melito (DM) tipo 2 foi feita por Allison et al., em 1994. Desde então, dezenas de estudos observacionais sobre a associação entre o HCV e DM tipo 2 foram publicados (Antonelli et al., 2005; Farshadpour et al., 2018; Fabiani et al., 2018). Diversos estudos epidemiológicos evidenciaram percentuais mais elevados de marcadores de infecção pelo HCV em pacientes com DM tipo 2 do que em controles saudáveis e análises de pacientes infectados pelo HCV sem cirrose mostraram maior prevalência de DM tipo 2 em comparação com controles HCV- 
negativos ou pacientes infectados pelo vírus da hepatite B (White et al., 2008; Naing et al., 2012).

Uma recente meta-análise que considerou um total de 1046 pacientes com infecção crônica por HCV e 1303 controles sem doença hepática mostrou que a infecção crônica pelo HCV está associada a um risco aumentado de DM tipo 2, independentemente da gravidade da doença hepática. O risco de DM tipo 2 é maior em pacientes HCV cirróticos que naqueles com HCV sem cirrose e a prevalência de infecção pelo HCV em pacientes com DM tipo 2 é maior do que em controles não diabéticos (Fabiani et al., 2018).

\subsubsection{Crioglobulinemia}

A CM é uma MEH comum em pacientes com infecção por HCV, detectada em 19-54\% dos pacientes (Lunel et al., 1994; Wong et al., 1996; Kayali et al., 2002; Himoto e Masaki, 2012) e caracteriza-se pela presença de ICs produzidos por proliferação benigna de células B.

As CGs são imunoglobulinas (Igs) caracterizadas por insolubilidade a baixa temperatura (abaixo de $37^{\circ} \mathrm{C}$ ) que voltam a se dissolver após aquecimento. Com base em sua composição imunoquímica, as CGs são classificadas como únicas (tipo I) ou mistas (tipos II e III), de acordo com o método de Brouet et al., 1974.

A CM tipo I consiste em Ig monoclonal mais frequentemente de isotipo IgM ou IgG. CGs IgM ocorrem em quase $6 \%$ das paraproteinemias IgM malignas, 
enquanto que as CGs IgG caracterizam quase $2 \%$ de todos os mielomas. As CG IgA de tipo I são raras (Lauletta et al., 2012).

A CM tipo II representa $50-60 \%$ de todas as CM e compreende um componente monoclonal IgM frequentemente acoplado a cadeias leves kappa, e IgG policlonal. As moléculas de IgM com atividade de FR têm capacidade de reagir com IgG intacta e/ou fragmento $F(a b) 2$ ' (Lauletta et al., 2012). Nenhum componente monoclonal está contido na CM do tipo III. As CGs do tipo III são caracterizadas por IgG policlonal com FR policlonal e representam 30 a 40\% das CM (Himoto e Masaki, 2012; Lauletta et al., 2012; Ferri et al., 2015). Assim, as CM do tipo II e III são referidas como CM mistas. O termo "essencial" define síndromes crioglobulinêmicas sem uma doença subjacente identificável.

Atualmente aceita-se que a CM ocorre em pacientes cronicamente infectados pelo HCV como resultado de interações específicas entre o vírus e o sistema imune do hospedeiro (D'Amico, 1993; Agnello, 1995; Sansonno e Dammacco, 2005). A infecção persistente por HCV está fortemente associada aos tipos II e III de CM e, ocasionalmente, pode estar associada à CM tipo I.

Os crioprecipitados contêm proteínas do núcleo do HCV, moléculas de IgG com atividades "anticore" específicas, e moléculas de IgM com atividade de FR (Himoto e Masaki, 2012).

Embora as CGs estejam frequentemente presentes em pacientes com infecção crônica por HCV, muitas vezes os níveis são baixos e os sintomas 
decorrentes de sua presença são muito leves ou ausentes. Apenas cerca de $5 \%$ dos indivíduos têm CM clinicamente aparente (Himoto e Masaki, 2012).

Em nosso meio, Parise et al., 2007, pesquisaram a presença de CGs em 202 pacientes com hepatite $C$ virgens de tratamento e relataram que em $27 \%$ dos mesmos a pesquisa de CGs foi positiva. Destes, 13 pacientes tinham manifestações clínicas maiores. Embora a CM tipo III tenha sido a mais frequentemente encontrada nesta série $(78 \%)$, casos sintomáticos tinham mais frequentemente CM tipo II.

A vasculite crioglobulinêmica é mediada por complexos imunes e caracteriza-se pelo envolvimento de pequenos vasos e proliferação de células $B$ (Agnello, 1995). A incidência de infecção pelo HCV na CM varia de $40 \%$ a $90 \%$, com variações geográficas (Sansonno e Dammacco, 2005). Por outro lado, CM sem infecção por HCV representa cerca de 5 a 10\% dos casos (Sansonno et al., 2007).

A CM secundária à infecção por HCV envolve frequentemente vários órgãos podendo causar manifestações cutâneas, neuropatia periférica e doença glomerular. As lesões cutâneas vão desde púrpura palpável nos membros inferiores a úlceras cutâneas crônicas, mais frequentes nas regiões supramaleolares. Outras manifestações cutâneas incluem o fenômeno de Raynaud, livedo reticular, urticária e edema. As artralgias envolvem mais frequentemente as mãos e os joelhos de forma simétrica e fraqueza está quase sempre presente (Cacoub et al., 2000; Sansonno et al., 2007). A lesão renal pode complicar a CM em quase 30\% dos casos (Sansonno e Dammacco, 2005). 
Características clínicas como hipertensão, proteinúria, hematúria microscópica, aglomerados de glóbulos vermelhos e insuficiência renal têm um curso indolente em cerca de $50 \%$ dos casos. Menos comums são síndromes nefríticas ou nefróticas que ocorrem respectivamente em $14 \%$ e $21 \%$ dos casos (Roccatello et al., 2007).

O envolvimento do sistema nervoso ao longo do curso da CM relacionada ao HCV varia de $17 \%$ a $60 \%$ (Authier et al., 2003). Neuropatia periférica (NP) pode representar o primeiro sinal clínico de CM (Ferri et al., 2004). O envolvimento do SNP com apresentação de NP sensitivomotora caracterizase pela presença de parestesias, fraqueza, dor e sensação de queimação, especialmente nos membros inferiores. É menos frequente o envolvimento do SNC (Origgi et al., 1998; Filippini et al., 2002).

Quadros clínicos menos comuns de vasculites crioglobulinêmicas são representados por envolvimento gastrointestinal e pulmonar (Terrier et al., 2010; Ramos-Casals et al., 2006).

O mecanismo intrínseco pelo qual o HCV promove a produção de CGs não está claro. A persistência viral pode representar um estímulo contínuo para o sistema imune do hospedeiro, incapaz de produzir anticorpos neutralizantes. Entre os antígenos virais, a proteína central desempenha um papel importante na constituição de CGs sendo o ligante relevante de lgG (Sansonno et al., 2003).

A interação entre HCV e linfócitos é capaz de modular funções celulares. A ativação in vivo e expansão de células B CD5-positivas foi considerada a 
principal fonte de moléculas $\operatorname{lgM}$ com atividade de FR na CM tipo III. $\mathrm{Na}$ formação de ICs crioprecipitantes, papel crucial é desempenhado pelo sistema do complemento. A ligação do complemento aos ICs em formação geralmente diminui o tamanho destes, mantendo-os em solução hl et al., 2000). Os níveis médios de frações C3 e C4 na fase solúvel do soro de pacientes com CM correlaciona-se com quantidades muito pequenas nos crioprecipitados (Sansonno e Dammacco, 2005). O componente 1q do complemento (C1q) é um complexo proteico envolvido no sistema complemento que faz parte do sistema imune inato. No crioprecipitado, a proteína C1q e a atividade de ligação C1q estão significativamente enriquecidas (Sansonno et al., 2003). A proteína central do HCV interage diretamente com o receptor para o domínio globular da proteína $\mathrm{C} 1 \mathrm{q}(\mathrm{gC} 1 \mathrm{q}-\mathrm{R})$ representando uma maneira eficiente de afetar a imunidade do hospedeiro por células T e B (Kittlesen et al., 2000).

\subsubsection{Neuropatia Periférica}

O comprometimento neurológico mais comum e bem conhecido associado à hepatite C é a NP. A prevalência de NP entre indivíduos com infecção crônica por HCV varia de acordo com a população estudada e com a definição de NP (Cacoub et al., 2005). Estudos normatizados de condução nervosa detectaram NP em 15,3\% das pessoas com HCV; no entanto, aproximadamente um terço tem doença subclínica (Santoro et al., 2006). Segundo Cacoub et al., 2000, a prevalência de NP sensitiva ou motora clinicamente sintomática é de aproximadamente 10\%. Santoro et al., 2006, 
relataram que $10.6 \%$ dos pacientes com HCV não tratados tinham evidências clínicas de NP e outros 4.7\% tinham evidências eletrofisiológicas de NP assintomática.

Foram inicialmente descritos casos de polineuropatia (PNP) sensitivomotora, principalmente distal, de início subagudo (Tembl et al., 1999), mas outras formas de NP podem ocorrer, como mononeuropatia múltipla - MNM (Nemni et al., 2003; Vigani et al., 2005; Santoro et al., 2006), mononeuropatia simples (MN) e neuropatia sensitiva essencialmente assimétrica. A NP associada ao HCV deve-se principalmente a dano axonal e a CM geralmente está presente (Nemni et al., 2003). Mais raramente podem ser encontradas outras formas de NP, como a neuropatia axonal motora pura (Costa et al., 2003), neuropatias de nervos cranianos (Marie et al., 2000) e neuropatia de fibras finas (Gemignani et al., 2010).

A NP pode ser subaguda, crônica, ou crônica com agudizações, sendo a subaguda a mais comum (Tembl et al., 1999), manifestando-se geralmente por sintomas sensitivos assimétricos, principalmente parestesias, que podem tornarse simétricos. Os sintomas de comprometimento motor são mais tardios e predominam nos membros inferiores.

A eletroneuromiografia (ENMG) geralmente mostra PNP sensitiva pura ou PNP sensitivomotora axonal (Nemni et al., 2003, Santoro et al., 2006; Biasiotta et al., 2014; Mapoure et al., 2018). 
Entre os indivíduos portadores de HCV com NP demonstrada por estudos de condução nervosa padrão, aproximadamente a metade $(52,8 \%)$ apresenta uma NP sensitivomotora axonal simétrica, enquanto o restante mostra MN ou MNM (Santoro et al., 2006).

Pode ocorrer NP desmielinizante na forma de uma PNP crônica inflamatória desmielinizante (Nemni et al., 2003; Authier et al., 2003; Boukhris et al., 2006; Chin et al., 2010), embora também tenham sido relatados casos de PNP desmielinizante inflamatória aguda (Lacaille et al., 1998; Chin et al., 2010). A PNP desmielinizante pode estar relacionada aos efeitos do vírus na proliferação dos linfócitos (Costa et al., 2003; Boukhris et al., 2006). Também foi descrito um caso de vasculite eosinofílica acompanhada por formação de granuloma em um paciente com hepatite $\mathrm{C}$ que apresentava títulos baixos de crioglobulinas (Yuki et al., 2014).

O tipo e gravidade da neuropatia dependem dos mecanismos patogenéticos envolvidos. Nemni et al., 2003, verificaram que pacientes com CM mais frequentemente apresentavam PNP moderada a grave, enquanto aqueles sem CM tendiam a apresentar MN leve a moderada ou MNM. Segundo Ferri et al., 1992, a prevalência de NP entre pessoas com HCV e CM aumenta para cerca de $90 \%$ se a neuropatia é definida apenas pela presença de parestesias.

Nemni et al., 2003, relataram que entre indivíduos com infecção crônica por HCV e NP 78\% demonstram CM. Porém, a presença de CGs não aumenta o risco geral de desenvolvimento de NP (Zaltron et al., 1998; Nemni et al., 2003; Cacoub et al., 2005; Santoro et al., 2006). 
Os mecanismos aventados para explicar a NP associada ao HCV incluem efeito citopático direto do HCV no nervo ou mecanismo imunomediado nos vasos epineurais. Outro mecanismo possível seria através de resposta imunológica humoral combinada a um excesso de ICs que, uma vez depositados na parede vascular, induzem resposta inflamatória por ativação do sistema do complemento. Com o processo inflamatório ocorrem infiltrações linfocíticas e histiocíticas em pequenos vasos e lesões isquêmicas ou inflamatórias em vários órgãos (Himoto e Masaki, 2012; Lauletta et al., 2012; Ferri et al., 2015). A deposição de CGs dentro do lúmen e/ou das paredes da vasa nervorum impede a circulação levando à isquemia nervosa (Vallat et al., 1980; Nemni et al., 1988; Taieb et al., 2010). Os vasos endoneurais demonstram hipertrofia das células endoteliais contribuindo para a obstrução do lúmen vascular (Nemni et al., 1988; Bonetti et al., 1997; Taieb et al., 2010).

O RNA-HCV foi isolado em homogeneizados de biópsia de nervo de pacientes por PCR in situ (Authier et al., 2003; Russi et al., 2018), o que pode sugerir papel direto do HCV na patogênese da NP.

A vasculite frequentemente afeta as artérias que nutrem o epineuro, enquanto o envolvimento de vasos endoneurais é menos frequente (Nemni et al., 1988; Bonetti et al., 1997; Russi et al., 2018). Os infiltrados vasculíticos da vasa nervorum são principalmente linfocíticos (Nemni et al., 1988), enquanto que os infiltrados em torno de vasos que nutrem o endoneuro contêm linfócitos T e macrófagos, e os que ocorrem ao redor dos vasos do epineuro consistem em monócitos, linfócitos T e B (Bonetti et al., 1997). Em geral, há degeneração 
axonal que ocorre na ausência de desmielinização primária (Bonetti et al., 1997) e que pode ser secundária à isquemia resultante da oclusão da microcirculação (Nemni et al., 1988; Bonetti et al., 1997). A NP associada à CM acompanha-se de queda dos níveis da fração C4 do complemento, níveis normais da fração C3 e aumento dos níveis de FR, o que não se observa com frequência nos casos de NP sem CM (Maisonobe et al., 2002).

A infecção por HCV também está associada à vasculite sistêmica do tipo poliarterite nodosa (PAN), que afeta vasos de pequeno e médio calibre (Cacoub et al., 2001; Kanda, 2003). Estes pacientes têm geralmente MNM sensitivomotora aguda grave envolvendo os quatro membros (Cacoub et al., 2001; Saadoum et al., 2011). A vasculite do tipo PAN difere da vasculite da CM pois afeta vasos maiores e os infiltrados que nela ocorrem são neutrofílicos, além de estar associada a angiite necrotizante. A diferenciação da vasculite tipo PAN da vasculite da CM mista é um desafio, já que mais de $90 \%$ dos doentes com vasculite tipo PAN confirmada têm CM (Cacoub et al., 2001).

Segundo Kanda, talvez a NP crioglobulinêmica em pacientes com hepatite $C$ seja superdiagnosticada por existir relação próxima entre a presença de anticorpos anti-HCV e CM nos soros dos pacientes, dado que nem sempre a CM é responsável pela NP (Kanda, 2003).

\subsubsection{Manifestações neuropsiquiátricas}

Vários relatos associaram a hepatite C crônica a distúrbios neurológicos e psiquiátricos em até $50 \%$ dos casos. As principais doenças neurológicas 
associadas ao HCV incluem eventos cerebrovasculares, doenças autoimunes, encefalopatia, mielite, encefalomielite e comprometimento cognitivo, além distúrbios psiquiátricos, como depressão, ansiedade e fadiga (Cacoub et al., 2000; Poynard et al., 2002; Forton et al., 2002; Hilsabeck et al., 2002; Weissenborn et al., 2006; Quarantini et al., 2009; Lowri et al., 2010; Monaco et al., 2015; Hjerrild et al., 2016; Yarlott et al., 2017). Estes transtornos não parecem correlacionar-se com a gravidade da doença hepática crônica subjacente e são independentes da encefalopatia hepática (Fletcher e McKeating, 2012).

O conhecimento atual sugere papel direto do vírus pelo menos parcial nos danos cerebrais. O cérebro parece ser um ambiente favorável para a replicação do HCV (Radkowski et al., 2002). Foi relatada diversidade de sequências virais entre o cérebro e o tecido hepático, o que pode sugerir evolução independente do HCV no SNC (Forton et al., 2004; Fletcher e McKeating, 2012).

Foram relatados casos de AVCs associados a hepatite C (Petty et al., 1996) tendo sido descritos AVCs isquêmicos e hemorrágicos que podem, inclusive, ser a primeira MEH de infecção por HCV. O mecanismo sugerido é produção de citocinas e aumento da aterogênese (Adinolfi et al., 2014). Outros estudos também confirmaram a associação de aterosclerose carotídea e infecção por HCV (Petta et al., 2012).

Muitos relatos sugerem associação entre infecção por HCV e mielopatia transversa (Zandman-Goddard et al., 2003; De Carli et al., 2009). Foram verificados mais frequentemente quadros de mielopatia recorrente simétrica ou 
levemente assimétrica com envolvimento motor, sensitivo e esfincteriano (Grewal et al., 2004; Aktipi et al., 2007; Stübgen, 2011). Sintomas sensitivos puros podem ocorrer como manifestação única ou inicial (Nolte et al., 2002). Alguns dos pacientes com mielopatia tinham NP motora pura associada e não foram observados sintomas visuais ou alterações dos potenciais evocados visuais que pudessem sugerir neuromielite óptica ou esclerose múltipla. As CGs estavam ausentes em muitos pacientes e o exame do líquido cefalorraquidiano (LCR) mostrava leve elevação do teor proteico e, em alguns casos, pleocitose. Não foram detectadas bandas oligoclonais. A associação com o HCV foi estabelecida pela presença de anticorpos anti-HCV, e/ou do RNA-HCV no soro e/ou LCR (Annunziata et al., 2005; Aktipi et al., 2007; Stübgen, 2011). Anticorpos que sugerem neuromielite óptica estavam ausentes nos pacientes nos quais 0 teste foi realizado por Aktipi e colaboradores em 2007.

O mecanismo fisiopatológico da lesão da medula espinal pelo HCV não está esclarecido. A ausência de CGs em muitos pacientes pode sugerir que a vasculite associada à CM não seja um fator importante nesta situação e que a invasão viral direta da medula espinal ou uma lesão imunomediada possam ser responsáveis pelo quadro (Grewal et al., 2004; Aktipi et al., 2007; Stübgen, 2011).

Existe clara associação entre HCV e redução na qualidade de vida relacionada à saúde (QVRS) dos pacientes cronicamente infectados comparados à população geral demonstrada por crescente corpo de evidências na literatura (Bonkovsky e Wooley, 1999; Rodger et al., 1999; Chong et al., 2003; 
Lowry et al., 2016). Uma grande variedade de sintomas apresentados por estes pacientes compromete sua QVRS afetando todos os aspectos de suas vidas.

Segundo Golden et al., 2005, depressão foi documentada em $28 \%$ dos pacientes infectados com HCV antes do tratamento antiviral através de Entrevista Clínica Estruturada do DSM- IV Eixo I: Versão Clínica. A depressão pode simplesmente estar relacionada com o peso psicológico da infecção crônica pelo HCV ou com seu tratamento, apesar de alguns estudos sugerirem que a infecção pelo HCV pode afetar diretamente o SNC e causar alterações na neurotransmissão serotoninérgica e dopaminérgica e, consequentemente, levar ao aparecimento dos sintomas depressivos (Rodger et al., 1999; Forton, 2006; Helbling et al., 2008). Este mecanismo poderia explicar outros sintomas relativos ao SNC observados na infecção pelo $\mathrm{HCV}$, como fadiga e comprometimento cognitivo, embora relação causal ainda precise ser estabelecida (Casato et al., 2005; Weissenborn et al., 2006).

A fadiga é uma das MEH mais comuns da infecção crônica pelo HCV com prevalência de cerca de 50\%, segundo Poynard et al., 2002, e constitui um preditor independente de baixa QVRS (Bonkovsky e Woolley, 1999). Alguns estudos mostraram maior nível de fadiga nos pacientes com infecção pelo HCV que em pacientes com infecção pelo vírus da hepatite $B$ (do inglês, Hepatitis $B$ virus, HBV) e controles sem hepatite (Seaman et al., 2009).

A encefalopatia hepática (EH) é a complicação neuropsiquiátrica mais grave do estágio final da cirrose causada por HBV e HCV. EH franca ocorre em aproximadamente $30 \%$ a $50 \%$ dos pacientes cirróticos e em 10 a $50 \%$ dos 
pacientes com shunts portossistêmicos e compreende um espectro de anormalidades neuropsiquiátricas, desde disfunção cognitiva sutil a coma, causado por shunt venoso portossistêmico, com ou sem doença hepática intrínseca (Sureka et al., 2015). A base fisiopatológica para as manifestações neurológicas da $\mathrm{EH}$ é a derivação do sangue do leito venoso portal para a circulação sistêmica, o que resulta em níveis plasmáticos elevados de manganês e amônia, induzindo distúrbios funcionais de astrócitos e neurônios.

Utiliza-se o termo encefalopatia hepática mínima (EHM) para o quadro de pacientes com cirrose ou shunts portossistêmicos que têm anormalidades sutis em funções cognitivas que não podem ser detectadas pelo exame clínico padrão, e que são evidenciadas apenas durante a realização de tarefas complexas. A prevalência de EHM varia entre $30 \%$ e $84 \%$ em pacientes com cirrose hepática. Os doentes que desenvolvem EHM têm mais frequentemente o álcool como etiologia da cirrose, história de EH manifesta no passado, doença hepática mais grave e varizes esofagogástricas (Dhiman e Chawla, 2009). A EHM é entendida como um distúrbio neurocognitivo leve que compreende alterações da atenção seletiva, velocidade de processamento da informação, percepção visual, habilidades visuoconstrutivas e deficiência nas habilidades motoras finas e coordenação, enquanto a inteligência geral e a linguagem estão preservadas (Weissenborn et al., 2003).

Embora as características neurológicas da EH sejam bem descritas em pacientes com cirrose hepática, relatos e estudos realizados nos últimos 20 anos destacam alterações no desempenho cognitivo de pacientes infectados com 
HCV que emergem muito antes de qualquer evidência de disfunção hepática (Foster et al., 1998; Forton et al., 2001; Forton et al., 2006; Perry et al., 2008).

Em uma revisão sobre o tema, Senzolo et al., 2011, verificaram que a maioria dos relatos sustentam a maior prevalência de alterações cognitivas em pacientes com infecção por HCV, que parece ser independente de história de abuso de substâncias, coexistência de depressão ou EH. Continua ainda indefinido se o comprometimento é diretamente atribuível à infecção em si ou é resultado de uma ou mais comorbidades associadas a esta condição. Déficits nos testes de atenção básica e sustentada, funções executivas, capacidade de aprendizagem verbal, memória verbal e memória de trabalho foram relatados isoladamente ou em combinação quando os pacientes foram comparados com indivíduos não portadores de hepatite C (Forton et al., 2001; McAndrews et al., 2005; Perry et al., 2008). Entretanto, relação causal definitiva entre comprometimento cognitivo e infecção pelo HCV não foi estabelecida de modo inequívoco.

A disfunção neurocognitiva relatada na hepatite C não se correlaciona com a gravidade da doença hepática subjacente, genótipo infectante ou taxa de replicação viral e independe da presença de EH ou EHM (Fletcher e Mckeating, 2012), diferentemente da hepatite B crônica. Portanto, a natureza desta condição seria distinta das complicações neuropsicológicas e neurofisiológicas potencialmente reversíveis observadas em indivíduos com EHM. Nos pacientes não cirróticos com doença crônica pelo HCV estudados por Weissenborn et al., 2004, níveis de ansiedade, fadiga, depressão, atenção e funções executivas 
mostraram-se alterados, enquanto habilidades motoras e funções visuoespaciais estavam relativamente preservadas, diferentemente do que ocorre na EHM, onde se verificam alterações nas funções visuoespaciais e habilidades motoras, sugerindo efeito específico do HCV no cérebro.

Nos pacientes com hepatite $C$ não cirróticos observou-se diminuição da capacidade de concentração, memória de trabalho, velocidade psicomotora e comprometimento da atenção sustentada (Forton et al., 2002; Perry et al., 2008). Estas alterações cognitivas geralmente são leves e podem ser diagnosticadas em cerca de um terço dos doentes. Os pacientes com baixa reserva cognitiva parecem ser particularmente susceptíveis a alterações neurocognitivas induzidas pelo vírus e os déficits parecem refletir alteração da função dos sistemas frontoestriatais, como habilidades motoras finas, aprendizagem e eficiência no processamento da informação. Outros estudos questionam essa associação (Cordoba et al., 2003; Soogoor et al., 2006; Abrantes et al., 2013; Lowry et al., 2016).

Alterações de neuroimagem também foram relatadas em pacientes com hepatite C, como aumento do número de lesões com hipersinal na substância branca periventricular na RM do crânio de pacientes com CM. Estudos com Espectroscopia por RM de Próton Único (ERM-1H) demonstraram aumento de colina nos gânglios da base e na substância branca em alguns pacientes. Entretanto, estes achados são inespecíficos e é incerta sua relação com alterações cognitivas (Casato et al., 2005). 
Achado intrigante é a detecção de cepas de HCV RNA-negativas, consideradas como formas replicativas intermediárias, possivelmente variantes do HCV específicas do cérebro, nos tecidos cerebrais em autópsias (Radkowsky et al., 2002). A possibilidade de ativação imunológica dentro do SNC resultante da infecção pelo HCV foi sugerida, mas ainda não provada. Sacconi et al., 2001, descreveram um paciente com encefalomielite aguda disseminada que se desenvolveu 50 dias após este ter contraído infecção pelo HCV por transfusão sanguínea.

Associação entre miastenia grave e infecção pelo vírus da hepatite $C$ foi sugerida por alguns relatos de casos, embora relação causal não tenha sido claramente definida (Halfon et al., 1996).

\subsection{Instrumentos para avaliação da cognição}

\subsubsection{Miniexame do Estado Mental}

Desenvolvido por Folstein et al., 1975, o Miniexame do Estado Mental (MEEM) é um dos testes mais utilizados em todo o mundo para rastrear a presença de comprometimento cognitivo. Os itens foram formalizados de forma a distinguir pacientes neurológicos de pacientes psiquiátricos, sendo constituído por onze questões que avaliam cinco áreas de função cognitiva: orientação, atenção, cálculo, memória (imediata e tardia) e linguagem. Como ressaltam Brucki et al., 2003, "como instrumento clínico, pode ser utilizado na detecção de perdas cognitivas, no seguimento evolutivo de doenças e no monitoramento de resposta ao tratamento ministrado". A escolaridade é uma variável que influencia 
a pontuação do MEEM e pode gerar falsos negativos em indivíduos com alta escolaridade (Uhlmann e Larson, 1991; Bertolucci et al., 1994; Lourenço e Veras, 2006). Considerando-se o grau de escolaridade, os pontos de corte sugeridos por Brucki et al., 2003, são: analfabetos, 20 pontos; de 1 a 4 anos de estudo, 25 pontos; de 5 a 8 anos de estudo, 26 pontos; entre 9 e 11 anos, 28 pontos e para 12 ou mais anos de estudo, 29. Soma de pontos muito baixa sugere a presença de demência, porém outros transtornos mentais também podem levar a resultados anormais no teste MEEM (Moraes et al., 2010).

Apesar do MEEM não avaliar todos os domínios cognitivos é o instrumento de rastreio cognitivo global mais utilizado e estudado em todo o mundo, além de ser usado também como padrão-ouro e referência na validação de outras avaliações (Melo e Barbosa, 2015).

\subsubsection{Testes para avaliação de funções executivas}

Por "funções executivas" entende-se um conjunto de habilidades cognitivas e princípios de organização necessários para lidar com as situações que se apresentam a cada momento na vida do indivíduo e no relacionamento com outros de forma a garantir uma conduta adequada, responsável e efetiva. Estas habilidades incluem planejamento, coordenação motora fina e autorregulação e dependem do funcionamento de áreas pré-frontais e dos circuitos frontoestriatais (Lezak et al., 2004).

A memória de trabalho é entendida como um sistema de capacidade limitada que permite armazenar e manipular temporariamente informações 
visuais ou verbais necessárias para compreensão, aprendizado, raciocínio e planejamento (Baddeley, 2003).

A disfunção cognitiva executiva pode ter um impacto significativo na capacidade de tomar decisões, mas é particularmente difícil de diagnosticar em alguém com uma pontuação normal no MEEM (Schindler et al., 1995).

Dentre os testes de avaliação de funções executivas mais utilizados no nosso meio estão o teste dos dígitos em ordem direta e indireta, o teste do desenho do relógio e o teste de fluência verbal.

\subsubsection{Teste do Desenho do Relógio}

O teste do desenho do relógio (TDR) é um teste de triagem para detecção de alterações cognitivas muito útil na prática clínica, usado para avaliar funções executivas, praxia construtiva, atenção e habilidades visuoespaciais. Essas funções são dependentes de padrões de funcionamento das regiões frontais e temporoparietais do cérebro (Royall et al., 1998). Para a realização da tarefa é necessário o concurso dos lobos temporais (processos linguísticos e de memória) e dos lobos frontais para execução (Sunderland et al., 1989; Cacho et al., 1999; Lourenço et al., 2008).

O TDR apresenta diversas versões, tanto em relação às instruções para sua realização quanto às normas de avaliação (Sunderland et al., 1989; Mendez et al., 1992; Shulman et al., 1993; Shulman, 2000). Solicita-se ao indivíduo o desenho de um mostrador de relógio com todos os números e com os ponteiros 
mostrando horário previamente estabelecido. Apesar do TDR parecer uma tarefa simples, exige que múltiplos domínios cognitivos funcionem de forma precisa. Para realizar a tarefa de desenhar um relógio o indivíduo deve se lembrar de como é a face do relógio, imaginá-lo e traduzir essa imagem num desenho em papel, o que exige funções visuopercetivas e visuomotoras (Peters e Pinto, 2008). Como depende da atividade normal de várias áreas cerebrais, o TDR é um teste sensível para a detecção de alterações cognitivas (Shulman, 2000). Shulman relatou níveis médios de sensibilidade e especificidade de $85 \%$ entre todas as escalas analisadas de 1983 a 1998.

Vários estudos avaliaram diferentes aspectos do TDR. Em um estudo com idosos da comunidade realizado por Fuzikawa et al., 2003, a confiabilidade inter e intra-examinador do TDR (pelo método de Shulman et al., 1993) mostrouse boa a excelente, embora os autores tenham constatado que os escores propostos talvez não sejam completamente adequados para populações de escolaridade muito baixa. Outra versão do TDR (escore máximo de 10 pontos) foi aplicada a 30 pacientes com demência leve a moderada (22 com doença de Alzheimer) e a 30 controles. Escores abaixo de 5 pontos discriminaram o grupo com comprometimento cognitivo do grupo controle, com $90 \%$ de sensibilidade e $83,3 \%$ de especificidade (Nitrini et al., 1994).

O TDR sofre forte influência de baixa escolaridade sobre o desempenho, o que constitui uma limitação. Segundo Aprahamian et al., 2010, "o TDR é um robusto teste de rastreio quando comparado com o MEEM ou o CAMCOG, independentemente da escala usada para sua interpretação. A combinação com 
o MEEM melhora significantemente sua performance, tornando-o equivalente ao CAMCOG".

O TDR foi validado para uso no Brasil e apresenta notas de corte para a doença de Alzheimer para a nossa população (Atalaia-Silva e Lourenço, 2008; Aprahamian et al., 2008; Lourenço et al., 2008; Aprahamian et al., 2010).

Segundo Tombaugh e Mclntyre, 1992, o TDR como instrumento de triagem tem sensibilidade e especificidade que se aproximam da do MEEM (87 e $86 \%$, respectivamente).

\subsubsection{Teste de Fluência Verbal}

O teste de fluência verbal (FV) consiste em avaliar em um minuto o maior número de palavras verbalizadas pelo paciente, de acordo com uma determinada categoria, semântica ou fonêmica. O teste de FV semântica (categoria animais) é o teste de FV mais empregado em estudos brasileiros que, além de avaliar funções executivas e linguagem, tem a vantagem de também testar a memória declarativa semântica. Os pontos de corte das versões brasileiras variam de acordo com a escolaridade e a idade (Brucki et al., 1997; Brucki e Rocha, 2004; Caramelli et al., 2007; Radanovic et al., 2009).

No estudo Brucki et al., 1997, foram avaliados 336 indivíduos sem demência e 65 pacientes com comprometimento cognitivo. Os autores não observaram diferenças de desempenho em função da idade, mas sim da escolaridade. As notas de corte que melhor discriminaram pacientes de controles 
foram 9 para escolaridade menor que 8 anos e 13 para escolaridade mais alta. A sensibilidade e a especificidade do teste foram baixas para os analfabetos (75\% e $79 \%$, respectivamente).

\subsubsection{Teste dos Dígitos em Ordem Direta e Indireta}

Os testes dos dígitos da bateria Wechsler Adult Intelligence Scale - Third edition (WAIS-III) é um dos testes mais conhecidos para a avaliação da atenção na modalidade auditiva que, apesar de ser concebido como uma tarefa de memória operacional, também demanda a atenção focalizada implicando na atenção executiva, que contribui para a manutenção ativa da informação na memória. A bateria WAIS-III encontra-se traduzida e adaptada para o Português e já estão disponíveis normas para a população brasileira (Nascimento e Figueiredo, 2002).

O teste dos dígitos (WAIS-III) de 1987 consiste em duas tarefas de repetição de uma sequência de números em ordem direta e inversa empregadas na avaliação principalmente da atenção, mas que também exige memória auditiva imediata, atenção e alerta mental. As duas formas do teste exigem repetição de sequências de dígitos em ordem direta (Díg OD) e depois em ordem indireta (Díg Ol) com número crescente de dígitos em cada sequência. Atualmente considera-se que 0 teste dos dígitos avalia principalmente a capacidade de memória de trabalho (auditiva) e a atenção (Figueiredo e Nascimento, 2007). 
Poucos estudos avaliaram o desempenho de pacientes brasileiros em testes de atenção. No estudo de Nitrini et al., 1994, os testes Díg OD e Díg OI foram aplicados a 30 pacientes com demência leve a moderada (22 com doença de Alzheimer) e a 30 controles, com prévio conhecimento dos diagnósticos. Escores abaixo de 5 no teste Díg OD e de 3 no teste Díg Ol apresentaram sensibilidade de $60 \%$ e especificidade de $80 \%$ e $96,7 \%$, respectivamente.

\subsubsection{Correlações entre o Miniexame do Estado Mental e o Teste do Desenho do Relógio}

O MEEM e o TDR são amplamente empregados em protocolos de pesquisa e em situações clínicas para rastreio e triagem de indivíduos com declínio cognitivo (Tombaugh e McIntyre, 1992; Shulman, 2000; Juby et al., 2002; Yang et al., 2016). Combinado com o MEEM o TDR tem uma sensibilidade de $84,9 \%$ e especificidade de $90.4 \%$ no rastreio de comprometimento cognitivo de idosos (Yang et al., 2016). A correlação entre o TDR e o MEEM varia de moderada $(0,30)$ a alta $(0,77)$, com média de 0,61 segundo Shulman, 2000. Os mais altos índices de correlação entre essas escalas foram os encontrados por Mendez et al., 1992, Royall et al., 1998, e por Shulman, 2000. Em nosso meio, Fuzikawa et al., 2003, encontraram correlação moderada entre o MEEM e o TDR em população de idosos com escolaridade formal muito baixa, e nenhuma diferença foi encontrada de acordo com gênero, idade ou escolaridade. Juby et al., 2002, correlacionaram o desempenho no TDR com a disfunção executiva 
(avaliada por meio de entrevista estruturada) e encontraram moderada sensibilidade e especificidade do TDR em indivíduos com MEEM normal.

\subsection{Avaliação de sintomas depressivos, ansiosos e de desesperança}

\subsubsection{Inventário de Depressão de Beck}

O Inventário de Depressão de Beck (do inglês Beck Depression Inventory, BDI) é um instrumento de autoavaliação para a detecção de sintomas depressivos, tanto em pacientes psiquiátricos como em indivíduos da população geral. Em 1996, a versão II do BDI foi reformulada por Beck et al. com o objetivo de se conseguir maior aderência aos critérios diagnósticos para depressão maior, de acordo com o Diagnostic and Statistical Manual of Mental Disorders IV (DSM-IV) da Associação Psiquiátrica Americana (1994). O BDI consiste em uma lista de declarações descritivas relacionadas a 21 aspectos da depressão (Beck et al., 1961). Para cada um destes aspectos existem 4 ou 5 afirmações que denotam gravidade crescente de sintomas depressivos.

A consistência interna do BDI varia de 0,73 a 0,92 com média de 0.86 para populações de pacientes psiquiátricos e 0,81 para populações de pacientes não-psiquiátricos (Beck et al., 1988a).

A validade da versão em Português do BDI e a validação deste questionário foram realizadas em população de universitários brasileiros e em população de indivíduos deprimidos por Gorestein e Andrade, que verificaram 
ter o inventário consistência interna de 0,81 na amostra de universitários brasileiros e de 0,88 na amostra de pacientes deprimidos.

\subsubsection{Inventário de Ansiedade de Beck}

O Inventário de Ansiedade de Beck (do inglês Beck Anxiety Inventory, BAl) consiste em 21 afirmações contendo sintomas comuns de ansiedade. A consistência interna do BAl com índice a de Cronbach é de 0,92 e a confiabilidade em uma semana é de 0,75 (Beck et al., 1988b). Os itens foram selecionados de forma a refletir sintomas característicos de ansiedade, tanto afetiva quanto cognitivamente, mas não de depressão.

\subsubsection{Escala de Desesperança de Beck}

A Escala de Desesperança de Beck (do inglês Beck Hoplessness Scale, BHS) é uma escala dicotômica com afirmações envolvendo cognições sobre desesperança. Consiste em 20 itens e foi idealizada para medir atitudes negativas sobre o futuro, falta de motivação e expectativas e pessimismo. Beck originalmente desenvolveu esta escala para prever quem cometeria suicídio e quem não o faria. O sujeito deve examinar e classificar cada uma das afirmações como certa ou errada para descrever sua atitude na direção da desesperança na última semana, incluindo o dia atual. O seu escore total é resultado da soma dos itens individuais (Beck e Steer, 1988). 


\subsection{Revisão da literatura}

\subsubsection{Neuropatias periféricas nos pacientes com infecção crônica por HCV}

Apartis et al., 1996, estudaram 15 pacientes (oito homens e sete mulheres) com média de idade de 61,2 anos com NP (10 com PNP e 5 com MNM) e CM mista essencial para verificar a positividade de anticorpos anti-HCV, os quais foram encontrados em 10 de 15 pacientes, sete com PNP e três com MNM. Estudos eletrofisiológicos permitiram que as NP fossem classificadas como axonopatias predominantemente sensitivas. Não houve diferença significativa entre os pacientes com e sem anticorpos anti-HCV em relação à duração e tipo de NP. Entretanto, pacientes com anticorpos anti-HCV pareciam ter acometimento mais grave, com déficit motor mais pronunciado. Três deles tinham NP sensitivomotora, enquanto todos os pacientes anti-HCV negativos tinham NP predominantemente sensitiva. O início do déficit motor foi subagudo ( $<4$ meses) em três pacientes com HCV e lentamente progressivo (> 6 meses) nos pacientes anti-HCV negativos.

Ripault et al., 1998, realizaram estudo prospectivo onde avaliaram 36 pacientes HCV com o objetivo estudar a prevalência de NP associada à hepatite C crônica e suas características clínicas, eletrofisiológicas e histológicas. NP foi diagnosticada em sete pacientes (19\%). Em três pacientes que apresentavam parestesias nas pernas, NP sensitiva axonal foi evidenciada por ENMG. Biópsia neuromuscular realizada em dois desses pacientes mostrou em um deles intensa diminuição de fibras mielinizadas associada a lesões vasculíticas. Biópsia de pele foi realizada no terceiro paciente com púrpura nos membros 
inferiores revelando vasculite leucocitoclástica. Foram detectadas CG séricas em dois desses pacientes. Os autores concluíram que a prevalência de NP na hepatite $\mathrm{C}$ crônica é de $8 \%$ e que pode estar associada à CM, sendo geralmente uma NP axonal com diminuição de fibras mielinizadas com presença de lesões vasculíticas, na ausência de CM.

Zaltron et al., 1998, estudaram 89 pacientes com infecção pelo HCV e CM sintomática ou assintomática realizando exames eletrofisiológicos para avaliar a prevalência de NP. Encontraram evidências eletrofisiológicas de NP em $37 \%$ significativamente associada com a presença de CM, idade avançada, maior reatividade ao FR e níveis de IgM, além de redução da atividade da fração C4 do complemento. Os autores concluíram que NP está presente na maioria dos pacientes com CM sintomática e que pode ser a primeira manifestação clínica. As evidências eletrofisiológicas de NP não se correlacionaram com os níveis séricos de CGs e nem ao tipo de CM. NP foi encontrada em 23/68 pacientes sem qualquer sintoma de CM, a não ser dores e parestesias.

Tembl et al., 1999, publicaram uma série de nove pacientes que apresentavam complicações neurológicas da infecção por hepatite $C$, sete dos quais apresentavam uma combinação de PNP sensitiva crônica, MNM e encefalopatia relacionados à CM. Os sintomas "não crioglobulinêmicos" consistiam em neuropatia óptica anterior e síndrome das pernas inquietas com neuropatia de fibras finas. Corticosteroides e ciclofosfamida foram utilizados e se mostraram úteis para o controle dos episódios de vasculite. O tratamento com Interferon- $\alpha$ levou à remissão da hepatite $\mathrm{C}$ em metade dos casos tratados. 
Cacoub et al., 1999, realizaram estudo retrospectivo de 1.614 pacientes com hepatite C crônica. O genótipo foi determinado em 566 pacientes, 143 dos quais eram portadores dos genótipos 2 ou 3 (25\%) e 423 dos genótipos 1, 4, 5 ou 6 (75\%). Parestesias foram referidas por $17 \%$ dos pacientes e DM por $7 \%$. CGs estavam presentes em 434 dos 1.083 pacientes (40\%). Todos os pacientes com CGs no soro tinham CM tipo II (65\%) ou tipo III (35\%). Os pacientes com CM eram mais velhos que aqueles sem CM (48,8 vs 45,5 anos). Embora parestesias fossem frequentemente relatadas, NP com anormalidades comprovadas por estudo eletrofisiológico raramente foi registrada em prontuário. Pelo menos uma MEH clínica foi observada em 1.202 pacientes (74\%) envolvendo principalmente as articulações, pele e músculos. Várias anormalidades imunológicas foram observadas, como a presença de CGs (40\%), anticorpos antinucleares (10\%) e anticorpos antimúsculo liso (7\%). A única associação significante entre o quadro clínico e anormalidades imunológicas foi observada em pacientes com $\mathrm{CM}$, que mais frequentemente relatavam artralgia, hipertensão arterial, púrpura e vasculite. A análise multivariada constatou que os principais fatores associados à presença de anormalidades clínicas ou biológicas extra-hepáticas em pacientes com Hepatite C foram sexo feminino, idade avançada e fibrose hepática avançada (Cacoub et al., 1999).

Cacoub et al., 2000, avaliaram prospectivamente 321 pacientes com HCV cronicamente infectados, com média de idade de 46 anos, recrutados de vários centros na França. $\mathrm{O}$ estudo objetivou determinar a prevalência de MEH associadas à infecção pelo HCV, identificar associações entre manifestações 
clínicas e biológicas e comparar os resultados obtidos em subgrupos HIV positivos versus grupos negativos para tal. Nesta casuística, 74 pacientes eram coinfectados por HIV e 72 pacientes estavam sendo tratados com Interferon. Os pacientes tratados foram comparados com 242 pacientes não tratados.

As MEH foram mais frequentes nos pacientes tratados do que nos pacientes não tratados e estavam associadas com a presença de CGs. NP sensitivas ou motoras foram mais frequentes nos pacientes tratados ( $18 \%$ vs 7\%) e estavam presentes antes do tratamento. Trinta e oito por cento dos pacientes apresentaram pelo menos uma MEH clínica, incluindo artralgia (19\%), manifestações cutâneas (17\%), xerostomia (12\%), xeroftalmia (10\%) e NP sensitiva (9\%). As principais anormalidades laboratoriais foram a CM mista em $56 \%$, trombocitopenia em $17 \%$, presença de anticorpos antinucleares em $41 \%$, FR em 38\%, anticorpos anticardiolipinas em 27\%, anticorpos antitireoglobulina em $13 \%$ e anticorpos antimúsculo liso em $9 \%$. Pelo menos um autoanticorpo estava presente em $70 \%$ dos soros. Os quatro parâmetros significativamente associados à presença de CGs eram vasculite sistêmica, soropositividade para HIV, positividade para FR e síndrome sicca (Cacoub et al., 2000).

Nemni et al., 2003, examinaram uma série de 51 pacientes com infecção crônica por HCV com NP para avaliar a prevalência de CG e esclarecer os mecanismos patogenéticos pelos quais 5 o HCV determina NP. Foram excluídos pacientes com outras causas de NP (DM, abuso de álcool, insuficiência renal, deficiência de vitaminas, distúrbios da tireoide, neoplasias, e NP tóxicas), com exceção da presença de gamopatia monoclonal.Todos os pacientes foram estudados clinicamente, sorologicamente e eletrofisiologicamente e 28 pacientes 
foram submetidos à biópsia de nervo. Quarenta pacientes tinham CGs presentes no soro. O exame clínico revelou quatro padrões diferentes de envolvimento de nervos periféricos, PNP, MN e /ou MNM, neuropatia craniana e PNP combinada com neuropatia craniana. A PNP era sensitivomotora simétrica com predominância de características sensitivas. Dos 40 pacientes com CM, 45\% tinham PNP, 40\% MN/MNM, 7,5\% neuropatia craniana e 7,5\% combinação de PNP e neuropatia craniana. Dentre os 11 pacientes sem CM, cinco pacientes tinham neuropatia craniana (46\%), quatro pacientes apresentavam MN (36\%), um paciente apresentava PNP (9\%) e um paciente combinou PNP e neuropatia craniana (9\%). A prevalência de PNP foi significativamente maior nos pacientes com CM em comparação aos que não a apresentavam (45\% vs $9 \%)$. A presença de neuropatia craniana foi significativamente maior nos pacientes com CGs (46\% vs $7,5 \%)$.

Os autores observaram que considerando neuropatia craniana, MN / MNM e PNP como expressão de um processo mononeurítico, houve diferença significativa entre os grupos de pacientes com CGs e os que não as apresentavam, com os pacientes sem CGs mais frequentemente desenvolvendo processos mononeuríticos bem definidos (90\%), quando comparados com pacientes com CGs (55\%). Pacientes com CGs apresentaram proporção significativamente maior de positividade do FR $(87,5 \%$ vs $18 \%)$ e níveis mais baixos de C4 (92,5\% vs $45,5 \%)$. Aumento de atividade de transaminases (alanina aminotransferase $(\mathrm{ALT})>70 \mathrm{U} / \mathrm{L}$ ), possível expressão do efeito citopático do HCV, foi encontrado em $67,5 \%$ dos pacientes com CGs em comparação com 45,5\% dos pacientes sem CGs, embora a diferença não tenha 
alcançado significância estatística. Biópsia de nervo foi realizada em 25 pacientes com CGs. Vasculite epineural foi encontrada em 32\% dos pacientes, perda fascicular de axônios em $40 \%$ e sinais de desmielinização e degeneração axonal em $28 \%$. Três dos 11 pacientes sem CGs foram submetidos à biópsia do nervo sural. Dois pacientes tinham vasculite epineural e um mostrou perda fascicular de axônios. Em todos os casos a preparação das fibras demonstrou degeneração axonal sem evidência de desmielinização. A comparação de características neuropatológicas não demonstrou nenhuma diferença significativa entre grupos com e sem CGs no soro.

No México, Téllez-Zenteno et al., 2003, também estudaram a frequência e os fatores de risco associados à NP em pacientes com infecção pelo HCV através da realização de estudo caso-controle com avaliação eletrofisiológica (estudos bilaterais das velocidades de condução motora e sensitiva) nos quatro membros. Trinta e um casos e 31 controles foram incluídos. Evidências de NP foram encontradas em 18 pacientes (58\%) portadores de HCV e em apenas três (10\%) sujeitos do grupo controle. Entre os fatores de risco para NP nos pacientes infectados pelo HCV os autores encontraram positividade do FR, presença de $\mathrm{CM}$ e cirrose ou hepatite ativa, idade avançada, tempo prolongado de evolução da infecção pelo HCV, alta carga viral e níveis baixos do complemento.

Em nosso meio, Vigani et al., 2005, descreveram um homem de 48 anos com infecção crônica pelo HCV e hepatite moderada à biópsia hepática, $\mathrm{CM}$ e NP sensitivomotora. O diagnóstico de MNM foi confirmado por exame clínico e ENMG. O paciente foi submetido a biópsia de nervo que revelou infiltrado inflamatório perineural, sinais de desmielinização e degeneração axonal. 0 
paciente foi tratado com Interferon- $\alpha$ e ribavirina por 48 semanas. Seis meses após o final da terapia o paciente teve resposta virológica sustentada (RVS) e remissão dos sintomas neurológicos, mas as CGs ainda eram detectáveis.

Em 2006, Santoro et al. estudaram prospectivamente 234 pacientes (120 mulheres) com média de idade de 52,3 anos de sete centros secundários ou terciários de atendimento na Itália. CGs foram detectadas nos soros de 29,3\% dos pacientes testados, constatando-se CM tipo II em todos os casos. Todos os pacientes eram virgens de tratamento. NP clínica foi diagnosticada em 25 dos 234 pacientes $(10,6 \%)$ e todos apresentavam evidências eletrofisiológicas de NP. Além disso, o exame eletrofisiológico revelou NP subclínica em 11 pacientes adicionais $(4,7 \%)$ e, portanto, o exame eletrofisiológico detectou NP em 36 dos 234 pacientes (15,3\%). PNP sensitivomotora axonal foi diagnosticada em $52,8 \%$ dos casos com NP e MNM em 47,2\%, respectivamente. Não foram encontrados sinais eletrofisiológicos de desmielinização ou envolvimento de nervos cranianos. NP não se correlacionou com a duração da infecção, carga viral ou sexo dos pacientes, mas sim com a idade. Trinta pacientes tinham queixas de dor, parestesias em queimação e fadiga, mas não mostravam sinais clínicos ou eletrofisiológicos de NP. Os pacientes com CGs não diferiram significativamente daqueles sem CGs quanto à idade, sexo, centro de referência, duração da infecção pelo HCV e achados eletrofisiológicos. Os autores verficaram que a prevalência de CM tende a aumentar significativamente com a idade dos pacientes e com a duração da doença. NP estava presente em $21 \%$ dos pacientes com CM versus $13 \%$ dos sem CM. 
Gomes et al., 2006, realizaram estudo na região amazônica para determinar a prevalência de NP através de parâmetros clínicos e neurofisiológicos em pacientes com infecção crônica por HCV. Foram avaliados 78 pacientes com média de idade de 45,5 anos. Parestesias foram relatadas por $34,6 \%$ dos pacientes, principalmente nos membros superiores. MNM foi encontrada em $14,1 \%$ dos pacientes e síndrome do túnel do carpo (STC) em $5,1 \%$. Todas as MNM ocorreram em homens e apenas um dos quatro pacientes com STC era mulher.

Boukhris et al., 2006, descreveram dois casos de PNP desmielinizante em pacientes infectados por HCV. Uma paciente de 77 anos com CM mista tipo Il desenvolveu déficit motor distal progressivo crônico e distúrbios sensitivos. Seus exames laboratoriais eram normais, com exceção da presença de CGs, aumento de ALT e diminuição da fração hemolítica do complemento. A outra paciente, com 68 anos de idade, tinha queixas sensitivas nos membros inferiores e apresentava CM mista tipo II. Os exames do LCR das duas pacientes eram normais. Em ambos os casos estudos de condução nervosa foram sugestivos de NP sensitivomotora mista axonal e desmielinizante. As biópsias de nervo sural mostraram desmielinização segmentar e perda grave de grandes fibras mielinizadas, bem como formações com aspecto "em bulbo de cebola" em ambos os casos. As duas pacientes melhoraram com tratamento, a primeira com tratamento antiviral e a segunda com corticosteróides por via oral.

Em um estudo de 40 pacientes com infecção crônica por HCV realizado no Egito por Al-Soud et al., 2011, NP foi diagnosticada por exame eletrofisiológico em 14 pacientes (35\%) e NP clínica foi verificada em 10 
pacientes (25\%). Os autores separaram os pacientes em grupos de acordo com o grau de lesão hepática e não observaram diferença estatística entre eles com relação à presença de NP e nem quanto às velocidades de condução sensitiva e motora. CGs séricas foram detectadas em 10 (71,43\%) pacientes com NP.

Na Alemanha, Yoon et al., 2011, estudaram 46 pacientes com infecção por HCV com CGs ausentes no soro (19 homens e 27 mulheres, com média de idade de 48 anos) e 28 controles (13 homens e 15 mulheres, com média de idade de 44 anos), com gênero e idades correspondentes. Os sintomas mais frequentemente relatados foram parestesias $(39 \%)$, dos quais $50 \%$ foram relatados como dor, $23,9 \%$ como dormência, $11 \%$ como câimbras noturnas nos membros inferiores, 8,7\% como alodinia e 6,5\% como sensação de ardência nos pés. Foram registrados potenciais evocados relacionados à dor (PERD) de todos os participantes, que também foram submetidos a avaliação clínica e exame eletrofisiológico para estudo da velocidade de condução sensitiva. Os autores dividiram os pacientes em três grupos, de acordo com a velocidade de condução sensitiva e avaliação clínica, sendo (1) pacientes sem sintomas neuropáticos e com velocidade de condução sensitiva normal; (2) pacientes com sintomas neuropáticos e velocidade de condução sensitiva normal e (3) pacientes com sintomas neuropáticos e velocidade de condução sensitiva anormal.

A prevalência de NP em pacientes com infecção por HCV com CG ausentes foi de $43,5 \%$, incluindo o comprometimento de fibras finas. Parestesias, dormência e câimbras noturnas foram os sintomas mais proeminentes, enquanto reflexo do tendão de Aquiles ausente e aumento do limiar de percepção de vibração foram as alterações neurológicas mais frequentes detectadas nesses 
pacientes. Velocidade de condução sensitiva e PERD foram anormais em 13 pacientes com sintomas neuropáticos (28\%). PERD anormal e velocidade de condução sensitiva normal foram encontrados em $11 \%$ dos pacientes com sintomas neuropáticos e em dois (4\%) sem sintomas neuropáticos. Anormalidades do PERD não se correlacionaram com a duração da doença, carga viral atual ou genótipo do HCV e foram mais frequentes $(48,5 \%)$ nos pacientes com Hepatite $\mathrm{C}$ tratados com Interferon do que em pacientes virgens de tratamento $(30,8 \%)$, no entanto a diferença não foi significativa. Os autores verificaram que todos os subtipos de vírus HCV podem induzir NP, não houve diferença entre pacientes tratados com Interferon e pacientes virgens de tratamento e a prevalência de NP sensitiva, incluindo a de pequenas fibras sensitivas, foi de $43,5 \%$ e concluíram que a detecção de NP associada ao HCV depende do método de avaliação.

No Egito, Khalek et al., 2012, compararam 80 pacientes com infecção por HCV recém diagnosticada, virgens de tratamento, com média de idade 40,1 anos, com 20 voluntários saudáveis com idades e gênero correspondentes, de forma a verificar a presença de NP. Foram excluídos pacientes HIV positivos, diabéticos, portadores de doenças autoimunes e transtornos hematológicos malignos e os que referiram consumo de álcool. Os pacientes foram submetidos a dosagens de anticorpos anti-GM1, ultrassom de abdome e biópsia hepática, além de exame eletrofisiológico dos nervos periféricos. A velocidade de hemossedimentação, proteína $\mathrm{C}$ reativa, FR e anticorpos antinucleares foram significativamente maiores nos pacientes que nos controles, enquanto a fração C4 do complemento foi significativamente menor. Outros parâmetros 
laboratoriais mostraram diferenças estatísticas significativas entre pacientes e controles, incluindo transaminases séricas e anticorpos antineuronais. Criócrito (porcentagem do volume do soro representado pelas CGs) maior que $0,1 \%$ foi encontrado em $15 \%$ dos pacientes. NP clínica foi diagnosticada em 36 dos 80 pacientes (45\%). Todos os que tinham diagnóstico clínico de NP tinham também evidência eletrofisiológica de NP. O exame eletrofisiológico revelou NP subclínica em 18 pacientes (22,5\%) e, portanto, 54 pacientes $(67,5 \%)$ foram diagnosticados com NP por eletrofisiologia. NP axonal predominantemente sensitiva foi encontrada em $70,3 \%$ dos pacientes (38/54) com NP afetando predominantemente os membros inferiores, e PNP mista desmielinizante e axonal sensitivomotora em 29,7\%, com predominância do acometimento sensitivo.

Houve correlação significativa da alteração da maioria dos parâmetros de condução nervosa com a idade dos pacientes, duração da doença, velocidade de hemossedimentação, positividade do FR, $\lg M$ e $\lg G$ anti-GM1, carga viral e presença de GC séricas. Todos os pacientes com CGs no soro tinham NP (10 com NP clínica e dois com NP subclínica). Foi verificada correlação negativa significativa entre os parâmetros de condução nervosa e baixos níveis séricos da fração C4 do complemento, mas não foi encontrada correlação significativa entre os parâmetros de condução nervosa e o estadiamento da fibrose hepática. Títulos elevados de anticorpos antineuronais estavam associados a anormalidades eletrofisiológicas em 92,6\% (50/54) dos casos de NP.

Abdelkader et al., 2014, realizaram estudo prospectivo cujo objetivo foi provar a associação entre NP e doença hepática crônica causada por HCV, além 
de avaliar a correlação entre a gravidade da disfunção hepática e a presença de NP e neuropatia autonômica e também investigar o papel do nível de vitamina B12 na etiologia da NP. Para tal, estudaram 50 pacientes que foram divididos em dois grupos, segundo o grau de disfunção hepática (25 pacientes com cirrose hepática leve e $25 \mathrm{com}$ cirrose hepática grave). Estes 50 pacientes foram comparados com 25 indivíduos saudáveis sem doença hepática, com distribuições de gênero e idade comparáveis a dos pacientes.

O exame neurológico mostrou que $22 \%$ dos pacientes apresentavam anormalidades sensitivas e 18\% anormalidades motoras, enquanto apenas $10 \%$ apresentavam ambas. O estudo eletrofisiológico mostrou anormalidade da VCS em 8 pacientes (32\%) do grupo com cirrose hepática leve e em 10 pacientes (40\%) no grupo com cirrose grave, totalizando 18 pacientes (36\%) com alteração da velocidade de condução sensitiva. A diferença estatística não foi significativa entre os grupos. Também não foi encontrada relação significativa entre o nível de vitamina B12 e NP afetando pacientes com doença hepática crônica relacionada ao $\mathrm{HCV}$.

Trabalho prospectivo foi realizado por Biasiotta et al., 2014, para estudar as características clínicas, neurofisiológicas e achados em biópsias cutâneas de pacientes com NP associadas com CM relacionada ao HCV. Dos 69 pacientes estudados, 47 (68\%) tinham NP, em sua grande maioria (45/47 pacientes) PNP simétrica predominantemente sensitiva distal envolvendo todas as modalidades sensitivas. Dos 45 pacientes com PNP, quatro tinham NP de fibras finas. Dois pacientes tinham MNM. Nenhum paciente tinha MN isolada ou NP predominantemente motora. Os autores relataram que os dois pacientes com 
MNM apresentavam distúrbios sensitivos imitando uma PNP distal simétrica de fibras mistas. Os pacientes com NP eram mais velhos que os que não apresentavam NP e a duração da infecção por HCV era maior, porém não foi verificada diferença na duração da $\mathrm{CM}$. A frequência de NP em pacientes com criócrito $\geq 5 \%$ não diferiu daquela dos pacientes com criócrito $<5 \%$. 0 desenvolvimento da NP não estava relacionado ao genótipo do HCV. Os autores verificaram que a densidade de fibras nervosas intraepidérmicas e a amplitude dos potenciais evocados sensitivos do nervo sural foram inversamente correlacionados com a duração da infecção pelo HCV. Dos 47 pacientes com NP, $29(62 \%)$ tinham dor neuropática e todos relataram parestesias. Quatro pacientes $(6,5 \%)$ apresentavam distúrbios sensitivos distribuídos distalmente, mas com estudo de condução nervosa normal, denotando neuropatia de fibras finas. A conclusão foi que as principais variáveis clínicas para o desenvolvimento de NP são idade e duração da infecção por HCV (Biasiotta et al., 2014).

Mariotto et al., 2014, estudaram uma coorte de 59 pacientes consecutivos com NP e infecção crônica por HCV que foram submetidos a biópsia do nervo sural. CGs foram detectadas em 39 pacientes (18 com PNP axonal, 11 com MNM sobreposta e 10 com MNM). Quatorze pacientes sem CGs circulantes tiveram teste positivo para $F R, 10$ dos quais tinham PNP, um apresentava uma forma de sobreposição e três, MNM. Entre os seis pacientes que foram negativos para CGs e FR, gammopatia IgM monoclonal com atividade anti-MAG (glicoproteína associada à mielina) foi detectada em três indivíduos com PNP desmielinizante. 
Mastroianni et al., 2017, estudaram retrospectivamente uma série de 783 pacientes com infecção por HIV para identificar síndrome do túnel do carpo (STC) e verificar sua relação com a infecção por HIV, terapia antiretroviral e comorbidades. Cento e oitenta e dois pacientes apresentavam NP dos quais 12 tiveram diagnóstico de STC com base em sinais e sintomas físicos, bem como em estudos de condução nervosa. Todos os pacientes com HIV nos quais foi verificada STC eram coinfectados por HCV. Sete pacientes tinham o genótipo 1 do HCV, quatro o genótipo 2 e um, o genótipo 3. Os autores verificaram que a duração da doença pelo HIV, terapia antiviral e positividade para HCV foram os mais importantes fatores de risco para o desenvolvimento de STC.

Russi et al., 2018, realizaram biópsias de nervo sural de 11 pacientes com hepatite $\mathrm{C}$ e sintomas neuropáticos, cinco dos quais portadores de $\mathrm{CM}$, utilizando hibridização in situ e imunofluorescência para a detecção de sequências genômicas e antigenômicas de RNA-HCV e glicoproteína E2 do HCV, respectivamente. Depósitos vasculares epineurais de glicoproteína E2 foram encontrados em quatro (80\%) dos pacientes com CM e em dois $(33,3 \%)$ pacientes sem CM. Essas descobertas foram realçadas pelo encontro de deposição perivascular de RNA replicativo positivo, embora não da fita negativa de RNA, nos extratos nervosos de todos os pacientes. Leves infiltrados de células inflamatórias sem depósitos de lgs e / ou proteínas do complemento foram encontrados em torno de pequenos vasos, sem alterações distintas de vasculite entre pacientes com e sem $\mathrm{CM}$. Os autores concluíram que os resultados indicavam que depósitos de RNA/ E2 de HCV nos vasos de nervos periféricos associados aos infiltrados inflamatórios perivasculares foram 
semelhantes em pacientes cronicamente infectados pelo $\mathrm{HCV}$, independentemente da ocorrência de CM. Dada a falha na demonstração de fitas negativas de RNA-HCV nas biópsias de nervo sural examinadas, é provável que os danos fossem causados por mecanismos imunomediados desencadeados pelo vírus.

Mapoure et al., 2018, estudaram 121 pacientes com hepatite C crônica na África subsaariana e verificaram que $62,8 \%$ apresentaram pelo menos uma manifestação neurológica, sendo as do SNP as mais comuns (50,4\%). A idade, maior duração da doença e alta carga viral foram significativamente associados às manifestações neurológicas. A NP foi a manifestação neurológica mais comum (49,6\%), apresentando-se principalmente como NP sensitiva $(47,9 \%)$. Idade maior que 55 anos e maior duração da doença hepática foram significativamente associados à presença de NP. A maioria dos participantes $(63,6 \%)$ era assintomática ao tempo do diagnóstico e $55,4 \%$ eram virgens de tratamento. CM foi encontrada em $72,9 \%$ dos pacientes, mista na maioria dos casos (92,8\%). O genótipo mais comum foi o 1, presente em $51,6 \%$ dos pacientes. Escores de fibrose de 87 participantes foram determinados, dos quais $69,2 \%$ apresentaram grau de fibrose significativo. Os sintomas mais comuns relatados durante o período do estudo foram câimbras (40,5\%), parestesias $(38,8 \%)$ e fadiga $(28,9 \%)$. Os autores encontraram anormalidade de nervos cranianos em $4,1 \%$ dos pacientes (mais frequentemente, a paralisia facial unilateral). 


\subsubsection{Alterações neuropsiquiátricas nos pacientes com hepatite C crônica}

Em 2002, Forton e colaboradores utilizaram bateria cognitiva computadorizada para estudar a função cognitiva de 27 pacientes com infecção crônica pelo HCV com carga viral positiva e hepatite leve comprovada por biópsia e a de 16 sujeitos que haviam clareado o HCV. Esses sujeitos foram comparados com grupo de 29 indivíduos saudáveis recrutados entre os funcionários da instituição onde foi realizado o estudo. Os participantes do estudo também preencheram questionários sobre depressão, fadiga e QVRS. Os pacientes com hepatite $\mathrm{C}$ crônica mostraram maior prejuízo em mais tarefas computadorizadas na atenção seletiva, concentração e memória de trabalho em comparação com controles saudáveis e com o grupo que clareou o HCV. Não houve diferenças estatísticas entre os indivíduos com e sem histórico de uso de drogas recreativas. Embora os pacientes infectados pelo HCV tivessem níveis mais elevados de depressão e tenham relatado prejuízos na QVRS, essas variáveis não se correlacionaram com os escores dos testes cognitivos. O estudo concluiu que comprometimento cognitivo leve era evidente em uma proporção de pacientes com infecção crônica por HCV histologicamente leve, que não podia ser explicado por depressão, fadiga ou histórico de abuso de drogas. Um subgrupo de 17 doentes infetados pelo HCV também foi submetido à ERM-1H, técnica que fornece informações sobre o metabolismo cerebral. A relação colina/creatina cerebral estava elevada nos gânglios da base e na substância branca, achado este que não se correlacionou com o abuso prévio de substâncias. Pacientes com comprometimento cognitivo tiveram mais anormalidades à ERM-1H. Os pacientes que tinham alteração em duas ou mais 
tarefas na bateria computadorizada tinham maior proporção de colina/creatina em comparação com os doentes não comprometidos. Os autores também concluíram que os pacientes HCV mostraram mais depressão, fadiga, e piores escores nos questionários de QVRS do que os que clarearam o HCV.

Kramer et al., 2002, usaram potenciais evocados P300 eventorelacionados, que se referem ao processamento cognitivo, numa coorte de 100 pacientes com hepatite C crônica não tratados. Avaliaram também a QVRS e fadiga através do Short-Form-36 (SF-36) - questionário com 36 questões para avaliação da qualidade de vida relacionada à saúde - e da Escala de Impacto da Fadiga. Os indivíduos infectados pelo HCV tinham latências de pico de P300 retardadas e redução da amplitude dos potenciais evocados quando comparados com controles normais, pareados por idade. Dezessete por cento dos pacientes HCV tinha latência de P300 fora da faixa normal ajustada para a idade, sugerindo leve, mas significante, comprometimento cognitivo. Medidas alteradas de P300 não foram relacionadas ao grau de atividade histológica da hepatite ou ao grau de alteração bioquímica dos pacientes e não mostraram relação com a gravidade da fadiga ou abuso de drogas ou álcool.

Hilsabeck et al., 2002, administraram bateria de testes para medidas de habilidades visuoconstrutivas, aprendizado, atenção visual sustentada, memória, concentração, velocidade de processamento psicomotor, rastreamento visual e flexibilidade mental a 66 pacientes infectados por HCV, dos quais 44 não tinham cirrose. Os pacientes com hepatite $C$ foram divididos em dois grupos, aqueles com hepatite $\mathrm{C}$ isolada e aqueles com hepatite $\mathrm{C}$ e outra doença comórbida crônica. Os pacientes constituíam um grupo 
heterogêneo, $27 \%$ fazendo uso de medicamentos psicotrópicos e $23 \%$ em tratamento com Interferon quando dos testes. A maioria da amostra (67\%) admitiu história de abuso de drogas ilícitas e três pacientes, uso de drogas no último mês. A maioria (69\%) negou uso atual de álcool e apenas 4\% da amostra relatou uso de álcool mais de duas a quatro vezes por mês.

Os pacientes com hepatite $\mathrm{C}$ foram comparados com um grupo de 14 pacientes com doenças hepáticas de outras etiologias. Desempenhos alterados variaram de zero (tarefa de cópia de desenho) a 49\% (atenção sustentada). Comprometimento em vários testes neuropsicológicos foi encontrado em cerca de $49 \%$ dos pacientes com hepatite C sem cirrose, nos domínios de atenção e memória de trabalho. Não houve diferenças significativas dos escores nos testes entre pacientes infectados pelo $\mathrm{HCV}$ isoladamente e pacientes com outras doenças crônicas do fígado. Entretanto, uma proporção maior de pacientes com HCV com doenças comórbidas teve desempenho comprometido que pacientes com hepatite $\mathrm{C}$ isolada ou que pacientes com outro tipo de doença hepática crônica. Diferenças significativas foram encontradas entre os pacientes com hepatite $C$ isolada e pacientes com hepatite $C$ mais outra condição crônica em quatro de oito medidas neuropsicológicas: tempo de cancelamento de dígitos, teste de trilhas, partes A e B e teste de associação símbolos-dígitos. Além disso, esses dois grupos de pacientes com hepatite $\mathrm{C}$ diferiram significativamente em relação ao nível de fibrose, com os pacientes com hepatite $C$ com outra comorbidade apresentando fibrose significativamente mais pronunciada. Maior grau de fibrose foi significativamente associado com pior funcionamento cognitivo. Os autores concluíram que lesão hepática progressiva pode resultar 
em problemas cognitivos nos pacientes com hepatite C, mesmo antes do desenvolvimento de cirrose (Hilsabeck et al., 2002).

Em estudo realizado em 2003, Hilsabeck et al. avaliaram 21 pacientes com hepatite C para estudar disfunção cognitiva subjetiva, depressão, ansiedade e fadiga e comparar essas categorias de sintomas com resultados de testes para avaliação de habilidades visuocontrutivas, aprendizagem, memória, atenção visual, velocidade psicomotora e flexibilidade mental. Os resultados revelaram que o comprometimento cognitivo variou de nove por cento dos pacientes em tarefa de visuoconstrução a 38\% em testes de atenção complexa, rastreamento visual e velocidade psicomotora. Maior gravidade da doença hepática, verificada por biópsia, foi associada com maior grau de comprometimento cognitivo. $\mathrm{O}$ prejuízo cognitivo objetivo não se correlacionou com queixas cognitivas subjetivas ou com sintomatologia psiquiátrica, sugerindo que parcela significativa dos pacientes com hepatite $\mathrm{C}$ tem dificuldades cognitivas que podem interferir com as atividades da vida diária.

Cordoba et al., 2003, realizaram um estudo para avaliar a QVRS e funções cognitivas de 120 pacientes com hepatite $\mathrm{C}$ em diferentes estágios da doença hepática. Para tanto, os autores avaliaram três grupos de pacientes que cobriam fases clinicamente relevantes da doença, sendo 40 pacientes com hepatite crônica, 40 com cirrose sem descompensações prévias e 40 com cirrose com descompensações prévias (ascite, hemorragia gastrointestinal ou encefalopatia hepática). O objetivo era investigar a influência da função cognitiva na QVRS e explorar possíveis associações entre a QVRS e características 
clínicas dos pacientes. Foi incluído grupo controle de 40 indivíduos saudáveis com idade, gênero e anos de escolaridade comparáveis (Cordoba et al., 2003).

Aos participantes foi aplicado o questionátio SF-36 (avaliação da QVRS), inventário de ansiedade, teste de aprendizagem verbal auditiva, teste de trilhas, teste de Stroop, julgamento de orientação de linha e teste de fluência verbal fonêmica. Pacientes com hepatite C crônica sem cirrose ou com cirrose compensada apresentaram diminuição da QVRS, apesar de resultados normais nos testes neuropsicológicos. Pacientes com cirrose descompensada exibiram uma diminuição adicional na QVRS e aumento nas anormalidades neuropsicológicas. A diminuição da QVRS associou-se à gravidade da insuficiência hepática, anormalidades neuropsicológicas e tratamento com betabloqueadores e diuréticos.

Weissenborn et al., 2003, estudaram a memória de pacientes com EH precoce. Foram aplicados testes a 45 pacientes cirróticos com graus baixos de EH (grau zero, 27 pacientes; mínima, 9 pacientes; grau I, 9 pacientes) e a 52 controles. A bateria de testes incluiu testes de memória imediata e tardia. A EHM foi diagnosticada pela Escala Psicométrica de Encefalopatia Hepática (EPEH) e pelo exame neurológico. A EPEH compreende o teste de trilhas partes A e B, teste de associação símbolos-dígitos, teste de rastreamento de linha e o teste de pontilhamento seriado. A etiologia do comprometimento hepático dos pacientes era variada, seis pacientes apresentando hepatite C, 12 pacientes hepatite $B$, cinco pacientes cirrose biliar primária, 11 pacientes cirrose de origem desconhecida, 7 pacientes hepatite autoimune, dois pacientes síndrome de Budd-Chiari, um paciente hemocromatose e um paciente colangite esclerosante 
primária. Pacientes e controles não diferiram significativamente em relação à idade e nível educacional. Foram encontradas diferenças estatísticas entre os grupos nos resultados da EPEH. Enquanto apenas os pacientes com EH precoce obtiveram resultados anormais na EPEH, uma comparação das médias dos resultados dos testes de pacientes e controles mostrou que mesmo os pacientes com grau zero de $\mathrm{EH}$ tiveram pontuação mais baixa que os controles na maioria dos subtestes da EPEH, embora os resultados estivessem dentro da faixa normal. Na maioria das tarefas de memória, os resultados foram semelhantes em pacientes com EH grau zero e controles. Resultados anormais foram observados especialmente em relação à memória imediata de itens apresentados visualmente. Os autores também realizaram estudo mais aprofundado, com ênfase especial nas diferenças entre as habilidades de recordação livre e reconhecimento em pacientes com doença hepática crônica não alcoólica, com e sem EH precoce, e verificaram que os pacientes com EH grau zero obtiveram resultados semelhantes aos controles em todos os testes, exceto dois. Os pacientes com EH precoce (EHM e EH grau I) pontuaram abaixo dos controles em todos os testes aplicados. Uma análise detalhada do desempenho no teste mostrou que os déficits dos pacientes estavam em atenção e percepção visual, e não na função memória (Weissenborn et al., 2003).

Ryan et al., 2004, estudaram 116 pacientes com infecção avançada por HIV, divididos em dois grupos de acordo com o status de anticorpos anti-HCV; 67 pacientes eram coinfectados HIV/HCV e 49 eram soronegativos para HCV. Os indivíduos foram submetidos a uma ampla gama de testes neuropsicológicos. A prevalência da encefalopatia relacionada ao HIV e de transtorno cognitivo- 
motor menor associado ao HIV foi avaliada usando um algoritmo modificado da Academia Americana de Neurologia. Os pacientes coinfectados tinham maior probabilidade de ter tido dependência de cocaína, opiáceos ou estimulantes, embora os pacientes infectados pelo HIV tivessem exames toxicológicos de urina positivos mais frequentemente no momento do teste. Em ambos os grupos foi verificada alta prevalência de depressão maior (42\%), equivalente nos dois grupos. Histórico de comprometimento neuropsicológico foi relatado muito frequentemente por ambos os grupos em todos os domínios (29-72\%). Nos testes de funções executivas os pacientes coinfectados exibiram maior comprometimento. Os autores concluíram que apesar da natureza avançada de sua coorte de HIV havia um impacto cognitivo detectável da coinfecção por HCV. Entretanto, com uma carga tão alta de comprometimento neuropsicológico no estudo, o significado clínico do efeito adicional causado pelo HCV não ficou claro. Embora as diferenças no funcionamento cognitivo não estivessem associadas a índices de doença hepática, apenas uma minoria de indivíduos tinha avaliação histopatológica do fígado, e é possível que uma proporção de pacientes coinfectados pelo HIV / HCV tivesse cirrose e EHM associadas.

Weissenborn et al., 2004, incluíram num estudo 30 pacientes HCV sem cirrose e sem doença hepática avançada (15 pacientes com queixas de fadiga leve e 15 com fadiga moderada, de acordo com a Escala de Impacto da Fadiga) e 15 voluntários sadios como controles com o objetivo de procurar evidências de envolvimento do SNC em pacientes infectados por HCV com doença hepática leve e determinar se a impressão subjetiva de fadiga dos pacientes era acompanhada de evidências objetivas de disfunção cerebral. Para tanto, 
realizaram exame neurológico, bateria de testes neuropsicológicos e ERM-1H. Foram excluídos pacientes com comorbidades clínicas e psiquiátricas, abuso de drogas atual e pacientes em tratamento com medicamentos psicotrópicos. Os pacientes com HCV mostraram déficits de atenção, distúrbios leves de memória, comprometimento funcional para atividades da vida diária e níveis mais altos de depressão e ansiedade. Mostraram também diminuição significante da proporção de n-acetil-aspartato (NAA)/creatina no córtex cerebral. O EEG estava alentecido em $25 \%$. Esses déficits estavam associados à fadiga e estavam também presentes nos pacientes com fadiga leve, embora de forma menos pronunciada. Os autores concluíram que os déficits cognitivos refletiam alterações de processos atencionais e funções executivas superiores, enquanto habilidades visuoconstrutivas e performance motora, que estão frequentemente comprometidos na EHM, estavam preservados.

Von Giesen et al., 2004, estudaram coorte de pacientes infectados pelo HIV e pelo HCV em um estágio mais precoce da doença, excluindo os sujeitos com demência associada ao HIV e os pacientes com evidências clínicas e/ou histológicas de cirrose. Foram estudados 43 pacientes coinfectados por HIV/HCV, 43 pacientes com HIV soronegativos para o HCV e 44 pacientes soronegativos para HIV e HCV que se apresentaram com sepse. Não houve diferenças significativas entre os grupos de pacientes em tarefas cognitivas. No entanto, foram verificados prejuízos significativos nas medidas eletrofisiológicas de velocidade psicomotora nos três grupos de estudo em comparação com controles HIV-negativos/HCV-negativos. Os grupos de pacientes mostraram lentidão significativa de movimentos alternados e tempos prolongados de 
resposta de contração muscular da mão. Os autores concluíram que a infecção com um dos vírus pode causar lentificação psicomotora subclínica que não se deteriora na coinfecção $\mathrm{HIV/HCV}$, pelo menos num estágio relativamente precoce da doença. História de uso de drogas intravenosas foi relatada por $48 \%$ dos indivíduos, mas não afetou a velocidade psicomotora em nenhum dos grupos. Os pacientes coinfectados apresentaram mais transtornos afetivos e depressão do que os portadores de HIV (Von Giesen et al., 2004).

Em 2005, Fontana et al. estudaram a frequência, tipo e gravidade do comprometimento cognitivo em um grande grupo de pacientes com hepatite $\mathrm{C}$ com fibrose avançada. Dez testes neuropsicológicos validados foram administrados aos 201 pacientes incluídos no estudo para avaliação da memória verbal, memória não verbal, FV, velocidade de processamento de informação, rastreamento visual, funções executivas e processamento verbal. Foi também realizada avaliação do humor, do consumo de álcool e história psiquiátrica. Os resultados das avaliações foram comparados com dados normativos da população com idade, gênero e escolaridades comparáveis. Foi verificado que $52 \%$ dos indivíduos preenchiam critérios do DSM-IV para o diagnóstico de transtorno por uso de álcool ao longo da vida, mas apenas 1,5\% faziam uso atual de álcool. Critérios do DSM-IV para diagnóstico de abuso de drogas foram preenchidos por $39 \%$ dos pacientes (nenhum fazendo uso atual). Os pacientes demonstraram comprometimento significativo da memória verbal e memória de trabalho (aprendizagem de dígitos em série) em relação à população. Evidências de comprometimento cognitivo foram encontradas em $33 \%$ dos indivíduos, isto é, pontuação abaixo da esperada em pelo menos quatro dos testes realizados. 
Gravidade da doença hepática, história psiquiátrica e abuso de substâncias não se correlacionaram com a presença de comprometimento cognitivo. Em contraste, os escores de quociente intelectual (QI) e depressão foram preditores significativos e independentes de comprometimento cognitivo.

McAndrews et al., 2005, estudaram a prevalência e significado da disfunção cognitiva em pacientes com hepatite $C$, na ausência de fatores de risco correlacionados. Para tal, investigaram uma coorte de 37 sujeitos através de testes neuropsicológicos (Escala Abreviada de Inteligência de Wechsler, teste de aprendizado verbal da Califórnia, teste breve de memória visual, teste dos dígitos, teste de trilhas, teste de associação símbolos-dígitos, teste de interferência de Stroop e teste de ordenação de cartões de Wisconsin). Foram aplicados o Inventário de Depressão de Beck e o inventário de avaliação de fadiga e realizada a ERM-1H. O grupo de pacientes foi comparado com 46 controles saudáveis. O grupo controle era mais jovem e tinha nível de escolaridade mais alto. A maioria dos pacientes (67\%) relatou história de abuso de drogas ilícitas, sem informações sobre uso recente ou atual. Na coorte com HCV, $29 \%$ dos pacientes apresentaram sintomas de depressão clinicamente significativos, enquanto apenas $2 \%$ dos controles o fizeram. O grupo HCV demonstrou somente eficiência de aprendizado marginalmente pior em relação aos controles, mesmo quando o efeito do grau de escolaridade foi removido (13\% dos pacientes mostraram um grau mais significativo de comprometimento neste teste) e a associação do resultado deste teste com variáveis que caracterizam a gravidade da doença hepática (grau de inflamação hepática, grau de fibrose e nível de ALT) não pode ser comprovada. Embora os pacientes 
relatassem mais fadiga e sintomas de depressão, esses não se correlacionaram com o grau de dificuldade de aprendizagem. Os marcadores de gravidade da doença hepática também não mostraram relação significativa com sintomatologia depressiva ou fadiga. Foram observados aumentos de colina na substância branca dos hemisférios cerebrais e redução de NAA na substância branca no grupo com hepatite $C$ e foi notada tendência de associação entre os níveis de NAA e eficiência de memória. Os autores concluíram que as diferenças observadas na eficiência de aprendizado e nos metabólitos cerebrais não podiam ser simplesmente atribuídas a gravidade da doença hepática, dado que a maioria dos pacientes do estudo apresentava fibrose de grau leve na biópsia hepática e que seria improvável que EHM fosse responsável pelo comprometimento cognitivo observado.

Soogoor et al., 2006, estudaram 199 pacientes com coinfecção HIV/HCV, 103 com infecção por HCV e 70 controles (irmãos dos pacientes) com idades entre 6 e 19 anos de 14 centros nos Estados Unidos da América (EUA) de 1989 a 1990 para avaliar a relação entre a infecção pelo HCV e medidas selecionadas de função cognitiva em indivíduos com Hemofilia. Todos os pacientes com HCV eram virgens de tratamento quando do estudo e foram submetidos à aplicação da Escala de Comportamento Adaptativo de Vineland, Escala de Inteligência de Wechsler apropriada para a idade, teste dos dígitos de Wechsler, testes de vocabulário e desenho de blocos como medidas de atenção, concentração, vocabulário expressivo e construção visuoespacial. O grupo não infectado por HIV/HCV teve pontuação significativamente maior do que o grupo coinfectado na Escala de Comportamento Adaptativo de Vineland; contudo, não 
foi observada diferença entre os sujeitos infectados por HCV e os HCV negativos. Inesperadamente, todos os escores de QI foram significativamente maiores no grupo monoinfectado por HCV do que no grupo não infectado. No Vocabulário de Wechsler, o grupo não infectado pontuou menos do que o grupo monoinfectado por HCV e que os indivíduos coinfectados com HIV/HCV. Após controlar múltiplos fatores que poderiam interferir na análise, os autores concluíram que a monoinfecção por HCV não foi associada com déficits no comportamento adaptativo, inteligência, atenção ou concentração.

Num outro estudo, Weissenborn et al., 2006, avaliaram 20 pacientes infectados com HCV com fadiga incapacitante e declínio cognitivo de causa desconhecida. Os pacientes foram submetidos a exame clínico e psicométrico, EEG, RM de crânio, análise do líquido cefalorraquidiano (LCR) e PET cerebral para estudar a capacidade de ligação de serotonina e do transportador de dopamina no cérebro de pacientes com Hepatite C. Além da EPEH, foram realizados testes de atenção dividida, comparação de modalidades, alternância de atenção e Go/no Go (para avaliação da capacidade de inibição de respostas automáticas). Aplicaram também a Escala de Ansiedade e Depressão Hospitalar, Inventário de Depressão de Beck, Escala de Impacto da Fadiga e SF36. Os resultados dos testes dos pacientes foram comparados com os de 14 controles saudáveis. Dois terços dos pacientes apresentaram resultados alterados nos testes de atenção. EEG, RM e LCR foram normais. No PET cerebral foi observada diminuição da capacidade de ligação dos transportadores de serotonina no mesencéfalo e/ou dos transportadores de dopamina no estriado em 14 dos 20 pacientes examinados (ligação anormal do transportador de 
dopamina estava presente em $60 \%$ dos pacientes e ligação anormal do transportador de serotonina em $50 \%$ dos pacientes). Os pacientes com resultados normais de PET cerebral não diferiram significativamente dos controles em relação aos resultados dos testes psicométricos. Entretanto, os pacientes com diminuição da ligação do transportador de serotonina e dopamina apresentaram desempenho significativamente prejudicado na maioria dos testes aplicados, com pontuações significativamente piores que controles saudáveis na Escala de Impacto da Fadiga, Escala de Depressão Hospitalar e no SF-36. Como essas medidas dependem de autorrelato, os achados anormais podem resultar de ansiedade devida ao conhecimento da infecção pelo HCV, e não das alterações somáticas. A conclusão dos autores foi que os dados indicam haver alteração na neurotransmissão serotoninérgica e dopaminérgica nos pacientes com infecção crônica por HCV com fadiga crônica e comprometimento cognitivo.

Karaivazoglou et al., 2007, avaliaram 32 pacientes gregos com hepatite C crônica sem EH usando medidas neuropsicológicas padronizadas, e os compararam com 20 controles saudáveis e 29 pacientes portadores de hepatite B. Treze dos 32 pacientes com hepatite C e 13 dos 29 pacientes com hepatite B tinham sido submetidos à biópsia hepática. No grupo com HBV, 20,7\% dos pacientes tinha cirrose bem compensada, enquanto no grupo com hepatite $\mathrm{C}$, $21,9 \%$ tinha cirrose compensada. Critérios rigorosos foram utilizados para excluir qualquer fator de risco para comprometimento cognitivo. Todos os participantes foram submetidos a avaliação psiquiátrica por meio de entrevista semiestruturada para exclusão de transtorno psicótico, depressão maior, transtorno bipolar e transtorno de personalidade grave. Nenhum paciente com 
hepatite estava em tratamento com Interferon no momento do estudo ou havia sido tratado nos últimos 12 meses antes da entrada no estudo. A bateria de testes neuropsicológicos aplicada constava de testes para avaliação da FV, aprendizagem verbal, memória, velocidade psicomotora, atenção, funções executivas, gravidade da depressão e fadiga. Não foram observadas diferenças entre os pacientes com hepatite $C$, hepatite $B$ e controles em relação à idade, nível educacional, depressão ou gravidade da fadiga. Pacientes com hepatite C tiveram desempenho significativamente pior que controles saudáveis no aprendizado verbal e memória. No entanto, os pacientes com hepatite $\mathrm{C}$ e hepatite B não foram estatisticamente diferentes com relação à função cognitiva, sugerindo que as anormalidades observadas não são específicas da hepatite C. O índice de inflamação hepática e os níveis séricos de transaminases não se correlacionaram com qualquer medida de desempenho cognitivo e não foi encontrada relação significativa entre o genótipo do HCV e função cognitiva. A capacidade cognitiva dos pacientes com hepatite $C$ foi associada ao grau de fibrose hepática. O declínio cognitivo não se correlacionou com o sofrimento psicológico dos pacientes, indicando que mecanismos biológicos podem estar implicados em sua patogênese. Após controle para idade e nível de escolaridade, os pacientes cirróticos e não cirróticos pareciam ser igualmente afetados. Os autores sugeriram que a falta de diferenças significativas entre pacientes com hepatites C e B em funções neuropsicológicas em seu estudo indica fortemente que hepatite viral crônica pode estar associada com declínio cognitivo sutil na ausência de cirrose avançada, independentemente da etiologia da doença. 
Thein et al., 2007, realizaram estudo clínico prospectivo com o objetivo de investigar o impacto do clareamento do HCV na função cognitiva. Os autores estudaram 19 pacientes com monoinfecção por HCV e 15 portadores de coinfecção HIV/HCV que foram tratados com Interferon-a e Ribarina. Testes neuropsicológicos (bateria computadorizada e testes de trilhas), Escala de Depressão, Ansiedade e Estresse de 42 tens e SF-36 para avaliar QVRS foram aplicados. Antes do tratamento, resultados dos testes neuropsicológicos, humor e QVRS eram semelhantes entre os grupos de pacientes portadores de HCV. As taxas de RVS foram semelhantes entre os grupos infectados por HCV, monoinfectados (68\%) e coinfectados HIV / HCV (73\%). A depuração terapêutica do HCV foi associada à melhora em algumas medidas cognitivas. A depuração viral sustentada induzida pelo tratamento também foi associada à melhora na QVRS física e mental. A magnitude do impacto do tratamento na QVRS foi considerável, com limitações nas atividades físicas e sociais atribuíveis à saúde em ambos os grupos, mas não foi observado maior impacto na QVRS no grupo infectado por HIV / HCV do que no monoinfectado pelo HCV. O desempenho cognitivo, o humor e a QVRS nos grupos infectado pelo HCV e coinfectado pelo HIV / HCV antes, durante e após o tratamento com Interferon e Ribavirina foram semelhantes. A RVS foi associada a melhora significativa no tempo de reação relacionado à atenção sustentada. Esta melhora na atenção sustentada foi independente da melhora na QVRS e do humor dos pacientes.

Em 2009, Quarantini et al. realizaram estudo neuropsicológico comparando pacientes infectados por HCV e por HBV sem comorbidades psiquiátricas. $\mathrm{O}$ desempenho neuropsicológico de 33 pacientes com hepatite $\mathrm{C}$ 
foi comparado ao de 22 pacientes com hepatite B. Foram excluídos pacientes em uso de medicamentos psicotrópicos, pacientes com retardo mental, demência, transtorno convulsivo, AVC, doença neurovascular, portadores de transtornos do eixo I do DSM-IV, história de abuso de álcool ou drogas ou dependência nos últimos seis meses, tratamento com Interferon nos últimos três meses, cirrose não compensada, câncer ou outras condições médicas graves. A bateria neuropsicológica incluiu: teste de aprendizado auditivo verbal de Rey, teste de trilhas partes $\mathrm{A}$ e $\mathrm{B}$, teste dos dígitos em ordem direta e inversa e figura complexa de Rey-Osterieth (cópia e recordação após 30 minutos). Os pacientes com hepatite $C$ tiveram desempenho pobre na recordação imediata da figura complexa de Rey-Osterieth e mostraram tendência a um baixo desempenho na memória tardia em comparação com pacientes com hepatite B. O grupo de pacientes com hepatite $\mathrm{C}$ teve pior desempenho nas tarefas de memória após ajuste para idade e escolaridade.

Huckans et al., 2009, estudaram pacientes com hepatite C, com e sem história de transtorno de uso de substâncias e os compararam com pacientes sem hepatite $\mathrm{C}$ e sem história de uso de abuso de drogas com o objetivo de determinar se a infecção pelo HCV estava associada a comprometimento cognitivo, além dos efeitos das comorbidades prevalentes e histórico de uso de drogas. Os participantes com história de abuso de drogas estavam em remissão por mais de 90 dias. Diferenças significativas entre os grupos foram encontradas nos domínios de memória verbal, atenção, processamento de informação visual e raciocínio/flexibilidade mental $(p \leq 0,05)$. As comparações post hoc indicaram que os pacientes com Hepatite $\mathrm{C}$ que não tinham história de uso de drogas 
tiveram desempenho significativamente pior do que os controles nos testes que medem aprendizagem verbal, atenção e raciocínio/flexibilidade mental, mas apenas os pacientes com Hepatite C com história de abuso de drogas tiveram pior desempenho que os controles em testes de processamento de informação visual acelerada. Os autores concluíram que os resultados indicam que a infecção crônica pelo HCV está associada a comprometimento cognitivo na ausência de uma história de abuso de drogas, com os déficits mais robustos na aprendizagem verbal e no raciocínio/flexibilidade mental.

Em 2010, Lowry et al. realizaram estudo piloto para investigar a capacidade funcional e funções cognitivas em uma população homogênea de 29 mulheres iatrogenicamente infectadas por HCV com doença hepática leve não tratadas e que não faziam uso de álcool ou drogas. Um grupo de 9 controles saudáveis também foi avaliado. As participantes do estudo foram submetidas a avaliação de humor, QVRS e avaliação neuropsicológica. Pacientes com infecção crônica por HCV relataram níveis significativamente mais altos de fadiga cognitiva do que controles e, na avaliação cognitiva, apresentaram déficits em comparação com controles nos testes de memória em geral, reconhecimento auditivo e atenção. A fadiga cognitiva aumentada se correlacionou apenas com a memória verbal tardia.

Partindo da premissa que a hepatite C causa disfunção cognitiva orgânica leve e que anormalidades no metabolismo cerebral foram verificadas na ERM-1H, Pattullo et al., 2011, realizaram estudo longitudinal com o objetivo de quantificar essas anormalidades em uma coorte de pacientes livres de fatores de risco relacionados à infecção crônica pelo $\mathrm{HCV}$ e para determinar se a 
depuração viral induzida pelo tratamento abolia essas anormalidades. Foram estudados 50 pacientes não cirróticos. Sessenta e oito por cento dos 50 pacientes com hepatite C tratados alcançaram RVS. Trinta e um dos 34 respondedores e nove dos 16 não-respondedores consentiram em repetir o teste cognitivo, os questionários de QVRS, fadiga e depressão e a ERM-1H seis meses após a conclusão da terapia antiviral. Cinquenta e oito indivíduos controles foram recrutados da mesma forma para participar da avaliação inicial. A bateria de testes neuropsicológicos constou dos seguintes testes: teste de aprendizado verbal da Califórnia-II, breve teste de memória visual, atenção visual e rastreamento, teste de adição auditiva ritmado, teste dos dígitos, teste de associação símbolos-dígitos, velocidade psicomotora, teste de trilhas partes A e $B$, teste de bater os dedos, teste de flexibilidade cognitiva, teste de interferência de Stroop e teste de Wisconsin.Trinta e nove dos 58 controles se apresentaram para as mesmas avaliações um ano após a avaliação inicial. Assim, 39 controles, 31 pacientes que alcançaram RVS e 9 não-respondedores foram incluídos na análise final. Os autores verificaram que antes de receber tratamento os pacientes apresentavam eficiência de aprendizado prejudicada, pior QVRS e escores de fadiga mais altos em comparação aos controles. A ERM1H demonstrou relação mais baixa de NAA/creatina no globo pálido dos pacientes com hepatite $C$ em comparação com os controles. A depuração viral foi associada a pequena, mas significativa, melhora nos escores de QVRS que, porém, não alcançou a dos controles. Após o tratamento, as alterações observadas na ERM-1H pré-tratamento se mantiveram, porém houve aumento na proporção de colina/creatina no globo pálido dos pacientes, que não se 
correlacionou com as medidas cognitivas. Os autores concluíram que o tratamento viral não reverte as alterações observadas na ERM-1H.

Como os níveis séricos de leptina aumentam na cirrose hepática e foi sugerido que possam ter um papel na mediação da fadiga, El-Gindy et al., 2012, estudaram 70 pacientes e 20 controles para avaliar a possível associação dos níveis séricos de leptina com a fadiga e com a gravidade da doença hepática em pacientes egípcios com hepatite $\mathrm{C}$ crônica. Os participantes foram submetidos a avaliação clínica e laboratorial, determinação do nível sérico de leptina por ELISA e avaliação de fadiga. A fadiga estava presente em $100 \%$ dos pacientes e em $65 \%$ dos indivíduos do grupo controle e houve diferença estatística significativa entre os casos e controles quanto à presença e gravidade desta. $\mathrm{O}$ nível sérico de leptina foi significativamente maior nos pacientes em comparação aos controles, porém não se correlacionou com a gravidade da doença hepática.

Em 2013, Abrantes et al. realizaram estudo transversal em nosso meio cujo objetivo foi comparar o desempenho cognitivo em pacientes com infecção crônica por HCV com grupo controle de indivíduos saudáveis, equivalentes quanto ao gênero, idade e escolaridade. Os autores usaram critérios muito rígidos de seleção, excluindo sujeitos com menos de cinco anos de escolaridade, história de acidente vascular encefálico, trauma cranioencefálico, demência, doença de Parkinson, esclerose múltipla, doença pulmonar obstrutiva crônica, insuficiência cardíaca congestiva, outras infecções virais (HIV, hepatite $B$, vírus linfotrópico $T$ humano), sífilis, comprometimento hepático significativo, depressão, uso de drogas ilícitas e psicotrópicos, alcoolismo, hipotireoidismo, deficiência de cobalamina ou ácido fólico e uso atual ou anterior de Interferon. 
Foi aplicada extensa bateria de testes neuropsicológicos aos participantes (MEEM, bateria breve de memória com figuras, teste de aprendizagem verbal auditivo de Rey, teste dos dígitos em ordem direta, teste de trilhas, teste de letras aleatórias, teste de Stroop, teste de nomeação de Boston, teste de FV, cópias de formas geométricas, teste de associação símbolos-dígitos e teste de similaridades). O inventário de depressão de Beck foi utilizado para detecção de sintomas depressivos. Não houve diferenças estatísticas significantes no relato de queixas cognitivas entre os grupos. O genótipo 1 foi responsável por $78,6 \%$ das infecções por HCV. Biópsias hepáticas foram realizadas por $58,6 \%$ dos indivíduos com hepatite C. Vinte e nove por cento foram classificados como portadores de fibrose grau zero, $58 \%$ como portadores de fibrose grau 1 e $11 \%$ de fibrose grau 2, com base no sistema METAVIR. Os autores não encontraram diferenças estatísticas significativas entre os grupos em relação ao desempenho cognitivo em nenhum dos testes aplicados.

Estudo transversal de base populacional foi realizado em 2014 por Chiu et al. com a finalidade de investigar se havia aumento de risco potencial para 0 desenvolvimento de demência em pacientes HCV. Para tanto, utilizaram-se do Banco de Dados Nacional de Pesquisa de Seguros de Saúde de Taiwan. Foram incluídos indivíduos com idade igual ou superior a 50 anos, num total de 58.570 pares de pacientes com hepatite $\mathrm{C}$ e pacientes não infectados pelo HCV (pareados por gênero, idade, renda, urbanização, DM, hipertensão, hipercolesterolemia, doença pulmonar obstrutiva crônica e depressão). Cada indivíduo foi seguido individualmente de 1997 a 2009 para identificar casos incidentes de demência. Ocorreram 2989 casos de demência na coorte de 
indivíduos com com hepatite $\mathrm{C}$ durante esse período. As taxas de incidência de demência diferiram da coorte não-HCV (56 vs 47,7 casos por 10.000 pessoa/ano). A taxa de risco ajustada foi de 1,36 (IC 95\%, 1.27-1.42)

Em 2016, o grupo de Lowry publicou outro estudo transversal de uma coorte de mulheres iatrogenicamente infetadas por HCV na Irlanda. Quarenta e três mulheres com hepatite $C$ crônica, 25 mulheres que haviam sido infectadas por HCV mas que clarearam o vírus e 18 controles saudáveis foram submetidas a inquérito psicossocial. Testes neuropsicológicos foram realizados por 20 pacientes com infecção crônica por HCV, 17 mulheres que que clarearam o vírus e 15 controles. A bateria de testes neuropsicológicos era composta por Teste de Leitura para Adultos de Wechsler, Escala Abreviada de Inteligência de Wechsler, teste de aprendizagem verbal, Escala de Memória de Wechsler, teste de atenção, teste de trilhas e o teste de interferência cor-palavra. Diferenças estatísticas significativas foram observadas entre os grupos em medidas de fadiga, dor e humor. Independentemente de terem ou não clareado o vírus, pacientes expostas ao HCV apresentavam graus significativamente mais elevados de estresse psicossocial do que os controles. Em relação ao desempenho nos testes neuropsicológicos, comparações entre os grupos de pacientes expostas ao HCV e grupo controle revelou diferenças significativas em tarefas de memória lógica tardia, no teste de alternância de atenção e atenção sustentada. As comparações post hoc revelaram que as participantes que clarearam o HCV exibiram significante alteração na memória lógica em relação ao grupo controle e cometeram mais erros do que as pacientes com hepatite $\mathrm{C}$ crônica no teste de alternância de atenção. Análises de correlações não 
identificaram qualquer relação significante entre carga viral, nível de ALT e escores de domínios psicossociais. De acordo com o inquérito psicossocial, dois subgrupos distintos foram claramente identificados como "comprometido" e "não comprometido". A análise de regressão logística identificou humor deprimido e fadiga cognitiva, em vez de status viral, como preditores significantes, do ponto de vista estatístico, do subgrupo ao qual o sujeito pertencia - "comprometido" ou "não comprometido". Os autores concluíram que estes achados coletivamente sugerem que outros fatores além da cronicidade da infecção pelo HCV ou atividade viral podem explicar o comprometimento psicossocial relacionado ao HCV. No teste neuropsicológico, das três tarefas onde foram observadas diferenças, duas revelam desempenhos relativamente piores dos indivíduos que clarearam o HCV, enfraquecendo sugestões de envolvimento viral em relatos de comprometimento cognitivo leve relacionado ao HCV. Os autores enfatizam que, além disso, diferenças estatísticas entre os grupos desaparecem se o coeficiente a é ajustado, mesmo minimamente, para comparações múltiplas usando o método de correção de Bonferroni.

Considerando que a infecção pelo vírus da hepatite $\mathrm{C}$ pode induzir fadiga crônica e disfunção cognitiva e que a replicação do vírus foi comprovada dentro do cérebro, sendo as células HCV-positivas micróglia e astrócitos, Pflugrad et al., 2016, supuseram que a disfunção cerebral orgânica em pacientes com hepatite $C$ pudesse estar associada com ativação da micróglia. As células da micróglia são células derivadas da linhagem monocítica da medula óssea com função imunológica no cérebro. A ativação crônica destas células leva ao recrutamento de macrófagos derivados de monócitos para o SNC. O receptor 
TSPO é expresso principalmente por células da micróglia ativada se a barreira hematoencefálica estiver intacta. Segundo Venneti et al., 2013, a micróglia é ativada em resposta a dano cerebral $\mathrm{e}$ isto pode ser medido in vivo usando o marcador [11C] - PK11195 no PET cerebral. Pflugrad et al. avaliaram a ativação da micróglia in vivo em 22 pacientes com anti-HCV positivo em comparação com seis controles sadios. Os pacientes com testes anti-HCV positivos foram subdivididos em relação ao seu estado de carga viral, escore da Escala de Impacto de Fadiga e pontuação no teste de atenção. Os autores estudaram 12 pacientes $(54,5 \%)$ com carga viral positiva de HCV $(7$ (58,3\%) com pontuação alterada na Escala de Impacto de Fadiga e 7 (58,3\%) com pontuação alterada no teste de atenção) e 10 pacientes (45,5\%) com anti-HCV positivo e carga viral negativa (5 (50\%) com Escala de Impacto de Fadiga alterada e 5 (50\%) com pontuação alterada no teste de atenção). Os resultados dos questionários implicaram uma taxa maior de fadiga, depressão e ansiedade em pacientes com hepatite $\mathrm{C}$ que nos controles. Entretanto, os escores médios de depressão dos pacientes eram apenas marginalmente alterados. Os pacientes com hepatite $\mathrm{C}$ tiveram pior desempenho que os controles, especialmente em relação à atenção e concentração. Os pacientes com carga viral positiva para HCV e os com carga viral negativa para o HCV não mostraram diferenças significativas. Diferenças significativas de ligação do marcador nos gânglios da base foram observadas após a subdivisão dos grupos de pacientes de acordo com seu escore no teste de atenção. Análise das correlações de Pearson mostraram correlação negativa significante entre a escala de atenção e a ligação do marcador no tálamo, amígdala, núcleo caudado, ponte, cerebelo, globo pálido, putamen e córtex 
temporal. A análise do mapeamento estatístico paramétrico do potencial de ligação de [11C] PK11195 mostrou que os pacientes sem déficit de atenção mostraram um acúmulo significativamente maior de marcador no putamen, núcleo caudado e tálamo em comparação com os controles. Pacientes com e sem fadiga não diferiram significativamente em relação à ligação específica do marcador no PET cerebral. A função cognitiva preservada foi associada significativamente com aumento da ativação da micróglia com predominância nos gânglios basais. Os autores interpretaram esses achados como prováveis indícios de efeito neuroprotetor da ativação da micróglia em pacientes infectados por HCV.

Kumar et al., 2017, incluíram em seu estudo 19 indivíduos com hepatite C clinicamente normais, com testes de função hepática normais, e 31 controles saudáveis. Todos os participantes do estudo foram submetidos a questionário para avaliação da QVRS, testes neuropsicométricos, RM tensor-difusão do crânio com tratografia e ERM-1H. Os testes neuropsicológicos incluíram teste de trilhas, teste de conexão de números, teste de conexão de figuras, teste de completar figuras, teste de associação símbolos-dígitos, desenho de bloco, organização de imagens e montagem de objetos. Os pacientes com hepatite C apresentaram pior desempenho no teste de conexão de figuras, associação símbolos-dígitos, desenho de blocos, organização de imagens, montagem de objetos e completar figuras em comparação com controles saudáveis. Diminuição significativa das medidas de QVRS foi observada em pacientes infectados pelo $\mathrm{HCV}$ em áreas de bem-estar físico, psicológico, social e ambiental. Os autores encontraram valores de anisotropia e de mioinositol 
significativamente diminuídos nos pacientes $\mathrm{HCV}$ em tratos sensitivos, fascículos longitudinais inferiores e feixes motores em comparação com os controles na tratografia por RM tensor-difusão. Os escores dos testes neuropsicológicos correlacionaram-se significativamente e positivamente com o valor da anisotropia dos feixes de fibras sensitivas, motoras e fascículos longitudinais inferiores e com todos os domínios da QVRS. A conclusão foi que foi possível identificar as alterações nos componentes celulares e no espaço extracelular da substância branca no cérebro de pacientes infectados por HCV usando a tratografia por RM tensor-difusão, que poderiam ser utilizadas como biomarcadores do comprometimento cognitivo em pacientes com hepatite $\mathrm{C}$ assintomáticos.

Barbosa et al., 2017, conduziram estudo exploratório prospectivo de braço único objetivando avaliar o impacto da RVS na função cognitiva e transtornos do humor de pacientes com hepatite C tratados com Interferon e Ribavirina. Foram incluídos pacientes com hepatite C clinicamente compensados e excluídos aqueles em uso de substâncias psicotrópicas, pacientes com escores menores que 24 pontos no MEEM, EH evidente, EHM, carcinoma hepatocelular, anemia severa, hipotireoidismo não tratado, síndrome de Addison e depressão maior antes do tratamento. Para avaliação neuropsicológica utilizaram o teste de Stroop (atenção seletiva e inibição), teste de trilhas partes A e B (atenção básica e atenção sustentada), teste de FV fonêmica e semântica, teste de Hopkins (aprendizado verbal e memória episódica e tardia), teste dos dígitos, teste de matrizes progressivas e vocabulário (WAIS III). Foram aplicados também inventários para avaliar 
sintomas depressivos. Vinte e um pacientes concluíram o tratamento (16 com RVS e 5 sem RVS). A maioria era de mulheres sem doença hepática avançada. Antes do tratamento foram observadas alterações na memória imediata e tardia e na atenção sustentada e seletiva. Independentemente da depuração viral no final do tratamento, houve melhora significativa na memória verbal imediata, memória verbal tardia, atenção seletiva, e na FV fonêmica. Os pacientes com RVS apresentaram melhora significativa na memória imediata e tardia em relação à avaliação inicial. A frequência de depressão antes do tratamento foi de $9,5 \%$ e, embora tenha subido para $52,4 \%$ durante o tratamento, retornou para 9,5\% seis meses após o término deste, sem diferença significativa entre os pacientes com e sem RVS. Os autores concluíram que a erradicação da infecção pelo HCV melhorou o desempenho cognitivo, mas não afetou a frequência de sintomas depressivos pelo menos até seis meses após o tratamento.

Em 2018, na África subsaariana Mapoure et al., 2018, estudaram uma coorte de 121 pacientes com hepatite $\mathrm{C}$ com média de idade de 59.1 anos. A duração média da infecção por HCV era de 32 meses (tempo entre o diagnóstico da hepatite $\mathrm{C}$ e a entrevista inicial para o estudo), senso a maioria dos pacientes assintomática quando do diagnóstico. À entrada no estudo, 55,4\% eram virgens de tratamento. Os pacientes foram submetidos ao MEEM, biópsia hepática, determinação do genótipo do HCV e da carga viral. O genótipo mais comum foi o 1, presente em $51,6 \%$ dos pacientes. Dos 87 participantes com escores de fibrose disponíveis, $69,2 \%$ apresentaram escore maior ou igual a 2 pelo sistema METAVIR. Foi verificado que idade, maior duração da doença e alta carga viral estavam significativamente associados às manifestações neurológicas. Os 
autores consideraram haver comprometimento cognitivo quando os escores do MEEM foram 24 ou menos. Não há menção de correção dos limites do MEEM com relação à escolaridade. Comprometimento cognitivo foi verificado em 8,3 \% da população do estudo, todos de grau leve (escores no MEEM de 20 a 24). Fadiga foi relatada por $28,9 \%$ dos pacientes.

No Paraná, De Almeida et al., 2018, realizaram estudo com o objetivo de elucidar o papel da interação entre a infecção por HIV e por HCV na expressão do comprometimento cognitivo, e examinar as diferenças no desempenho em testes para avaliação das funções cognitivas entre pacientes infectados pelo $\mathrm{HIV/HCV}, \mathrm{HIV}$ isolado ou HCV isolado. Cento e vinte e oito participantes foram submetidos a uma bateria neuropsicológica abrangente, compreendendo 18 testes de vários domínios cognitivos. Foram excluídos pacientes que tomavam mais de duas doses de bebida alcoólica por dia, uso de drogas ilícitas nos últimos 30 dias e, para os participantes com hepatite C, critérios adicionais de exclusão incluíram tratamento com Interferon e Ribavirina nos últimos 12 meses e cirrose não compensada. Os participantes foram agrupados de acordo com seu estado sorológico. Vinte pacientes eram portadores de hepatite C isolada, 48 eram portadores de HIV isolado, 12 tinham coinfecção HIV/HCV e 48 eram controles saudáveis. As frequências dos subtipos $\mathrm{B}$ e $\mathrm{C}$ do HIV entre os grupos infectados pelo HIV e HIV/HCV foram comparáveis. Foi verificada maior prevalência de comprometimento neuropsicológico nos três grupos com infecção em comparação com os controles, porém não foram encontradas diferenças estatísticas significantes entre os grupos mono e coinfectados. O grupo coinfectado $\mathrm{HIV} / \mathrm{HCV}$ apresentou o maior percentual de comprometimento 
neuropsicológico global, embora as diferenças entre os grupos coinfectados e monoinfectados não atingissem significância estatística. A infecção pelo HCV foi associada com déficits cognitivos, independentemente do grau de disfunção hepática que, porém, não determinou efeito aditivo na função cognitiva dos pacientes com HIV. Comparado aos controles, o grupo monoinfectado por HCV mostrou taxas significativamente elevadas de alteração em somente três das 18 medidas individuais dos testes que representam apenas dois domínios cognitivos (FV e função motora), embora tendência no mesmo sentido tenha sido observada em cinco outros testes de função executiva, velocidade de processamento, aprendizado e memória tardia. O comprometimento cognitivo se mostrou independente da carga viral de HCV no sangue periférico e no LCR. Porquanto não tenha sido encontrado efeito aditivo global no estudo, houve alguma evidência de efeitos aditivos da coinfecção HIV/HCV na velocidade de processamento de informações, função executiva e FV na comparação do grupo coinfectado com os outros três grupos. O comprometimento neuropsicológico foi independente do genótipo do HCV.

Na Alemanha, Dirks et al., 2018, estudaram 132 pacientes não-cirróticos (46 com hepatite C, 22 com hepatite B, 27 com hepatite autoimune, 29 com colangite biliar primária e 8 com hepatite autoimune/ colangite biliar primária) que completaram questionários abordando humor, fadiga e cognição. Oitenta e oito pacientes foram submetidos a avaliação neuropsicológica abrangente. Os grupos de pacientes foram comparados entre si e com 33 controles saudáveis. Os escores de fadiga, ansiedade e depressão estavam significativamente aumentados, e o escore mental do SF-36 diminuído significativamente em todos 
os grupos de pacientes em comparação aos controles. A fadiga foi significativamente mais pronunciada nos pacientes com hepatite $\mathrm{C}$ que nos pacientes com hepatite $B$. Pacientes com hepatite $C$ tiveram pontuação significativamente pior que pacientes com hepatite $B$, mas não que pacientes com hepatite autoimune e colangite biliar primária no SF-36. Pacientes com hepatite $\mathrm{C}$, hepatite autoimune e colangite biliar primária, mas não os pacientes com hepatite $B$, tiveram desempenho significativamente pior que os controles no aprendizado verbal. O reconhecimento de palavras foi prejudicado em pacientes com hepatite $\mathrm{C}$, hepatite autoimune e colangite biliar primária e 0 reconhecimento de figuras em pacientes com hepatite $\mathrm{C}$, exclusivamente. Os pacientes com hepatite $C$ também se saíram pior que os controles e que os pacientes com hepatite B quanto ao estado de alerta e memória de trabalho. Os autores concluíram que os perfis neuropsicológicos dos pacientes com hepatite C são semelhantes aos dos pacientes com hepatite autoimune e colangite biliar primária, mas diferem daqueles dos pacientes com hepatite $B$, sugerindo uma resposta autoimune como uma possível causa para as anormalidades.

McCready et al., 2018, realizaram estudo com imagens de RM funcional para examinar a ativação cerebral de 20 pacientes adultos com hepatite $C$ não tratados, de forma a determinar se, em relação aos 26 controles não infectados, os adultos com infecção crônica por HCV exibiam diferenças na ativação cerebral durante uma tarefa de recompensa adiada, uma medida da tendência de escolher recompensas imediatas menores ao invés de recompensas tardias maiores, que mede a impulsividade. Os autores verificaram que o grupo com hepatite $\mathrm{C}$ exibiu menos ativação no giro occipital lateral esquerdo, precuneus e 
giro frontal superior. Houve também efeitos interativos significativos no giro frontal medial bilateral, ínsula esquerda, precuneus esquerdo, lobo parietal inferior esquerdo e região occipito-temporal direita. O grupo controle mostrou uma relação positiva entre impulsividade e ativação, enquanto o grupo com hepatite C exibiu relação negativa, com os pacientes com cargas virais altas escolhendo recompensas imediatas com mais frequência do que aqueles com baixa carga viral, independentemente da dificuldade de escolha. Os resultados mostraram que os pacientes com hepatite $\mathrm{C}$ exibem maior comportamento impulsivo quando escolhas e impulsividade estão negativamente relacionadas à ativação em regiões importantes para o controle cognitivo.

Em 2018, García-García et al. estudaram 38 pacientes com cirrose hepática e 24 controles saudáveis sem doença hepática. Os pacientes cirróticos foram divididos de acordo com a presença ou ausência de EHM, detectada através da EPEH. Os pacientes foram classificados como portadores de EHM quando o escore na EPEH foi $\leq 4$ pontos. O objetivo do estudo foi avaliar a aprendizagem verbal e a memória de evocação nesses grupos e, também, a relação entre alterações de memória, integridade estrutural e conectividade funcional do sistema hipocampal. Os pacientes cirróticos, tanto com EHM quanto sem, apresentaram pior desempenho em comparação aos controles nos testes de aprendizado verbal e memória de evocação. Pacientes com EHM apresentaram prejuízos na aprendizagem, memória tardia e reconhecimento, em comparação com pacientes com cirrose sem EHM e controles. Pacientes cirróticos (tanto com EHM quanto sem EHM) apresentaram redução do volume da fímbria do hipocampo em comparação aos controles. Volumes maiores nos 
subcampos do hipocampo foram associados a melhor desempenho da memória em pacientes com cirrose sem EHM e controles. Também foram observadas alterações de conectividade funcional nos pacientes com EHM. Em comparação aos controles, os pacientes com EHM tinham menor conctividade funcional présubiculum e pré-cuneus bilateralmente que se correlacionaram com comprometimento cognitivo e alteração de memória. Segundo os autores, alterações na conectividade funcional do sistema hipocampal poderiam contribuir para o déficit de aprendizado a longo prazo e para os déficits de memória de pacientes com EHM. 


\section{Justificativa e Objetivos}

Em 2009, fui convidada a participar de um projeto da Clínica de Moléstias Infecciosas do Hospital das Clínicas da Faculdade de Medicina da USP (HCFMUSP) que propunha estudar as manifestações extra-hepáticas do HCV, realizando avaliações neurológicas numa série de casos virgens de tratamento encaminhados à Clínica de Moléstias Infecciosas pelo banco de sangue do HCFMUSP ou por serviços de saúde pública do município de São Paulo. Considerando a hipótese de que a infecção crônica pelo HCV pode causar alterações detectáveis no SNP e no SNC, e que pode associar-se também a maior prevalência de quadros de alterações afetivas e do humor, decidimos estudar, neste grupo selecionado, manifestações neurológicas e neuropsicológicas que estivessem presentes. Numa etapa posterior, de forma a poder se estimar se as alterações cognitivas, afetivas e do humor encontradas nesses pacientes são distintas do esperado em indivíduos não portadores do vírus da hepatite $C$, fez-se necessária a inclusão de um grupo controle. Trata-se, portanto, de um estudo observacional, retrospectivo e prospectivo, casocontrole.

Os pacientes que participaram deste estudo foram atendidos e acompanhados pela Clínica de Moléstias Infecciosas do HCFMUSP e foram submetidos a avaliação clínica e laboratorial e, também, à realização de biópsia 
hepática, conforme determinação do infectologista responsável pelo atendimento destes pacientes e a seguir encaminhados para avaliação neurológica.

\subsection{Objetivos primário}

1. Identificar e quantificar alterações da função nervosa periférica e central associadas à infecção pelo HCV em pacientes virgens de tratamento sem sinais de encefalopatia hepática franca em pacientes que procuram - HCFMUSP, de forma a se ter uma visão das complicações neurológicas nos pacientes portadores de HCV em nosso meio.

2. Identificar e quantificar quadros de ansiedade, depressão, desesperança e disfunção cognitiva nos pacientes portadores de HCV e comparar os dados obtidos com dados de controles não portadores de infecção pelo vírus da hepatite $\mathrm{C}$.

\subsection{Objetivo secundário}

Verificar se existe relação das possíveis alterações neurológicas, cognitivas e psicológicas com o genótipo viral, grau de fibrose hepática e com a presença de autoanticorpos nos pacientes portadores do HCV, virgens de tratamento. 


\section{Método}

\subsection{Seleção de pacientes}

Setenta e seis pacientes adultos, de ambos os sexos, com mais de 18 anos de idade, portadores da infecção crônica pelo vírus da hepatite $\mathrm{C}$ foram encaminhados para avaliação neurológica no período de 20 de agosto de 2009 a 15 de fevereiro de 2016, provindos da Divisão de Moléstias Infecciosas e Parasitárias do HCFMUSP. Estes pacientes não tinham sinais ou sintomas de insuficiência hepática franca e não haviam recebido tratamento específico para a hepatite C. Foram excluídos os pacientes com reações sorológicas positivas para o vírus da imunodeficiência adquirida (HIV), hepatite B (HBV) e sífilis. Os pacientes assinaram o Termo de Consentimento Livre e Esclarecido, conforme modelo do Comitê de Ética do HCFMUSP (Anexo A). A amostra de pacientes foi constituída por 76 pacientes (40 mulheres), que foram separados em grupos por faixas de idade (21-30, 31-40, 41-50, 51-60, 61-70 e 71 anos de idade ou mais) e por faixas de escolaridade (analfabetos, 1-4, 5-8, 9-11 e 12 anos ou mais de escolaridade).

\subsection{Seleção do grupo controle}

Os pacientes portadores de infecção crônica pelo HCV foram comparados com população de indivíduos controles, não portadores de HCV, HVB ou HIV, 
que foram recrutados entre acompanhantes, cônjuges, familiares dos pacientes do estudo, familiares e acompanhantes de pacientes do HCFMUSP e voluntários não acompanhados por nenhuma doença na instituição e assinaram o Termo de Consentimento Livre e Esclarecido, conforme modelo do Comitê de Ética do HCFMUSP (Anexo B). O grupo controle foi constituído por 78 indivíduos, sendo 43 mulheres e 35 homens, que foram separados em grupos por faixas de idade (21-30, 31-40, 41-50, 51-60, 61-70 e 71 anos de idade ou mais) e por faixas de escolaridade (analfabetos, 1-4, 5-8, 9-11 e 12 anos ou mais de escolaridade), equivalentes às do grupo dos pacientes portadores de infecção crônica pelo HCV.

\subsection{Avaliações e testes realizados pelos pacientes}

Os pacientes foram submetidos a: anamnese, questionamento sobre uso de álcool e drogas recreativas, exame clínico, exame neurológico, avaliação cognitiva breve e avaliação do humor, ansiedade e desesperança.

A avaliação cognitiva breve consistiu dos seguintes testes:

\subsubsection{Miniexame do estado mental}

O teste, método de pontuação e os pontos de corte para cada faixa de escolaridade podem ser encontrado no Anexo C. Os pontos de corte considerados foram os obtidos por Brucki et al., 2003. 


\subsubsection{Teste do desenho do relógio}

O teste do desenho do relógio (Sunderland et al., 1989; Manos e Wu, 1994; Shulman, 2000; Larner, 2013) foi aplicado para avaliar funções executivas. Para este estudo, os métodos de pontuação de Sunderland et al., 1989, e o de Shulman, 2000, foram escolhidos porque são os mais frequentemente utilizados na literatura e capturam tanto aspectos qualitativos (Shulman) quanto quantitativos (Sunderland) do teste do desenho do relógio (TDR). Vários estudos na literatura assinalam que as escalas de Shulman et al.,1993, Mendez et al., 1992, e Sunderland et al., 1989, são as que têm maior precisão diagnóstica, quando comparadas com exames neuropsiquiátricos, mesmo quando usados em populações com diferentes características culturais e níveis educacionais (Borson et al., 1999; Shulman, 2000; Aprahamian et al., 2010). O teste, método de pontuação e os pontos de corte para cada faixa de escolaridade podem ser encontrados no Anexo D.

\subsubsection{Teste de fluência verbal na categoria semântica}

O teste e o método de pontuação encontram-se no Anexo E (Brucki et al., 1997).

\subsubsection{Teste dos dígitos}

O teste dos dígitos (Wechsler Adult Intelligence Scale - WAIS-III) em ordem direta e indireta (Nascimento e Figueiredo, 2002; Lezak, Howieson e Loring, 
2004), para avaliação da atenção. O teste, método de pontuação e pontos de corte podem ser encontrados no Anexo F.

\subsubsection{Inventário de Depressão de Beck, Inventário de Ansiedade de Beck, Escala de Desesperança de Beck}

O grau de depressão, ansiedade e desesperança foi avaliado pelo Inventário de Beck (Beck et al., 1961; Gorenstein et al., 1996; Gorenstein et al., 1999; Gomes-Oliveira et al., 2012), aplicado por psicólogo credenciado (Anexos G, $\mathrm{H}$ e I). Neste estudo foram utilizados o BDI, BAI e a BHS traduzidos e adaptados para o Português por Cunha, que foram testados em amostras clínicas e na população geral demonstrando dados satisfatórios de fidedignidade e validade (Cunha, 2001).

\subsection{Exames laboratoriais realizados pelos pacientes}

Os pacientes foram submetidos a exames laboratoriais realizados pelo Laboratório Central do HCFMUSP, cuja listagem completa encontra-se no Anexo J. Os exames realizados pelos pacientes no Laboratório de Hormônios Genética Molecular da Disciplina de Endocrinologia da FMUSP encontram-se no Anexo K.

A dosagem de crioglobulinas (método precipitação) foi realizada pelo Laboratório de Imunologia Humoral da Disciplina de Reumatologia da FMUSP.

As biópsias hepáticas foram solicitadas pela Divisão de Moléstias Infecciosas e Parasitárias do HCFMUSP e analisadas pela Divisão de Anatomia 
Patológica do HCFMUSP. O grau de fibrose hepática e atividade inflamatória nas biópsias hepáticas realizadas antes de outubro de 2010 foram classificados de acordo com a classificação da Sociedade Brasileira de Patologia (SBP), de 2000,

e foram transformadas para classificação METAVIR de 1994 (Bedossa e Poynard, 1996), segundo tabela de conversão de equivalência aproximada da Sociedade Brasileira de Patologia (Mello et al., 2007), que se encontra no Anexo L. Somente foram considerados os resultados de biópsia hepáticas realizadas dentro de menos de 18 meses em relação à entrevista inicial.

\subsection{Avaliações e testes realizados pelos indivíduos do grupo controle}

Os indivíduos deste grupo foram submetidos a entrevista clínica, avaliação cognitiva breve e avaliação de depressão, ansiedade e desesperança pela aplicação do Inventário de Beck. A avaliação cognitiva breve consistiu de miniexame do estado mental (Folstein et al., 1975; Brucki et al., 2003; Larner, 2013) [Anexo C], teste do desenho do relógio (Sunderland et al., 1989; Manos e Wu, 1994; Shulman, 2000; Larner, 2013) [Anexo D], teste de fluência verbal categoria semântica (Brucki et al., 1997) [Anexo E] e teste dos dígitos (Wechsler Adult Intelligence Scale - WAIS-III) em ordem direta e indireta (Lezak, Howieson, Loring, 2004) [Anexo F].

O grau de depressão, ansiedade e desesperança foi avaliado pelo Inventário de Beck (Beck et al., 1961; Gorenstein et al., 1999; Gomes-Oliveira et al., 2012) aplicado por psicólogo credenciado (Anexos G, H e I). 


\subsection{Exames laboratoriais realizados pelos participantes do grupo controle}

Os exames laboratoriais realizados pelos indivíduos do grupo controle encontram-se listados no Anexo M.

\subsection{Metodologia de Análise de dados}

Os dados foram coletados em planilha utilizando o programa Excel e a análise foi realizada com o SPSS (IBM SPSS Statistics).

O Software utilizado nos testes estatístico foi o SPSS 20 (Statistical Package for the Social Sciences). Foram utilizados os seguintes testes:

- $\quad$ Estatísticas Descritivas (média, desvio padrão);

- Teste Mann-Whitney para amostras independentes (Independent Samples Mann - Whitney U test);

- $\quad$ Teste Qui-Quadrado (Pearson Chi-Square);

- $\quad$ Correlações de Pearson (Pearson Correlation);

- $\quad$ Correlações de Spearman (Spearman's rho);

- Regressão Logística;

- Teste de Wilcoxon para amostras relacionadas (Related Samples Wilcoxon Signed Rank test);

- Regressão Múltipla Stepwise.

Foram seguidas as orientações de Massad et al., 2004, para interpretação dos testes. 


\subsection{Desfecho primário}

Identificação e quantificação de alterações neurológicas, cognitivas e psicológicas com a infecção pelo vírus da hepatite $\mathrm{C}$ e comparação das alterações presentes nos pacientes com indivíduos não portadores do HCV, HBV ou HIV.

\subsection{Desfecho secundário}

Verificar se existe associação entre alterações neurológicas e psicológicas com a carga viral do vírus da hepatite $\mathrm{C}$, com a intensidade do comprometimento hepático (grau e fibrose e atividade inflamatória) e com a presença de autoanticorpos séricos. 


\section{Resultados}

No período de 20 de agosto de 2009 a novembro de 2016 foram incluídos 154 indivíduos, 76 pacientes portadores de infecção crônica pelo HCV e 78 indivíduos para participarem do grupo controle. Dois sujeitos do grupo controle foram excluídos por não terem realizado os exames solicitados para inclusão. As características demográficas do grupo dos pacientes e do grupo controle estão discriminadas na Tabela 1.

Tabela 1 - Características demográficas dos participantes do estudo

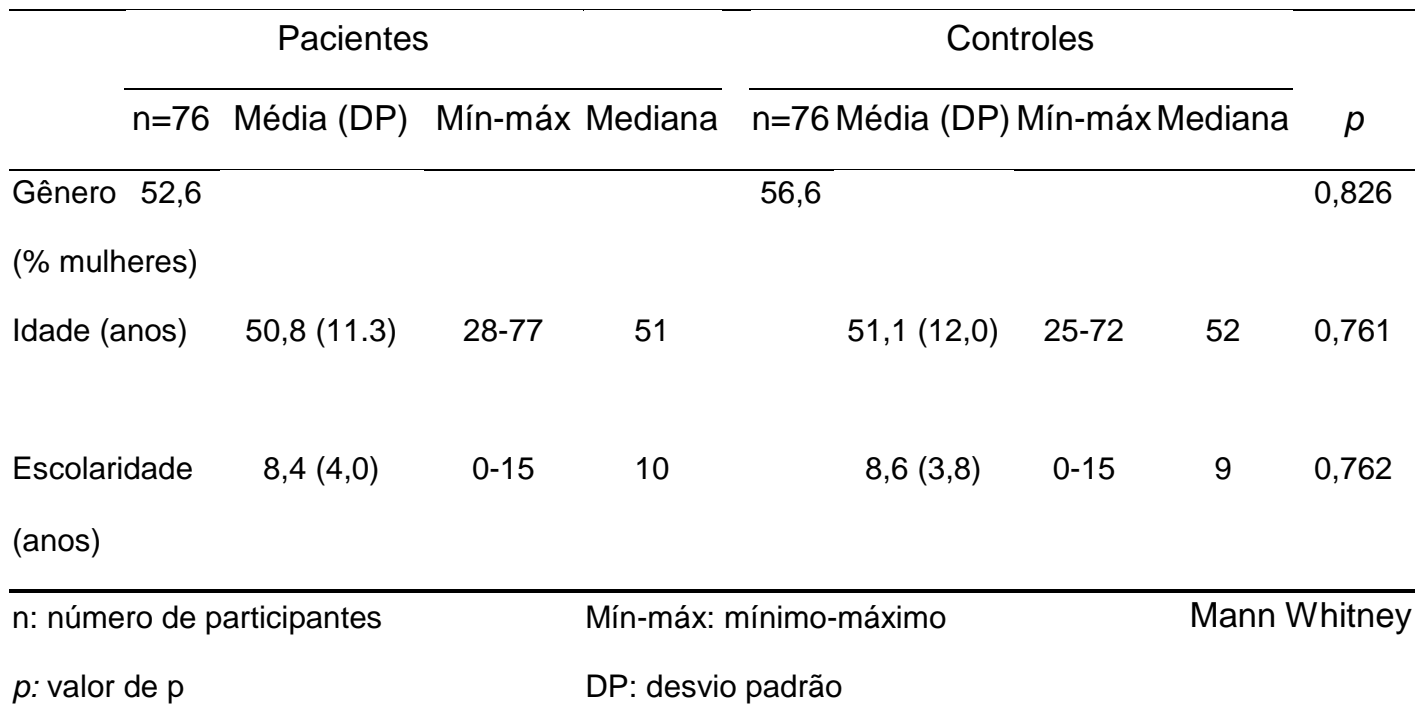

Os pacientes portadores de infecção crônica por HCV foram comparados com grupo de sujeitos controles não portadores de HCV separados por faixas de equivalência de gênero, idade e escolaridade. As faixas etárias dos pacientes e controles e a distribuição destas por gênero são mostradas na Tabela 2. 
Tabela 2 - Distribuição dos grupos por gênero e faixas de idade

\begin{tabular}{|c|c|c|c|c|c|c|c|}
\hline & \multirow[b]{2}{*}{ Gênero } & \multicolumn{2}{|c|}{ Pacientes } & \multicolumn{2}{|c|}{ Controles } & \multicolumn{2}{|c|}{ Total } \\
\hline & & $\mathrm{n}$ & $\%$ & $\mathrm{n}$ & $\%$ & $\mathrm{n}$ & $\%$ \\
\hline \multicolumn{8}{|l|}{$\begin{array}{l}\text { Faixa etária } \\
\text { (anos) }\end{array}$} \\
\hline \multirow[t]{3}{*}{ 21-30 } & & 3 & 2 & 4 & 2,6 & 7 & 4,6 \\
\hline & Mulheres & 1 & 0,7 & 3 & 2 & 4 & 2,6 \\
\hline & Homens & 2 & 1,3 & 1 & 0,7 & 3 & 2 \\
\hline \multirow[t]{3}{*}{$31-40$} & & 14 & 9,2 & 13 & 8,6 & 27 & 17,8 \\
\hline & Mulheres & 7 & 4,6 & 6 & 3,9 & 13 & 8,6 \\
\hline & Homens & 7 & 4,6 & 7 & 4,6 & 14 & 9,2 \\
\hline \multirow[t]{3}{*}{$41-50$} & & 20 & 13,2 & 18 & 11,8 & 38 & 25 \\
\hline & Mulheres & 12 & 7,9 & 7 & 7,9 & 19 & 12,5 \\
\hline & Homens & 8 & 5,3 & 11 & 7,2 & 19 & 12,5 \\
\hline \multirow[t]{3}{*}{$51-60$} & & 23 & 15,1 & 25 & 16,5 & 48 & 31,6 \\
\hline & Mulheres & 12 & 7,9 & 18 & 11,8 & 30 & 19,7 \\
\hline & Homens & 11 & 7,2 & 7 & 4,6 & 18 & 11,8 \\
\hline \multirow[t]{3}{*}{$62-70$} & & 14 & 9,2 & 14 & 9,2 & 28 & 18,4 \\
\hline & Mulheres & 8 & 5,3 & 9 & 5,9 & 17 & 11,2 \\
\hline & Homens & 6 & 3,9 & 5 & 3,3 & 11 & 7,2 \\
\hline \multirow[t]{3}{*}{$>71$} & & 2 & 1,3 & 2 & 1,3 & 4 & 2,6 \\
\hline & Mulheres & 0 & 0 & 0 & 0 & 0 & 0 \\
\hline & Homens & 2 & 1,3 & 2 & 1,3 & 4 & 2,6 \\
\hline TOTAL & & 76 & 50 & 76 & 50 & 152 & 100 \\
\hline
\end{tabular}

Os genótipos do HCV na amostra de pacientes e os graus de fibrose e inflamação que estes apresentavam na biópsia hepática (segundo o sistema METAVIR) estão representados na Tabela 3. 
Tabela 3 - Graus de Fibrose e inflamação hepática dos pacientes com hepatite C e genótipos virais

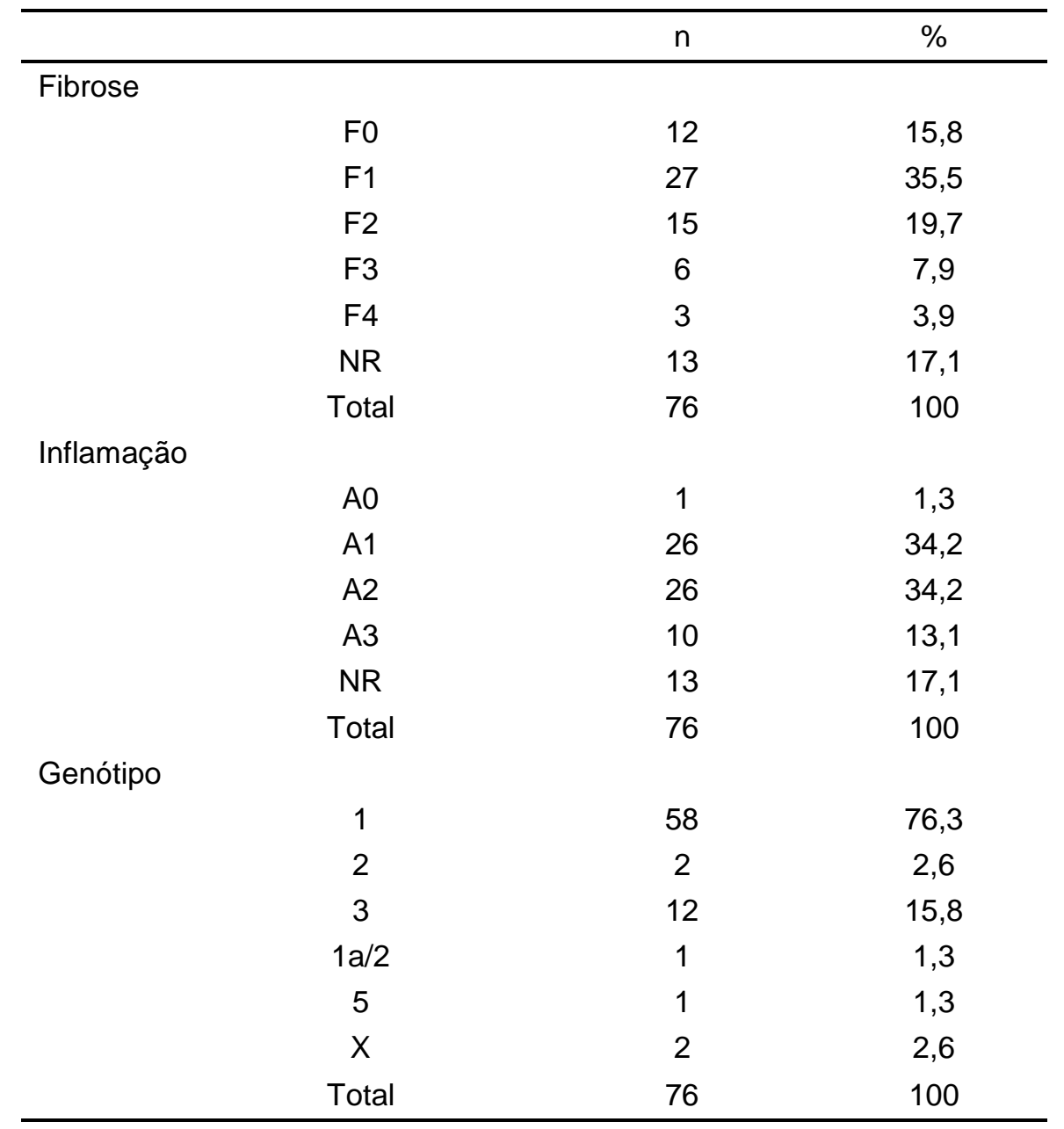

n: número de pacientes

A: grau de inflamação

F: grau de fibrose hepática

NR: não realizado

A classificação dos pacientes com relação à história de etilismo e uso de drogas se encontra na Tabela 4. Foi considerado etilismo leve o uso de até $20 \mathrm{~g}$ de álcool por dia, etilismo moderado o uso de 20 a $50 \mathrm{~g}$ de álcool por dia e etilismo grave o uso de mais de $50 \mathrm{~g}$ de álcool por dia. 
Tabela 4 - História de etilismo e uso de drogas dos pacientes com hepatite C

\begin{tabular}{lcc}
\hline & $\mathbf{n}$ & $\%$ \\
\hline Etilismo leve & 17 & 22,4 \\
Moderado & 10 & 13,2 \\
Grave & 4 & 5,3 \\
Total & 31 & 40,8 \\
& & \\
Uso de drogas inaláveis & 12 & 15,8 \\
Uso de drogas injetáveis & 4 & 5,3 \\
Ambas & 6 & 7,9 \\
Total & 22 & 28,9 \\
& & \\
Somente etilismo & 13 & 17,1 \\
Somente drogas & 4 & 5,3 \\
Etilismo e uso de drogas & 18 & 23,7 \\
Total & 35 & 46,1 \\
Sem informações & 4 & 5,3 \\
\hline
\end{tabular}

n: número de pacientes

As NP encontradas nos pacientes com hepatite $\mathrm{C}$ se encontram na Tabela 5 , as encontradas nos controles na Tabela 6 e as neuropatias agrupadas encontradas nos dois grupos estão na Tabela 7. 
Tabela 5 - Neuropatias periféricas nos pacientes com hepatite C, crioglobulinas, metabolismo da glicose e genótipos

\begin{tabular}{|c|c|c|c|c|c|}
\hline Paciente & Tipo de NP & CGs & $\begin{array}{c}\text { Met } \\
\text { glicose }\end{array}$ & HOMA & Genótipo \\
\hline 1 & MN fibular & + & - & 1,0 & 3 \\
\hline 2 & Med bi & - & - & 2,4 & 1 \\
\hline 3 & Rad & - & _- & FD & 1 \\
\hline 4 & Med bi & - & - & 1,48 & 1 \\
\hline 5 & Med bi/PNP & - & - & 1,3 & 1 \\
\hline 9 & $\operatorname{Rad}$ & - & $\mathrm{IG}$ & 4,46 & 1 \\
\hline 12 & PNP assim & - & - & 1,5 & 1 \\
\hline 15 & $\mathrm{NP}$ motora pura $4 \mathrm{~mm}$ & - & IG & 2,14 & 1 \\
\hline 17 & MN safeno & - & - & 2,0 & 5 \\
\hline 18 & Med bi/PNP & - & $\mathrm{IG}$ & 6,1 & 1 \\
\hline 20 & Med bi & - & - & 1,3 & 3 \\
\hline 28 & PNP assim & - & - & FD & 1 \\
\hline 31 & PNP & NR & - & 3,0 & 1 \\
\hline 37 & MN fibular traumática & + & - & 1,8 & 1 \\
\hline 44 & PNP & + & $\mathrm{IG}$ & 4,6 & 1 \\
\hline 45 & PNP & - & DM & 7 & 1 \\
\hline 48 & Rad & NR & $\mathrm{IG}$ & 3,2 & 1 \\
\hline 55 & PNP & - & - & 1,4 & 1 \\
\hline 56 & MNM & - & - & 0,5 & 1 \\
\hline 61 & Med bi/PNP & + & $\mathrm{DM}$ & 239,5 & 1 \\
\hline 62 & Uln uni/PNP & - & DM & FD & 1 \\
\hline 64 & PNP & - & - & FD & 1 \\
\hline 65 & Med bi & - & - & FD & 1 \\
\hline 66 & Med bi & - & - & 1,5 & 1 \\
\hline 67 & PNP & - & IG & 4,4 & 1 \\
\hline 68 & Rad & - & - & FD & 1 \\
\hline 71 & PNP & - & - & 0,6 & 1 \\
\hline 74 & Med bi & - & - & 2,4 & 1 \\
\hline 75 & Uln bi/Med uni/PNP & - & DM & 18,4 & 2 \\
\hline \multicolumn{3}{|c|}{ NP: neuropatia periférica } & \multicolumn{3}{|c|}{ mm: membros } \\
\hline \multicolumn{3}{|c|}{ Crio: crioglobulinas no soro } & \multicolumn{3}{|c|}{ Med: neuropatia do mediano } \\
\hline \multicolumn{3}{|c|}{ Met glicose: metabolismo da glicose } & \multicolumn{3}{|c|}{ Ulnar: neuropatia do ulnar } \\
\hline \multicolumn{3}{|c|}{ HOMA: homeosthasis method assessment } & \multicolumn{3}{|c|}{ Uni: unilateral } \\
\hline \multicolumn{3}{|c|}{ PNP: polineuropatia } & \multicolumn{3}{|c|}{ Bi: bilateral } \\
\hline \multicolumn{3}{|c|}{ MN: mononeuropatia } & \multicolumn{3}{|c|}{ NR: não realizado } \\
\hline \multicolumn{3}{|c|}{ MNM: mononeuropatia múltipla } & \multirow{2}{*}{\multicolumn{3}{|c|}{$\begin{array}{l}\text { IG: intolerância à glicose } \\
\text { DM: diabetes melito } \\
\text { +: presentes }\end{array}$}} \\
\hline $\begin{array}{l}\text { Rad: radiculopa } \\
-: \text { ausentes }\end{array}$ & & & & & \\
\hline
\end{tabular}


Tabela 6 - Neuropatias periféricas no grupo controle

\begin{tabular}{lll}
\hline Controle & NP \\
\hline 15 & Med bi \\
29 & Med bi \\
35 & Med bi \\
38 & Med bi & \\
40 & PNP & \\
41 & Med bi & \\
42 & Uln uni traum/PNP & \\
50 & Rad & \\
52 & PNP & \\
54 & Rad & \\
56 & Med bi & \\
61 & Med uni/Rad/Sequela PI \\
62 & Rad & infantil \\
72 & Med bi & Med: neuropatia do mediano \\
\hline NP: neuropatia periférica & MN: mononeuropatia & Ulnar: neuropatia do ulnar \\
PNP: polineuropatia & Traum: traumática & \\
Rad: radiculopatia & Bi: bilateral &
\end{tabular}


Tabela 7 - Neuropatias agrupadas no grupo de pacientes e grupo controle

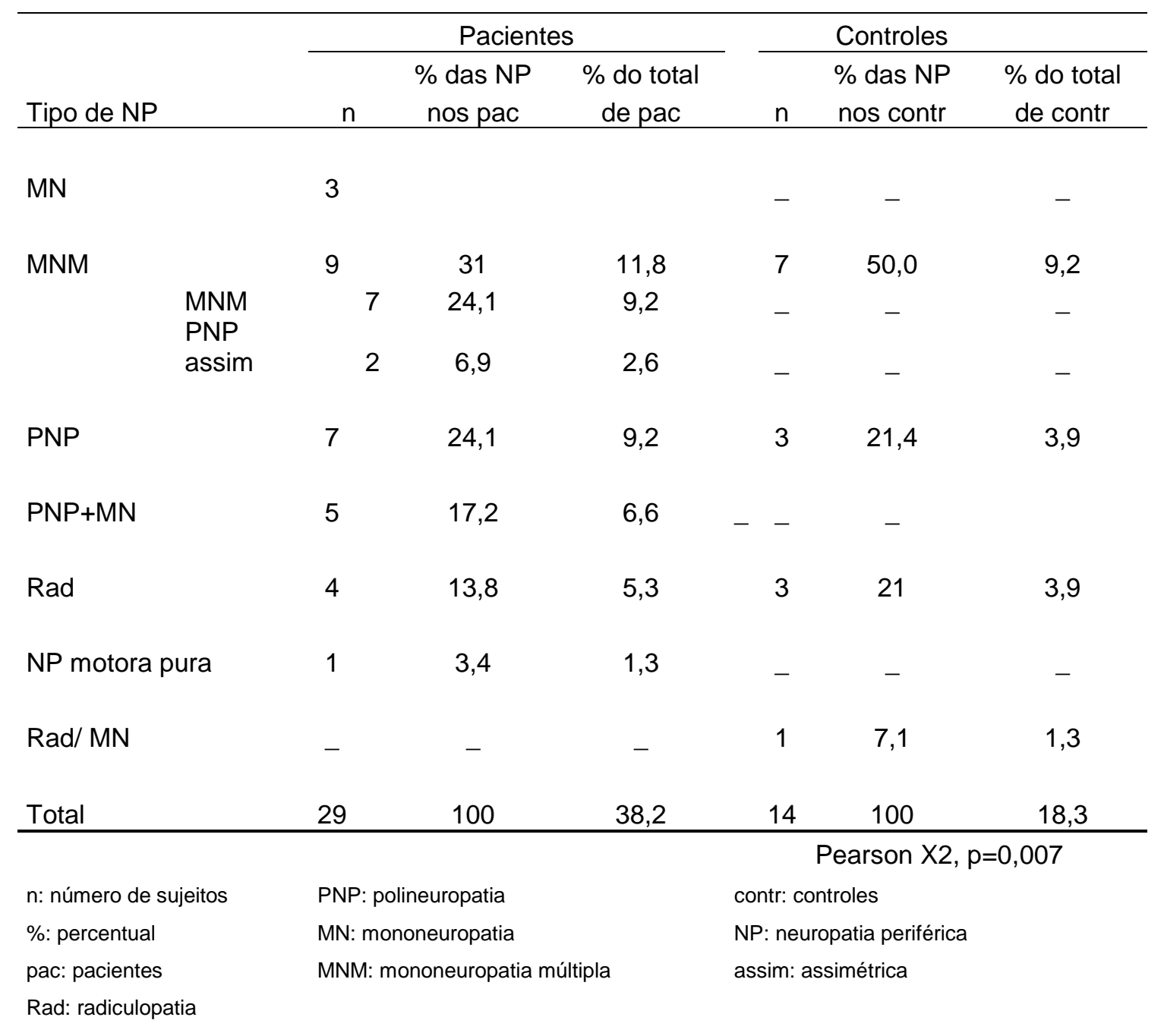

Interpretamos os casos de PNP assimétricas como MNM confluentes.

Cinco pacientes tinham quadro clínico de PNP sensitiva $(71,4 \%)$ e dois de PNP sensitivomotora $(28,6 \%)$.

Onze pacientes (14,5\%) queixavam-se de fraqueza e 41 (53,9\%) queixavam-se de dores e/ou parestesias nos membros. Destes, 20 pacientes $(26,3 \%)$ tinham queixas de parestesias ou dores, porém sem sinais objetivos de 
NP. No grupo controle, 16 sujeitos $(21,1 \%)$ queixavam-se de parestesias/dores, dos quais seis indivíduos $(7,9 \%)$ sem sinais objetivos de NP $(p<0,0001)$.

Em $85,5 \%$ dos pacientes $(65 / 76)$ foi realizada a dosagem de crioglobulinemia. Seis pacientes $(9,2 \%)$ em que foi realizada a pesquisa de CGs apresentaram resultados positivos (Tabela 5). Quatro pacientes com crioglobulinemia detectável apresentavam NP (três PNP, um MN).

Cinco pacientes $(6,6 \%)$ e sete controles $(9,2 \%)$ apresentavam DM franco e já estavam recebendo tratamento para tal. Na Tabela 8 se encontram os pacientes e controles com NP em relação à presença de DM e os tipos de neuropatias periféricas por eles apresentados. 
Tabela 8 - Comparação de pacientes e controles com NP em relação à presença de DM franco

\begin{tabular}{|c|c|c|c|c|c|c|c|c|}
\hline & \multicolumn{4}{|c|}{ Pacientes com NP } & \multicolumn{4}{|c|}{ Controles com NP } \\
\hline & \multicolumn{2}{|c|}{$\mathrm{DM}$} & \multicolumn{2}{|c|}{ sem DM } & \multicolumn{2}{|r|}{$\mathrm{DM}$} & \multicolumn{2}{|c|}{ sem DM } \\
\hline & $\mathrm{n}$ & $\%$ & $\mathrm{n}$ & $\%$ & $\mathrm{n}$ & $\%$ & $n$ & $\%$ \\
\hline PNP & 1 & 3,4 & 6 & 20,7 & 2 & 14,28 & - & - \\
\hline $\mathrm{PNP}+\mathrm{MN}$ & 3 & 10,3 & 4 & 13,8 & 1 & 7,1 & - & - \\
\hline MN/MNM & - & - & 11 & 37,9 & 1 & 7,1 & 6 & 42,9 \\
\hline Radiculopatia & - & - & 4 & 13,8 & - & - & 3 & 21,4 \\
\hline $\mathrm{Rad}+\mathrm{MN}$ & - & - & - & - & - & - & 1 & 7,1 \\
\hline TOTAL & 4 & 13,8 & 25 & 86,2 & 4 & 28,6 & 10 & 71,4 \\
\hline n: número de sujeitos & & & PNP: & neuropatia & & & & \\
\hline NP: neuropatia periférica & & & $M N: n$ & neuropatia & & & & \\
\hline DM: diabetes melito & & & MNM & noneuropatia & múlti & & & \\
\hline
\end{tabular}

Além dos cinco pacientes com hepatite C com DM franco, outros 17 pacientes apresentavam IG (22,4\%). Portanto, 22 pacientes $(28,9 \%)$ apresentavam DM ou IG 28,9\%. Dez (45,5\%) pacientes com alteração no metabolismo da glicose, $10(45,5 \%)$ tinham algum tipo de acometimento do SNP.

Dentre os 22 pacientes com alteração do metabolismo da glicose $3,6 \%$ (18/76) eram portadores do genótipo 1, 2,6\% (2/76) do genótipo 2, e 2,6\% (2/76) do genótipo 3 (Tabela 9). 
Tabela 9 - Metabolismo da glicose, crioglobulinemia e genótipos HCV

\begin{tabular}{|c|c|c|c|c|}
\hline Paciente & HOMA & IG/DM & CGs & Genótipo \\
\hline 1 & 1 & - & pos & 3 \\
\hline 2 & 2,4 & - & neg & 1 \\
\hline 3 & FD & _ & neg & 1 \\
\hline 4 & 1,5 & - & NR & 1 \\
\hline 5 & 1,3 & - & neg & 1 \\
\hline 6 & 0,7 & - & neg & 1 \\
\hline 7 & 1,1 & - & neg & 3 \\
\hline 8 & 1,4 & - & neg & 1 \\
\hline 9 & 4,5 & IG & neg & 1 \\
\hline 10 & 3 & IG & neg & 3 \\
\hline 11 & 5,5 & IG & neg & 3 \\
\hline 12 & 1,6 & - & neg & 1 \\
\hline 13 & 0,7 & - & neg & 1 \\
\hline 14 & 1,5 & - & neg & 1 \\
\hline 15 & 2,1 & - & neg & 1 \\
\hline 16 & 1 & - & neg & 1 \\
\hline 17 & 2 & - & NR & 5 \\
\hline 18 & 5,9 & IG & neg & 1 \\
\hline 19 & 2,5 & - & neg & 1 \\
\hline 20 & 1,2 & _ & neg & 3 \\
\hline 21 & 0,5 & - & neg & 1 \\
\hline 22 & 2,8 & - & neg & 2 \\
\hline 23 & 2,9 & - & neg & 1 \\
\hline 24 & 2,1 & - & neg & 1 \\
\hline 25 & 1,7 & - & pos & 3 \\
\hline 26 & FD & - & neg & 1 \\
\hline 27 & 1,9 & - & neg & 1 \\
\hline 28 & 4 & IG & neg & 1 \\
\hline 29 & 0,6 & - & neg & 1 \\
\hline 30 & 0,6 & - & neg & 1 \\
\hline 31 & 3 & IG & NR & 1 \\
\hline 32 & 2,3 & - & neg & 3 \\
\hline 33 & 0,9 & - & neg & 1 \\
\hline 34 & 0,6 & - & neg & 3 \\
\hline 35 & 2,2 & - & neg & 1 \\
\hline 36 & 0,6 & - & neg & NR \\
\hline 37 & 1,8 & - & pos & 1 \\
\hline 38 & 3,7 & $I G$ & neg & 2 \\
\hline 39 & 2,4 & - & neg & 1 \\
\hline
\end{tabular}


Tabela 9 - Metabolismo da glicose, crioglobulinemia e genótipos HCV

\begin{tabular}{|c|c|c|c|c|}
\hline Paciente & HOMA & IG/DM & CGs & Genótipo \\
\hline 40 & 0,8 & $\ldots$ & NR & 1 \\
\hline 41 & 1,2 & _ & neg & 1 \\
\hline 42 & 1,3 & - & NR & 3 \\
\hline 43 & 2,9 & - & neg & 1 \\
\hline 44 & 4,5 & IG & pos & 1 \\
\hline 45 & 6,8 & DM & neg & 1 \\
\hline 46 & 1,6 & - & neg & 1 \\
\hline 47 & 1,6 & _ & neg & 3 \\
\hline 48 & 3,2 & IG & neg & 1 \\
\hline 49 & 1,8 & - & NR & 1 \\
\hline 50 & 2,2 & _ & NR & 1 \\
\hline 51 & 12 & IG & pos & 1 \\
\hline 52 & 2,3 & _- & neg & NR \\
\hline 53 & FD & _ & NR & 1 \\
\hline 54 & 0,8 & _ & NR & 3 \\
\hline 55 & 0,6 & _ & neg & 1 \\
\hline 56 & 0,5 & _ & neg & 1 \\
\hline 57 & 2,4 & _ & neg & 1 \\
\hline 58 & 4,5 & IG & neg & 1 \\
\hline 59 & 1,7 & _ & NR & 3 \\
\hline 60 & 4,22 & $I G$ & neg & 1 \\
\hline 61 & 244,7 & DM & pos & 1 \\
\hline 62 & FD & $\mathrm{DM}$ & neg & 1 \\
\hline 63 & 19,6 & $\mathrm{DM}$ & NR & 1 \\
\hline 64 & 3 & $I G$ & neg & 1 \\
\hline 65 & 1,5 & _ & neg & 1 \\
\hline 66 & 5,3 & IG & neg & 1 \\
\hline 67 & 1,9 & - & neg & 1 \\
\hline 68 & FD & _ & neg & 1 \\
\hline 69 & 3,9 & $I G$ & neg & 1 \\
\hline 70 & 3,1 & IG & neg & 1 \\
\hline 71 & 0,6 & - & neg & 1 \\
\hline 72 & 2,8 & - & neg & 1 \\
\hline 73 & 3 & IG & neg & 1 \\
\hline 74 & 1,2 & - & neg & 1 \\
\hline 75 & 17,9 & DM & neg & 2 \\
\hline 76 & FD & & neg & 1 \\
\hline
\end{tabular}


HOMA: Homeosthasis Method Assessment

IG: intolerância à glicose

DM: diabetes melito

CGs: crioglobulinas
NR: não realizado

pos: pesquisa positiva

neg: pesquisa negativa Conclusão

$\mathrm{Na}$ Tabela 10 podem ser vistos os resultados da pesquisa de autoanticorpos realizada nos pacientes com hepatite $\mathrm{C}$ e o percentual de positividade nos testes realizados.

Tabela 10 - Autoanticorpos nos pacientes com hepatite C

\begin{tabular}{|c|c|c|c|c|}
\hline & & $\mathbf{n}$ & $\%$ & $\%$ nos ex real \\
\hline Anticardiolipinas & reag & 12 & 15,8 & 20,7 \\
\hline \multirow[t]{2}{*}{$\lg M$} & não reag & 46 & 60,5 & 79,3 \\
\hline & $\mathrm{n}^{\circ}$ ex realiz & 58 & 76,3 & - \\
\hline Anticardiolipinas & reag & 3 & 3,9 & 5,2 \\
\hline \multirow[t]{3}{*}{$\lg G$} & não reag & 55 & 72,4 & 94,8 \\
\hline & $\mathrm{n}^{\circ}$ ex realiz & 58 & 77,6 & \\
\hline & & & & - \\
\hline \multirow[t]{3}{*}{ Anti-DNA } & reag & 5 & 6,6 & 9,8 \\
\hline & não reag & 46 & 60,5 & 90,2 \\
\hline & $\mathrm{n}^{\circ}$ ex realiz & 51 & 67,1 & - \\
\hline \multirow[t]{3}{*}{ Anti-RNP } & reag & 1 & 1,3 & 3,2 \\
\hline & não reag & 30 & 39,5 & 93,8 \\
\hline & $\mathrm{n}^{0}$ ex realiz & 31 & 40,8 & - \\
\hline \multirow[t]{3}{*}{ Anti-SM } & reag & 0 & 0 & 0 \\
\hline & não reag & 36 & 47,4 & 100 \\
\hline & $\mathrm{n}^{\circ}$ ex realiz & 36 & 47,4 & - \\
\hline \multirow[t]{3}{*}{ Anti-SSA/RO } & reag & 5 & 6,6 & 7,6 \\
\hline & não reag & 61 & 80,3 & 92,4 \\
\hline & $\mathrm{n}^{\circ}$ ex realiz & 66 & 86,8 & - \\
\hline \multirow[t]{3}{*}{ Anti-SSB/LA } & reag & 6 & 7,9 & 9,2 \\
\hline & não reag & 59 & 77,6 & 90,8 \\
\hline & $\mathrm{n}^{0}$ ex realiz & 65 & 85,5 & - \\
\hline Antitirosina & reag & 6 & 7,9 & 18,8 \\
\hline \multirow[t]{2}{*}{ fosfatase (IA-2) } & não reag & 26 & 34,2 & 81,3 \\
\hline & $\mathrm{n}^{\circ}$ ex realiz & 32 & 42,1 & _- \\
\hline
\end{tabular}


Tabela 10 - Autoanticorpos nos pacientes com hepatite C

\begin{tabular}{|c|c|c|c|c|}
\hline & & $\mathrm{n}$ & $\%$ & $\%$ nos ex real \\
\hline \multirow[t]{3}{*}{ Anti-TGB } & reag & 7 & 9,2 & 18,9 \\
\hline & não reag & 30 & 39,5 & 81,1 \\
\hline & ํo ex realiz & 37 & 48,7 & - \\
\hline \multirow[t]{3}{*}{ Anti-TPO } & reag & 8 & 10,5 & 22,9 \\
\hline & não reag & 27 & 35,5 & 77,1 \\
\hline & $\mathrm{n}^{\circ}$ ex realiz & 35 & 46,1 & - \\
\hline \multirow[t]{3}{*}{ Antimúsculo liso } & reag & 17 & 22,4 & 26,2 \\
\hline & não reag & 48 & 63,2 & 73,8 \\
\hline & $\mathrm{n}^{\circ}$ ex realiz & 65 & 85,5 & - \\
\hline \multirow[t]{3}{*}{ ANCA } & reag & 4 & 5,3 & 8,5 \\
\hline & não reag & 43 & 56,6 & 91,5 \\
\hline & $\mathrm{n}^{\circ}$ ex realiz & 47 & 61,8 & - \\
\hline \multirow[t]{3}{*}{ Anti-GAD } & reag & 1 & 1,3 & 2,8 \\
\hline & não reag & 35 & 47,4 & 97,2 \\
\hline & $\mathrm{n}^{\circ}$ ex realiz & 36 & 48,7 & - \\
\hline \multirow[t]{3}{*}{ Anticélula parietal } & reag & 2 & 2,6 & 3,3 \\
\hline & não reag & 58 & 76,3 & 96,7 \\
\hline & $\mathrm{n}^{\circ}$ ex realiz & 60 & 78,9 & - \\
\hline \multirow[t]{3}{*}{ Antimitocôndria } & reag & 0 & 0 & 0 \\
\hline & não reag & 63 & 84,2 & 100 \\
\hline & $\mathrm{n}^{\circ}$ ex realiz & 63 & 84,2 & - \\
\hline \multirow[t]{3}{*}{ Anti-LKM1 } & reag & 1 & 1,3 & 1,6 \\
\hline & não reag & 63 & 82,9 & 98,4 \\
\hline & $\mathrm{n}^{\circ}$ ex realiz & 64 & 7,9 & - \\
\hline Antirreceptor & reag & 4 & 5,3 & 13,8 \\
\hline \multirow[t]{2}{*}{ TSH(TRAb) } & não reag & 25 & 32,9 & 8,6 \\
\hline & $\mathrm{n}^{\circ}$ ex realiz & 29 & 38,2 & - \\
\hline
\end{tabular}

reag: reagente

não reag: não reagente

$\mathrm{n}$ : número de pacientes
Anti-TGB: antitireoglobulina

Anti--TPO: antitireoperoxidase

Anti-SM: anti-Smith

ํo ex realiz: número de exames realizados ANCA: anticorpos anticitoplasma de neutrófilos

$\%$ ex real: percentual dos exames realizados Anti-RNP: antirribonucleoproteína

Anti-GAD: antidescarboxilase do ácido glutâmico

Anti-LKM1: anticorpos contra a fração microssomal de fígado e rim 
A Tabela 11 mostra os resultados das dosagens de gamaglobulinas séricas, do FR, das frações C3 e C4 do complemento, FAN-HEp2 e CGs na amostra de pacientes.

Tabela 11 - Gamaglobulinas, frações do complemento, FAN-HEp2, FR e crioglobulinas nos pacientes com hepatite $\mathrm{C}$

\begin{tabular}{|c|c|c|c|c|}
\hline & & $\mathbf{n}$ & $\%$ & $\%$ nos ex real \\
\hline \multirow[t]{3}{*}{ Gamaglobulinas } & elev & 30 & 39,5 & 46,9 \\
\hline & $\mathrm{nl}$ & 34 & 44,7 & 53,1 \\
\hline & no ex real & 64 & 84,2 & - \\
\hline \multirow[t]{3}{*}{ Fração C3 } & baixo & 7 & 9,2 & 12,1 \\
\hline & normal & 51 & 87,9 & 87,9 \\
\hline & no ex real & 58 & 76,3 & - \\
\hline \multirow[t]{3}{*}{ Fração C4 } & baixo & 11 & 14,5 & 19,3 \\
\hline & normal & 46 & 60,5 & 80,7 \\
\hline & no ex real & 57 & 75,0 & - \\
\hline \multirow[t]{3}{*}{ FAN-HEp2 } & reag & 7 & 9,2 & 10,9 \\
\hline & não reag & 57 & 75,0 & 89,1 \\
\hline & $\mathrm{n}^{\circ}$ ex real & 64 & 84,2 & - \\
\hline \multirow[t]{3}{*}{ FR } & reag & 16 & 21,1 & 26,7 \\
\hline & não reag & 44 & 57,9 & 57,9 \\
\hline & no ex real & 60 & 78,9 & - \\
\hline \multirow[t]{3}{*}{ CGs } & reag & 6 & 7,9 & 9,4 \\
\hline & não reag & 58 & 76,3 & 90,6 \\
\hline & no ex real & 64 & 84,2 & \\
\hline \multicolumn{2}{|c|}{ n: número de pacientes } & não re & reagente & reag: reagente \\
\hline \multicolumn{2}{|l|}{ \%: percentual } & elev: $n$ & co elevado & baixo: nível sérico baixo \\
\hline \multicolumn{2}{|c|}{ nl: nível sérico normal } & CGs: & linas & \\
\hline \multicolumn{5}{|c|}{ no ex real: número de exames realizados } \\
\hline \multicolumn{5}{|c|}{$\%$ ex real: percentual dos exames realizados } \\
\hline \multicolumn{5}{|c|}{ Fração C3: fração C3 do complemento } \\
\hline \multicolumn{5}{|c|}{ Fração C4: fração C4 do complemento } \\
\hline
\end{tabular}

$\mathrm{Na}$ Tabela 12 se encontram resultados de determinações de autoanticorpos nos pacientes com hepatite $\mathrm{C}$ portadores de NP em comparação com os pacientes com hepatite C que não apresentavam NP. 
Tabela 12 - Autoanticorpos nos pacientes com hepatite C, com e sem neuropatias periféricas

\begin{tabular}{|c|c|c|c|c|c|c|c|c|}
\hline & & \multicolumn{3}{|c|}{ Pacientes COM NP } & \multicolumn{3}{|c|}{ Pacientes SEM NP } & \multirow[b]{2}{*}{$p$} \\
\hline & & $\mathrm{n}$ & $\begin{array}{c}\% \text { nos pac } \\
\text { com NP }\end{array}$ & $\begin{array}{c}\% \text { nos } \\
\text { ex } \\
\text { real } \\
\end{array}$ & $\mathrm{n}$ & $\begin{array}{c}\% \text { nos pac } \\
\text { sem NP }\end{array}$ & $\begin{array}{c}\% \text { nos } \\
\text { ex } \\
\text { real } \\
\end{array}$ & \\
\hline Anticardio- & reag & 4 & 13,8 & 20 & 8 & 17 & 21,1 & 0,925 \\
\hline \multirow[t]{2}{*}{ lipinas IgM } & não reag & 16 & 55,2 & 80 & 30 & 63,8 & 78,9 & \\
\hline & $\mathrm{n}^{\circ}$ ex real & 20 & 69 & - & 38 & 80,9 & - & \\
\hline Anticardio- & reag & 0 & 0 & 0 & 3 & 6,4 & 7,7 & 0,544 \\
\hline \multirow[t]{2}{*}{ lipinas IgG } & não reag & 19 & 65,5 & 100 & 36 & 76,6 & 92,3 & \\
\hline & $\mathrm{n}^{\circ}$ ex real & 19 & 65,5 & - & 39 & 83,0 & - & \\
\hline \multirow[t]{3}{*}{ Anti-DNA } & reag & 3 & 16,7 & 16,7 & 2 & 4,3 & 6,1 & 0,224 \\
\hline & não reag & 15 & 50 & 83,3 & 31 & 66 & 93,9 & \\
\hline & $\mathrm{n}^{\circ}$ ex real & 18 & 62,1 & - & 33 & 70,2 & - & \\
\hline \multirow[t]{3}{*}{ Anti-RNP } & reag & 0 & 0 & 0 & 1 & 2,1 & 4,5 & - \\
\hline & não reag & 9 & 31 & 100 & 21 & 43,5 & 95,5 & \\
\hline & $\mathrm{n}^{\circ}$ ex real & 9 & 31 & - & 22 & 44,7 & - & \\
\hline \multirow[t]{3}{*}{ Anti-SM } & reag & 0 & 0 & 0 & 0 & 0 & 0 & - \\
\hline & não reag & 13 & 44,8 & 100 & 23 & 48,9 & 100 & \\
\hline & $\mathrm{n}^{\circ}$ ex real & 13 & 44,8 & - & 23 & 48,9 & - & \\
\hline \multirow[t]{3}{*}{ Anti-SSA/RO } & reag & 4 & 13,8 & 17,4 & 1 & 2,1 & 2,3 & $0,028^{*}$ \\
\hline & não reag & 19 & 65,5 & 82,6 & 42 & 89,4 & 97,7 & \\
\hline & $\mathrm{n}^{\circ}$ ex real & 23 & 79,3 & - & 43 & 91,5 & - & \\
\hline \multirow[t]{3}{*}{ Anti-SSB/LA } & reag & 4 & 13,8 & 18,2 & 2 & 4,3 & 4,7 & 0,075 \\
\hline & não reag & 18 & 62,1 & 81,8 & 41 & 87 & 95,3 & - \\
\hline & $\mathrm{n}^{\circ}$ ex real & 22 & 75,9 & - & 43 & 91,5 & & \\
\hline \multirow{3}{*}{$\begin{array}{l}\text { Antitirosina } \\
\text { fosfatase }\end{array}$} & reag & 4 & 13,8 & 40 & 2 & 4,3 & 9,1 & $0,038^{*}$ \\
\hline & não reag & 6 & 20,7 & 60 & 20 & 42,6 & 90,9 & - \\
\hline & $\mathrm{n}^{\circ}$ ex real & 10 & 34,5 & - & 22 & 46,8 & & \\
\hline
\end{tabular}


Tabela 12 - Autoanticorpos nos pacientes HCV com e sem NP

\begin{tabular}{|c|c|c|c|c|c|c|c|c|}
\hline & & \multicolumn{3}{|c|}{ Pacientes COM NP } & \multicolumn{3}{|c|}{ Pacientes SEM NP } & \multirow[b]{2}{*}{$p$} \\
\hline & & $\mathrm{n}$ & $\begin{array}{c}\% \text { nos pac } \\
\text { com NP }\end{array}$ & $\begin{array}{l}\% \text { nos } \\
\text { ex } \\
\text { real }\end{array}$ & $n$ & $\begin{array}{c}\% \text { nos pac } \\
\text { sem NP }\end{array}$ & $\begin{array}{l}\% \text { nos } \\
\text { ex } \\
\text { real }\end{array}$ & \\
\hline \multirow[t]{3}{*}{ Anti-TGB } & reag & 2 & 6,9 & 16,7 & 5 & 10,6 & 20 & 0,809 \\
\hline & não reag & 10 & 34,5 & 83,3 & 20 & 42,6 & 80 & \\
\hline & $n^{0}$ ex real & 12 & 41,4 & - & 25 & 53,2 & - & \\
\hline \multirow[t]{3}{*}{ Anti-TPO } & reag & 1 & 3,4 & 9,1 & 7 & 14,9 & 29,2 & 0,189 \\
\hline & não reag & 10 & 34,5 & 90,9 & 17 & 36,2 & 70,8 & \\
\hline & $\mathrm{n}^{0}$ ex real & 11 & 37,9 & - & 24 & 51,1 & - & \\
\hline Antimúsculo & reag & 6 & 20,7 & 25 & 11 & 23,4 & 26,8 & 0,871 \\
\hline \multirow[t]{2}{*}{ liso } & não reag & 18 & 62,1 & 75 & 30 & 63,8 & 73,2 & \\
\hline & $\mathrm{n}^{\circ}$ ex real & 24 & 82,8 & - & 41 & 87,2 & - & \\
\hline \multirow[t]{3}{*}{ ANCA } & reag & 2 & 6,9 & 13,3 & 1 & 2,1 & 3,2 & 0,193 \\
\hline & não reag & 13 & 44,8 & 86,7 & 30 & 63,8 & 96,8 & \\
\hline & $\mathrm{n}^{0}$ ex real & 15 & 51,7 & - & 31 & 66 & - & \\
\hline \multirow[t]{3}{*}{ Anti-GAD } & reag & 0 & 0 & 0 & 1 & 2,1 & 4,3 & - \\
\hline & não reag & 12 & 41,4 & 100 & 22 & 46,8 & 95,7 & \\
\hline & $\mathrm{n}^{0}$ ex real & 12 & 41,4 & - & 23 & 48,9 & - & \\
\hline Anticélula & reag & 1 & 3,4 & 4,8 & 1 & 2,1 & 2,6 & 0,651 \\
\hline \multirow[t]{2}{*}{ parietal } & não reag & 20 & 69 & 95,2 & 38 & 80,9 & 97,4 & \\
\hline & $\mathrm{n}^{\circ}$ ex real & 21 & 72,4 & - & 39 & 83 & - & \\
\hline Antimito- & reag & 0 & 0 & 0 & 0 & 0 & 0 & - \\
\hline \multirow[t]{2}{*}{ côndria } & não reag & 21 & 72,4 & 100 & 42 & 89,4 & 100 & \\
\hline & $\mathrm{n}^{\circ}$ ex real & 21 & 72,4 & - & 42 & 89,4 & - & \\
\hline
\end{tabular}


Tabela 12 - Autoanticorpos nos pacientes HCV com e sem NP

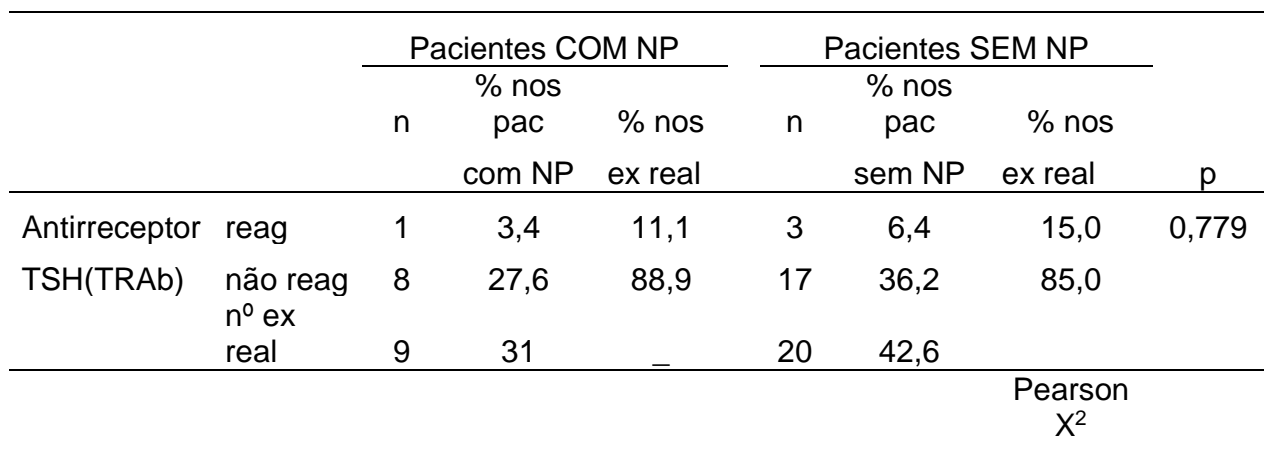

n: número de pacientes

$p$ : valor de $p$

reag: reagente

não reag: não reagente

Anti--TPO: antitireoperoxidase
Anti-SM: anti-Smith

TSH: hormônio tireoestimulante

Anti-RNP: antirribonucleoproteína

Anti-TGB: antitireoglobulina

$\%$ ex real: percentual dos exames realizados

Anti-GAD: anti-descarboxilase do ácido glutâmico

Anti-LKM1: anticorpos contra a fração microssomal de fígado e rim

ANCA: anticorpos anticitoplasma de neutrófilos

Conclusão

A tabela 13 mostra a comparação entre pacientes com hepatite $C$ com NP e sem NP em relação às dosagens de gamaglobulinas séricas, frações C3 e C4 do complemento, FAN-HEp2, FR e CGs. 
Tabela 13 - Gamaglobulinas, complemento, FAN-HEp2, FR e crioglobulinas nos pacientes com hepatite $\mathrm{C}$, com e sem neuropatias periféricas

\begin{tabular}{|c|c|c|c|c|c|c|c|c|}
\hline & & & Pacientes C & NP & & Pacientes S & NP & \\
\hline & & $\mathrm{n}$ & $\begin{array}{c}\% \text { nos pac } \\
\text { com NP }\end{array}$ & $\begin{array}{l}\% \text { nos } \\
\text { ex real }\end{array}$ & $\mathrm{n}$ & $\begin{array}{c}\% \text { nos pac } \\
\text { sem NP }\end{array}$ & $\begin{array}{l}\% \text { nos } \\
\text { ex real }\end{array}$ & $p$ \\
\hline Gama & elev & 15 & 1,7 & 62,5 & 15 & 31,9 & 37,5 & 0,052 \\
\hline & $\mathrm{nl}$ & 9 & 31 & 37,5 & 25 & 53,2 & 62,5 & \\
\hline & $\mathrm{n}^{\circ}$ ex real & 24 & 82,8 & - & 40 & 85,1 & - & \\
\hline Fração C3 & baixo & 2 & 6,9 & 11,1 & 5 & 10,6 & 12,5 & 0,880 \\
\hline & normal & 16 & 55,2 & 88,9 & 35 & 74,5 & 87,5 & \\
\hline & $\mathrm{n}^{\circ}$ ex real & 18 & 62,1 & - & 40 & 85,1 & - & \\
\hline Fração C4 & baixo & 5 & 17,2 & 27,8 & 6 & 12,8 & 15,4 & 0,270 \\
\hline & normal & 13 & 44,8 & 72,2 & 33 & 70,2 & 8,5 & \\
\hline & $\mathrm{n}^{\circ}$ ex real & 18 & 62,1 & - & 39 & 83,0 & - & \\
\hline FAN-HEp2 & reag & 4 & 13,8 & 18,2 & 3 & 6,4 & 7,1 & 0,179 \\
\hline & não reag & 18 & 62,1 & 81,8 & 39 & 83,0 & 92,9 & \\
\hline & no ex real & 22 & 75,9 & - & 42 & 89,4 & - & \\
\hline FR & reag & 7 & 24,1 & 38,9 & 9 & 19,1 & 21,4 & 0,161 \\
\hline & não reag & 11 & 37,9 & 61,1 & 33 & 70,2 & 78,6 & \\
\hline & $\mathrm{n}^{\circ}$ ex real & 18 & 62,1 & - & 42 & 89,4 & - & \\
\hline CGs & reag & 4 & 13,8 & 16,0 & 2 & 4,3 & 5,1 & 0,145 \\
\hline & não reag & 21 & 72,4 & 84,0 & 37 & 78,7 & 94,9 & \\
\hline & no ex real & 25 & 86,2 & & 39 & 83,0 & & \\
\hline & & & & & & & Pear & $n X^{2}$ \\
\hline $\mathrm{n}$ : número de & acientes & & não reag: não r & gente & & reag: reagente & & \\
\hline$\%$ : percentual & & & elev: nível séric & levado & & baixo: nível sér & baixo & \\
\hline nl: nível sérico & tormal & & ํo ex real: núm & de exam & aliza & & & \\
\hline$\%$ ex real: per & entual dos ex & שT S & lizados & & & $p$ : valor de $p$ & & \\
\hline
\end{tabular}

As comparações entre pacientes pportadores de HCV e controles em relação aos testes para avaliação cognitiva se encontram na tabela Tabela 14. 
Tabela 14 - Comparações de médias obtidas pelos participantes do estudo nos testes para avaliação de funções cognitivas

\begin{tabular}{|c|c|c|c|c|c|c|c|c|c|}
\hline & \multicolumn{4}{|c|}{ Pacientes } & \multicolumn{4}{|c|}{ Controles } & \multirow[b]{2}{*}{$p$} \\
\hline & $\mathrm{n}=76$ & Média (DP) & $\begin{array}{l}\text { Mín- } \\
\text { máx }\end{array}$ & Mediana & $\mathrm{n}=76$ & Média (DP) & $\begin{array}{l}\text { Mín- } \\
\text { máx }\end{array}$ & Mediana & \\
\hline MEEM & & $27,7(2,9)$ & $20-30$ & 29 & & $28(2,5)$ & $17-30$ & 29 & 0,758 \\
\hline \multicolumn{10}{|l|}{ FV } \\
\hline TDR & & $8,4(1,9)$ & $0-10$ & 9 & & $8,2(1,8)$ & $1-10$ & 8,5 & 0,281 \\
\hline \multicolumn{10}{|l|}{ Díg } \\
\hline \multirow{2}{*}{\multicolumn{2}{|c|}{ Díg Ol }} & $4,1(1,3)$ & $0-8$ & 4 & & $4,0(1,3)$ & $2-7$ & 4 & 0,464 \\
\hline & & & & & & & & \multicolumn{2}{|c|}{ Mann-Whitney } \\
\hline \multicolumn{4}{|c|}{ n: quantidade de indivíduos } & \multicolumn{6}{|c|}{ TDR: teste do desenho do relógio } \\
\hline \multicolumn{4}{|c|}{ Mín-máx: mínimo-máximo } & \multicolumn{6}{|c|}{ FV sem: fluência verbal semântica } \\
\hline \multicolumn{4}{|c|}{ DP: desvio padrão } & \multicolumn{6}{|c|}{ Díg OD: dígitos em ordem direta } \\
\hline \multicolumn{4}{|c|}{$p$ : valor de $p$} & \multicolumn{6}{|c|}{ Díg Ol: dígitos em ordem indireta } \\
\hline
\end{tabular}

A Tabela 15 mostra os escores obtidos por pacientes com hepatite $\mathrm{C} \mathrm{e}$ controles no MEEM. A proporção dos escores entre os grupos não mostrou diferença significativa (Pearson $\mathbf{X}^{2}, \mathbf{p}=0,086$ ). 
Tabela 15 - Escore obtidos por pacientes e controles no Miniexame do Estado Mental

\begin{tabular}{lccccc}
\hline & \multicolumn{2}{c}{ Pacientes } & & \multicolumn{2}{c}{ Controles } \\
\cline { 2 - 3 } \cline { 5 - 6 } Escore & $\mathrm{n}$ & $\%$ & & $\mathrm{n}$ & $\%$ \\
\hline 30 & 31 & 40,8 & & 30 & 39,5 \\
29 & 14 & 18,4 & & 13 & 17,1 \\
28 & 6 & 7,9 & & 11 & 11,5 \\
27 & 3 & 3,9 & & 7 & 9,2 \\
26 & 5 & 6,6 & & 4 & 5,3 \\
25 & 4 & 5,3 & & 1 & 1,3 \\
24 & 2 & 2,6 & & 7 & 9,2 \\
23 & 5 & 6,6 & & 0 & 0 \\
22 & 2 & 2,6 & & 2 & 2,6 \\
21 & 3 & 3,9 & & 0 & 0 \\
20 & 1 & 1,3 & & 0 & 0 \\
17 & 0 & 0 & & 1 & 1,3 \\
\hline n: número de sujeitos & & & & $\%:$ percentual
\end{tabular}

A comparação entre o grupo de pacientes com hepatite $\mathrm{C}$ e controles somente dos sujeitos com mais de quatro anos de escolaridade não mostrou diferença significativa (Mann-Whitney, $p=0,90$ ), e as proporções dos escores entre os grupos também não foi diferente (Pearson $\mathbf{X}^{2}, p=0,216$ ), embora um número maior de pacientes que controles teve escores mais baixos no MEEM ( $\leq$ 23).

$\mathrm{Na}$ tabela 16 se encontram os resultados de comparações entre os pacientes com hepatite $\mathrm{C}$ e controles em relação os subtestes do miniexame do estado mental. 
Tabela 16 - Subtestes do Miniexame do Estado Mental - comparação entre pacientes e controles

\begin{tabular}{|c|c|c|c|c|c|c|}
\hline & \multicolumn{2}{|c|}{ Pacientes } & \multicolumn{2}{|c|}{ Controles } & \multirow{2}{*}{$\begin{array}{c}\text { Regressão } \\
\text { logística } \\
p \\
\end{array}$} & \multirow{2}{*}{$\begin{array}{c}\text { Análise } \\
\text { multivariada } \\
p\end{array}$} \\
\hline & $\begin{array}{c}\text { normal } \\
n\end{array}$ & $\begin{array}{c}\text { alterado } \\
n\end{array}$ & $\begin{array}{c}\text { normal } \\
n\end{array}$ & $\begin{array}{c}\text { alterado } \\
n\end{array}$ & & \\
\hline $\begin{array}{l}\text { Escore total } \\
\text { Orientacão }\end{array}$ & 58 & 18 & 62 & 14 & 0,426 & 0,736 \\
\hline temporal & 72 & 4 & 70 & 4 & 0,567 & 0,493 \\
\hline Atenção e cálculo & 51 & 25 & 47 & 29 & $0,037^{*}$ & 0,947 \\
\hline $\begin{array}{l}\text { Memória imediata } \\
\text { Memória de }\end{array}$ & 75 & 1 & 75 & 1 & 1,0 & 1,0 \\
\hline evocação & 42 & 34 & 56 & 20 & $0,009^{* *}$ & $0,023^{*}$ \\
\hline Desenho & 57 & 19 & 61 & 15 & 0,436 & 0,438 \\
\hline Frase & 63 & 13 & 61 & 15 & 0,676 & 0,677 \\
\hline Comando & 76 & 0 & 73 & 3 & 0,800 & 0,810 \\
\hline Repetição & 76 & 0 & 75 & 1 & 0,316 & 0,317 \\
\hline Leitura & 76 & 0 & 74 & 2 & 0,155 & 0,156 \\
\hline $\begin{array}{c}n: \text { número de participant } \\
{ }^{*}: p<0,05\end{array}$ & & & $\begin{array}{c}p: \text { valor de } p \\
{ }^{* *}: p<0,01\end{array}$ & & & Pearson $\mathbf{X}^{2}$ \\
\hline
\end{tabular}

No pareamento dos grupos, o teste de Wilcoxon mostrou que não existiam diferenças significativas entre os grupos $(p=0,487)$.

A análise de coerência mostrou que $14,5 \%$ dos pacientes caíram no intervalo de MEEM de até 23 inclusive, contra apenas 3,9\% dos controles, o que mostra que o resultado é coerente com o que esperávamos, isto é, os pacientes têm desempenho pior neste teste do que os controles (11 pacientes $(14,5 \%)$ tiveram pontuação no $M E E M \leq 23$ vs três sujeitos $(4,0 \%)$ do grupo controle). A diferença estatística foi significante (Pearson $\left.\mathbf{X}^{2}, p=0,025\right)$. A média de idade dos pacientes com escores no MEEM $\leq 23$ foi de 54,2 anos (DP:10,6) e a mediana foi de 50 anos; a média de idade dos controles com pontuação $\leq 23$ no MEEM foi de 67,7 anos (DP: 3,21) e a mediana foi de 69 anos.

Na comparação de todos os pacientes que perderam pontos na ME com os que não perderam pontos, não foram verificadas diferenças estatísticas com 
relação ao gênero, grau de escolaridade, grau de fibrose à biópsia hepática e escores obtidos no BDI, porém foi verificada diferença estatística significante com relação à idade dos pacientes $(p=0,021)$.

Houve diferença significante entre os pacientes com pontuação $\leq 23$ no MEEM e os que obtiveram $>23$ pontos em relação a memória de evocação $(p=$ 0,006).

Não foram verificadas diferenças entre os pacientes portadores de HCV com escores $\leq 23$ no MEEM e aqueles com escores $>23$ em relação ao gênero, idade, grau de depressão, grau de fibrose à biópsia hepática, presença de CGs ou genótipos $(p>0,05)$, entretanto, a diferença do grau de escolaridade entre estes dois grupos de pacientes foi significante (Mann Whitney, $p=0,028$ ).

$\mathrm{Na}$ Tabela 17 se encontra o número de citações no teste de FV semântica de pacientes e controles. A média de citações no grupo dos pacientes foi de 17.3 (DP 5,19) e a mediana de 18.0. No grupo controle a média foi de 17.8 (DP 6,25) e a mediana de 17.0.

A Tabela 18 mostra os sujeitos com fluência verbal aquém do esperado para o grau de escolaridade. 
Tabela 17 - Fluência Verbal Semântica de pacientes e controles (categoria animais)

\begin{tabular}{|c|c|c|c|c|}
\hline \multirow{2}{*}{ № de citações } & \multicolumn{2}{|c|}{ Pacientes } & \multicolumn{2}{|c|}{ Controles } \\
\hline & $\mathrm{n}$ & $\%$ & $\mathrm{n}$ & $\%$ \\
\hline 7 & 2 & 2,6 & 1 & 1,3 \\
\hline 8 & 1 & 1,3 & 0 & 0 \\
\hline 9 & 4 & 5,7 & 4 & 5,7 \\
\hline 10 & 3 & 3,9 & 2 & 2,6 \\
\hline 11 & 1 & 1,3 & 2 & 2,6 \\
\hline 12 & 4 & 5,7 & 3 & 3,9 \\
\hline 13 & 3 & 3,9 & 8 & 10,5 \\
\hline 14 & 1 & 1,3 & 7 & 9,2 \\
\hline 15 & 7 & 9,2 & 6 & 7,9 \\
\hline 16 & 4 & 5,7 & 4 & 5,7 \\
\hline 17 & 7 & 9,2 & 2 & 2,6 \\
\hline 18 & 5 & 6,6 & 5 & 6,6 \\
\hline 19 & 7 & 9,2 & 5 & 6,6 \\
\hline 20 & 9 & 11,9 & 4 & 5,7 \\
\hline 21 & 6 & 7,9 & 7 & 9,2 \\
\hline 22 & 1 & 1,3 & 4 & 5,7 \\
\hline 23 & 6 & 7,9 & 2 & 2,6 \\
\hline 24 & 2 & 2,6 & 0 & 0 \\
\hline 25 & 0 & 0 & 2 & 2,6 \\
\hline 27 & 0 & 0 & 2 & 2,6 \\
\hline 28 & 0 & 0 & 0 & 0 \\
\hline 29 & 1 & 1,3 & 2 & 2,6 \\
\hline 30 & 1 & 1,3 & 1 & 1,3 \\
\hline 32 & 0 & 0 & 1 & 1,3 \\
\hline 33 & 1 & 1,3 & 0 & 0 \\
\hline 35 & 0 & 0 & 1 & 1,3 \\
\hline 39 & 0 & 0 & 1 & 1,3 \\
\hline TOTAL & 76 & 100 & 76 & 100 \\
\hline
\end{tabular}

Mann Whitney, $p=0,959$

№: número

$\%$ : percentual

$\mathrm{n}$ : número de sujeitos 
Tabela 18 - Sujeitos com Fluência Verbal aquém da esperada para o grau de escolaridade

\begin{tabular}{ccccccc}
\hline & \multicolumn{2}{c}{ Pacientes } & & \multicolumn{3}{c}{ Controles } \\
\cline { 2 - 3 } \cline { 5 - 7 } Sujeito & Obtido & Esperado & & Sujeito & Obtido & Esperado \\
\hline 23 & 10 & 12 & & 1 & 9 & 12 \\
37 & 9 & 12 & & 28 & 10 & 12 \\
58 & 10 & 12 & & 38 & 11 & 12 \\
60 & 7 & 12 & & 40 & 9 & 12 \\
61 & 8 & 12 & & 43 & 9 & 12 \\
62 & 10 & 12 & & 50 & 9 & 12 \\
63 & 7 & 12 & & 66 & 7 & 9 \\
65 & 9 & 12 & & 72 & 10 & 12 \\
68 & 9 & 12 & & 73 & 11 & 12 \\
69 & 9 & 12 & & & & \\
\hline
\end{tabular}

Obtido: número de citações obtido

Pearson $\mathbf{X}^{2}, p=0,323$

Esperado: número mínimo de citações esperado para o grau de escolaridade do sujeito

O teste de Wilcoxon mostrou que não há diferenças estatísticas na FV semântica entre as amostras pareadas de pacientes e controles $(p=0,91)$.

A análise de coerência mostrou que $96,1 \%$ dos pacientes caíram no intervalo de FV semântica de até 24 inclusive contra $86,8 \%$ dos controles, o que nos leva a concluir que o resultado é coerente com o que esperávamos, isto é, os pacientes têm desempenho pior nesse teste do que os controles, embora tenham obtido escores normais no teste (isto é, nove ou mais citações para analfabetos e 12 ou mais para os sujeitos escolarizados). Com valores de corte de 25 citações ou mais a diferença entre pacientes e controles tem significância estatística $(p=0,049)$.

Considerando-se somente sujeitos com mais de quatro anos de escolaridade, também não foram observadas diferenças significativas entre os grupos (Mann Whitney, $p=0,705$; Pearson $\mathbf{X}^{2}, p=0,217$ ). 
A Tabela 19 mostra as pontuações obtidas pelos sujeitos do estudo no TDR segundo os critérios de pontuação de Sunderland.

Tabela 19 - Pontuação de pacientes e controles no Teste do Desenho do Relógio (critérios de Sunderland)

\begin{tabular}{lccccc}
\hline & \multicolumn{2}{c}{ Pacientes } & & \multicolumn{2}{c}{ Controles } \\
\cline { 2 - 3 } \cline { 5 - 6 } № de pontos & $\mathrm{n}$ & $\%$ & & $\mathrm{n}$ & $\%$ \\
\hline 10 & 24 & 30,3 & & 22 & 28,9 \\
9 & 27 & 35,5 & & 17 & 22,4 \\
8 & 7 & 9,2 & & 16 & 21,1 \\
7 & 7 & 9,2 & & 8 & 10,5 \\
6 & 6 & 7,9 & & 8 & 10,5 \\
5 & 3 & 3,9 & & 4 & 5,3 \\
4 & 1 & 1,3 & & 1 & 1,3 \\
3 & 1 & 1,3 & & 0 & 0 \\
TOTAL & 76 & 100 & & 76 & 100 \\
\hline & & & & Mann Whitney, $\mathrm{p}=0,281$ \\
№: número & & n: número de sujeitos & & \\
\%: percentual & & & &
\end{tabular}

A comparação do desempenho dos pacientes no TDR usando os critérios de critérios de Sunderland e os de Shulman não mostrou diferença estatística significante (Mann Whitney, $p=0,526$ ), assim como o desempenho dos controles (Mann Witney, $p=0,928$ ).

Na Tabela 20 está representado o desempenho de pacientes e controles no TDR. Se considerarmos desempenho normal 8 pontos ou mais e compararmos com desempenho com algum grau de alteração ( $\leq 7$ pontos) a diferença entre os grupos passa a ser significante (Pearson $\mathbf{X}^{2}, p=0,049$ ). 
Tabela 20 - Desempenho de pacientes e controles no Teste do Desenho do Relógio critérios de Sunderland

\begin{tabular}{lcccc} 
Desempenho & $\mathrm{n}$ & $\%$ & $\mathrm{n}$ & $\%$ \\
\hline Normal & 51 & 67,1 & 39 & 51,3 \\
Leve alteração & 14 & 18,4 & 24 & 31,6 \\
Alterado & 9 & 11,8 & 12 & 15,8 \\
Muito alterado & 2 & 2,6 & 1 & 1,3 \\
TOTAL & 76 & 100 & 76 & 100 \\
\hline & & \multicolumn{3}{c}{ Pearson X2, $\mathrm{p}=0,403$} \\
n: número de sujeitos & Desempenho & normal: 9-10 pontos \\
NR: não realizado & \multicolumn{3}{l}{ leve alteração: 7-8 pontos } \\
\%: percentual & \multicolumn{3}{l}{ alterado: 5-6 pontos } \\
& & muito alterado: $\leq 4$ pontos
\end{tabular}

No pareamento de amostras o teste de Wilcoxon não mostrou diferenças significativas entre pacientes com hepatite $C$ e controles $(p=0,333)$. Não foi verificada diferença entre os escores de TDR sem pareamento entre pacientes e controles e os escores de TDR com pareamento das amostras.

$\mathrm{Na}$ análise de coerência, 34,2 \% dos pacientes caíram no intervalo de escores de TDR de até 8 inclusive contra $50 \%$ dos controles e portanto, o resultado é incoerente com o que esperávamos, isto é, os pacientes têm melhor desempenho no TDR que os controles.

Quando considerados somente os resultados de pacientes e controles com mais de quatro anos de escolaridade não se verificaram diferenças significativas na distribuição dos escores entre os dois grupos (Mann Whitney, $p=0,052)$. Também não se observaram diferenças entre os grupos no teste $\mathbf{X}^{2}$ de Pearson $(p=0,064)$.

A pontuação no teste do desenho do relógio, segundo os critérios de Shulman se encontra na tabela Tabela 21. 
Tabela 21 - Pontuação no teste do Desenho do Relógio - critérios de Shulman

\begin{tabular}{|c|c|c|c|c|c|c|}
\hline \multirow[b]{2}{*}{ № de pontos } & \multicolumn{2}{|c|}{ Pacientes } & \multicolumn{2}{|c|}{ Controles } & \multicolumn{2}{|c|}{ Total } \\
\hline & $\mathrm{n}$ & $\%$ & $\mathrm{n}$ & $\%$ & $\mathrm{n}$ & $\%$ \\
\hline 5 & 31 & 40,8 & 31 & 40,8 & 61 & 41,4 \\
\hline 4 & 21 & 27,6 & 13 & 17,1 & 34 & 21,1 \\
\hline 3 & 12 & 15,8 & 22 & 28,9 & 34 & 22,4 \\
\hline 2 & 6 & 7,9 & 5 & 6,6 & 11 & 7,2 \\
\hline 1 & 4 & 5,3 & 3 & 1,3 & 7 & 5,3 \\
\hline 0 & 2 & 2,6 & 2 & 2,6 & 4 & 2,6 \\
\hline TOTAL & 76 & 100 & 76 & 100 & 152 & 100 \\
\hline
\end{tabular}

Os resultados do teste dos dígitos em ordem direta e em ordem indireta estão nas Tabelas 22 e 23. 
Tabela 22 - Teste dos dígitos em ordem direta e indireta de pacientes e participantes do grupo controle

\begin{tabular}{|c|c|c|c|c|c|}
\hline & \multicolumn{3}{|c|}{ Pacientes } & \multicolumn{2}{|c|}{ Controles } \\
\hline & & $\mathrm{n}$ & $\%$ & $\mathrm{n}$ & $\%$ \\
\hline \multicolumn{6}{|c|}{ № de dígitos OD } \\
\hline & 9 & 2 & 2,6 & 1 & 1,3 \\
\hline & 8 & 5 & 6,6 & 12 & 15,8 \\
\hline & 7 & 17 & 22,4 & 15 & 19,7 \\
\hline & 6 & 18 & 23,7 & 20 & 26,3 \\
\hline & 5 & 24 & 31,6 & 20 & 26,3 \\
\hline & 4 & 7 & 9,2 & 6 & 7,9 \\
\hline & 3 & 1 & 1,3 & 2 & 2,6 \\
\hline NR & & 2 & 2,6 & - & - \\
\hline TOTAL & & 76 & 100 & 76 & 100 \\
\hline \multicolumn{6}{|c|}{ № de dígitos OI } \\
\hline & 8 & 1 & 1,3 & 0 & 0 \\
\hline & 7 & 3 & 3,9 & 3 & 3,9 \\
\hline & 6 & 6 & 7,9 & 10 & 13,2 \\
\hline & 5 & 13 & 17,1 & 8 & 10,5 \\
\hline & 4 & 28 & 36,8 & 26 & 34,2 \\
\hline & 3 & 18 & 23,7 & 21 & 27,6 \\
\hline & 2 & 4 & 5,3 & 8 & 10,5 \\
\hline & 0 & 1 & 1,3 & - & - \\
\hline NR & & 2 & 2,6 & - & - \\
\hline TOTAL & & 76 & 100 & 76 & \\
\hline \multicolumn{6}{|c|}{ Díg OD: Mann-Whitney, $p=0,394$} \\
\hline \multicolumn{6}{|c|}{ Díg Ol: Mann Whitney, p=0,464 } \\
\hline \multicolumn{4}{|c|}{ NR: teste não realizado } & \multicolumn{2}{|c|}{ n: número de sujeitos } \\
\hline \multicolumn{4}{|c|}{ №: número de dígitos corretamente lembrados } & \multicolumn{2}{|c|}{$\%$ : percentual } \\
\hline
\end{tabular}


$\mathrm{Na}$ Tabela 23 se encontram os pacientes e controles que tiveram baixo desempenho nos testes dos dígitos.

Tabela 23 - Sujeitos com baixo desempenho nos testes dos dígitos em ordem direta e indireta

\begin{tabular}{|c|c|c|c|c|c|}
\hline & \multicolumn{2}{|c|}{ Pacientes } & & \multicolumn{2}{|c|}{ Controles } \\
\hline & $\mathrm{n}$ & $\%$ & & $\mathrm{n}$ & $\%$ \\
\hline \multicolumn{6}{|l|}{ № de dígitos OD } \\
\hline$\leq 4$ & 8 & 10,5 & & 8 & 10,5 \\
\hline$\leq 3$ & 1 & 1,3 & & 2 & 2,6 \\
\hline$<3$ & 0 & 0,0 & & 0 & 0 \\
\hline \multicolumn{6}{|l|}{ № de dígitos OI } \\
\hline$\leq 3$ & 23 & 30,3 & & 29 & 38,2 \\
\hline$\leq 2$ & 5 & 6,6 & & 8 & 10,5 \\
\hline$<2$ & 1 & 1,3 & & 0 & 0 \\
\hline Díg OD: Pearson $\mathbf{X}^{2}, \mathrm{p}=0,650$ & & & $\begin{array}{l}\text { Díg Ol: Pearson } \mathbf{X}^{2} \\
p=0,563\end{array}$ & & \\
\hline n: número de sujeitos & & & OD: dígitos em ordem direta & & \\
\hline$\%$ : percentual & & & Ol: dígitos em ordem inversa & & \\
\hline
\end{tabular}

Considerando-se os resultados de pacientes e controles com cinco ou mais anos de escolaridade, também não observamos diferenças entre os grupos, tanto no teste Díg OD (Mann Whitney, $p=0,790$; Pearson $\mathbf{X}^{2}, p=0,796$ ), quanto no teste Díg OI (Mann Whitney, $p=0,533$; Pearson $\mathbf{X}^{2}, p=0,492$ ).

No pareamento de amostras o teste de Wilcoxon não mostrou diferenças entre pacientes e controles $(p=0,737)$ no teste Díg OD ou no teste Díg Ol $(p=0,365)$. 
A proporção de pacientes e controles com sintomas indicativos de depressão mínima ou ausente, leve, moderada ou grave se encontram na Tabela 25.

Tabela 24 - Comparação das médias obtidas pelos participantes do estudo no Inventário de Beck para Depressão, Ansiedade e Desesperança

\begin{tabular}{|c|c|c|c|c|c|c|c|c|c|}
\hline & \multicolumn{4}{|c|}{ Pacientes } & \multicolumn{4}{|c|}{ Controles } & \multirow[b]{2}{*}{$p$} \\
\hline & $\mathrm{n}=76$ & Média (DP) & Mín-máx & Mediana & $\mathrm{n}=76$ & Média (DP) & Mín-máx & Mediana & \\
\hline BDI & & $11,7(9,3)$ & $0-40$ & 9 & & $10,6(9,5)$ & $0-51$ & 7,5 & 0,332 \\
\hline BAI & & $10,3(10,0)$ & $0-63$ & 8 & & $9,8(10,0)$ & $0-50$ & 8 & 0,459 \\
\hline \multirow[t]{2}{*}{ BHS } & & $4,2(3,9)$ & $0-17$ & 3 & & $3,9(3,1)$ & $0-15$ & 3 & 0,803 \\
\hline & & & & & & & & \multicolumn{2}{|c|}{ Mann Whitney } \\
\hline \multicolumn{5}{|c|}{ n: quantidade de indivíduos } & \multicolumn{5}{|c|}{ BDI: inventário de depressão de Beck } \\
\hline \multicolumn{5}{|c|}{ DP: desvio padrão } & \multicolumn{5}{|c|}{$\begin{array}{l}\text { BAl: inventário de ansiedade de Beck } \\
\text { BHS: escala de desesperança de Beck }\end{array}$} \\
\hline \multicolumn{10}{|c|}{ Mín-máx: mínimo-máximo } \\
\hline$p$ : valc & de $p$ & & & & & & & & \\
\hline
\end{tabular}


Tabela 25 - Graus de Depressão, Ansiedade e Desesperança dos pacientes e controles, segundo Beck

\begin{tabular}{|c|c|c|c|c|c|c|c|}
\hline & & \multicolumn{2}{|c|}{ Pacientes } & \multicolumn{2}{|c|}{ Controles } & \multicolumn{2}{|c|}{ Total } \\
\hline & & $\mathrm{n}$ & $\%$ & $\mathrm{n}$ & $\%$ & $\mathrm{n}$ & $\%$ \\
\hline \multirow[t]{5}{*}{ Depressão } & Mínima & 42 & 55,2 & 42 & 55,2 & 84 & 55,3 \\
\hline & Leve & 17 & 22,4 & 24 & 31,6 & 41 & 26,8 \\
\hline & Moderada & 12 & 15,8 & 7 & 9,2 & 19 & 12,5 \\
\hline & Grave & 5 & 6,6 & 3 & 4 & 8 & 5,3 \\
\hline & TOTAL & 76 & 100 & 76 & 100 & 152 & 100 \\
\hline \multirow[t]{5}{*}{ Ansiedade } & Mínima & 46 & 60,5 & 54 & 71,1 & 100 & 65,8 \\
\hline & Leve & 20 & 26,3 & 11 & 14,5 & 31 & 20,3 \\
\hline & Moderada & 8 & 10,5 & 6 & 7,9 & 14 & 9,2 \\
\hline & Grave & 2 & 2,6 & 5 & 6,6 & 7 & 4,6 \\
\hline & TOTAL & 76 & 100 & 76 & 100 & 152 & 100 \\
\hline \multirow[t]{5}{*}{ Desesperança } & Mínima & 52 & 68,4 & 53 & 69,7 & 105 & 69,1 \\
\hline & Leve & 17 & 22,4 & 16 & 21,1 & 33 & 21,7 \\
\hline & Moderada & 4 & 5,3 & 6 & 7,9 & 10 & 2,6 \\
\hline & Grave & 3 & 4 & 1 & 1,3 & 4 & 2,6 \\
\hline & TOTAL & 76 & 1 & 76 & 100 & 152 & 100 \\
\hline & & & & & \multicolumn{3}{|c|}{ Mann Whitney, $p=0,332$} \\
\hline \multicolumn{4}{|c|}{ n: número de participantes } & \multicolumn{4}{|c|}{$\%$ : percentual } \\
\hline \multirow[t]{4}{*}{ Depressão } & Mínima: 0-9 pontos & & & Ansiedade & \multicolumn{3}{|c|}{ Mínima: 0-10 pontos } \\
\hline & Leve: $10-18$ pontos & & & & \multicolumn{3}{|c|}{ Leve: $11-19$ pontos } \\
\hline & Moderada: $19-29$ pontos & & & & \multicolumn{3}{|c|}{ Moderada: $20-30$ pontos } \\
\hline & Grave: $30-63$ pontos & & & & \multicolumn{3}{|c|}{ Grave: $31-63$ pontos } \\
\hline \multirow[t]{4}{*}{ Desesperança } & Mínima: 0-4 pontos & & & & & & \\
\hline & Leve: $5-8$ pontos & & & & & & \\
\hline & Moderada: $9-13$ pontos & & & & & & \\
\hline & Grave: $14-20$ pontos & & & & & & \\
\hline
\end{tabular}

Considerando-se somente pacientes e controles sem depressão ou com depressão de qualquer grau, as diferenças entre os grupos também não foram significativas $(p=0,137)$ embora uma proporção maior de pacientes que controles apresentasse sintomas de depressão grave ou moderada $(22,4 \%$ vs $13,2 \%$; $p=$ 0,137) [Tabela 26]. 
Tabela 26 - Depressão, Ansiedade e desesperança reestratificados

\begin{tabular}{|c|c|c|c|c|c|c|c|}
\hline & & \multicolumn{2}{|c|}{ Pacientes } & \multicolumn{2}{|c|}{ Controles } & \multicolumn{2}{|c|}{ Total } \\
\hline & & $\mathrm{n}$ & $\%$ & $\mathrm{n}$ & $\%$ & $\mathrm{n}$ & $\%$ \\
\hline \multicolumn{8}{|l|}{ Depressão } \\
\hline & Qualquer grau & 34 & 44,7 & 34 & 44,7 & 68 & 44,7 \\
\hline & Moderada/grave & 17 & 22,4 & 10 & 13,2 & 27 & 17,8 \\
\hline & TOTAL & 51 & 67,1 & 44 & 57,9 & 95 & 62,5 \\
\hline \multicolumn{8}{|l|}{ Ansiedade } \\
\hline & Qualquer grau & 30 & 39,5 & 22 & 28,9 & 52 & 34,2 \\
\hline & Moderada/grave & 10 & 13,2 & 21 & 27,6 & 31 & 20,5 \\
\hline & TOTAL & 40 & 52,6 & 43 & 56,6 & 83 & 54,6 \\
\hline \multicolumn{8}{|c|}{ Desesperança } \\
\hline & Qualquer grau & 24 & 31,8 & 23 & 30,3 & 47 & 15,8 \\
\hline & Moderada/grave & 7 & 9,21 & 7 & 9,2 & 14 & 9,2 \\
\hline & TOTAL & 31 & 40,8 & 30 & 39,5 & 61 & 40,1 \\
\hline $\begin{array}{l}\text { n: número de } \\
\text { participantes }\end{array}$ & & & & & $\begin{array}{l}\text { son } X^{2}, \\
390\end{array}$ & & \\
\hline$\%$ : percentual & & & & & & & \\
\hline
\end{tabular}

As correlações positivas encontradas no grupo de 152 sujeitos podem ser vistas na Tabela 27 e as correlações negativas na Tabela 28. 
Tabela 27 - Correlações positivas encontradas no grupo de 152 sujeitos

\begin{tabular}{|c|c|c|c|}
\hline Variável & Variável & $\begin{array}{c}\text { Coeficiente } \\
\text { de } \\
\text { Pearson }\end{array}$ & $\mathrm{p}$ \\
\hline Grupo pacientes & Parestesias/dores & 0,310 & $<0,01$ \\
\hline Grupo pacientes & Dormência & 0,355 & $<0,01$ \\
\hline Grupo pacientes & Met glicose & 0,332 & $<0,01$ \\
\hline Díg OI & Gênero & 0,239 & $<0,01$ \\
\hline MEEM & Escolaridade & 0,548 & $<0,01$ \\
\hline FV sem & Escolaridade & 0,409 & $<0,01$ \\
\hline TDR & Escolaridade & 0,399 & $<0,01$ \\
\hline Díg OD & Escolaridade & 0,300 & $<0,01$ \\
\hline Escolaridade & Díg Ol & 0,466 & $<0,01$ \\
\hline Escolaridade & Met glicose & 0,218 & $<0,01$ \\
\hline MEEM & FV sem & 0,452 & $<0,01$ \\
\hline MEEM & TDR & 0,547 & $<0,01$ \\
\hline MEEM & Díg OD & 0,322 & $<0,01$ \\
\hline MEEM & Díg OI & 0,466 & $<0,01$ \\
\hline FV sem & TDR & 0,291 & $<0,01$ \\
\hline FV sem & Díg OD & 0,370 & $<0,01$ \\
\hline FV sem & Díg OI & 0,460 & $<0,01$ \\
\hline TDR & Díg OD & 0,280 & $<0,01$ \\
\hline TDR & Díg OI & 0,392 & $<0,01$ \\
\hline Díg OD & Díg Ol & 0,616 & $<0,01$ \\
\hline BDI & $\mathrm{BAI}$ & 0,480 & $<0,01$ \\
\hline BDI & BHS & 0,423 & $<0,01$ \\
\hline BDI & HOMA & 0,447 & $<0,01$ \\
\hline $\mathrm{BAI}$ & $\mathrm{BHS}$ & 0,421 & $<0,01$ \\
\hline CGs & HOMA & 0,401 & $<0,01$ \\
\hline Fibrose & Idade & 0,349 & $<0,01$ \\
\hline Fibrose & Inflamação & 0,593 & $<0,01$ \\
\hline Parestesias/dores & Dormência & 0,516 & $<0,01$ \\
\hline Parestesias/dores & Fraqueza & 0,353 & $<0,01$ \\
\hline Parestesias/dores & Cansaço & 0,213 & $<0,01$ \\
\hline Parestesias/dores & Met glicose & 0,248 & $<0,01$ \\
\hline
\end{tabular}


Continuação

Tabela 27 - Correlações positivas encontradas no grupo de 152 sujeitos

\begin{tabular}{llcc}
\hline Variável & Variável & Coeficiente de Pearson & $p$ \\
\hline Dormência & Fraqueza & 0,282 & $<0,01$ \\
Dormência & Cansaço & 0,226 & $<0,01$ \\
Dormência & Met glicose & 0,213 & $<0,01$ \\
Cansaço & Met glicose & 0,290 & $<0,01$ \\
Grupo pacientes & Met glicose & 0,332 & $<0,01$ \\
Gênero & TDR & 0,171 & $<0,05$ \\
Gênero & Díg OD & 0,174 & $<0,05$ \\
BDI & Idade & 0,208 & $<0,05$ \\
Escolaridade & Dormência & 0,166 & $<0,05$ \\
Escolaridade & cansaço & 0,175 & $<0,05$ \\
MEEM & Fraqueza & 0,162 & $<0,05$ \\
FV sem & Fraqueza & 0,180 & $<0,05$ \\
FV sem & Met glicose & 0,179 & $<0,05$ \\
Fibrose & Díg OD & 0,326 & $<0,05$ \\
BDI & NP & 0,338 & $<0,05$ \\
BHS & HOMA & 0,303 & $<0,05$ \\
\hline
\end{tabular}

CGs: crioglobulinas

FV sem: fluência verbal semântica

TDR: teste do desenho do relógio

Díg OD: teste dos dígitos em ordem direta

Díg Ol: teste dos dígitos em ordem indireta

NP: neuropatia periférica

Inflamação: grau de inflamação hepática (sistema

METAVIR)
MEEM: miniexame do estado mental

BDI: Inventário de Depressão de Beck

BAI: Inventário de Ansiedade de Beck

BHS: Escala de Desesperança de Beck

Fibrose: grau de fibrose hepática (sistema METAVIR)

HOMA: homeosthasis method assessment

Met glicose: metabolismo da glicose 
Tabela 28 - Correlações negativas encontradas no grupo de 152 sujeitos

\begin{tabular}{|c|c|c|c|}
\hline Variável & Variável & Coef. de Pearson & $\mathbf{p}$ \\
\hline Gênero & BAI & $-0,255$ & $<0,01$ \\
\hline Idade & Escolaridade & $-0,397$ & $<0,01$ \\
\hline Escolaridade & $\mathrm{BDI}$ & $-0,215$ & $<0,01$ \\
\hline MEEM & Idade & $-0,241$ & $<0,01$ \\
\hline Idade & FV sem & $-0,253$ & $<0,01$ \\
\hline Idade & TDR & $-0,217$ & $<0,01$ \\
\hline MEEM & BDI & $-0,243$ & $<0,01$ \\
\hline MEEM & BHS & $-0,280$ & $<0,01$ \\
\hline FV sem & BDI & $-0,249$ & $<0,01$ \\
\hline FV sem & $\mathrm{BAl}$ & $-0,216$ & $<0,01$ \\
\hline BDI & Díg OD & $-0,234$ & $<0,01$ \\
\hline BDI & Díg OI & $-0,239$ & $<0,01$ \\
\hline Fibrose & Fraqueza & $-0,354$ & $<0,01$ \\
\hline HOMA & Cansaço & $-0,463$ & $<0,01$ \\
\hline Gênero & $\mathrm{BDI}$ & $-0,196$ & $<0,05$ \\
\hline Gênero & Fraqueza & $-0,167$ & $<0,05$ \\
\hline Idade & Parestesias/dores & $-0,161$ & $<0,05$ \\
\hline Idade & Fraqueza & $-0,199$ & $<0,05$ \\
\hline Idade & Cansaço & $-0,186$ & $<0,05$ \\
\hline Escolaridade & BHS & $-0,182$ & $<0,05$ \\
\hline MEEM & HOMA & $-0,276$ & $<0,05$ \\
\hline FV sem & $\mathrm{BHS}$ & $-0,171$ & $<0,05$ \\
\hline FV sem & HOMA & $-0,248$ & $<0,05$ \\
\hline TDR & $\mathrm{BDI}$ & $-0,207$ & $<0,05$ \\
\hline Díg OD & BAI & $-0,169$ & $<0,05$ \\
\hline BAI & Parestesias/dores & $-0,174$ & $<0,05$ \\
\hline CGs & Cansaço & $-0,264$ & $<0,05$ \\
\hline Fibrose & Parestesias/dores & $-0,249$ & $<0,05$ \\
\hline Fibrose & Dormência & $-0,258$ & $<0,05$ \\
\hline NP & Fraqueza & $-0,308$ & $<0,05$ \\
\hline $\mathrm{NP}$ & Met glicose & $-0,355$ & $<0,05$ \\
\hline \multicolumn{2}{|c|}{ Coef.: coeficiente } & CGs: crioglobulinas & \\
\hline \multicolumn{2}{|c|}{ MEEM: miniexame do estado mental } & BDI: Inventário de Depressão & \\
\hline \multicolumn{2}{|c|}{ FV sem: fluência verbal semântica } & BAI: Inventário de Ansiedade & \\
\hline \multicolumn{2}{|c|}{ TDR: teste do desenho do relógio } & BHS: Escala de Desesperança & \\
\hline \multicolumn{2}{|c|}{ Díg OD: teste dos dígitos em ordem direta } & Fibrose: grau de fibrose hepáti & \\
\hline \multicolumn{2}{|c|}{ Díg Ol: teste dos dígitos em ordem indireta } & HOMA: homeosthasis method & \\
\hline \multicolumn{2}{|c|}{ NP: neuropatia periférica } & Met glicose: metabolismo da g & \\
\hline
\end{tabular}


As correlações positivas encontradas no grupo de pacientes estão listadas na Tabela 29 e as negativas na Tabela 30.

Tabela 29 - Correlações positivas entre as variáveis estudadas encontradas no grupo dos pacientes

\begin{tabular}{llcc}
\hline Variável & \multicolumn{1}{c}{ Variável } & Coef. De Pearson & p \\
\hline Escolaridade & MEEM & 0,533 & $<0,01$ \\
Escolaridade & FV sem & 0,391 & $<0,01$ \\
Escolaridade & TDR & 0,471 & $<0,01$ \\
Escolaridade & Díg OI & 0,413 & $<0,01$ \\
MEEM & FV sem & 0,434 & $<0,01$ \\
MEEM & TDR & 0,584 & $<0,01$ \\
MEEM & Díg OI & 0,424 & $<0,01$ \\
TDR & Díg OI & 0,394 & $<0,01$ \\
Díg OD & FV sem & 0,331 & $<0,01$ \\
Díg OD & Díg OI & 0,639 & $<0,01$ \\
Díg OI & FV sem & 0,471 & $<0,01$ \\
Díg OI & Díg OD & 0,639 & $<0,01$ \\
BDI & BAI & 0,504 & $<0,01$ \\
BDI & BHS & 0,493 & $<0,01$ \\
BDI & Met glic & 0,342 & $<0,01$ \\
BDI & HOMA & 0,447 & $<0,01$ \\
BAl & BHS & 0,320 & $<0,01$ \\
CGS & HOMA & 0,401 & $<0,01$ \\
Fibrose & Inflamação & 0,593 & $<0,01$ \\
Fibrose & Fraqueza & 0,354 & $<0,01$ \\
& & & Continua
\end{tabular}


Tabela 29 - Correlações positivas entre as variáveis estudadas encontradas no grupo dos pacientes

\begin{tabular}{llcc}
\hline Variável & \multicolumn{1}{c}{ Variável } & Coef. De Pearson & $\mathbf{p}$ \\
\hline Fibrose & Idade & 0,349 & $<0,01$ \\
NP & Dormência & 0,357 & $<0,01$ \\
NP & Fraqueza & 0,402 & $<0,01$ \\
NP & Cansaço & 0,301 & $<0,01$ \\
HOMA & Met glic & 0,419 & $<0,01$ \\
Etilismo prévio & Uso de droga prévio & 0,380 & $<0,01$ \\
Idade & Met glic & 0,264 & $<0,05$ \\
Escolaridade & Díg OD & 0,292 & $<0,05$ \\
MEEM & Díg OD & 0,233 & $<0,05$ \\
TDR & FV sem & 0,256 & $<0,05$ \\
Díg OD & Fibrose & 0,326 & $<0,05$ \\
BDI & Idade & 0,247 & $<0,05$ \\
NP & Parest/dores & 0,260 & $<0,05$ \\
HOMA & BHS & 0,303 & $<0,05$ \\
Parest/dores & Fraqueza & 0,282 & $<0,05$ \\
dormência & Cansaço & 0,239 & $<0,05$ \\
HOMA & BHS & 0,303 & $<0,05$ \\
Etilismo prévio & Gênero & & $<0,01$ \\
Uso de drogas & Gênero & BHS: Escala de Desesperança de Beck & \\
\hline Coef. : coeficiente & & Fibrose: grau de fibrose hepática (METAVIR) & \\
MEEM: miniexame do estado mental & MOMA: homeosthasis method assessment & \\
FV sem: fluência verbal semântica & & $<0,01$ \\
\hline TDR: teste do desenho do relógio & CGs: crioglobulinas & \\
Díg OD: teste dos dígitos em ordem direta & BDI: Inventário de Depressão de Beck & \\
Díg OI: teste dos dígitos em ordem indireta & metabolismo da glicose & \\
NP: neuropatia periférica & & Conclusão \\
Inflamação: grau de inflamação hepática (sistema METAVIR) & &
\end{tabular}


Tabela 30 - Correlações negativas entre as variáveis estudadas encontradas no grupo dos pacientes

\begin{tabular}{|c|c|c|c|}
\hline \multirow[b]{2}{*}{ Variável } & \multicolumn{3}{|c|}{ Coef } \\
\hline & Variável & Pearson & $p$ \\
\hline Met glic & FV sem & $-0,314$ & $<0,01$ \\
\hline Met glic & Cansaço & $-0,484$ & $<0,01$ \\
\hline Met glic & HOMA & $-0,463$ & $<0,01$ \\
\hline Etilismo prévio & $\mathrm{BAl}$ & 0,313 & $<0,01$ \\
\hline Idade & MEEM & $-0,26$ & $<0,05$ \\
\hline Idade & NP & $-0,282$ & $<0,05$ \\
\hline Idade & Fraqueza & $-0,236$ & $<0,05$ \\
\hline Escolaridade & Met glicose & $-0,261$ & $<0,05$ \\
\hline MEEM & $\mathrm{BDI}$ & $-0,282$ & $<0,05$ \\
\hline MEEM & BHS & $-0,23$ & $<0,05$ \\
\hline MEEM & Met glicose & $-0,276$ & $<0,05$ \\
\hline FV sem & BDI & $-0,248$ & $<0,05$ \\
\hline FV sem & HOMA & $-0,248$ & $<0,05$ \\
\hline TDR & Idade & $-0,256$ & $<0,05$ \\
\hline TDR & BDI & $-0,241$ & $<0,05$ \\
\hline TDR & Met glicose & $-0,269$ & $<0,05$ \\
\hline Díg OD & Cansaço & $-0,25$ & $<0,05$ \\
\hline Díg OI & BDI & $-0,235$ & $<0,05$ \\
\hline BDI & FV sem & $-0,248$ & $<0,05$ \\
\hline BDI & Díg OI & $-0,235$ & $<0,05$ \\
\hline BAI & Parest/dores & $-0,304$ & $<0,05$ \\
\hline BAI & NP & $-0,25$ & $<0,05$ \\
\hline BAI & Dormência & $-0,238$ & $<0,05$ \\
\hline CGS & Cansaço & $-0,264$ & $<0,05$ \\
\hline Fibrose & NP & $-0,263$ & $<0,05$ \\
\hline Fibrose & Parest/dores & $-0,249$ & $<0,05$ \\
\hline Fibrose & Dormência & $-0,258$ & $<0,05$ \\
\hline NP & Parest/dores & $-0,26$ & $<0,05$ \\
\hline NP & Met glicose & $-0,265$ & $<0,05$ \\
\hline Met glicose & TDR & $-0,269$ & $<0,05$ \\
\hline HOMA & MEEM & $-0,276$ & $<0,05$ \\
\hline Fraqueza & gênero & $-0,254$ & $<0,05$ \\
\hline Fraqueza & Idade & $-0,236$ & $<0,05$ \\
\hline \multicolumn{2}{|l|}{ Coef.: coeficiente } & \\
\hline \multicolumn{2}{|c|}{ MEEM: miniexame do estado mental } & \multicolumn{2}{|c|}{$\begin{array}{l}\text { Beck } \\
\text { BAl: Inventário de Ansiedade de }\end{array}$} \\
\hline \multicolumn{2}{|c|}{ FV sem: fluência verbal semântica } & \multicolumn{2}{|c|}{ Beck } \\
\hline \multicolumn{2}{|c|}{ TDR: teste do desenho do relógio } & \multirow{2}{*}{\multicolumn{2}{|c|}{$\begin{array}{l}\text { BHS: Escala de Desesperança de Beck } \\
\text { Fibrose: grau de fibrose hepática (METAVIR) }\end{array}$}} \\
\hline \multicolumn{2}{|c|}{ Díg OD: teste dos dígitos em ordem direta } & & \\
\hline \multicolumn{2}{|c|}{$\begin{array}{l}\text { Díg Ol: teste dos dígitos em ordem indireta } \\
\text { NP: neuropatia } \\
\text { periférica }\end{array}$} & \multicolumn{2}{|c|}{$\begin{array}{l}\text { HOMA: homeosthasis method assessment } \\
\text { Met glicose: metabolismo da } \\
\text { glicose }\end{array}$} \\
\hline Inflamação: grau de & & & Conclus \\
\hline
\end{tabular}


As correlações dos resultados de pesquisa e dosagens de autoanticorpos, carga viral, FR, gamaglobulinas séricas, frações do complemento e crioglobulinas se referem somente ao grupo de pacientes e são mostradas na Tabela 31.

Tabela 31 - Correlações de Spearman - variáveis laboratoriais dos pacientes

\begin{tabular}{|c|c|c|c|}
\hline Variável & Variável & Coef. & $p$ \\
\hline Ac anti-SSB/LA & CGs & 0,350 & $<0,01$ \\
\hline Ac anticardiolipinas IgG & $\mathrm{FR}$ & 0,391 & $<0,01$ \\
\hline ANCA & FAN-Hep2 & 0,473 & $<0,01$ \\
\hline ANCA & CG & 0,854 & $<0,01$ \\
\hline Ac anti-LKM1 & FAN-Hep2 & 0,359 & $<0,01$ \\
\hline Fração C3 & Fraç C4 & 0,413 & $<0,01$ \\
\hline Fração C3 & $\mathrm{FR}$ & 0,422 & $<0,01$ \\
\hline Fração C4 & $\mathrm{FR}$ & 0,440 & $<0,01$ \\
\hline FAN-Hep2 & CGs & 0,350 & $<0,01$ \\
\hline Fibrose & Inflamação & 0,748 & $<0,01$ \\
\hline Gênero & \multirow{2}{*}{$\begin{array}{l}\text { Fraç C4 } \\
\text { Anti-SS-A/RO }\end{array}$} & 0,381 & $<0,01$ \\
\hline Escolaridade & & $-0,375$ & $<0,01$ \\
\hline MEEM & \multirow{2}{*}{$\begin{array}{l}\text { Memória de evocação } \\
\text { Anti-rec-TSH(TRAb) }\end{array}$} & $-0,705$ & $<0,01$ \\
\hline $\mathrm{BDI}$ & & $-0,385$ & $<0,01$ \\
\hline BAI & Anti-rec-TSH(TRAb) & $-0,374$ & $<0,01$ \\
\hline NP & Ac antitirosina fosfatase & 0,367 & $<0,05$ \\
\hline Gamaglobulinas & Fração C4 & 0,274 & $<0,05$ \\
\hline Gamaglobulinas & $\mathrm{FR}$ & 0,268 & $<0,05$ \\
\hline Gamaglobulinas & NP & 0,275 & $<0,05$ \\
\hline Ac anticardiolipinas $\lg M$ & Fração C3 & 0,282 & $<0,05$ \\
\hline Ac anticardiolipinas $\lg G$ & Ac anti-TPO & 0,447 & $<0,05$ \\
\hline $\mathrm{NP}$ & Ac anti-SSA/RO & 0,271 & $<0,05$ \\
\hline NP & Ac antitirosina fosfatase & 0,367 & $<0,05$ \\
\hline Ac antitireoglobulina & Ac anti-TPO & 0,403 & $<0,05$ \\
\hline Ac antitireoglobulina & ANCA & 0,355 & $<0,05$ \\
\hline Ac antitireoglobulina & FAN-Hep2 & 0,412 & $<0,05$ \\
\hline Ac antitireoglobulina & CGs & 0,352 & $<0,05$ \\
\hline Ac anti-TPO & FAN-Hep2 & 0,357 & $<0,05$ \\
\hline CGs & $\mathrm{FR}$ & 0,309 & $<0,05$ \\
\hline Carga viral & Fibrose & $-0,291$ & $<0,05$ \\
\hline Carga viral & \multirow{2}{*}{$\begin{array}{l}\text { Ac anticélula parietal } \\
\text { Fraç C4 }\end{array}$} & $-0,259$ & $<0,05$ \\
\hline Fibrose & & 0,402 & $<0,05$ \\
\hline Fibrose & Ac anticardiolipina IgG & 0,268 & $<0,05$ \\
\hline
\end{tabular}


Tabela 31 - Correlações de Spearman - variáveis laboratoriais dos pacientes

\begin{tabular}{llcc}
\hline Variável & Variável & Coef. & $\mathrm{p}$ \\
\hline Inflamação & Fraç C4 & 0,312 & $<0,05$ \\
Inflamação & Ac anticardiolipina IgG & 0,305 & $<0,05$ \\
Inflamação & Ac anti-SS-B/LA & 0,256 & $<0,05$ \\
Inflamação & CGs & 0,251 & $<0,05$ \\
CGs & Gênero & 0,243 & $<0,05$ \\
CGs & ANCA & 0,353 & $<0,05$ \\
CGs & Ac anti-LKm1 & 0,256 & $<0,05$ \\
NP & Idade & 0,263 & $<0,05$ \\
NP & BAI & 0,286 & $<0,05$ \\
Gênero & Fraç C3 & 0,297 & $<0,05$ \\
Idade & Ac anti-SS-B/LA & 0,293 & $<0,05$ \\
Memória de evocação & Díg OI & $-0,266$ & $<0,05$ \\
Memória de evocação & BHS & 0,269 & $<0,05$ \\
Díg OD & Ac anti-SS-A/RO & $-0,243$ & $<0,05$ \\
Díg OI & Ac anti-SS-A/RO & 0,271 & $<0,05$ \\
FV sem & Ac antitireoglobulina & $-0,347$ & $<0,05$ \\
BDI & Fraç C3 & $-0,385$ & $<0,05$ \\
BDI & Fraç C4 & $-0,294$ & $<0,05$ \\
BDI & FR & $-0,305$ & $<0,05$ \\
BAI & Fraç C3 & $-0,374$ & $<0,05$ \\
BAI & Fraç C4 & $-0,297$ & $<0,05$ \\
\hline Coet Co, & &
\end{tabular}

Coef. Coeficiente rho de Spearman

Ac: anticorpo

CGs: crioglobulinas

FR: fator reumatóide

ANCA: anticorpos anticitoplasmáticos de neutrófilos

NP: neuropatia periférica

Fraç C3: fração C3 do complemento

anti-TPO: antitireoperoxidase

Fraç C4: fração C4 do complemento

MEEM: miniexame do estado mental

FAN-HEp2: anticorpos antinucleares contra células HEp2

FV sem: fluência verbal semântica

Díg OD: teste dos dígitos em ordem direta

BHS: Escala de Desesperança de Beck

Díg Ol: teste dos dígitos em ordem indireta

BDI: Inventário de Depressão de Beck

Fibrose: grau de fibrose hepática (METAVIR)

BAI: Inventário de Ansiedade de Beck

Inflamação: grau de inflamação hepática (METAVIR)

Conclusão

As correlações positivas verificadas no grupo controle se encontram na

Tabela 32 e as correlações negativas, na Tabela 33. 
Tabela 32 - Correlações positivas entres as variáveis encontradas no grupo controle

\begin{tabular}{|c|c|c|c|}
\hline Variável & Variável & Coef. de Pearson & p \\
\hline Escolaridade & MEEM & 0,567 & $<0,01$ \\
\hline Escolaridade & FV sem & 0,430 & $<0,01$ \\
\hline Escolaridade & TDR & 0,324 & $<0,01$ \\
\hline Escolaridade & Díg OD & 0,305 & $<0,01$ \\
\hline Escolaridade & Díg OI & 0,525 & $<0,01$ \\
\hline MEEM & FV sem & 0,478 & $<0,01$ \\
\hline MEEM & TDR & 0,516 & $<0,01$ \\
\hline MEEM & Díg OI & 0,440 & $<0,01$ \\
\hline MEEM & Díg OD & 0,414 & $<0,01$ \\
\hline MEEM & Cansaço & 0,300 & $<0,01$ \\
\hline FV sem & Escolaridade & 0,430 & $<0,01$ \\
\hline FV sem & Díg OD & 0,397 & $<0,01$ \\
\hline FV sem & Díg OI & 0,460 & $<0,01$ \\
\hline FV sem & TDR & 0,333 & $<0,01$ \\
\hline Díg OD & TDR & 0,421 & $<0,01$ \\
\hline Díg OD & Díg OI & 0,604 & $<0,01$ \\
\hline Díg OI & Gênero & 0,286 & $<0,01$ \\
\hline Díg OI & Escolaridade & 0,525 & $<0,01$ \\
\hline Díg OI & TDR & 0,388 & $<0,01$ \\
\hline BDI & BAI & 0,455 & $<0,01$ \\
\hline BDI & BHS & 0,339 & $<0,01$ \\
\hline BHS & BAI & 0,553 & $<0,01$ \\
\hline MEEM & Dormência & 0,262 & $<0,05$ \\
\hline MEEM & Fraqueza & 0,266 & $<0,05$ \\
\hline NP & Parestesias/dores & 0,733 & $<0,01$ \\
\hline NP & Dormência & 0,476 & $<0,01$ \\
\hline NP & Fraqueza & 0,423 & $<0,01$ \\
\hline NP & Cansaço & 0,358 & $<0,01$ \\
\hline NP & DM & 0,339 & $<0,01$ \\
\hline DM & Parestesias/dores & 0,733 & $\begin{array}{l}<0,01 \\
\text { Continua }\end{array}$ \\
\hline
\end{tabular}


Tabela 32 - Correlações positivas entres as variáveis encontradas no grupo controle

\begin{tabular}{llcc}
\hline Variável & Variável & Coef. de Pearson & $\mathrm{p}$ \\
\hline DM & Dormência & 0,476 & $<0,01$ \\
DM & Fraqueza & 0,423 & $<0,01$ \\
DM & Cansaço & 0,358 & $<0,01$ \\
Gênero & Díg OI & 0,286 & $<0,05$ \\
Idade & BHS & 0,228 & $<0,05$ \\
Escolaridade & Fraqueza & 0,255 & $<0,05$ \\
FV sem & NP & 0,229 & $<0,05$ \\
FV sem & Fraqueza & 0,259 & $<0,05$ \\
\hline
\end{tabular}

Coef.: coeficiente

NP: neuropatia periférica

MEEM: miniexame do estado mental

FV sem: fluência verbal semântica

BDI: Inventário de Depressão de Beck

TDR: teste do desenho do relógio

BAI: Inventário de Ansiedade de Beck

DM: diabetes melito

BHS: Escala de Desesperança de Beck

Díg OI: teste dos dígitos em ordem direta

Díg OD: Dígitos em ordem direta

Conclusão

Tabela 33 - Correlações negativas entre as variáveis encontradas no grupo controle

\begin{tabular}{llcc}
\hline Variável & Variável & Coef. de Pearson & $\mathrm{p}$ \\
\hline Idade & Escolaridade & $-0,348$ & $<0,01$ \\
MEEM & BHS & $-0,348$ & $<0,01$ \\
MEEM & DM & $-0,300$ & $<0,01$ \\
FV sem & BAI & $-0,315$ & $<0,01$ \\
FV sem & BHS & $-0,352$ & $<0,01$ \\
BHS & MEEM & $-0,348$ & $<0,01$ \\
DM & MEEM & $-0,300$ & $<0,01$ \\
DM & NP & $-0,339$ & $<0,01$ \\
Díg OD & BDI & $-0,276$ & $<0,05$ \\
FV sem & BDI & $-0,247$ & $<0,05$ \\
Díg OI & BDI & $-0,251$ & $<0,05$ \\
Díg OI & BHS & $-0,278$ & $<0,05$ \\
FV sem & BDI & $-0,247$ & $<0,05$ \\
\hline
\end{tabular}

Coef.: coeficiente

DM: diabetes melito

MEEM: miniexame do estado mental

BAI: Inventário de Ansiedade de Beck

BDI: Inventário de Depressão de Beck

BHS: Escala de Desesperança de Beck

Díg OD: teste dos dígitos em ordem direta

Díg OI: teste dos dígitos em ordem indireta 


\section{Discussão}

Neste estudo caso-controle, buscou-se verificar se sinais de comprometimento do sistema nervoso periférico e do sistema nervoso central são mais frequentes em portadores de infecção crônica pelo HCV. Para analisar nossos resultados e compará-los com dados da literatura, dividiremos esta discussão nos dois tópicos principais: comprometimento do sistema nervoso periférico e do sistema nervoso central.

\subsection{Comprometimento do sistema nervoso periférico}

Neste estudo, as neuropatias periféricas em geral foram muito mais frequentes nos pacientes com HCV do que nos controles $(39,5 \%$ vs $18,3 \%$, $\mathrm{p}=0,007)$. Em uma revisão da literatura, Cacoub et al., 2005, observaram que a prevalência de NP entre doentes com infecção crônica por HCV varia de acordo com a população estudada e a definição de NP.

As taxas de prevalência encontradas em diversos estudos variam enormemente e isto se deve a muitos fatores, como a idade dos doentes, presença ou não de CGs, já ter ou não o paciente realizado tratamentos prévios com antivirais, exclusão ou não de pacientes com DM e história de alcoolismo e coinfecção por HIV, como enfatizado por Mônaco et al., 2012, e Yoon et al., 2011. Alguns estudos foram baseados em dados de prontuários e outros foram estudos 
prospectivos, em pacientes com infecção recente, e outros ainda, em pacientes com infecção de longa data. Na maioria dos estudos realizados foram excluídos doentes com insuficiência renal, diabetes, coinfecção por HIV e hepatite B e doentes já tratados com antivirais. Neste estudo exluímos pacientes que já haviam recebido tratamento para $\mathrm{HCV}$, pacientes com hepatite $\mathrm{B}$ e com HIV, porém não excluímos pacientes com DM, ou uso de álcool e drogas.

A ampla variabilidade também poderia ser atribuída à diferença de métodos e ferramentas utilizadas para o diagnóstico da NP. O percentual de NP em pacientes com hepatite C crônica varia significativamente em diferentes estudos, mesmo quando os mesmos instrumentos diagnósticos foram utilizados, como verificamos nos resultados dos estudos que se seguem.

NP foi diagnosticada clinicamente por Cacoub et al. em seu estudo multicêntrico publicado em 2000 em 9\% dos pacientes com hepatite C utilizando dados registrados nos prontuários dos pacientes. Setenta e quatro pacientes nesta casuística tinham coinfecção por HIV e não há referência de quais pacientes com NP eram ou não coinfectados. Além disso, 72 pacientes estavam sendo tratados com Interferon, que também pode ser um fator que pode gerar confusão com relação à causa da NP.

Santoro et al., 2006, reportaram diagnóstico clínico de NP em 10,6\% dos pacientes. Foram excluídos pacientes com DM, insuficiência renal, deficiências vitamínicas, doenças da tireoide, pacientes que faziam uso de álcool ou de substâncias tóxicas e portadores de neoplasias. 
Mapoure et al., 2018, encontraram NP em 49,6\% dos pacientes com hepatite C crônica, não tendo excluído pacientes com DM, HIV ou que faziam uso de álcool.

Khalek et al., 2012, relataram proporção de $45 \%$ dos pacientes com hepatite $\mathrm{C}$ em sua casuística com NP, mas foram excluídos pacientes com HIV, DM, doenças autoimunes, pacientes que consumiam álcool e portadores de transtornos hematológicos malignos.

Num estudo caso-controle de Téllez-Zenteno et al., 2003, evidências eletrofisiológicas de NP foram encontradas em $58 \%$ do grupo com hepatite C e em $10 \%$ dos controles. A discrepância com os nossos resultados deve-se provavelmente ao fato de, no nosso caso, o diagnóstico ter sido clínico e aos critérios de exclusão de pacientes e controles nos estudos. De modo geral, o exame neurológico tem uma acurácia diagnóstica menor na detecção de NP do que os testes eletrofisiológicos, como fica claro pelos resultados dos diversos estudos.

Al-Soud et al., 2011, diagnosticaram NP em 35\% dos pacientes com infecção pelo HCV por exame eletrofisiológico. Nesta casuística foram excluídos pacientes com DM, insuficiência renal, deficiência de vitamina B12, linfomas, hanseníase, uso de álcool, pacientes com edema de membros inferiores, pacientes em uso de Interferon e drogas como amiodarona, isonizida e dapsona.

NP foi diagnosticada através de exame eletrofisiológico por TéllezZenteno et al., 2013, em 58\% dos pacientes com hepatite C; por Santoro et al., 2006, em 15,3\%; por Gomes et al., 2006, em 19,2\%; por Al-Soud et al., 2011, 
em 35\%; por Khalek et al., 2012, em 67,5\% e por Abdelkader et al., 2014, em 36\%. Yoon et al., 2011, estudaram pacientes HCV sem CGs detectáveis no soro e diagnosticaram clinicamente NP em 28\%. Com a utilização de exame eletrofisiológico, além de exame dos potenciais evocados relacionados à dor, estes autores diagnosticaram NP em 43,5\%. Neste estudo foram também incluídos pacientes tratados com Interferon.

Também usando exame eletrofisiológico, Zaltron et al., 1998, encontraram NP em 37\% dos pacientes com CGs detectáveis no soro. Biasiotta et al., 2014, também estudaram somente pacientes com CM e encontraram NP em $68 \%$.

Em nosso estudo decidimos reportar todas as NP encontradas, incluindo a neuropatia compressiva do mediano e as radiculopatias, dado ser este um estudo caso-controle, e de forma a evitar viés de seleção. Outros estudos de NP em pacientes com infecção por HCV geralmente excluem pacientes com neuropatias do nervo mediano e radiculopatias por serem estas neuropatias comuns na população (Santoro et al., 2006). Entretanto não podemos pressupor que a infecção por HCV não possa ter um papel no seu aparecimento ou manifestação.

Estudos epidemiológicos de síndrome do túnel do carpo (STC) mostram ser esta realmente uma afecção comum, com prevalência ajustada por idade em torno de 5\% na população geral (de Krom et al., 1992; Atroshi et al., 1999; Middleton e Anakwe, 2014). 
Em seu estudo eletrofisiológico de pacientes com hepatite C, Gomes et al., 2006, encontraram 5\% dos pacientes HCV com STC. Em nosso estudo encontramos evidências clínicas de neuropatia do mediano sugestivas de STC em nove pacientes $(11,8 \%)$ associada ou não a outras NP. Oito controles $(10,5 \%)$ em nosso estudo tinham sinais de STC ao exame neurológico, portanto a prevalência foi semelhante nos dois grupos. Entretanto o percentual de pacientes e controles portadores de STC em nosso estudo, $11,8 \%$ e 10,5\%, foi maior que as taxas previamente relatadas (de Krom et al., 1992; Atroshi et al., 1999; Middleton e Anakwe, 2014).

Köşkderelioğlu et al., 2016, encontraram evidências de STC em 23,3\% dos pacientes estudados. Além do diagnóstico ter sido através de exame eletrofisiológico, é possível que este percentual maior seja devido ao fato de pacientes do estudo terem média de idade de 57,5 anos, dado ser a idade mais avançada fator de risco para NP (Martyn e Hughes, 1997; Baldereschi et al., 2007).

Estudando pacientes com HIV com NP, Mastroianni et al., 2017, encontraram $6,6 \%$ com STC. Todos os pacientes que apresentavam STC tinham coinfecção por HCV. O autor sugere que a presença de HCV pode ser um fator de risco para o desenvolvimento de STC.

Vários autores observaram que a idade mais avançada é um importante fator de risco para manifestações extra-hepáticas clínicas e biológicas da hepatite C crônica e especialmente para o desenvolvimento de NP (Zaltron et al., 1998; Téllez-Zenteno et al., 2003; Santoro et al., 2006; Yoon et al., 2011; 
Khalek et al., 2012; Biasiotta et al., 2014; Mapoure et al., 2018), o que também pudemos verificar em nosso estudo.

A maior prevalência de NP em pacientes HCV com idades mais avançadas pode refletir maior susceptibilidade ao dano nervoso em idosos (Martyn e Hughes, 1997), além de vários outros fatores associados à presença do vírus e ao desenvolvimento de $\mathrm{MEH}$, como por exemplo intolerância à glicose.

Com relação a distribuição por gêneros não ter sido diferente entre os pacientes com e sem NP, este achado está de acordo com os relatos de Santoro et al., 2006, de Al-Soud et al., 2011, e de Mapoure et al., 2018.

Parestesias foram relatadas por $53,9 \%$ dos pacientes em nossa casuística. Esta proporção é maior do que a encontrada por Cacoub et al., 1999, de 17\%, em estudo retrospectivo; por Mapoure et al., 2018, de 38,8\%; por Yoon et al, 2011, de 39\% e por Gomes et al., 2006, de 34,6\%. Nem todos os pacientes com NP em nosso estudo relataram parestesias ou dores. Vinte pacientes $(26,3 \%)$ relataram queixas de dores ou parestesias nos membros sem sinais objetivos de NP, o que só foi relatado por seis indivíduos do grupo controle $(7,9 \%)$, tendo esta diferença sido muito significativa $(p<0,0001)$.

Biasiotta et al., 2014, verificaram que quatro pacientes $(6,5 \%)$ de sua amostra apresentaram distúrbios sensitivos distribuídos distalmente, mas com achados normais no estudo de condução nervosa, denotando uma neuropatia de fibras finas.

Yoon et al., 2011, estudaram os pacientes registrando a velocidade de condução nervosa e potenciais evocados relacionados à dor. O estudo padrão 
da velocidade de condução nervosa foi anormal em $28 \%$ dos pacientes, enquanto o estudo dos potenciais evocados relacionados à dor revelou prevalência bem mais alta, de $43.5 \%$. Uma proporção elevada dos pacientes $(15,5 \%)$ tinha neuropatia de fibras finas.

A queixa típica e mais comum em pacientes que sofrem de neuropatia de fibras finas é queimação nos pés (Gorson et al., 2008). Parestesias, dores lancinantes e sintomas negativos, como dormência, estão presentes em aproximadamente $50 \%$ dos pacientes.

É bastante provável que pelo menos uma parte dos nossos pacientes com queixas de parestesias e dores nas extremidades sem sinais objetivos de NP no exame neurológico tenha neuropatia de fibras finas. Porém, como não foram realizados estudos eletrofisiológicos e outros exames para detecção de neuropatia de fibras finas nos nossos casos, não foi possível afirmar quantos desses pacientes eram portadores dessa afecção.

Nemni et al., 2003, observaram em seu estudo que os pacientes com hepatite $\mathrm{C}$ nos quais não foram detectadas CGs no soro, mais frequentemente apresentavam MNM, enquanto os pacientes com $\mathrm{CM}$ mais frequentemente apresentavam quadros de PNP, como também foi observado por Biasiotta e colaboradores. Em nosso estudo, a maior parte dos pacientes não apresentava CM e 12 apresentavam MN ou MNM, o que coincide com o relato de Nemni et al., 2003.

Neste estudo encontramos PNP simétrica não associada com MN ou MNM em 9,2\% (7/76) dos pacientes. A prevalência de PNP crônica em todas as 
faixas etárias na população é estimada em $1 \%$ e sua incidência é de aproximadamente 0,7 por 1000 pessoas-ano (Visser et al., 2015; Hanewinckel et al., 2016). Atualmente a estimativa mais confiável da prevalência de PNP crônica na população é baseada nos resultados do Estudo Longitudinal Italiano do Envelhecimento (do inglês Italian Longitudinal Study of Aging, ILSA,), um estudo de base populacional que enfocou doenças crônicas em idosos (Baldereschi et al., 2007). PNP foi diagnosticada em 334 dos 4478 participantes, com prevalência de 7,5\% (prevalência ajustada à idade de 7,0\%, padronizada para a população italiana). Este percentual de PNP clinicamente diagnosticada $(9,2 \%)$ do total de pacientes do estudo é semelhante ao relatado por Köşkderelioğlu et al., 2016, que reportaram PNP sensitivomotora em 13,3\% dos seus pacientes.

A proporção de pacientes com PNP encontrada por Nemni et al., 2003, nos pacientes com HCV com e sem CM por exame eletrofisiológico foi de 37,3\% e a prevalência de PNP foi significativamente maior em pacientes com CM em comparação com pacientes sem CM (45\% vs 9\%).

Dos pacientes com NP em nosso estudo, PNP simétrica sem MN ou MNM sobrepostas representou $24,1 \%$ dos casos. Este achado é menor que o relatado por Biasiotta et al., 2014, que encontaram 95,7\% dos pacientes HCV portadores de CM com PNP simétrica. Entretanto, além de estudar os pacientes com exame eletrofisiológico, todos os pacientes tinham $\mathrm{CM}$, o que pode justificar a alta prevalência de PNP.

Em nosso meio, Gomes et al., 2006, não encontraram nenhum caso de PNP em seu estudo eletrofisiológico. 
Authier et al., 1993, encontraram PNP axonal distal em 83,3\% (25/30) dos pacientes com CM, MNM em 10\% (3/30) e PNP desmielinizante em 6,7\% (2/30), através de exame eletrodiagnóstico.

Mapoure et al., 2018, não discriminaram o tipo de NP, relatando ser sensitiva em $96.7 \%$ dos pacientes, semelhante ao encontrado por Al-Soud et al., 2011.

Dos 59 pacientes com NP estudados por Mariotto et al., 2014, 30,5\% tinha PNP, 20,3\% PNP com MNM ou MN sobrepostas e $22 \%$ tinha MNM diagnosticadas por exame eletrofisiológico.

Khalek et al., 2012, encontraram PNP axonal predominantemente sensitiva afetando os membros inferiores em 38 dos 54 pacientes com NP (70,3\%). PNP mista desmielinizante e axonal sensitivomotora foi encontrada em 29,7\%, com predominância do acometimento sensitivo.

Como não realizamos estudo eletrofisiológico em nosso estudo, não pudemos definir qual o tipo de NP, se axonal, desmielinizante ou mista.

Dos pacientes com NP portadores de infecção por HCV estudados por Santoro et al., 2006, através de exame eletrofisiológico, PNP foi encontrada em $52,8 \%$ dos pacientes e MNM em 47.2\%, o que contrasta com nossos resultados de $24,1 \%$ dos pacientes com PNP clinicamente diagnosticada dos 29 pacientes com NP entre os pacientes com hepatite C.

A associação significativa entre idade e NP recebe apoio de evidências de que as manifestações extra-hepáticas da infecção pelo HCV aumentam com idade (Cacoub et al., 1999). Em nosso estudo, a presença de CGs se 
correlacionou NP, apesar da baixa prevalência de CM (13,3\% dos pacientes com NP).

No estudo de Biasiotta et al., 2014, o desenvolvimento de NP foi significativamente associado à duração da infecção por HCV (definido como tempo decorrido desde o diagnóstico), mas não estava relacionado à duração da CM ou o nível CGs no soro. Estes achados argumentam contra um estudo anterior de Gemignami et al., 2005, no qual foi investigada uma grande amostra de indivíduos com CM e foi reportada maior frequência de NP em pacientes com níveis séricos altos de CGs.

O fato de a NP não ter mostrado associação com o genótipo do HCV pode dever-se à variação limitada nos genótipos no nosso grupo de pacientes.

A hipótese mais aceita para explicar a NP relacionada ao HCV é que esta resulta de mecanismos imunomediados desencadeados pelo vírus, e não da infecção direta do nervo e de replicação viral intrínseca (Authier et al., 2003). Em contraste com o cérebro, não existem atualmente evidências de que os nervos periféricos sejam locais permissivos para a replicação do HCV (Adinolfi et al., 2015). Segundo Cacoub et al., 1999, PNP simétrica predominante sensitiva envolve a infiltração perivascular de linfócitos e monócitos de vasos de pequeno calibre e a MNM, envolvendo um ou dois nervos não contíguos, é causada por uma afecção mais sistêmica e envolve inflamação de vasos de tamanho médio, com uma miríade de células inflamatórias, acompanhadas de necrose vascular. 


\subsubsection{Relação de neuropatia periférica e alterações do metabolismo da glicose nos pacientes com hepatite C}

Neste estudo verificamos que cinco pacientes $(6,6 \%)$ e sete controles $(9,2 \%)$ tinham DM franco. A diferença não teve significância estatística.

A maioria dos estudos mostra uma prevalência maior de DM tipo 2 nos portadores de infecção crônica por HCV (Grimbert et al., 1996; Mason et al., 1999; Knobler et al., 2000). Esta associação ocorre independente da presença de cirrose, muito embora, a associação entre cirrose e intolerância à glicose seja conhecida de longa data (Allison et al., 1994; Lonardo et al., 2009). Foi demonstrado, inclusive, que a prevalência de DM foi significativamente maior entre pacientes com cirrose por HCV que em pacientes com cirrose devida a outras etiologias (Allison et al., 1994; Knobler et al., 2000).

Knobler et al., 2000, relataram que 75 a $80 \%$ dos cirróticos com HCV eram intolerantes à glicose, e 50\% desses cirróticos desenvolveram DM tipo 2 em comparação com apenas $9 \%$ dos cirróticos não portadores de HCV. Isto sugere um efeito diabetogênico direto do HCV, além do dano hepático. As taxas de DM tipo 2 são ainda maiores no contexto de graus mais elevados de fibrose hepática, esteatose ou cirrose (Knobler et al., 2000; Papatheodoridis et al., 2006; Zein et al., 2000). Portanto, mesmo na ausência de cirrose ou terapia antiviral, a infecção crônica por HCV, está associada ao DM tipo 2 (Grimbert et al., 1996; Mason et al., 1999; Knobler et al., 2000; Pazhanivel e Jayanthi, 2010).

Segundo Huang et al., 2014, DM de início recente prediz a descompensação da cirrose hepática em pacientes HCV com relação de risco 
de incidência (hazard ratio) de 2,5 (IC 95\%, 1.61-3.90), após ajuste para diversos fatores.

Em alguns estudos a presença de fibrose e cirrose demonstrou ser um fator de risco independente que contribui para a progressão para DM tipo 2 (Knobler et al., 2000; Papatheodoridis et al., 2006; Zein et al., 2000).

Meta-análise publicada em 2012 por Naing et al. mostrou que os pacientes infectados pelo HCV apresentam maior risco de desenvolvimento de DM tipo 2 do que pacientes não infectados (RR: 1,68, IC 95\%, 1.15-2.45). Estes resultados foram semelhantes aos de outra meta-análise de 34 estudos realizada por White et al., 2008, que mostrou risco significativamente maior de DM tipo 2 em pacientes com HCV do que em portadores de HBV (RR:1,8, IC $95 \%, 1.20-2.40)$

Em 2018, Fabiani et al. também publicaram revisão sistemática sobre o tema e concluíram que a infecção pelo HCV está associada a um risco aumentado de DM tipo 2 independentemente da gravidade da doença hepática associada em pacientes com hepatite crônica por HCV e pacientes HCV com cirrose. Como esperado, o risco de DM tipo 2 é maior em pacientes HCV cirróticos que naqueles com hepatite crônica sem cirrose. A prevalência de infecção pelo HCV em pacientes com DM tipo 2 é maior que em controles não diabéticos, o que não se observa na hepatite B.

Dados cumulativos sugerem que o DM tipo 2 é aproximadamente duas a três vezes mais prevalente nos pacientes com HCV do que nos que têm infecção por HBV. Acredita-se, portanto, que o risco de DM tipo 2 entre pacientes 
com HCV é significante e é maior que associação ao acaso ou dependente de cirrose hepática (Hammerstad et al., 2015).

Segundo Matsumoto et al., 2012, um fator preditivo para o desenvolvimento de DM tipo 2 em pacientes positivos para HCV com cirrose hepática é o nível de albumina menor que 39 gramas por litro e, além disso, segundo Hammerstad et al., 2015, índice de massa corporal (IMC) elevado, fibrose grau 4 ao exame elastográfico do fígado, duração da infecção pelo HCV, resposta à terapia prévia e história familiar positiva para DM tipo 2 podem predizer o desenvolvimento de DM tipo 2.

Naing et al., 2012, verificaram que DM tipo 2 era mais prevalente em pacientes com hepatite $C$ do sexo masculino (RR: 1,26; IC95\%: 1,03-1,54) e idade superior a 40 anos (RR: 7,39; IC 95\%, 3.82-9.38).

Embora grande número de estudos relate risco aumentado de DM em pacientes com infecção crônica pelo HCV, alguns estudos não puderam confirmar essa associação na ausência de disfunção hepática, talvez devido a variações sutis no genótipo do HCV, etnia, gravidade da doença hepática e outras variáveis (Missiha et al., 2008; Mangia et al., 1998).

Mangia et al., 1998, acompanharam prospectivamente 385 pacientes com hepatite $\mathrm{C}$ não cirróticos hospitalizados e concluíram que a prevalência de DM não foi significativamente diferente da população italiana em geral.

Um fator que pode ter influído para a baixa proporção de DM tipo 2 nos nossos pacientes, talvez seja o fato de poucos deles apresentarem graus elevados de fibrose hepática. Somente $14,3 \%$ dos 63 pacientes que realizaram 
biópsia tinham fibrose grau 3 ou 4, segundo o sistema METAVIR. Um paciente diabético tinha fibrose grau 3 , um paciente grau 2 , um paciente grau 1 e dois pacientes não haviam sido submetidos à biópsia.

Na infecção crônica pelo HCV, o DM tipo 2 também foi relacionado com determinados genótipos do HCV. Moucari et al., 2008, relataram que a resistência à insulina foi mais frequente em pacientes com os genótipos 1 e 4 do HCV em contraste com os pacientes portadores de genótipos 2 e 3 que, apesar de IMC e circunferências abdominais similares, tinham uma taxa de $22 \%$ de resistência à insulina, em comparação com 40,1\% dos pacientes com pacientes com genótipos 1 e 4. Também Sersté et al., 2010, relataram que a resistência à insulina é mais comum em pacientes com genótipos 1 e 4 do que nos portadores de genótipos 2 e 3.

No Japão os pacientes com genótipo 2 do HCV apresentaram uma taxa mais alta de DM do que o genótipo 1 (Arao et al., 2003).

Em nosso estudo, 76,3 \% dos pacientes eram portadores do genótipo 1, e 15, 8 \% do genótipo tipo 3, que parece causar menor predisposição ao DM tipo 2 que os genótipos 1, 2 e 4 . Somente $5,3 \%$ dos nossos pacientes tinham outros genótipos que parecem conferir um risco maior de DM tipo 2. Entretanto, além dos pacientes com DM tipo 2, 17 pacientes (22,4\%) em nossa casuística apresentavam intolerância à glicose, o que é uma proporção bastante elevada.

A intolerância à glicose $(\mathrm{IG})$ é aproximadamente quatro vezes mais frequente em pacientes com infecção crônica pelo HCV que na população de controles saudáveis. Constituem fatores predisponentes para IG a idade 
avançada e níveis mais altos de alanina aminotransferase (Burman et al., 2015; White et al., 2008).

Vinte e dois dos nossos pacientes (28,9\%) tinham DM melito ou IG, 18 $(23,7 \%)$ tinham genótipo 1, 2,6\% (2/76) o genótipo 2 e 2,6\% (2/76) o genótipo 3, o que está de acordo com os dados publicados (Mason et al., 1999; Mihm, 2010; Sersté et al., 2010).

A infecção crônica pelo HCV pode levar ao aumento da resistência insulina, pois o vírus da hepatite $\mathrm{C}$ prejudica a via de sinalização da insulina de várias maneiras, incluindo aumento da produção de fator de necrose tumoral-a, fosforilação dos receptores de insulina e superexpressão do supressor de citocinas, SOC-3 (Hammerstad et al., 2015; Parvaiz et al., 2011). Acredita-se que o fator de necrose tumoral- $\alpha$ afete a fosforilação do substrato do receptor de insulina diminuindo a captação de glicose e acarretando hiperinsulinemia compensatória (Parise e Oliveira, 2007). A proteína do núcleo do HCV induz a degradação proteossômica de IRS-1 e IRS-2 (substratos do receptor de insulina), bloqueando a sinalização intracelular de insulina (Aytug et al., 2003; Chang, 2016). Além disso, aumento da esteatose hepática e alterações dos níveis circulantes das adipocitocinas podem ter efeito adicional sobre a sensibilidade à insulina na hepatite C crônica (Jonsson et al., 2005). A avaliação histológica do pâncreas de paciente com HCV mostrou evidências de que as células pancreáticas $\beta$ estavam infectadas pelo vírus e que apresentavam alterações morfológicas e defeitos funcionais com liberação atenuada de insulina em resposta à glicose (Masini et al., 2005). 


\subsubsection{Relação de neuropatias periféricas e presença de crioglobulinemia}

Neste estudo encontramos crioglobulinemia em 9,2\% (6/65) dos pacientes nos quais o teste foi realizado. Houve correlação da presença de CGs com a queixa de cansaço e com o índice HOMA. Encontramos CM em 13,8\% dos pacientes com NP. Nos pacientes sem NP, somente 4,3\% tinham CM. Dos seis pacientes com CM detectada, quatro tinham NP $(66,7 \%)$, sendo dois com MN, um com PNP e um com PNP com MNM sobreposta.

A proporção de pacientes com CM por nós encontrada é baixa, porém o percentual de detecção de $\mathrm{CM}$ em pacientes com $\mathrm{HCV}$ varia amplamente nas diversas séries, de 8,8 a $70 \%$. Muitas dessas diferenças podem ser causadas por vieses de seleção de população e tempo de espera para se verificar a crioprecipitação (Persico et al., 2003; Charles e Dustin, 2009). Além disso, a avaliação clínica da CM não é padronizada, e o teste laboratorial para a detecção de CGs é propenso a resultados falso-negativos (Charles e Dustin, 2009). Não há valor de referência aceito internacionalmente e essa falta de padronização dificulta a interpretação e pode levar a um diagnóstico incorreto de CM (Vermeersch et al., 2008). Indivíduos saudáveis podem ter baixas quantidades de CGs detectáveis (Vermeersch et al., 2008). Segundo Voma e Levinson, a maioria dos pacientes têm baixas concentrações (100-300 mg / L) de CGs séricas entre as altas concentrações $(60.000-80.000 \mathrm{mg} / \mathrm{L})$ de proteínas séricas normais. É difícil isolar pequenas quantidades de CGs sem contaminação por proteínas séricas normais. Os métodos analíticos para CGs não acompanharam os avanços recentes na tecnologia, os volumes de amostra necessários para dosagem de CGs são grandes (5-10 mL de soro), a taxa de análise é baixa (o 
resultado leva de 3 a 7 dias) e as técnicas de quantificação de rotina necessitam de refinamento. A grande variabilidade na prevalência de $\mathrm{CM}$ na infecção pelo HCV pode refletir diferenças na sensibilidade das técnicas analíticas como, por exemplo, a filtração em gel, que tem maior sensibilidade do que o método de crioprecipitação convencional (Okuse et al., 2003).

Até $30 \%$ a $40 \%$ dos pacientes com CM tipo II e pacientes ocasionais com CM tipo III não apresentam CGs circulantes detectáveis na apresentação, o que pode, em parte, ser devido a problemas técnicos (Johnson et al., 1993).

Quando existe a suspeita clínica de vasculite crioglobulinêmica, resultado negativo dos testes laboratoriais de rotina para dosagem de CGs não exclui doença mediada por crioglobulinas (Kay e McCluskey, 2005).

A CM está associada ao aumento da duração da infecção pelo HCV; pacientes com CM têm uma duração de infecção por HCV que é quase duas vezes maior que em pacientes com CM ausente (Lunel et al., 1994). Portanto existe diferença se a população estudada tem infecção por HCV recentemente adquirida ou tem a infecção de longa data. Em sua maioria, os pacientes desta casuística foram encaminhados pelo banco de sangue com infecção recentemente diagnosticada, embora não saibamos há quanto tempo tenha sido adquirida dado que a maior parte dos pacientes desconhece como adquiriram a infecção.

Outra explicação é que a prevalência de CM é variável no mundo. Até $60 \%$ dos indivíduos infectados pelo HCV no sul da Europa têm CM, enquanto a 
prevalência entre os pacientes HCV nos EUA é consideravelmente menor, de 10 a 50\% (Charles e Dustin, 2009).

Numa população italiana de pacientes com hepatite $C$ foi encontrada uma taxa de incidência anual de 6\% (Adinolfi et al., 1996).

Lunel et al., 1994, encontraram CM em 54,3\% de seus pacientes com Hepatite C na França em 1994; Adinolfi et al., 1996, em 46\% na Itália; Cacoub et al., 1999, em 40\% na França; Nagasaka et al., 2001, em 42,5\% no Japão; Persico et al., 2003, em 8,8\% na Itália; Al-Soud et al., 2011, em 25\% no Egito;Khalek et al., 2012, em 15\% no Egito; Mapoure et al., 2018, em 72,9\% em Camarões. Em pacientes multitransfundidos, Perniola et al., 1999, encontraram CM em $66 \%$ dos pacientes. Em nosso meio, Parise et al., 2007, encontraram 27\% de 202 pacientes HCV virgens de tratamento com CM detectável.

Não está claro se as diferenças nas prevalências de CM verificadas em pacientes portadores de HCV se devem a fatores genéticos não identificados. Alguns estudos se concentraram nos alelos HLA, porém com amostras pequenas de pacientes, e comparações entre eles são complicadas pela variação dos métodos de tipagem de HLA e diferentes populações geográficas com diferentes frequências de HLA. No entanto, estudos relacionaram a presença de subtipos de antígenos HLA classe II DR2 (DRB1*1601, DQB1 ${ }^{* 0502), ~ H L A-B 8, ~ H L A-D R 3, ~ H L A-D R 11 ~ e ~ D R 5-D Q 3 ~ c o m ~ C M ~(G r a g n a n i ~ e t ~}$ al., 2013).

Foi identificada associação significativa de vasculite crioglobulinêmica com polimorfismos de nucleotídeo único (SNPs) próximos aos genes NOTCH4 
e MHC de classe II (Zignego et al., 2014). Níveis significativamente elevados de citocinas inflamatórias, como interleucina (IL) - 1- $\beta$, IL-6 e fator de necrose tumoral-a, foram observados, sugerindo que a inflamação induzida pelas CGs tenha um papel na patogênese da doença (Antonelli et al., 2009).

Pacientes com CM relacionada ao HCV comumente apresentam NP, com prevalência relatada variando de $9 \%$ a mais de $70 \%$ (Ferri et al., 1992; Ammendola et al., 2005; Cacoub et al., 2005; Ammendola et al., 2007). As diferenças devem-se principalmente aos critérios diagnósticos para NP, ou seja, a existência de queixas de dores e parestesias, sinais objetivos de NP ou evidências eletrofisiológicas.

Zaltron et al., 1998, estudaram pacientes com hepatite C e NP com exame eletrofisiológico, e verificaram a presença de CM em $50 \%$ dos pacientes. Authier et al., 1993, encontraram CM em 53,3\% dos pacientes com NP diagnosticada por exame eletrofisiológico. Santoro et al., 2006, relataram que 29,3\% dos pacientes com HCV e NP testados tinham CM. Al-Soud et al., 2011, detectaram CM em $71,4 \%$ dos pacientes com NP diagnosticada por exame eletrofisiológico. Mariotto et al., 2014, encontraram CM em 66,1\% dos pacientes com HCV e NP.

Em indivíduos não portadores de HCV o nível sérico de CGs é próximo de zero. Nível sérico de CGs acima de $50 \mathrm{mcg} / \mathrm{mL}$ é geralmente considerado clinicamente significativo (Della Rossa et al., 2010).

Quando os pacientes com hepatite C com CM são comparados como um grupo sem CM, a gravidade da doença geralmente é maior no grupo com 
CM. Entretanto os estudos mostram falta de correlação entre a concentração sérica de CGs e a gravidade da doença (Voma e Levinson, 2016; Charles e Dustin, 2009). A maioria dos indivíduos com CM é assintomática e a correlação entre os níveis séricos de CGs e manifestações clínicas da síndrome de CM é fraca, mesmo quando os níveis séricos são altos, o que indica que os sintomas clínicos e a gravidade da doença não dependem simplesmente da concentração sérica de CGs. Muitos pacientes com infecção crônica pelo HCV têm CM sem o quadro de vasculite crioglobulinêmica, o que foi verificado em um estudo de 1083 pacientes não selecionados com infecção crônica pelo HCV em que $40 \%$ tinham baixas concentrações de CGs no soro e apenas 2,1\% apresentavam vasculite crioglobulinêmica (Cacoub et al., 1999).

Embora a fisiopatologia da NP relacionada à doença crônica por HCV seja controversa, a deposição de micropartículas de HCV-RNA e CGs, invasão viral direta do endotélio, invasão viral direta do nervo e inflamação mononuclear perivascular foram implicadas no desenvolvimento de lesões vasculíticas relacionadas ao HCV (Agnello et al., 1992; Agnello e Ábel, 1997; Bonetti et al., 1997; Adinolfi et al., 2015).

Na maioria dos casos de NP associadas à CM mista as características patológicas são indicativas de alterações nervosas isquêmicas, como consequência de vasculite de pequenos vasos ou, menos frequentemente, de arterite necrosante de vasos de tamanho médio (Kanda., 2003; Authier et al., 2003).

Authier et al., 2003, detectaram fitas genômicas positivas de RNA-HCV em tecido muscular e nervos periféricos em 10 de 30 pacientes estudados. 0 
estudo anatomopatológico mostrou lesões vasculares inflamatórias em $87 \%$ dos pacientes, incluindo arterite necrosante (6/30), vasculite de pequenos vasos (12/30), do tipo linfocítica (9/12) ou leucocitoclástica (3/12), e infiltrados inflamatórios perivasculares (8/30). Todos os pacientes com arterite necrosante apresentavam PNP distal desmielinizante e CM.

Depósitos vasculares epineurais de glicoproteína E2 do HCV foram encontrados em quatro (80\%) dos pacientes com CM e em dois $(33,3 \%)$ pacientes sem CM, respectivamente por Russi et al., 2018. Não foi encontrada a fita negativa do RNA viral, demonstrando replicação in situ. Em pacientes sem CM imunocomplexos ou mecanismos autoimunes induzidos pelo HCV poderiam desempenhar um papel patogenético na indução de inflamação vascular e perivascular, que pode ser causada por uma população de células imunocompetentes e potencialmente fagocitárias intrínsecas do nervo (Bonetti et al., 1999; Kanda, 2003).

Exames laboratoriais que sugerem a presença de CGs são FR positivo (presente em aproximadamente dois terços dos pacientes), juntamente com baixos níveis de C4 e níveis normais ou levemente diminuídos de C3 (Zignego et al., 2014).

\subsubsection{Autoanticorpos}

Em nosso estudo quase a metade (46,2\%) dos pacientes testados mostraram elevação do teor de gamaglobulinas no sangue e alguns tipos de autoanticorpos foram detectados em percentagem maior que $20 \%$ dos pacientes testados (anticardiolipinas IgM, anti-TPO e antimúsculo liso). 
Marcadores sorológicos que refletem autoimunidade nos pacientes HCV são amplamente conhecidos. No fígado de pacientes com HCV, células B e T podem se acumular nos tratos portais formando centros germinativos, caracterizados por expansões mono ou oligoclonais de células B que secretam autoanticorpos (Palazzi et al., 2012). Em consequência de sua natureza linfotrópica, o HCV pode desencadear e sustentar uma expansão clonal de células B que causa um amplo espectro de distúrbios autoimunes / linfoproliferativos, através de um processo com múltiplas etapas (Antonelli et al., 2005; Ferri et al., 2015). Anticorpos não órgão-específicos, particularmente anticorpos antimúsculo liso e anticorpos antinucleares, entre outros, são frequentemente encontrados em portadores crônicos de HCV (Marconcini et al., 2013; Gatselis et al., 2005).

Vários autores descreveram níveis séricos de enzimas hepáticas mais elevados em pacientes com HCV portadores deanticorpos não órgão-específicos (Narciso-Schiavon e Schiavon, 2015; Peng et al., 2001; Cassani et al., 1997) que provavelmente refletem a gravidade das lesões hepáticas (Marconcini et al., 2013; Chrétien et al., 2009).

Nos casos de portadores destes autoanticorpos, a principal preocupação é discriminar entre hepatite autoimune e doença hepática viral; este conhecimento influenciará as escolhas de tratamento (Narciso-Schiavon e Schiavon, 2015).

Alguns autores argumentam que a positividade dos anticorpos antinucleares em pacientes com HCV pode ser um epifenômeno (Palazzi et al., 2012; Narciso-Schiavon et al., 2009). Anticorpos antinucleares detectados por 
imunofluorescência em células HEp-2 foram observados na maioria dos estudos de indivíduos com infecção crônica por HCV. Neste estudo, a imunofluorescência em células HEp-2 foi positiva em 12,5\% dos pacientes testados, em títulos baixos. Entretanto 2 pacientes tiveram títulos de 1/320 e 2 de $1 / 160$. Foi relatado que o padrão relacionado ao HCV geralmente é pontilhado (Sène et al., 2007), que é menos significativo clinicamente, mas somente 2 pacientes tinham esse padrão; outros 4 tinham padrão nuclear homogêneo.

Cassani et al., 1997, encontraram anticorpos antinucleares em 9\% dos pacientes com hepatite C na Itália; Cacoub et al., 1999, em 10\% na França; Cacoub et al., 2000, em 41\% na França; Peng et al., 2001, em 22,9\% em Taiwan; Stefanova-Petrova et al., 2007, em 18.4\%, na Bulgária; Chrétien et al., 2009, em 30\% na França; Badiani et al., 2010, em 12\% no Brasil, e Narciso-Schiavon et al., 2009, em 9,4\%, também no Brasil.

O autoanticorpo mais comumente encontrado na hepatite $C$ crônica é o anticorpo antimúsculo liso, que exibe grande variação em sua prevalência (Chrétien et al., 2009; Narciso-Schiavon e Schiavon, 2015;).

Em nossa casuística encontramos positividade para 0 anticorpo antimúsculo liso em 26,2\% dos pacientes testados (17/65). Cassani et al., 1997, encontraram anticorpos antimúsculo liso em $20 \%$ dos pacientes portadores de HCV na Itália; Cacoub et al., 1999, em 7\% na França; Peng et al., 2001, em 78\% em Taiwan; Stefanova-Petrova et al., 2007, em 16,9\% na Bulgária; Chrétien et al., 2009, em 15\%, na França e Marconcini et al., 2013, em 26,7\% no Brasil. O percentual encontrado por nós é muito próximo ao de Marconcini e colaboradores, em nosso meio. 
Os anticorpos anti-DNA de cadeia dupla são marcadores sorológicos do lúpus eritematoso sistêmico. Nos pacientes com infecção por HCV, estes anticorpos são geralmente encontrados em pequenas percentagens, mas em algumas séries eles podem chegar a 25\% (Palazzi et al., 2012; Omagari et al., 2003). Em nosso estudo, encontramos anti-DNA nativo em $9,6 \%$ dos pacientes testados $(5 / 52)$.

Exames laboratoriais que sugerem a presença de CGs são FR positivo, baixos níveis de C4 e níveis normais ou levemente diminuídos de C3 (Himoto e Masaki, 2012). Em nosso estudo, o FR foi detectado em 26,7\% (16/60) dos pacientes testados, o que está de acordo com a literatura. O FR, que reconhece a porção Fc das moléculas de lgG como seus antígenos, aparece frequentemente em soros de pacientes com $\mathrm{CM}$ relacionada ao $\mathrm{HCV}$, com frequências relatadas de 6 a 99\% (Lee et al., 1998; Persico et al., 2003; Siagris et al., 2004; Dore et al., 2007; Ramos-Casals et al., 2005; Lidar et al., 2012; Himoto e Masaki, 2012). Também foi relatado que os pacientes com hepatite $\mathrm{C}$ têm frequentemente FR em níveis de até $50 \mathrm{Ul} / \mathrm{mL}$ (Leone et al., 2002), porém três dos nossos pacientes com FR positivo, tinham níveis maiores que $80 \mathrm{Ul} / \mathrm{mL}$.

Os anticorpos citoplasmáticos antineutrófilos (ANCA) também podem estar estão presentes nos soros de pacientes com CM relacionada ao HCV (Lamprecht et al., 2003; Stefanova-Petrova et al., 2007; Palazzi et al., 2012). Lamprecht e colaboradores encontraram ANCA em 10,2\% dos pacientes com hepatite C e Stefanova-Petrova et al., 2007, em 13,2\%. Neste estudo anticorpos citoplasmáticos antineutrófilos foram detectados em 6,4\% (3/47). A ocorrência desses autoanticorpos não está necessariamente relacionada à vasculite 
crioglobulinêmica relacionada ao HCV (Lamprecht et al., 2003). ANCA geralmente está associado a graves síndromes vasculíticas como a poliangiite microscópica (granulomatose de Wegener) e sua forma limitada renal, glomerulonefrite necrosante idiopática, e a granulomatose eosinofílica com poliangiite [síndrome de Churg-Strauss] (Kallenberg et al., 2006). Wu et al., 2002, relataram anticorpos antiproteínase 3 em 55,6\% de seus 516 pacientes e anticorpos antimieloperoxidase em 4,8\%.

Quadros clínicos graves de vasculites associadas a ANCA não são observados nos pacientes com hepatite C com ANCA presentes no soro, em particular a poliangiite microscópica (Palazzi et al., 2012).

Anticorpos antiLKm1 estão envolvidos na hepatite autoimune e estavam presentes em $1,5 \%$ dos nossos pacientes (1/65). Percentagem de $0,5 \%$ foi encontrada por Chrétien et al., 2009. Em nosso meio, Badiani et al., 2010, não detectaram estes anticorpos em sua série de 92 pacientes e. Marconcini et al., 2013, encontraram-nos em 6,8\% de seus pacientes.

Em nossa casuística verificamos baixos níveis da fração C4 em 20,7\% (12/58) dos pacientes, níveis baixos de C3 em 11,9\% (7/59) dos pacientes e títulos aumentados de FR em 26,7\% (16/60) dos pacientes. A combinação de nível baixo da fração C4 e títulos aumentados de FR são considerados muito sugestivos da presença de CM (Gorevic, 2012). Portanto é possível que os doentes que mostraram níveis baixos de C4 e títulos altos de FR podem ter CM não detectada. 
Apesar de termos verificado que $31,6 \%$ (6/19) dos pacientes com NP nos quais a dosagem de $\mathrm{C} 4$ foi realizada tinham níveis baixos de $\mathrm{C} 4$ versus $15,4 \%$ (6/39) dos pacientes sem NP, a diferença não foi significante, o mesmo tendo ocorrido com relação à positividade do FR.

O sistema complemento compreende 30 proteínas séricas e de superfície celular fortemente reguladas para responder aos ativadores por três vias independentes (clássica, alternativa e lectina ligadora de manana) evoluídas principalmente para reconhecer e destruir microorganismos patogênicos (Gorevic, 2012; El-Shamy et al., 2018). A ativação das vias clássica, alternativa e da lectina foi relatada na infecção crônica pelo HCV e / ou crioglobulinemia. A infecção pelo HCV leva à desregulação das respostas imunes mediadas pelo complemento. Evidências clínicas e experimentais apoiam o envolvimento do complemento nas manifestações intra e extra-hepáticas da infecção pelo HCV, como a fibrose hepática e a CM tipo II, no entanto, apenas informações limitadas estão disponíveis sobre os mecanismos pelos quais o sistema complemento está envolvido na doença intra e extra-hepática induzida pelo HCV (El-Shamy et al., 2018).

Em um estudo proteômico de amostras de soro de pacientes infectados pelo HCV, o grau de fibrose hepática foi associado a uma diminuição nos níveis de C3 e C4 e relacionado ao Fator $\mathrm{H}$, uma proteína reguladora da ligação ao C3b (Gangadharan et al., 2007). O HCV promove regulação para baixo da atividade de C4 através de inibição induzida pelo núcleo do HCV no fator-1 estimulador a montante e de inibição do fator-1 regulador de Interferon induzida pela proteína NS5A (Banerjee et al., 2011). Além disso, o HCV regula para baixo 
a síntese de C3 e C4 nos hepatócitos através da inibição do hepatócito MICA / B (Kim et al., 2014). Esta depressão seletiva de C4 implica fortemente a ativação da via clássica do complemento na formação de CGs.

Encontramos FR no soro de $16 / 60$ pacientes (26,7\%). Cacoub et al., 2000, encontraram-no em 38\%. A produção de FR ocorre amplamente em várias infecções, seja em resposta a complexos imunes formados por anticorpos e microrganismos infectantes, seja em função da infecção direta e da estimulação de células B policlonais. Na CM Tipo II a contribuição de FR/IgM e IgM para o conteúdo proteico total apresenta um espectro de concentrações e clonalidade, com representação favorecida de idiotipos reativos de $\lg M$ principalmente o idiotipo Wa, que está presente em $84 \%$ das CM Tipo II nos pacientes HCV (De Rosa e Agnello, 2009; Ferri et al., 2004). Isso permite a observação de FR em CM mistas em pacientes que têm FR aparentemente negativo e de CGs que são compostas quase inteiramente de IgM com cadeias leves kappa (El- Shamy et et al., 2018).

Outros tipos de autoanticorpos estão intimamente ligados ao envolvimento de órgãos em pacientes com CM relacionada ao HCV. Entre 6 e $26 \%$ dos pacientes com hepatite C queixam-se de xerostomia e/ou xeroftalmia síndrome sicca (Cacoub et al., 1999; Cacoub et al., 2000; Sansonno e Dammacco, 2005; Stefanova-Petrova et al., 2007). Encontramos anticorpos antiSSA/RO e anti-SSB/LA em 7,6\% e 10,6\% dos pacientes testados, respectivamente. Conquanto pacientes com infecção crônica por HCV possam se queixar de secura de mucosas, a soropositividade para anticorpos antiSSA/RO e para anti-SSB/LA são muito mais baixas na síndrome sicca associada 
ao HCV que em pacientes com síndrome de Sjögren primária (Narciso-Schiavon et al., 2009; Palazzi et al., 2012). Segundo Cacoub et al., 2017, menos de 5\% dos pacientes com diagnóstico de síndrome de Sjögren definida são portadores de HCV.

Segundo o Registro HISPAMEC, grupo de estudo multicêntrico internacional dedicado à coleta de dados sobre doenças autoimunes sistêmicas coexistentes com a infecção crônica pelo HCV, a doença autoimune sistêmica mais frequentemente descrita nos pacientes com infecção pelo HCV foi a síndrome de Sjögren (47,4\%) [Ramos-Casals et al., 2009].

Em uma revisão recente da literatura, Younossi et al., 2016, relataram uma prevalência de síndrome de Sjögren de 11,9\% em pacientes com HCV (razão de risco 2.29).

Embora os sintomas de síndrome sicca sejam frequentes em pacientes infectados com HCV, síndrome de Sjögren caracterizada pela presença de anticorpos anti-SSA ou antiSSB e uma histologia típica de glândulas salivares é incomum nos pacientes com infecção por HCV (Cacoub et al., 2017).

Um grande estudo transversal de pacientes com síndrome de Sjögren definida (critérios internacionais de 1993) mostrou que os pacientes com síndrome de Sjögren associada ao HCV eram mais velhos, mais frequentemente do sexo masculino e apresentavam mais vasculite, neuropatia periférica e neoplasia em comparação com aqueles com síndrome de Sjögren primária. Eles também tinham mais frequentemente FR positivo, CM e, com menor frequência, anticorpos anti-SSA ou SSB (Ramos-Casals et al., 2009). 
Encontramos correlação entre NP e anticorpos anti SSA/RO. Houve diferença significante entre os pacientes com e sem NP em relação à positividade para este anticorpo. No estudo multicêntrico comparando síndrome de Sjögren associada à infecção por HCV com a síndrome de Sjögren primária, Ramos-Casals et al., 2005, encontraram $16 \%$ de NP nos pacientes com síndrome de Sjögren associada à hepatite C e 7 \% nos pacientes com síndrome de Sjögren primária. Metade dos pacientes com síndrome de Sjögren associada ao $\mathrm{HCV}$ tinha CGs presentes no soro associadas ao $\mathrm{FR}$, contra $9 \%$ dos pacientes com a doença primária (Ramos-Casals et al., 2005). Nossos pacientes com NP e anticorpos anti-SSA/RO no soro tinham média de idade de 60 anos, teor elevado de gamaglobulinas séricas e somente um paciente tinha CGs presentes no soro. Três pacientes apresentavam PNP com MN sobrepostas e um apresentava neuropatia bilateral do mediano.

Encontramos correlação entre a presença de NP e a positividade de anticorpos antitirosina fosfatase (IA2) e verificamos diferença estatística significativa entre pacientes com e sem NP em relação à presença de anticorpos anti-IA2. O anticorpo antitirosina fosfatase (IA2) reage com antígenos de células de ilhotas pancreáticas e é um dos marcadores de DM de etiologia autoimune (Brooks-Worrell e Palmer, 2011). Embora classicamente a presença de anticorpos seja associada ao DM tipo 1, evidências de envolvimento do sistema imune na fisiopatologia do DM tipo 2 têm se acumulado. Entretanto, somente um dos pacientes com positividade sérica para o anticorpo antitirosina fosfatase (IA2) tinha intolerância à glicose. 
Himoto et al., 2012, estudaram a relação dos anticorpos anticardiolipinas nos pacientes com doença crônica por HCV e os encontraram em $13 \%$ de 45 pacientes. No entanto, nenhum dos pacientes preenchia os critérios para síndrome de anticorpos antifosfolípides.

No presente estudo anticorpos IgM anticardiolipinas foram detectados em $20,6 \%$ dos pacientes e anticorpos IgG anticardiolopinas em 5,2\%.

A carga viral de HCV (RNA-HCV) não mostrou relação com alterações do sistema nervoso periférico, intolerância à glicose e testes usados para avaliação cognitiva. A única correlação encontrada foi negativa com o grau de fibrose à biópsia hepática. Em estudos retrospectivos e transversais, os níveis séricos de RNA-HCV não foram associados à taxa de progressão da fibrose na Hepatite C (Poynard et al., 2002). A maioria dos estudos transversais relatou a ausência de correlação entre os níveis séricos de RNA-HCV e grau de atividade inflamtória ou grau de lesão hepática.

$\mathrm{Na}$ maioria dos estudos de comprometimento do sistema nervoso em relação à infecção pelo HCV não foi verificada correlação com a carga viral, porém Mapoure e colaboradores encontraram associação significativa dos níveis séricos de RNA-HCV e NP. Téllez-Zenteno et al., 2003, relataram alta carga viral entre os fatores de risco para NP nos pacientes por eles estudados. Nos casos estudados por Khalek et al., 2012, também foi verificada correlação de NP e carga viral.

Segundo Czaja e Carpenter, 1997, pacientes com HLA-DR3 e infecção crônica por HCV têm níveis mais elevados de Igs no soro e uma frequência três 
vezes maior de doença hepática severa do que pacientes com HLA-DR4. Os pacientes com hepatite viral crônica e genótipo HLA-DR3 têm um aumento de cinco vezes na prevalência de doenças imunológicas simultâneas comparadas aos pacientes com HLA-DR4. Assim, os transtornos autoimunes podem ser 0 resultado de fatores virais que atuam num substrato genético favorável ao desenvolvimento desses transtornos.

Em nossa casuística constatamos a presença de sinais e sintomas clínicos de envolvimento do sistema nervoso periférico com frequência similar à de muitos estudos da literatura reforçando as evidências de que a infecção crônica pelo HCV compromete o sistema nervoso periférico. Quando comparado com a literatura, nosso estudo tem algumas limitações, como a ausência de estudos eletrofisiológicos e de biópsia de nervos periféricos mas apresenta alguns aspectos positivos importantes: todos os casos foram examinados de modo prospectivo pela mesma neurologista e antes do início do tratamento antiviral.

Passaremos agora a segunda parte da discussão, que se refere aos aspectos neuropsiquiátricos dos pacientes com hepatite $\mathrm{C}$ de nossa casuística.

\subsection{Alterações neuropsiquiátricas nos pacientes com hepatite $C$}

\subsubsection{Depressão}

Em nosso estudo verificamos que $44,7 \%$ dos pacientes tinha sintomas depressivos. Apesar de não ser diferente do observado no grupo controle, este percentual é elevado e está de acordo com outros relatos na literatura (Golden 
et al., 2005; Cruz Neves et al., 2006). A depressão é considerada uma das MEH mais frequentes da infecção crônica pelo HCV e, segundo Golden et al.,2005, um terço ou mais dos infectados pelo HCV tem depressão, frequentemente não diagnosticada.

O fato de termos encontrado a mesma porcentagem de sintomas depressivos nos pacientes e controles talvez seja devido ao fato de termos recrutado os controles entre cônjuges, parentes dos pacientes do estudo, parentes de outros pacientes do HCFMUSP e pessoas com nível socioeconômico semelhante. Nos diversos estudos os critérios de seleção de controles nem sempre são claros e os sujeitos podem ser de estratos sociais muito diferentes daquele dos pacientes com este tipo de afecção. Embora não tenha atingido significância estatística, uma maior proporção de pacientes que controles apresentava sintomas de depressão moderada ou grave $(22,4 \%$ vs $13,2 \%)$

Também não verificamos diferenças significativas entre pacientes e controles em relação aos sintomas de ansiedade e de desesperança.

Wessely e Pariante, 2002, realizaram uma revisão abrangente e controversamente afirmaram que não há evidências de que a infecção pelo HCV por si só esteja associada à fadiga e depressão e basearam a conclusão em 3 argumentos: (1) a maioria, se não todos os estudos neste campo, são metodologicamente falhos e não levam em conta fatores de confusão; (2) não há relação entre fadiga e marcadores de inflamação hepática; (3) em estudos retrospectivos selecionados, não houve maior proporção de pacientes com Hepatite C com fadiga em comparação com doadores não infectados 
(Hoofnagle, 1997) e não foi encontrada proporção maior infecção por HCV entre pacientes com fadiga crônica (Dale et al., 1991).

Uma revisão de sintomas neuropsiquiátricos comumente associados à infecção pelo HCV de Cruz Neves e colaboradores mostrou que a depressão maior estava relacionada à percepção da doença, incapacidade funcional, baixa qualidade de vida, fadiga grave e com a presença de comorbidade psiquiátrica ativa. Estes autores verificaram que todos os estudos analisados em sua revisão de 2005 reportam sistematicamente um aumento da prevalência de depressão maior nestes doentes (com percentuais entre 5.7\% e 45\% dos pacientes estudados), com a exceção do estudo de Johnson et al., 1998.

Karaivazoglou et al., 2007, não encontraram diferenças significativas entre pacientes com hepatite $\mathrm{C}$ e controles em relação a sintomas depressivos ou gravidade da fadiga.

Dirks et al., 2018, avaliaram pacientes com hepatite C, hepatite B e hepatite autoimune utilizando a Escala de Ansiedade e Depressão Hospitalar. Todos os grupos de pacientes demonstraram graus mais elevados de ansiedade e depressão que controles, mas não houve diferença nos escores de depressão entre os grupos de pacientes. Os autores observaram que os escores médios dos pacientes nesta escala estavam dentro do normal ou muito pouco alterados.

A patogênese dos sintomas de alterações neuropsiquiátricas relacionadas à infecção crônica por HCV é mal compreendida e ainda está para ser determinado se a ocorrência de depressão é um fator de risco ou uma consequência da infecção. A relação entre hepatite $C$ e depressão é complexa. 
Pacientes com depressão podem ter uma incidência maior de infecção pelo HCV. Um grande contingente de usuários de drogas intravenosas tem infecção por HCV, muitos dos quais têm depressão clínica (Johnson et al., 1998). Por outro lado, a depressão pode existir como um fenômeno reativo ao diagnóstico e preocupações com a saúde e evolução da doença (Rodger et al., 1999) ou pode ser secundária a sintomas como fadiga e comprometimento cognitivo (McDonald et al., 2002; Forton et al., 2002).

Também se aventa a hipótese que um efeito biológico da própria infecção pelo HCV possa estar por trás da depressão. O HCV pode afetar diretamente o SNC através da alteração da neurotransmissão dopaminérgica e serotoninérgica com sintomas depressivos resultantes (Weissenborn et al., 2006; Cozzi et al., 2006).

Segundo meta-análise de 2016 de Hughes et al., nos EUA a prevalência de hepatite $\mathrm{C}$ em populações psiquiátricas $(17,4 \%)$ é significativamente maior que a da população geral (1\%), sugerindo que indivíduos com infecção por HCV são mais propensos a sofrer de problemas psiquiátricos como depressão. Entretanto, doença mental grave pode não ser fator de risco isolado para infecções virais como hepatite $\mathrm{C}$, hepatite $\mathrm{B}$ e síndrome da imunodeficiência adquirida, mas pode ser melhor interpretada como associada a fatores com grande potencial de confusão, como baixo nível socioeconômico, abuso de drogas recreativas e de álcool, e sexo com múltiplos parceiros.

No presente estudo não foram excluídos pacientes com depressão para comparação dos resultados dos testes cognitivos com os dos controles o que, porém, não influenciou os resultados, dado que a proporção de pacientes e 
controles relatando sintomas depressivos, ansiosos e de desesperança foi a mesma nos dois grupos.

Dado que a presença de depressão maior pode acarretar prejuízos nas funções executivas (McDermott e Ebmeir 2009; Snyder, 2012), a maioria dos estudos para avaliar comprometimento cognitivo nos pacientes com HCV exclui pacientes com depressão. Existem também alguns dados que apoiam que mesmo em pacientes com depressão menor podem ocorrer alterações cognitivas envolvendo a memória de trabalho e a fluência verbal (Klimkeit et al., 2011). Portanto é razoável considerar a exclusão de pacientes com depressão quando se avalia a prevalência de comprometimento cognitivo em pacientes com infecção crônica por HCV. Entretanto a exclusão de pacientes HCV relatando sintomas de depressão nos estudos de cognição pode levar a um viés de seleção, com maior inclusão de pacientes com baixo risco de desenvolvimento de disfunção cognitiva, como considerado por Abrantes et al., 2013. Além disso, as elevadas taxas de depressão relatadas em pacientes HCV podem ser manifestação neuropsiquiátrica resultante da ação direta ou indireta do vírus no SNC (Weissenborn et al., 2006; Forton et al., 2002) e portanto, a exclusão desses pacientes pode resultar em viés de seleção, dado que seriam avaliados somente pacientes com menos manifestações cognitivas da infecção por HCV.

Embora comorbidades psiquiátricas maiores, abuso de substâncias em períodos concomitante ou anterior e as consequências psicológicas de ter uma ameaça crônica de vida possam ser responsáveis pela maioria das manifestações neuropsiquiátricas, vários estudos indicaram um papel primário para o HCV. A depressão é menos frequentemente observada em pacientes 
infectados com hepatite B tratados com Interferon em comparação com aqueles com infecção por HCV (Ferenci e Staufer, 2008).

\subsubsection{Alterações de funções cognitivas}

Os testes para avaliação cognitiva utilizados neste estudo são de fácil aplicação e amplamente utilizados na prática por clínicos e neurologistas para rastreio de alterações cognitivas, não necessitando do concurso de profissionais especializados para aplicá-los. Em outros estudos foram empregadas baterias de testes neuropsicológicos aplicadas por profissionais especializados.

Em nosso estudo 23,7 \% dos pacientes tiveram escores do MEEM aquém do esperado para seu grau de escolaridade. Embora McAndrews et al., 2005, e Kramer et al., 2002, tenham utilizado outros testes para avaliar os pacientes, encontraram percentuais menores de alteração cognitiva, em 13\% e $16 \%$ dos pacientes estudados, respectivamente, mesmo utilizando instrumentos para avaliação neuropsicológica mais sofisticados. A proporção de pacientes com alteração cognitiva em nosso estudo, é mais baixa do que os $38 \%$ encontrados por Hilsabeck et al., 2003, e dos 33\% por Fontana et al., 2005. Entretanto, não verificamos diferença significante entre os pacientes e controles com relação aos escores totais no MEEM e nos outros testes utilizados para avaliação de funções cognitivas.

No estudo de Mapoure et al., 2018, a prevalência de comprometimento cognitivo foi $8.3 \%$. Entretanto, estes autores consideraram como alterados os pacientes com escores $\leq 24$ no MEEM, sem levar em consideração o grau de 
escolaridade dos indivíduos que, como já foi demonstrado, afeta o resultado do MEEM (Uhlmann e Larson, 1991; Bertolucci et al., 1994; Lourenço e Veras, 2006).

Como esperado, a escolaridade teve uma correlação positiva com os escores do MEEM, com os escores obtidos no TDR, na FV semântica e no teste dos dígitos, tanto em ordem direta quanto indireta. Os escores no Inventário de Depressão de Beck tiveram influência negativa nos escores do MEEM somente no grupo de pacientes, assim como a presença de DM. No grupo controle a presença de DM também influenciou o resultado no MEEM. Os escores obtidos no BDI tiveram influência negativa nos outros testes (FV semântica, TDR, Díg OD e Díg OI) no grupo dos pacientes, enquanto no grupo controle influenciaram negativamente a FV semântica e os testes de atenção (dígitos OD e OI), mas não os escores no MEEM e no TDR.

A maioria dos nossos pacientes apresentava graus baixos de fibrose hepática. O grau de fibrose não se correlacionou com os escores nos testes cognitivos, a não ser o teste Díg OD. Portanto, de modo geral, não podemos atribuir os resultados ao grau de fibrose hepática, dado também não terem sido verificadas diferenças estatísticas entre os grupos dos pacientes e dos controles com relação aos escores no MEEM e nos outros testes.

A associação de DM com os escores no MEEM pode ter várias explicações, como a presença de microangiopatia cerebral e o mal-estar físico influenciando funções excutivas. 
O único componente do MEEM que mostrou diferença significativa em relação aos grupos foi a memória de evocação. Trinta e quatro pacientes $(44,7 \%)$ perderam pontos na memória de evocação e 20 controles $(26,3 \%)[p=0,009]$. $O$ fato de mais de $40 \%$ dos nossos pacientes terem apresentado alteração na memória de evocação concorda com os dados de Mapoure e colaboradores que também observaram alteração de memória tardia, porém numa percentagem menor dos pacientes (26,4\%), assim como com Quarantini et al., 2009, que observaram mais alteração de memória nos pacientes com hepatite $\mathrm{C}$ em relação aos pacientes com hepatite $B$. Eles verificaram que o grupo de pacientes HCV teve pior desempenho nas tarefas de memória após ajuste para idade e grau de escolaridade na recordação imediata da figura de Rey-Osterieth e tendência a um baixo desempenho na recordação tardia da mesma figura. Em 2010, embora aplicando bateria de testes diferente, Lowry et al., 2010, também verificaram alterações primariamente na memória de pacientes com carga viral positiva para HCV, que não foram observadas no grupo com anti-HCV positivo, mas com carga viral negativa. Além da memória, os autores também encontraram em suas pacientes atraso no reconhecimento auditivo e alteração da atenção sustentada.

Nos nossos pacientes com hepatite $\mathrm{C}$ a alteração da memória de evocação não se correlacionou com o índice de inflamação hepática ou com o genótipo, o que está de acordo com pesquisas anteriores (Forton et al., 2002; Kramer et al., 2002; McAndrews et al., 2005).

Dos pacientes que tiveram escores no MEEM aquém do mínimo esperado para seu grau de escolaridade, $88,9 \%$ perderam pontos em atenção e 
cálculo (16/18), 77,8\% (14/18) na memória de evocação, 11,1\% (2/18) em orientação temporal, um na memória imediata e 55,6\% (10/18) nos subtestes de linguagem $(5,6 \%(1 / 18)$ somente na escrita da frase, $16,7 \%(3 / 18)$ somente no desenho dos pentágonos e 33,3\% (6/18) em ambos). A diferença entre os pacientes e controles com MEEM aquém do esperado nos subtestes de linguagem não foi significativa $(p=0,937)$.

Dirks et al., 2018, observaram que os pacientes com hepatite C, pacientes com hepatite autoimune e pacientes com colangite biliar primária sem cirrose hepática tiveram desempenho significativamente pior que os controles no aprendizado de palavras, mas não pacientes com hepatite B. O reconhecimento de figuras se mostrou alterado somente nos pacientes com infecção por HCV e não nos outros grupos. Pacientes com hepatite $C$ também tiveram pior desempenho que controles e pacientes com Hepatite $\mathrm{B}$ quanto à atenção e memória de trabalho. Os autores concluíram que o perfil neuropsiquiátrico de pacientes com hepatite $\mathrm{C}$ é similar ao dos pacientes com hepatite autoimune $\mathrm{e}$ dos com colangite biliar primária, mas difere do perfil de pacientes com HBV, sugerindo uma resposta autoimune como uma causa possível para essas diferenças.

Em 2002, Forton et al. utilizaram bateria computadorizada de testes neuropsicológicos e verificaram que a concentração/atenção e a velocidade psicomotora foram os principais domínios prejudicados nos pacientes com infecção crônica por HCV. Não houve diferenças estatísticas entre os indivíduos com e sem histórico de uso de drogas recreativas. Embora os pacientes com hepatite $\mathrm{C}$ tivessem níveis mais elevados de depressão e tenham relatado 
prejuízos na qualidade de vida, essas variáveis não se correlacionaram com os escores dos testes cognitivos.

O padrão de disfunção cognitiva observado nos pacientes com hepatite C nos estudos realizados por vários autores compreendem déficits de atenção, velocidade de processamento, memória de trabalho e funções executivas que, segundo Perry et al., 2008, em conjunto, sugerem que existam alterações frontais subcorticais que remetem às encontradas nos pacientes com infecção por HIV.

Cordoba et al., 2003, avaliaram 120 pacientes com hepatite C (40 com hepatite C sem cirrose, 40 com cirrose compensada (sem descompensações prévias) e 40 com cirrose (com descompensações prévias) não verificaram alterações nos testes cognitivos de pacientes com hepatite $C$ sem cirrose e nos pacientes com cirrose compensada.

Soogoor et al., 2006, também não puderam observar diferenças significativas entre pacientes hemofílicos com cepatite $\mathrm{C}$ e pacientes HCVnegativos. Os autores relatam que inesperadamente todos os escores de quociente intelectual foram significativamente maiores no grupo com hepatite $\mathrm{C}$ que no grupo não infectado. No Vocabulário de Wechsler o grupo não infectado pontuou menos que o grupo monoinfectado por $\mathrm{HCV}$ e que indivíduos coinfectados com HIV/HCV. Todos os testes foram prospectivamente avaliados pelo neuropsicólogo do estudo para validação. Após controlar múltiplos fatores que poderiam interferir na análise, os autores concluíram que a monoinfecção por HCV não foi associada com déficits no comportamento adaptativo, inteligência, atenção ou concentração. 
Abrantes et al., 2013, não verificaram nenhuma diferença estatística significativa entre pacientes e controles em seu estudo em qualquer dos testes realizados. Os autores utilizaram extensa bateria de testes neuropsicológicos e critérios muito rigorosos na seleção dos pacientes excluindo pacientes em uso de qualquer medicamento psicotrópico, história de uso e drogas, etilismo e depressão, entre outros.

McAndrews et al., 2005, verificaram alterações metabólicas cerebrais nos pacientes com hepatite $\mathrm{C}$ em sua investigação (aumento de colina e redução de NAA na substância branca cerebral) e uma tendência de associação entre os níveis de NAA e eficiência de memória, mas só puderam observar que, em relação aos controles, o grupo com infecção por HCV demonstrou somente uma eficiência de aprendizado marginalmente pior, usando bateria de testes de 10 medidas cognitivas. Apenas 13\% dos pacientes demonstraram nível clínico de comprometimento de aprendizagem.

A variação de resultados entre os diversos estudos, é mais provavelmente devida ao uso de diferentes testes neuropsicológicos para os vários domínios em cada estudo, pelo menos parcialmente. O MEEM usado em nosso estudo tem uma sensibilidade menor para o comprometimento cognitivo e avalia menos domínios em comparação com as detalhadas baterias de testes neuropsicológicos utilizados nos outros estudos.

Em alguns estudos, como os de Hilsabeck et al., 2002, e de Fontana et al., 2005, a proporção de pacientes cirróticos foi de $51 \%$ e $38 \%$, respectivamente. Em nossa casuística o percentual de pacientes com graus elevados de fibrose 
hepática (F3 e F4) foi de $14,3 \%$ e se aproxima do verificado na coorte de Mapoure et al., 2018, que foi de 17\%.

No presente estudo os escores obtidos no MEEM tiveram correlação negativa com a idade, o que é demonstrado em vários estudos (Butler et al., 1996; Callahan et al., 1996; Jacqmin-Gadda et al., 1997) e também com os escores obtidos no BDI e na BHS, o que está de acordo com a literatura que mostra que os pacientes com sintomas depressivos têm maior possibilidade de apresentarem algum transtorno de cognição (McDermott e Ebmeir, 2009; Klimkeit et al., 2011; Snyder, 2012).

A correlação positiva dos escores obtidos no MEEM com o grau de escolaridade está em concordância com vários estudos (Uhlmann e Larson, 1991; Bertolucci et al., 1994; Lourenço e Veras, 2006). Também foi verificada correlação do MEEM com o TDR, como foi verificado por vários autores (Juby et al., 2002; Tombaugh e Mclntyre, 1992; Mendez et al., 1992; Royall et al., 1998; Shulman, 2000; Fuzikawa et al., 2003; Yang et al., 2016). Os escores obtidos no MEEM mostraram correlação positiva significante com a FV semântica, o que foi relatado em outros estudos (Montiel et al., 2014).

Nos nossos pacientes não pudemos observar alteração em relação aos controles nos testes subtestes de atenção e cálculo do MEEM e no teste dos Díg OD e Díg OI, o que está em concordância com Abrantes et al., 2013, e com Soogoor et al., 2006.

O grau de fibrose se correlacionou com a idade, presença de neuropatia periférica $(p<0,05)$ e grau de inflamação hepática biópsia. A correlação com a 
presença de NP provavelmente se deve ao fato de pacientes com neuropatia periférica também terem idades mais avançadas. Tanto o grau de fibrose, quanto a presença de neuropatia tiveram correlação significante com a idade.

Houve correlação do grau de fibrose com o teste dos dígitos em OD. Isto provavelmente se deve ao fato de pacientes com graus mais elevados de fibrose terem comprometimento da atenção básica, talvez por EHM.

Mesmo utilizando testes simples usados de maneira rotineira na prática diária pudemos verificar que existe diferença significativa na memória de evocação entre pacientes e controles. Esta diferença não pode ser explicada por depressão, nível de escolaridade, idade dos pacientes, ou presença de comorbidades como DM, dado estas variáveis não terem sido diferentes entre os grupos.

A análise dos escores obtidos no MEEM mostrou que mais pacientes que controles têm escores $\leq 23$ pontos. Dos 18 pacientes com escores aquém dos esperados para seu grau de escolaridade 11 tinham escores $\leq 23$ pontos enquanto entre os 12 controles com escores de MEEM mais baixos que os esperados para seu grau de escolaridade somente três obtiveram 23 pontos ou menos. Usando como nível de corte o escore de 23 pontos, a diferença entre pacientes e controles passa a ter significância estatística. Essa diferença não pode ser explicada pela idade, dado que a média de idade dos pacientes com baixos escores no MEEM ( $\leq 23$ pontos) foi de 54,2 anos e a mediana de 50 anos, muito menores do que a média de idade dos controles que obtiveram 23 pontos ou menos, de 67,7 anos e mediana de 69 anos. A média de escolaridade dos pacientes com escores de MEEM $\leq 23$ foi de 4,91 anos e a mediana de 4 anos; 
no grupo controle a média foi de 3,3 anos e a mediana de 4 anos. No grupo dos pacientes história de etilismo e uso de drogas ilícitas não mostrou correlação com os escores obtidos no MEEM, o que mostra que a presença de infecção crônica por HCV pode ser responsabilizada pelos prejuízos à cognição e que a detecção destes prejuízos depende do nível de corte adotado para análise.

Não houve diferença entre os pacientes portadores de HCV com escores $\leq 23$ e aqueles com escores >23 no MEEM em relação ao gênero, idade, grau de depressão, grau de fibrose à biópsia hepática, presença de CGs ou genótipos. Entretanto o grau de escolaridade e ME foram mostraram diferenças significativas.

O uso de drogas recreativas intravenosas e dependência de álcool são comorbidades extremamente comuns e observadas em até $70 \%$ e $30 \%$ dos pacientes com HCV, respectivamente nos EUA (Rosenbloom et al., 2005; ElSerag et al., 2002). Estas comorbidades, por sua vez, também poderiam ser associadas ao comprometimento cognitivo.

Em 2002, Forton et al. compararam um grupo de pacientes com HCV com infecção ativa, um grupo com fatores de risco para HCV, mas RNA - HCV negativo, e uma população de pacientes com HCV que foram tratados com sucesso e eliminaram o vírus, mas com condições pré-mórbidas correspondentes. O grupo infectado pelo HCV mostrou maior comprometimento em mais testes neuropsicológicos do que o grupo HCV-clareado; estes achados foram independentes de história de uso de drogas intravenosas, relatada por $50 \%$ dos pacientes. 
Kramer et al., 2002, compararam um grupo de pacientes com HCV com consumo mínimo de álcool com um grupo com consumo moderado a grave de álcool e não encontraram efeito da história do uso de álcool sobre o comprometimento cognitivo associado ao HCV.

Em nosso estudo $30,6 \%$ (22/72) pacientes fizeram uso de drogas recreativas, 4 utilizaram somente drogas injetáveis $(5,6 \%), 12(16,7 \%)$ somente drogas inaláveis e $6(8,3 \%)$ utilizaram ambos.

Não encontramos diferenças significativas na proporção de pacientes com sintomas depressivos entre os pacientes que haviam feito uso de drogas recreativas em relação aos que não relataram uso de drogas. Pudemos verificar que os escores no BAI mostraram correlação com história de alcoolismo. Não observamos diferenças entre os etilistas e não etilistas com relação à presença de depressão. Tanto o uso de drogas anterior, quanto história de etilismo não influenciaram os resultados dos testes cognitivos. Portanto, não podemos atribuir os resultados no MEEM a estes fatores.

Trinta e três pacientes $(43,4 \%)$ dos pacientes perderam pontos na ME, porém, a comparação da memória de evocação entre os pacientes com graus baixos (grau zero ou 1) de fibrose hepática com os pacientes com graus moderados ou altos (graus 2, 3 ou 4) não mostrou significância estatística. Entretanto, dos 11 pacientes com pontuação $\leq 23$ no MEEM seis $(54,5 \%)$ apresentavam graus moderados ou altos de fibrose hepática. Neste subgrupo de pacientes, não podemos descartar que o baixo desempenho no MEEM possa ser devido a EHM. 
No teste de FV semântica não foram observadas diferenças entre pacientes e controles quando se utilizou os pontos de corte habituais (12 para indivíduos escolarizados e 9 para analfabetos), entretanto, algum grau de alteração da fluência verbal semântica os doentes com hepatite $C$ apresentam, dado que, com nível de corte de 25 citações ou mais, existe diferença entre os pacientes e controles, porém não aparente clinicamente. Seria bastante interessante estudar a conectividade das redes neurais frontotemporais esquerdas em pacientes com infecção crônica por hepatite C. Não dispomos ainda de nenhum estudo nesta área.

Os déficits cognitivos de pacientes com hepatite $C$ sem sinais de encefalopatia, mesmo quando com graus avançados de fibrose, são bastante sutis. Não podemos descartar a possibilidade de que a diferença na memória de evocação entre pacientes e controles possa ser devida a EHM. Para tanto, haveria necessidade de outros testes que são sugeridos para se afastar EHM e dosagem do nível de amônia no sangue.

Está bem estabelecido que o comprometimento cognitivo é frequentemente detectado em pacientes com cirrose, mesmo na ausência de EH clínica e é denominado encefalopatia mínima (Ferenci et al., 2002; Mattarozzi et al., 2004; Giménez-Garzó et al., 2017; Ridola et al., 2018). A EHM é detectada em pacientes clinicamente assintomáticos através de testes psicométricos e métodos neurofisiológicos apropriados. Podem ser detectados déficits de orientação visuoespacial, transtornos da atenção, alteração de memória, tempo de reação, velocidade de processamento da informação, alteração da percepção visual, habilidades visuoconstrutivas, deficiência nas habilidades motoras finas 
e coordenação, enquanto a inteligência geral e a linguagem são preservadas, além de alentecimento do EEG e prolongamento da latência de potenciais evocados cognitivos (Ferenci et al., 2002; Weissenborn et al., 2003; Ridola et al., 2018).

A EHM é clinicamente relevante por afetar a qualidade de vida, o desempenho no trabalho e a capacidade de dirigir, além de ser um fator de risco de quedas e de encefalopatia hepática franca em pacientes com doença hepática crônica (Groeneweg et al., 2000; Stinton e Jayakumar, 2013; Ridola et al., 2018).

A transição entre os estágios de doença hepática e o comprometimento cognitivo é gradual e a demarcação exata do início da EHM é difícil (Ridola et al., 2018).

Matarozzi e colaboradores encontraram também alterações da memória verbal e visual imediata nos pacientes com cirrose hepática com EHM.

A caracterização do comprometimento cognitivo em pacientes com hepatite $\mathrm{C}$ mesmo sem cirrose hepática tem sido assunto de vários estudos. Defeitos na recordação verbal e memória de trabalho foram encontradas em um terço dos pacientes portadores de infecção por HCV, incluindo indivíduos com fibrose avançada do fígado e história de abuso de álcool e / ou abuso de drogas intravenosas, como no estudo de Fontana et al., 2005. Em contraste com relatos anteriores, o desempenho cognitivo não foi afetado pelo grau de fibrose.

No estudo de Karaivazoglu et al., 2007, um grupo de pacientes com hepatite $\mathrm{C}$ outro com hepatite $\mathrm{B}$ foram estudados em comparação com controles 
saudáveis. No grupo com hepatite B $20,7 \%$ dos pacientes tinha cirrose bem compensada, enquanto no grupo com hepatite $\mathrm{C}$ havia $21,9 \%$ com cirrose compensada, isto é, sem sinais clínicos de EH franca. Os pacientes com com hepatite $\mathrm{C}$ tiveram desempenho significativamente pior do que controles saudáveis no aprendizado verbal e memória. No entanto, os pacientes com hepatite $C$ e hepatite $B$ não foram estatisticamente diferentes com relação à função cognitiva, sugerindo que as anormalidades observadas não são específicas para o HCV. No estudo foram excluídos pacientes com depressão, o que também pode ter afetado os resultados.

Como foi verificado por Giménez-Garzó et al., 2017, doentes com cirrose hepática de diversas etiologias que não apresentam EHM na Escala Psicométrica de Encefalopatia Hepática (Psychometric Hepatic Encephalopathy Score) - EPEH - ou seja, doentes classificados como "sem EHM" já têm algumas alterações neurológicas que não são detectadas por esta escala, considerada “padrão-ouro” para EHM. Giménez-Garzó et al., 2017, mostraram que a EPEH não tem sensibilidade suficiente para detectar alterações neurológicas precoces numa proporção de pacientes cirróticos. Usando bateria de 12 testes neuropsicológicos verificaram que pacientes "sem" EHM já apresentavam déficits em um número significativo de testes. Cerca de $40 \%$ dos pacientes "sem EHM" pela EPEH mostraram alteração em pelo menos 2 dos 12 testes. Os pacientes com EHM apresentam déficits em muitos dos testes e $50 \%$ deles tiveram desempenho alterado em pelo menos sete testes. Testes de associação símbolos-dígitos, D2 (que avalia atenção seletiva/sustentada e concentração mental), teste de coordenação bimanual e visuomotores são mais sensíveis do 
que a EPEH segundo estes autores, que também mostraram que diferentes grupos de pacientes têm dificuldades em conjuntos definidos de testes e concluem que as primeiras alterações neurológicas são diferentes em diferentes pacientes (Giménez-Garzó et al., 2017).

García-García et al., 2018, verificaram que pacientes cirróticos (de variadas etiologias) tanto com EHM quanto "sem EHM" apresentaram pior desempenho em comparação com os controles nos testes de aprendizado verbal e memória de evocação. Pacientes com EHM apresentaram prejuízos na aprendizagem, memória tardia e reconhecimento, em comparação com pacientes com cirrose sem EHM e com os controles.

Segundo Blank et al., 2016, os vírus RNA de fita única, ligantes de RNA de fita dupla e os Interferons tipo 1 compartilham uma via inflamatória que leva à ativação da cadeia 1 do receptor de Interferon nas células endoteliais e epiteliais cerebrais. Utilizando o perfil genético, identificaram que o comportamento do ligante de quimiocina derivado do endotélio (CXCL10) mediou mudanças comportamentais por comprometimento da plasticidade sináptica, causando comportamento depressivo e disfunção cognitiva.

A indução de CXCL10 em células endoteliais microvasculares do cérebro humano pela infecção pelo HCV foi demonstrada por Liu et al., 2011. Wilkinson et al., 2010, também verificaram aumento da transcrição de IL-8, fator quimiotático de linfócito (IL-16) e de CXCL10 nas amostras cerebrais pacientes com hepatite C. Assim, é possível que os sintomas neuropsiquiátricos em pacientes com infecção por HCV sejam relacionados com a ativação da via da 
cadeia do receptor do Interferon 1 conduzindo à regulação positiva da expressão de CXCL10 e alteração da plasticidade sináptica.

García-García et al., 2018, verificaram que pacientes com cirrose hepática de variadas etiologias com e sem EHM mostraram níveis aumentados de IL6 e IL18 no soro, GMP cíclico no plasma e níveis sanguíneos de amônia, comparados com os controles.

Vários estudos apoiam a ideia de uma interação entre a hiperamonemia e inflamação nas alterações neurológicas na EHM (Montoliu et al., 2009; Felipo et al., 2012; García-García et al., 2018). A hiperamonemia induz a neuroinflamação, que desempenha um papel importante no comprometimento neurológico na EHM. Além disso, os níveis séricos de citocinas pró-inflamatórias, IL-6 e a IL-18 correlacionam-se com a presença de EHM (Montoliu et al., 2009).

Nos pacientes cirróticos "sem" EHM a combinação de níveis aumentados de amônia e IL-18 poderia contribuir para um baixo desempenho na memória de evocação, segundo os resultados obtidos por García-García et al., 2018.

Weissenborn et al., 2003, mostraram que mesmo os pacientes com grau zero de $\mathrm{EH}$ tiveram pontuação mais baixa que os controles na maioria dos subtestes da EPEH, embora os resultados estivessem dentro da faixa normal. Resultados anormais foram observados especialmente em relação à memória imediata dos itens apresentados visualmente. Concluíram que o desempenho da memória em pacientes com EH precoce pode ser devido a déficits de atenção que interferem na codificação do material a ser memorizado. 
O processo de atenção é uma função básica que interfere na execução de outros altos processos cognitivos, como codificação e armazenamento de memória de longo prazo. O processo de controle cognitivo e processos atencionais são suportados por redes neurais como o Default Mode Network (rede de modo padrão), a rede de saliência (cíngulo dorsal anterior e córtex frontoinsular orbital) com conectividade robusta com estruturas subcorticais e límbicas envolvido na detecção e filtragem de estímulos salientes e no recrutamento de redes funcionais relevantes e a rede frontoparietal esquerda (rede relacionada à linguagem e cognição) [Sridharan et al., 2008]. A rede de modo padrão conecta o córtex cingulado posterior, pré-cuneus, região frontal medial e parietal inferior e algumas regiões do giro temporal médio e exibe alto nível de atividade neuronal durante o repouso (van den Heuvel e Hulshoff Pol, 2010). Acredita-se que a rede de modo padrão exerça um importante papel na memória episódica, consolidação de memórias e em processos que exigem introspecção (Raichle et al., 2001; Uddin et al., 2011). Estudo de Sestieri et al., 2011, mostrou que a recuperação da memória (memória de evocação) ativa regiões nodais posteriores da rede de modo padrão, particularmente o giro angular, mas também regiões parietais mais anteriores e dorsais. Seus resultados sugerem que as regiões parietais da rede de modo padrão suportam diretamente a recuperação da memória, enquanto que as regiões parietais que não fazem parte da rede de modo padrão (mais anteriores e dorsais) estão mais envolvidas em processos pós-recuperação, como a tomada de decisão baseada em memória. $\mathrm{O}$ giro angular e o cíngulo posterior/pré-cuneus são significativamente ativados durante a recuperação da memória. 
Estudos com RM funcional em pacientes com hepatite $\mathrm{C}$ com vistas ao entendimento da interferência da infecção nos processos cognitivos são necessários e poderão elucidar muitas dúvidas que existem em relação às alterações neuropsiquiátricas nos portadores de infecção por HCV e devem ajudar a definir a relação de mudanças de conectividade com a atividade inflamatória do cérebro.

Até o momento foram publicados dois estudos usando RM funcional. Um estudo realizado por McCready et al., 2018, mostrou que os pacientes com hepatite $\mathrm{C}$ exibem menor ativação no giro occipital lateral esquerdo, pré-cuneus e giro frontal superior que controles saudáveis quando da realização de tarefa de recompensa adiada, mostrando uma alteração no controle de impulsos.

Kharabian Masouleh et al., 2017, testaram a hipótese de que a infecção crônica pelo HCV está associada ao volume de substância cinzenta e a alterações de conectividade funcional comparativamente a controles pareados saudáveis. Testes foram utilizados para avaliar fadiga, depressão e desempenho cognitivo. O estágio de fibrose hepática e carga viral foram quantificados nos pacientes. Em comparação com os controles, os pacientes positivos para HCV tiveram escores mais altos de fadiga e depressão e piores escores de atenção. Os grupos tiveram um desempenho similar em outros domínios cognitivos. Os autores relataram maior atividade em uma região no lóbulo parietal anterosuperior direito nos pacientes, enquanto que diferenças no volume da substância cinzenta não foram encontradas. A análise de conectividade funcional post hoc mostrou maior conectividade dessa região com o córtex somatossensitivo primário e secundário, lobos temporais e occipitais nos 
pacientes. A maior média de atividade no grupo parietal superior foi associada com melhor desempenho de memória e atenção, mas não com fadiga, depressão, carga viral ou nível de fibrose hepática nos s pacientes. Os autores concluíram que os resultados sugerem um mecanismo compensatório na hepatite $\mathrm{C}$ crônica e explicam resultados equívocos na literatura sobre déficits cognitivos em pessoas infectadas.

García-García et al., 2018, verificaram que pacientes cirróticos (tanto com EHM, quanto sem EHM) apresentaram redução do volume da fímbria do hipocampo em comparação aos controles. Volumes maiores nos subcampos do hipocampo foram relacionados a um melhor desempenho da memória em pacientes com cirrose sem EHM e controles. Em comparação com os controles estudados, os pacientes com EHM tinham menor conectividade funcional do présubiculum e pré-cuneus bilateralmente, que se correlacionaram com comprometimento cognitivo e alteração de memória (García-García et al., 2018).

A Espectroscopia por RM de Próton Único (ERM-1H) fornece informação sobre o metabolismo cerebral e foi utilizada para testar a hipótese de que um mecanismo biológico fundamenta a disfunção neuropsicológica relatada na infecção por HCV. Neste sentido existem evidências de que alteração da neurotransmissão monoaminérgica pode ocorrer e contribuir para a fisipatologia da disfunção cerebral associada ao vírus da hepatite $\mathrm{C}$, provenientes de estudos que mostraram elevações significativas na colina cerebral e redução de NAA em pacientes infectados pelo HCV sem cirrose (Forton et al., 2002, Weissenborn et al., 2004; McAndrews et al., 2005; García-García et al., 2018). Estes achados coincidem com os relatados na infecção pelo HIV (Meyerhoff et al., 1999). A 
colina é um osmólito que funciona como um marcador de síntese de membranas neuronais e renovação celular. Aumento de colina é consistente com proliferação glial e lesão de membranas celulares (Yarlott et al., 2017).

A detecção de intermediários replicativos de HCV (RNA de cadeia negativa) no SNC e diferentes variantes virais no SNC, fígado e soro suporta o conceito de replicação do HCV no cérebro. Embora os comprometimentos cognitivos leves observados na infecção pelo HCV não sejam progressivos, como na demência associada ao HIV, foi sugerido que possam resultar da ativação imune cerebral, possivelmente como resultado da infecção do SNC pelo HCV (Forton et al., 2002).

Resultados de estudos de SPECT cerebral (Beta-CIT-SPECT) de Weissenborn et al., 2006, implicam alterações na neurotransmissão monoaminérgica na fisiopatologia da disfunção cerebral associada ao HCV. Os pacientes demonstraram reduções significativas da ligação do transportador de serotonina (SERT) no hipotálamo e mesencéfalo e do transportador de dopamina (DAT) no estriatum. A redução anormal da ligação de SERT e DAT foi evidente em $50-60 \%$ dos casos expostos ao $\mathrm{HCV}$, incluindo 4 pacientes com anti-HCV positivo e PCR-HCV negativo. Não houve correlações entre os dados de SPECT e fadiga, humor ou QVRS. Entretanto, os pacientes com ligação aletarda de DAT ou de DAT e SERT tiveram pior desempenho nos testes cognitivos em comparação com controles saudáveis e pacientes infectados pelo HCV com SPECT cerebrais normais.

Várias citocinas pró-inflamatórias parecem ser ativadas na infecção crônica pelo HCV (Zampino et al., 2013). Verificou-se que os macrófagos 
hepáticos produzem concentrações elevadas de IL-1 $\beta$ no fígado infectado com HCV. Em culturas in vitro de hepatócitos e células hepáticas em estrela infectadas pelo HCV, a IL-1 $1 \beta$ secretada pelas células em estrela mostrou induzir a produção de várias citocinas pró-inflamatórias e quimiocinas, tais como IL-6, IL-8 e proteínas inflamatórias de macrófagos (MIP-1 $\alpha$ e MIP-1ß), por hepatócitos (Nishitsuji et al., 2013).

É possível que a disfunção neurológica relacionada ao HCV esteja também relacionada aos efeitos das citocinas inflamatórias circulantes e das quimiocinas que chegam ao cérebro através da barreira hematoencefálica alterada (Monaco et al., 2012). Evidências de um papel direto das citocinas próinflamatórias periféricas na determinação do comprometimento da função cognitiva foram obtidas de modelos animais. Especificamente aumentos de IL-1 e IL-6 periféricas parecem se correlacionar com o aumento dos níveis das mesmas citocinas no córtex pré-frontal e hipocampo (Palin et al., 2007). No cérebro o HCV parece também ser capaz de induzir uma resposta inflamatória local, uma vez que os macrófagos infectados in vitro com o HCV são capazes de produzir fator de necrose tumoral-a e IL-8 (Senzolo et al., 2011; Zampino et al., 2013).

Em síntese, os sintomas relativos à disfunção do SNC estão presentes apenas em uma proporção de indivíduos com infecção pelo HCV. Em outros, é uma condição verdadeiramente assintomática. É provável que esses sintomas resultem de uma interação complexa entre fatores genéticos virais e do hospedeiro e eventos estressores externos. 
Este estudo tem várias limitações, como a ausência de estudos eletrofisiológicos e de biópsia de nervos periféricos $\mathrm{O}$ tamanho relativamente pequeno dos grupos limita o poder estatístico do estudo. Os examinadores estavam cientes do estado sorológico dos participantes. Os participantes com histórico de uso de álcool e drogas não foram excluídos, embora não tenhamos encontrado diferenças entre os que tinham e não tinham história de abuso de álcool e drogas ilícitas nos escores do inventário de Beck e na avaliação cognitiva.

Os testes utilizados para a triagem cognitiva, muito úteis na prática clínica, carecem da sensibilidade das baterias neuropsicológicas mais completas e isso pode levar a uma subestimação do ônus real sobre a cognição representada pela infecção crônica pelo HCV. No entanto, o MEEM é uma ferramenta muito útil para o clínico e seu subteste para a memória de longo prazo, por mais simples que seja, mostrou diferença estatística entre pacientes e controles.

O grupo controle foi composto principalmente por familiares, cônjuges ou parentes de pacientes não portadores de HCV da mesma instituição. Este fato pode ser positivo pois os participantes têm antecedentes sociais semelhantes, o que pode explicar a falta de diferença entre os grupos em relação aos escores do Inventário de Beck, ao menos em parte.

Um aspecto positivo deste estudo reside no fato de que os pacientes e controles foram avaliados pela mesma neurologista e pelo mesmo psicólogo e acrescenta alguns dados para a compreensão do ônus da infecção pelo vírus da hepatite $\mathrm{C}$ nos pacientes em nosso país. 


\section{Conclusões}

O estudo caso-controle realizado mostrou que os pacientes portadores de infecção por HCV apresentam NP clinicamente diagnosticada em percentual significantemente maior que controles não portadores de HCV. As MNM constituíram a forma mais frequente de envolvimento dos nervos periféricos nos pacientes com hepatite C.

As NP encontradas no grupo controle eram mais frequentemente neuropatias compressivas do nervo mediano, radiculopatias e PNP associadas a DM.

Queixas de parestesias e dores foram muito frequentes nos pacientes com hepatite $\mathrm{C}$.

A pesquisa de CGs foi positiva em $9,2 \%$ dos pacientes em que foi realizada, quatro dos quais apresentavam NP. A presença de CGs correlacionou-se positivamente com o índice HOMA e com a queixa de cansaço.

Intolerância à glicose foi verificada em $22,4 \%$ dos pacientes portadores de HCV. No total, 27,6\% dos pacientes mostraram alteração no metabolismo da glicose. Não houve diferença na prevalência de DM entre os grupos. 
Os autoanticorpos detectados em percentuais expressivos dos pacientes foram o antimúsculo liso, antitireoperoxidase, IgM anticardiolipinas, antitireoglobulina, antitirosina fosfatase e antirreceptor de TSH.

A positividade de anticorpos antitirosina fosfatase e Anti-SS-A/RO no soro de pacientes com hepatite C com NP mostrou diferença estatística significante em relação aos pacientes com hepatite C que não apresentavam sinais clínicos de NP.

A presença de NP se correlacionou com a idade, alteração do metabolismo da glicose, nível sérico de gamaglobulinas e grau de fibrose à biópsia hepática, mas não com a presença de CGs.

Nenhuma correlação foi encontrada entre genótipos do HCV e outras variáveis clínicas ou laboratoriais estudadas.

Graus mais elevados de fibrose à biópsia hepática no estudo anatomopatológico do fígado dos pacientes com infecção crônica por HCV se correlacionaram com a idade, presença de NP, alteração no metabolismo da glicose, grau de inflamação hepática ao estudo anatomopatológico, queixas de parestesias, dores, dormência, fraqueza e com os escores obtidos no teste Díg OD.

Os escores dos testes utilizados para avaliação cognitiva (MEEM, FV semântica, TDR e testes dos dígitos em ordem direta e indireta) não mostraram diferenças estatísticas entre os pacientes e o grupo controle. 
A análise dos componentes do MEEM mostrou que pacientes com hepatite C têm diferença significativa em relação aos controles na tarefa de memória de evocação.

Mais pacientes que controles obtiveram escores de 23 pontos ou menos no MEEM.

A comparação de pacientes com MEEM com escores $\leq 23$ com os demais mostrou diferença significativa no grau de escolaridade e na memória de evocação. Mais da metade dos pacientes com escores de 23 pontos ou menos no MEEM apresentavam graus moderados ou altos de fibrose hepática. Neste subgrupo de pacientes, não podemos descartar que EHM seja responsável pelo prejuízo à cognição.

Não encontramos diferenças entre pacientes e controles em relação a sintomas depressivos, de ansiedade ou de desesperança, mesmo não tendo excluído pacientes com história de etilismo ou uso de drogas ilícitas.

História de etilismo se correlacionou somente com os escores no Inventário de Ansiedade de Beck, com o gênero (gênero masculino relatando mais etilismo) e com história de uso de drogas ilícitas. Correlações do histórico de uso de drogas recreativas foram verificadas com o gênero (gênero masculino relatando mais uso de drogas) e história de etilismo. 


\section{Anexos}

Anexo A - Termo de Consentimento Livre e Esclarecido

HOSPITAL DAS CLÍNICAS DA FACULDADE DE MEDICINA DA UNIVERSIDADE DE SÃO PAULO-HCFMUSP

MODELO DE TERMO DE CONSENTIMENTO LIVRE E ESCLARECIDO

DADOS DE IDENTIFICAÇÃO DO SUJEITO DA PESQUISA OU RESPONSÁVEL LEGAL

1. NOME:

DOCUMENTO DE IDENTIDADE No : SEXO :.$M \square F \square$

DATA NASCIMENTO:

ENDEREÇO № APTO:

BAIRRO CIDADE

CEP: TELEFONE: DDD

)

2.RESPONSÁVEL LEGAL

NATUREZA

(grau

de

parentesco

tutor,

curador

etc.)

DOCUMENTO DE IDENTIDADE

DATA NASCIMENTO.: .....................

ENDEREÇO:

BAIRRO:

CEP:

№

CIDADE

TELEFONE:DDD

SEXO: $M \square F \square$

\section{DADOS SOBRE A PESQUISA}

1. TÍTULO DO PROTOCOLO DE PESQUISA: MANIFESTAÇÕES

NEUROLÓGICAS DO VÍRUS DA HEPATITE C

PESQUISADOR : : IDA FORTINI

CARGO/FUNÇÃO: Médica Neurologista do HCFMUSP......... INSCRIÇÃO CONSELHO REGIONAL № 41611

UNIDADE DO HCFMUSP: DEPARTAMENTO DE NEUROLOGIA DO HC DA FMUSP

3. AVALIAÇÃO DO RISCO DA PESQUISA:

RISCO MÍNIMO X RISCO MÉDIO

RISCO BAIXO RISCO MAIOR

4.DURAÇÃO DA PESQUISA: 24 MESES.

HOSPITAL DAS CLÍNICAS DA FACULDADE DE MEDICINA DA UNIVERSIDADE DE SÃO PAULO-HCFMUSP

Essas informações estão sendo fornecidas para sua participação voluntária neste estudo. Algumas pesquisas realizadas em outros países sugerem que 0 vírus da Hepatite $\mathrm{C}$, além de causar doença no fígado, pode causar também 
doenças na pele, nos rins, no sistema nervoso e nas articulações. O estudo "Manifestações Neurológicas do Vírus da Hepatite C", visa verificar se você tem alguma alteração do sistema nervoso causada por esse vírus.

Aceitando participar, o senhor ou a senhora será entrevistado, através de um questionário. Nesse questionário haverá perguntas sobre as formas de transmissão do vírus da Hepatite $\mathrm{C}$, sobre doenças que o (a) senhor (a) já teve e também sobre algum problema de saúde que possa ter no momento. $O$ (a) senhor (a) é livre para responder ou não às perguntas; sinta-se à vontade para "pular" algumas perguntas que não queira responder.

O (a) senhor(a) será entrevistado pelo neurologista que lhe fará algumas perguntas e o examinará (exame neurológico clínico) e fará alguns testes simples de memória e de atenção. Depois o (a) senhor (a) responderá a um questionário para que possamos verificar se você tem algum grau de depressão, desesperança ou ansiedade.

Se necessário, será solicitada eletroneuromiografia (exame de função dos nervos), eletroencefalograma e ressonância magnética da cabeça (também se for necessário).

O estudo ajudará a entendermos melhor esta doença e nos ajudará a verificar quais alterações é necessário estarmos atentos para buscar, a fim de podermos tratar.

Neste estudo o (a) senhor (a) não tomará nenhuma droga em estudo. Não existe risco, porque o (a) senhor (a) será somente examinado e fará alguns exames clínicos, que não trazem nenhum risco para a sua saúde.

Somente no final do estudo poderemos concluir pela presença de algum benefício, modificando a forma de atendimento dos futuros pacientes com Hepatite C. No momento, o benefício direto para o participante será o tratamento dos sintomas de alterações no sistema nervoso e o acompanhamento com o neurologista, não só durante o período de realização do estudo, mas enquanto este acompanhamento for necessário.

Em qualquer etapa do estudo, o (a) senhor (a) terá acesso aos profissionais responsáveis pela pesquisa para esclarecimento de eventuais dúvidas. $O$ principal investigador é a Dra Ida Fortini, que pode ser encontrada na Clínica Neurológica do Hospital das Clínicas da Faculdade de Medicina da USP localizada à Av. Dr. Enéas Carvalho de Aguiar no 255, 5ํandar, Cerqueira César. Telefone: 22616401 . Se você tiver alguma consideração ou dúvida sobre a ética da pesquisa, entre em contato com o Comitê de Ética em Pesquisa (CEP) - Rua Ovídio Pires de Campos, 225 - 5ํandar - tel: 2261-6442 ramais 16, 17, 18 ou 20,

FAX: 2261-6442 ramal 26 - E-mail: cappesq@hcnet.usp.br

As informações obtidas serão analisadas em conjunto com outros pacientes, não sendo divulgada a identificação de nenhum paciente. $O$ (a) senhor (a) poderá desistir da pesquisa a qualquer momento e o seu atendimento não será prejudicado, caso desista de sua participação.

Os resultados da pesquisa estarão à disposição, caso tenha interesse em conhecer os resultados desse estudo. Não haverá despesas pessoas para o participante em qualquer fase do estudo, incluindo exames e consultas. Também 
não haverá compensação financeira relacionada à sua participação neste estudo.

\section{HOSPITAL DAS CLÍNICAS DA FACULDADE DE MEDICINA DA UNIVERSIDADE DE SÃO PAULO-HCFMUSP}

Acredito ter sido suficientemente informado a respeito das informações que li ou que foram lidas para mim, descrevendo o estudo. MANIFESTAÇÕES NEUROLÓGICAS DO Vírus DA HEPATITE C.

Eu discuti com a Dra Ida Fortini sobre a minha decisão em participar nesse estudo. Ficaram claros para mim quais são os propósitos do estudo, os procedimentos a serem realizados, seus desconfortos e riscos, as garantias de confidencialidade e de esclarecimentos permanentes. Ficou claro também que minha participação é isenta de despesas e que tenho garantia do acesso a tratamento hospitalar quando necessário. Concordo voluntariamente em participar deste estudo e poderei retirar o meu consentimento a qualquer momento, antes ou durante o mesmo, sem penalidades ou prejuízo ou perda de qualquer benefício que eu possa ter adquirido, ou no meu atendimento neste Serviço.

Assinatura do paciente/representante legal

Data

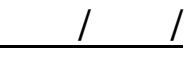

Assinatura da testemunha

Data (para casos de pacientes menores de 18 anos, analfabetos, semi-analfabetos ou portadores de deficiência auditiva ou visual).

(Somente para o responsável do projeto)

Declaro que obtive de forma apropriada e voluntária o Consentimento Livre e Esclarecido deste paciente ou representante legal para a participação neste estudo.

Assinatura do responsável pelo estudo Data $1 \quad 1$ 


\title{
Anexo B - Parecer da Comissão de Ética em Pesquisa do HCFMUSP
}

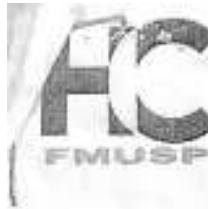

\author{
Hospital das Clínicas da FMUSP
}

Comissăo de Ética para Análise de Projetos de Pesquisa - CAPPesq

\section{PROJETO DE PESQUISA}

Titulo: MANIFESTAÇŐES NEUROLÓGICAS DO VIRUS DA HEPATITE C Pesquisador Responsável: Prof.Dr. Ricardo Nitrini

Versảo: 2

Pesquisador Executante: Ida Fortini

CAAE: 21543913.0 .0000 .0068

Instituiça: HCFMUSP

Departamento: NEUROLOGIA

\section{PARECER CONSUBSTANCIADO DO CEP}

Registro on-line: 11373

Número do Parecer: 535.317

Data da Relatoria: $19 / 02 / 2014$

Apresentaçăo do Projeto: A nova versăo do projeto atende às exigências desta Comissằ.

Objetivo da Pesquisa: Estudo tem objetivo acadêmico (doutorado da pesquisadora executante) Identificar e quantificar alteraçøes da funçăo nervosa periférica e central associadas à infecção pelo virus da hepatite $\mathrm{C}$ nos pacientes virgens de tratamento, sem sinais de encefaiopatia hepática que procuram o Hospital das Clinicas da FMUSP. A avaliaçăo neurológica inciuirá evidẻncia/histórico de quadros de ansiedade, depressäo e desesperança nos pacientes com infeço pelo HCV e será felta comparativamente a controles sem infeçăo pelo HCV, A correlaçăo das possiveis alteraçరెes neurológicas, cognitivas e psicológicas com carga viral e com a presença de autoanticorpos também será avaliada.

Avaliação dos Riscos e Beneficios: Risco mínimo referindo-se à punçăo venosa para coleta de amostra de sangue para análise laboratorial.

Comentários e Consideraçōes sobre a Pesquisa: Os pesquisadores reescreveram o texto original conforme solicitado por esta Comissão. Na seção Métodos, a avaliaçâo neurológica foi descrita mais detalhadamente bem como foi estabelecido o painel de auto anticorpos a serem pesquisados. No entanto, não foram mencionadas as informaçø̋es solicitadas previamente: - as unidades do Complexo HCFMUSP envolvidas nas avaliaçס̄es laboratoriais e exames de imagem bem como năo foi incluida a anuência das mesmas quanto à sua participaçăo no projeto;

- o delineamento do cronograma de atividades

os recursos financeiros para a execuçăo do projeto tambèm nāo foram mencionados.

Consideraçöes sobre os Termos de apresentação obrigatória: TCLE adequado.

Recomendaçōes: Nesta nova versão, ainda-năo foram incluidas as unidades do Complexo HCFMUSP envolvidas nas avaliaçōes laboratoriais/exames de imagem, a anuêncla das mesmas, - delineamento do cronograma de atividades e os recursos financeiros para a execuçăo do projeto.

Rua Dr, Ovidio Pires de Campos, 225 - Prédio da Administraçăo - $5^{2}$ andar CEP 05403-010 - São Paulo - SP.

$55112661-7585$ - 5511 2661- 6442 ramais: $16,17,18$ | marcia.carvalho@hc.fm.usp.br 


\section{Hospital das Clínicas da FMUSP}

Comissão de Ética para Análise de Projetos de Pesquisa - CAPPesq

Conclusōes ou Pendências e Lista de Inadequaçōes: Os pesquisadores procederam as alteraç̄es no texto do projeto conforme solicitado embora haja algumas pendências que esta Comissăo entende que nåo năo devem comprometer sua viabilizaçäo.

\section{Situaçiolo do Parecer: Aprovado}

Necessita Apreciaçăo da CONEP: Nă

Consideraçōes Finais a critério do CEP: Em conformidade com a Resoluçăo CNS n² 466/12 cabe ao pesquisador: a) desenvolver o projeto conforme delineado; b) elaborar e apresentar relatórios parciais e final; c)apresentar dados solicitados pelo CEP, a qualquer momento; d) manter em arquivo sob sua guarda, por 5 anos da pesquisa, contendo fichas individuais $e$ todos os demais documentos recomendados pelo CEP; e) encaminhar os resultados para publicaçăo, com os devidos créditos aos pesquisadores associados e ao pessoal técnico participante do projeto; $f$ ) justificar perante ao CEP interrupçăo do projeto ou a nåo publicação dos resultados.

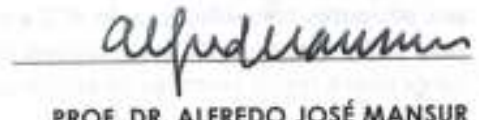

PROF, DR. ALFREDO JOSÉ MANSUR Coordenador

Comissāo de Ética para Análise de Projetos de Pesquisa - CAPPesq

Rua Dr. Ovidio Pires de Campos, 225 - Prédio da Administraçăo - $5^{2}$ andar

$$
\text { CEP 05403-010 - Săo Paulo - SP. }
$$

$55112661-7585-55112661-6442$ ramais: $16,17,18$ | marcia.carvalho@enc.fm, usp.br 
Anexo C - Mini Exame do Estado Mental

Orientação Temporal - questões 1a até 1e

Orientação Espacial - questões 2a até 2e, pontuando 1 para cada item correto da resposta, máximo de 10 pontos.

Registros - questão 3; pontuação máxima de 3 pontos.

Atenção e cálculo - questão 4; pontuação máxima 5 pontos.

Lembrança ou memória de evocação - questão; pontuação máxima 3 pontos.

Linguagem - questões 6 até 10; pontuação máxima 9 pontos.

\section{Identificação do Paciente}

Nome:

Data de nascimento/idade: Sexo:

Escolaridade: Analfabeto ( ); 1 a 4 anos ( ); 5 a 8 anos ( ); 9 a 11 anos (); 12 anos ou mais ( )

Avaliação em: Avaliador:

\section{1- Orientação Temporal}

a- Qual é o (a) Dia da semana?_1

b- Dia do mês? 1

c- Mês? 1

d- Ano? 1

e- Hora aproximada? 1

2- Orientação Espacial - Onde estamos?

a- Local? 1

b- Instituição (casa, rua)?_1

c- Bairro? 1

d- Cidade? 1

e- Estado?_1

\section{Registros}

3. Mencione 3 palavras levando 1 segundo para cada uma. Peça ao paciente para repetir as 3 palavras que você mencionou. Estabeleça um ponto para cada resposta correta.

-Vaso, carro, tijolo. 3

4. Atenção e cálculo

Sete seriado $(100-7=93-7=86-7=79-7=72-7=65)$.

Estabeleça um ponto para cada resposta correta. Interrompa a cada cinco respostas. Ou soletrar a palavra MUNDO de trás para frente. 5

\section{Lembranças (memória de evocação)}

Pergunte o nome das 3 palavras aprendidos na questão 2. Estabeleça um ponto para cada resposta correta. 3

\section{Linguagem}

5. Aponte para um lápis e um relógio. Faça o paciente dizer o nome desses objetos conforme você os aponta. 2 
6. Faça o paciente. Repetir "nem aqui, nem ali, nem lá". 1

7. Faça o paciente seguir o comando de 3 estágios. "Pegue o papel com a mão direita. Dobre o papel ao meio. Coloque o papel na mesa". 3

8. Faça o paciente ler e obedecer ao seguinte: FECHE OS OLHOS. 1

9. Faça o paciente escrever uma frase de sua própria autoria. (A frase deve conter um sujeito e um objeto e fazer sentido).

(Ignore erros de ortografia ao marcar o ponto) 1

10. Copie o desenho abaixo.

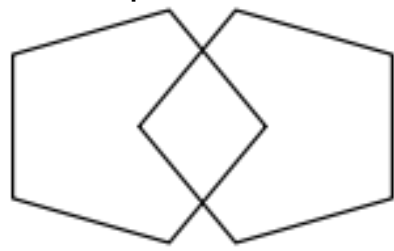

Estabeleça um ponto se todos os lados e ângulos forem preservados e se os lados da intersecção formarem um quadrilátero. 1

\section{AVALIAÇÃO do escore obtido: TOTAL DE PONTOS OBTIDOS}

Pontos de corte - MEEM segundo Brucki et al. (2003)

20 pontos para analfabetos

25 pontos para idosos com um a quatro anos de estudo

26 pontos para idosos com cinco a oito anos de estudo

28 pontos para aqueles com 9 a 11 anos de estudo

29 pontos para aqueles com mais de 11 anos de estudo. 
Anexo D - Teste do Desenho do Relógio

Neste estudo, fornecemos o desenho de um círculo e solicitamos ao paciente que desenhasse os números e colocasse os ponteiros marcando nove horas e vinte minutos. As instruções eram repetidas nos casos de dúvida. Segundo o método de pontuação de Sunderland (1989), os escores atribuídos podem variar de 1 a 10. Abaixo reproduzimos 0 método de pontuação.

Teste do Desenho do Relógio: pontuação de Sunderland et al., 1989. Escore 1: não houve iniciativa ou não conseguiu. $O$ desenho não é interpretável.

Escore 2: o desenho indica que a solicitação foi de certa forma compreendida, mas o resultado tem pouca semelhança com um relógio. Escore 3: distorção na numeração, faltam números ou estes estão fora do mostrador ou os ponteiros estão ausentes. Escore 4: os números estão faltando ou colocados fora dos limites do relógio.

Escore 5: a numeração foi colocada em ordem inversa ou concentrada em alguma parte do relógio.

Escore 6: interpretação errada da solicitação de desenho dos ponteiros (desenho de "relógio digital", indicar as horas colocando círculos nos números, etc.)

Escore 7: os ponteiros estão em posição alterada, porém são compreensíveis; hora errada, mas números corretos.

Escore 8: existem pequenos erros no tamanho e posição dos ponteiros.

Escore 9: há pequeno erro no tamanho dos ponteiros, porém a posição está certa e a hora correta.

Escore 10: desenho correto.

Sunderland et al. (1989) consideram o valor 6 como o ponto de corte ideal (para uma escala de 10 pontos) na condição de comando.

Considera-se um desempenho normal quando a pontuação é de 9 ou 10; uma pontuação menor do que 7 (sete) denota anormalidade e pontuações entre 6 e 8 como suspeitas de anormalidade.

\section{Teste do Desenho do Relógio: método de pontuação de Shulman (2000).}

No método de avaliação de Shulman et al. (1993), a pontuação pode variar de zero a 5 pontos, com um ponto de corte igual a 3 . Os critérios para atribuição dos escores são os seguintes:

Escore 5: atribuído ao relógio perfeito, tolerando-se pequenos desvios de posicionamento e espaçamento dos números.

Escore 4: desenho do relógio com erros menores, mas com a hora marcada corretamente e números com impressão geral de um relógio.

Escore 3: correspondeu a uma representação incorreta da hora, mas com organização visuoespacial adequada.

Escore 2: correspondeu a um relógio com desorganização visuoespacial moderada dos números, de modo que não havia representação precisa da hora.

Escore 1 foi atribuído ao nível grave de desorganização visuoespacial. 
Escore 0: foi dado quando houve incapacidade de fazer qualquer representação razoável de um relógio ou quando o indivíduo se recusou a fazer uma tentativa.

Os pacientes que obtiveram escores menor ou igual a 3 foram considerados portadores de déficit cognitivo. 
Anexo E - Teste da Fluência Verbal Categoria Semântica (animais)

Para o teste de FV semântica, solicita-se ao paciente que fale o maior número de palavras de acordo com uma determinada categoria que, neste estudo foi nomes de animais, em um minuto. A pontuação é feita contando-se o número de nomes de animais citados pelo paciente, não sendo consideradas as repetições (Brucki et al., 1997; Montiel et al., 2014). 
Anexo F - Teste dos Dígitos em Ordem Direta e Indireta

No teste de Dígitos o examinador lê em voz alta uma sequência de números. Para cada item de Dígitos na OD, o examinado repete os números na mesma ordem em que foram falados.

Para cada item de Dígitos na Ol, o sujeito repete os números que the foram apresentados na ordem inversa. Cada item apresenta duas tentativas, com sequencias diferentes, e cada tentativa apresenta 0 mesmo número de dígitos. Tanto na ordem direta quanto na inversa, a aplicação é suspensa após o fracasso nas duas tentativas do mesmo item. 


\section{Anexos G - Inventário de Depressão de Beck (BDI)}

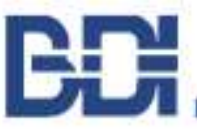

Data:

\begin{tabular}{|c|c|c|}
\hline Nome: & Estado Civil & Idade: \\
\hline Ocupaç̧̄o: & Escolaridade & \\
\hline
\end{tabular}

Este questionairio consiste em 21 grupos de afimmaçồes. Depois de ler cuidadosamente cada grupo, faça um circulo em tomo do nùmero $(0,1,2$ ou 3$)$ próximo à afirmaçào, em cada gnupo, que descreve melhor a maneira que você tem se sentido na ultima semana, incluindo hoje. Se várias afirmações num grupo porecercen se aplicar igualnente bent, faça um circulo en cada uma. Tome o cuidado de ler todas as afirmaçeses, em cada grupo, antes de fazer a sua escolha.

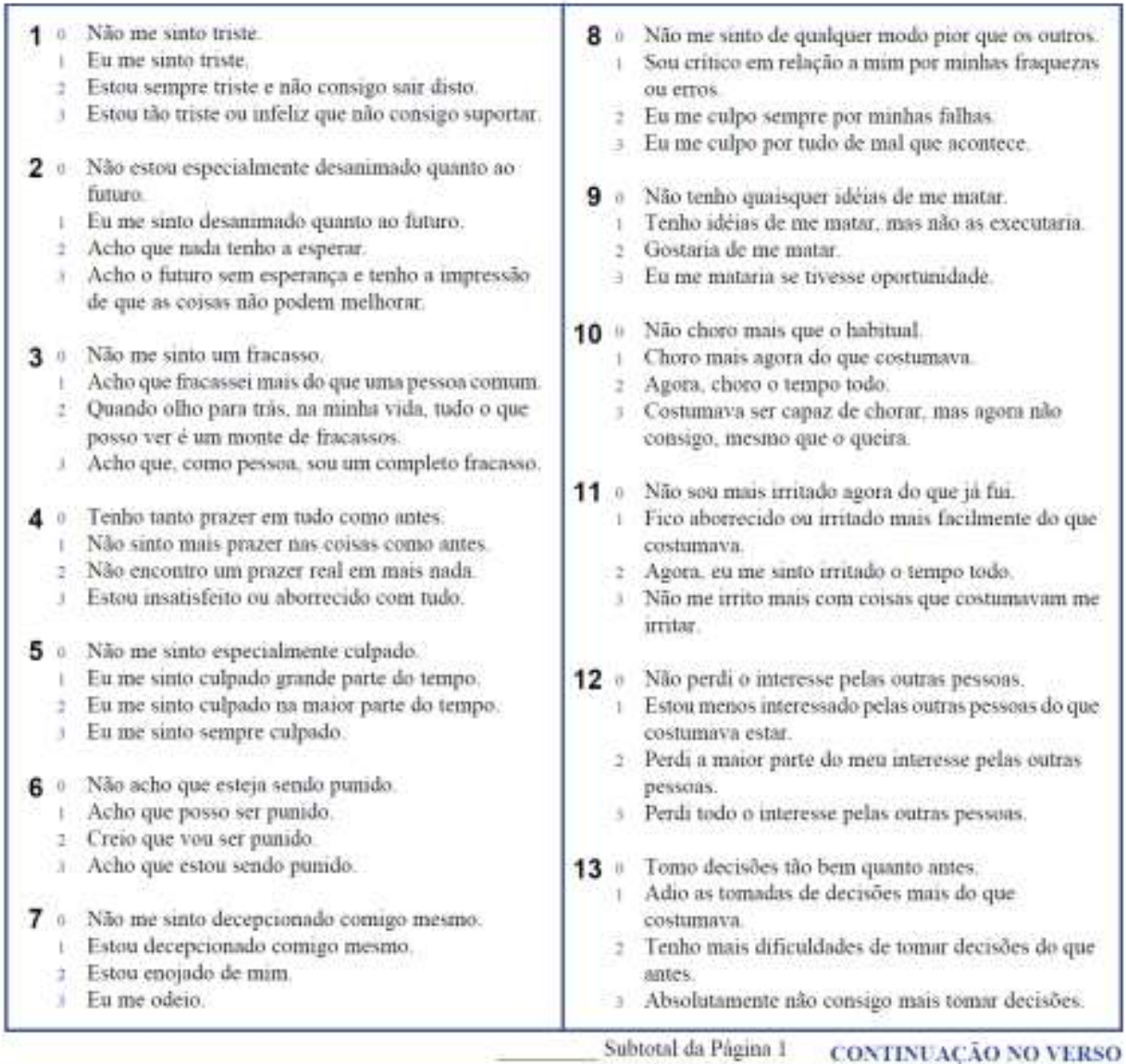

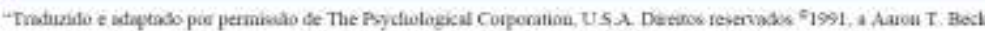

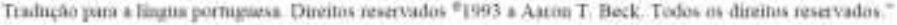

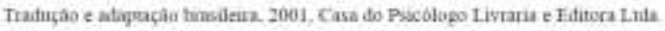

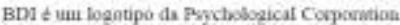


14 Não acho que de qualquer modo pareço pior do que antes.

1 Estou preocupido em estar parecendo velho ou sem atrativo.

2. Acho quue há mudanças permanentes na minha aparencia, que me fazem parecer sem atrativo.

3 Acredito que pareço feio.

15 . Posso trabalhar tâo bem quanto antes

1 E preciso algum esforço extra para fazer alguma coisa.

2 Tenho que me esforçar muito para fazer alguma coisa

3. Na๊o consigo mats fazer qualquer trabalho

16 - Consigo dormir tào bem como o habitual. Não durmo th้o bem como costumava.

2 Acordo 1 a 2 horas mais cedo do que habitualmente e acho dificil voltar a dormir.

3 Acordo várias boras mais cedo do que costumava e nẩo consigo voltar a dormir

17 Nầo fico mais cansado do que o habitual.

Fico cansado mais facilmente do que costumava

2 Fico cansado em fazer qualquer coisa.

Estou cansado demais para fazer qualquer coisa.

180 O meu apetite nầ estấ pior do que o habitual Meu apetite naño é tào bom como costumava set Meu apetite é muito pior agora.

Absolutamente nito tenho mais apetite
19 Nào tenho perdido muito peso se é que perdi algum recentemente

Perdi mais do que 2 quilos e meio

Perdi mais do que 5 quilos.

3 Perdi mais do que 7 quilos.

Estou tentando perder peso de propósito. comendo menos Sim Nầ

20 Nẫo estou mais preocupado com a minha saúde do que o habitual.

Estou preocupado com problemas fisicos, tais como dores, indisposiç̧ื้ do estổmago ou constipaçio

2 Estou muito preocupado com problemas físicos e é dificil pensar em outra coisa.

3 Estou tầ preocupado com meus problemas físicos que nẫo consigo pensar em qualquer outra coisa.

21 . Nảo notei qualquer mudança recente no meu interesse por sexo

1 Estou menos interessado por sexo do que costumava

2 Estou muito menos interessado por sexo agora

Perdi completamente o interesse por sexo.

O paciente marca a declaração mais aplicável a si mesmo em cada item. A pontuação para cada item varia de 0 a 3 e a pontuação total pode variar de 0 a 62. A somatória dos pontos em cada item determina o escore total. Consideram-se:

05 a 09: pacientes sem depressão ou com depressão mínima;

10 a 18: depressão leve a moderada; isto é, o paciente apresenta alguns sintomas depressivos, mas sem interferência com o trabalho ou a sociedade.

19 a 29: depressão moderada a grave. O paciente tem sintomas que interferem levemente no trabalho ou na vida social.

30 a 63: depressão grave. O paciente tem ideação suicida ou os sintomas que apresenta interferem intensamente com o trabalho ou a vida social e podem determinar a total incapacidade de trabalhar. 


\section{Anexo H - Inventário de Ansiedade de Beck (BAI)}

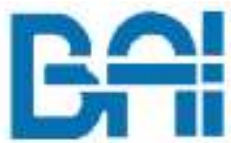

Data:

Nome:

Estado Civil:

Idade:

Sexo:

Ocupação:

Escolaridade:

Abaixo está uma lista de sintomas comuns de ansiedade. Por favor, leia cuidadosamente cada item da lista. Identifique o quanto vocẻ tem sido incomodado por cada sintoma durante a última semana, incluindo hoje, colocando um " $\mathrm{x}$ " no espaço correspondente, na mesma linha de cada sintoma.

\begin{tabular}{|c|c|c|c|c|}
\hline & $\begin{array}{l}\text { Absoluta- } \\
\text { mente não }\end{array}$ & $\begin{array}{l}\text { Levemente } \\
\text { Nio me inice- } \\
\text { bioder muito }\end{array}$ & $\begin{array}{l}\text { Moderada- } \\
\text { mente } \\
\text { Foi maito desagri- } \\
\text { divel mas pude } \\
\text { auperar }\end{array}$ & $\begin{array}{l}\text { Gravemente } \\
\text { Dificilmente poude } \\
\text { sapostar }\end{array}$ \\
\hline \multicolumn{5}{|l|}{ 1. Dormència ou formigamento. } \\
\hline \multicolumn{5}{|l|}{ 2. Sensação de calor. } \\
\hline \multicolumn{5}{|l|}{ 3. Tremores nas pernas. } \\
\hline \multicolumn{5}{|l|}{ 4. Incapaz de relaxar. } \\
\hline \multicolumn{5}{|l|}{ 5. Medo que aconteça o pior. } \\
\hline \multicolumn{5}{|l|}{ 6. Atordoado ou tonto. } \\
\hline \multicolumn{5}{|c|}{ 7. Palpitação ou aceleraçâo do coração. } \\
\hline \multicolumn{5}{|l|}{ 8. Sem equilibrio. } \\
\hline \multicolumn{5}{|l|}{ 9. Aterrorizado. } \\
\hline \multicolumn{5}{|l|}{ 10. Nervoso. } \\
\hline \multicolumn{5}{|l|}{ 11. Sensação de sufocação. } \\
\hline \multicolumn{5}{|l|}{ 12. Tremores nas màos. } \\
\hline \multicolumn{5}{|l|}{ 13. Trềmulo. } \\
\hline \multicolumn{5}{|l|}{ 14. Médo de perder o controle. } \\
\hline \multicolumn{5}{|l|}{ 15. Dificuldade de respirar. } \\
\hline \multicolumn{5}{|l|}{ 16. Medo de morrer. } \\
\hline \multicolumn{5}{|l|}{ 17. Assustado. } \\
\hline \multicolumn{5}{|c|}{ 18. Indigestão ou desconforto no abdömen. } \\
\hline \multicolumn{5}{|l|}{ 19. Sensaçảo de desmaio. } \\
\hline \multicolumn{5}{|l|}{ 20. Rosto afogueado. } \\
\hline 21. Suor (não devido ao calor). & & & & \\
\hline
\end{tabular}

O paciente assinala o quanto cada um dos sintomas o incomodou no último mês, marcando 0 se o sintoma não o incomodou nenhum um 
pouco; 1 se o incomodou levemente (não incomodou muito); 2 se incomodou moderadamente e 3 se o incomodou muito.

A pontuação total é calculada encontrando a soma dos 21 itens e pode variar de 0 a 63. Considera-se:

0 a 21: baixo grau de ansiedade;

22 a 35: ansiedade moderada;

36 ou mais: ansiedade grave, preocupante. 


\section{Anexo I - Escala de Desesperança de Beck (BHS)}

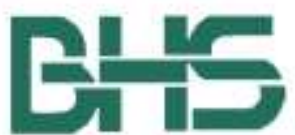

Data:

\begin{tabular}{|c|c|c|}
\hline Nome: & Estado Civil: & Idade: $\quad$ Sexo: \\
\hline Ocupaçầ: & Escolaridade: & \\
\hline
\end{tabular}

Este questionário consiste em 20 afirmaçỏes. Por favor, leia as afirmaçỏes cuidadosamente, uma por uma. Se a afirmaçào descreve a sua atitude na última semana, incluindo hoje, escureça o circulo com " $\mathrm{C}$ ", indicando CERTO na mesma linha da afirmação. Se a afirmaçào nào descreve a sua atitude, escureça o circulo com " $E$ ", indicando ERRADO, na mesma linha da afirmação. Por favor, procure ler cuidadosamente cada afirmação.

1. Penso no futuro com esperança e entusiasmo.

(C) E

2. Seria melhor desistir, porque nada há que eu possa fazer para tomar as coisas melhores para mim. assim para sempre.

4. Não consigo imaginar que espécie de vida serả a minha em dez anos.

5. Tenho tempo suficiente para realizar as coisas que quero fazer.

6. No futuro, eu espero ter sucesso no que mais me interessa.

7. Meu futuro me parece negro.

8. Acontece que tenho uma sorte especial e espero conseguir mais coisas boas da vida do que uma pessoa comum.

9. Simplesmente nào consigo aproveitar as oportunidades e nåo há razào para que consiga, no futuro.

10. Minhas experiências passadas me prepararam bem para o futuro.

11. Tudo o que posso ver à minha frente é mais desprazer do que prazer.

12. Não espero conseguir o que realmente quero.

13. Quando penso no futuro, espero ser mais feliz do que sou agora.

14. As coisas simplesmente não se resolvem da mineira que eu quero.

15. Tenho uma grande fé no futuro.

16. Nunca consigo o que quero. Assim, é tolice querer qualquer coisa.

17. É pouco provável que eu vả obter qualquer satisfação real, no futuro.

18. O futuro me parece vago e incerto.

19. Posso esperar mais tempos bons do que maus.

20. Não adianta tentar realmente obter algo que quero, porque provavelmente nảo vou conseguir. 
como "correto" e 1 (hum) para cada afirmação assinalada como "errado". O intervalo de pontuação é de 0 a 20. O escore total é a soma da pontuação de cada item. O grau de desesperança é classificado em nível mínimo (0 a 4 pontos), leve (5 a 8 pontos), moderado (9 a 13 pontos) e grave (14 a 20 pontos). 
Anexo $\mathbf{J}$ - Exames laboratoriais realizados pelos pacientes no Laboratório

\section{Central do HCFMUSP}

Ácido úrico (método enzimático colorimétrico automatizado);

Alanina amino transferase (método cinético automatizado);

Aldolase (método cinético automatizado);

Alfafetoproteína (método eletroquimioluminescência);

Amilase (método cinético automatizado);

Amônia (método cinético automatizado);

Aspartato amino transferase (método cinético automatizado);

Bilirrubina total (método colorimétrico automatizado);

Bilirrubina direta (método colorimétrico automatizado);

Bilirrubina indireta (método colorimétrico automatizado);

Capacidade total de ligação de Ferro (método colorimétrico automatizado);

Ceruloplasmina (método nefelometria);

Colesterol (método enzimático colorimétrico automatizado);

Alanina amino transferase (método cinético automatizado);

Creatino fosfoquinase (método cinético automatizado);

Creatinina (método colorimétrico cinético);

Desidrogenase láctica (método cinético automatizado);

Eletroforese de proteínas (método semi-quantitativo de separação eletroforética em Agarose $\mathrm{pH}$ alcalino);

Fator V (método Owren modificado);

Ferritina (método eletroquimioluminescência);

Fosfatase alcalina (método cinético automatizado);

Fósforo (método enzimático colorimétrico automatizado), cálcio total (método colorimétrico automatizado), ferro sérico (método colorimétrico automatizado);

Fração C3 do complemento (método imunoturbidimétrico);

Fração C4 do complemento (método imunoturbidimétrico);

Gama glutamil transferase (método cinético automatizado);

Glicemia (hexoquinase);

HDL colesterol (método enzimático colorimétrico automatizado);

Hemograma completo (método automatizado, microscopia, coloração panóptica);

Hemoglobina glicada [método HPLC (CLAE) - certificado por NGSP-EUA

(National Glyco Hemoglobin Standardization Program);

LDL colesterol (método cinético automatizado);

Lipase (método enzimático colorimétrico automatizado);

Peptídeo C (método eletroquimioluminescência MO);

Plaquetas (método automatizado, fônio);

Potássio (método eletrodo íon seletivo);

Proteína $\mathrm{C}$ reativa (método imunoturbidimétrico);

Sódio (método eletrodo íon seletivo);

Tempo de protrombina (método Quick modificado);

Tempo de trombina (método Jim modificado);

Tempo de tromboplastina parcial ativada (método Proctor e Rapaport modificado); 
Transferrina (método imunoturbimétrico);

Triglicérides (método enzimático colorimétrico automatizado);

Ureia (método cinético automatizado);

VLDL colesterol (método enzimático colorimétrico automatizado);

Anticorpo anti-célula parietal: pesquisa (método imunofluorescência indireta);

Anticorpo anti-mitocôndria: pesquisa (método imunofluorescência indireta);

Anticorpos anti-cardiolipina IgM: dosagem (método ELISA);

Anticorpos anti-cardiolipina IgG: dosagem (método ELISA);

Anticorpos anti-DNA nativo (anti-DNA de fita dupla): dosagem (método ELISA);

Anticorpo anti-microssoma de fígado e rim [anti-LKM-1]: pesquisa (método imunofluorescência indireta);

Anticorpo anti-músculo-liso: pesquisa (método imunofluorescência indireta);

Anticorpos anti-SS-A/RO (método ELISA);

Anticorpos anti-SS-B/LA (método ELISA);

Fator anti-núcleo / FAN HEP2 (método imunofluorescência indireta);

Fator reumatóide (método nefelometria);

Anticorpos anti-citoplasma de neutrófilos [ANCA] (método imunofluorescência indireta);

Anticorpos anti-RNP/SM: pesquisa (método ELISA);

Anticorpos anti-SM: pesquisa (método ELISA);

Anticorpos anti-JO1 (anti-histidil T-RNA sintetase): pesquisa (método ELISA);

Anticorpos anti-SCL 70 (anti-topaisomerase I): pesquisa (método ELISA);

Antígeno carcinoembriogênico [CEA] (método eletroquimioluminescência);

Hepatite A - anticorpos totais (método quimioluninescência);

Hepatite A - anticorpos IgM (método quimioluninescência);

Hepatite B-anti-HBS (método eletroquimioluminescência);

Hepatite B-anti-HBc total (método Abbott - Axsym - MEIA - Semi-Quantitativo Automatizado);

Hepatite B-HBSAg - Eletroquimioluminescência;

Anticorpos anti-HIV 1/2 (método Vitros - Quimioluminescência Amplificada

(Imunométrica) Semi-Quantitativo Automatizado);

Anticorpos anti-HTLV $1 / 2$ - pesquisa (método imunoenzimático);

Sorologia para Treponema pallidum (método imunoenzimático);

VDRL (método floculação).

Genotipagem para o vírus da Hepatite C (método HCV VERSANT® - LiPA)

Genotipagem para o vírus da Hepatite C (método Abbott RealTime HCV genotype II): paciente 1, 3, 10

Detecção qualitativa de RNA do HCV por PCR no soro (método reação de Polimerização em Cadeia ([PCR] - COBAS AMPLICOR® v2.0 - Roche)

Detecção qualitativa de RNA do HCV por Reação de Polimerização em Cadeia (PCR) (Roche Diagnostics)

Na urina foram realizados os seguintes exames: porfirinas urinárias / urina de 24 horas (método HPLC (CLAE) - Certificado por NGSP-EUA - National Glyco Hemoglobin Standardization Program).

$\mathrm{O}$ índice HOMA foi calculado segundo a fórmula: insulinemia de jejum $(\mu \mathrm{U} / \mathrm{mL})$ X glicemia de jejum (mmol/L) / 22,5 (Matthews et al, 1985; Wallace e Matthews, 2002). 
Anexo K - Exames realizados pelo Laboratório de Hormônios e Genética Molecular da Disciplina de Endocrinologia da FMUSP

Insulina (método eletroquimioluminescência $\mathrm{MO}$ );

Anticorpo anti-receptor de TSH - TRAb (método eletroquimioluminescência); Anticorpo anti-descarboxilase do ácido glutâmico - GAD (método radioimunoensaio $\mathrm{RSR}$ );

Anticorpos anti-peroxidase tireoidiana - anti-TPO (método fluoroimunoensaio indireto Wallac AutoDELFIA);

Anticorpo anti-tireoglobulina (fluoroimunoensaio indireto $A D$ );

Globulina ligadora dos hormônios sexuais [SHBG] (método imunofluorométrico AD);

Hormônio tireoestimulante (método imunofluorométrico $A D$ );

Triiodotironina (método imunofluorométrico $A D$ );

Tiroxina livre (método imunofluorométrico $A D$ ). 
Anexo L - Tabela de equivalência entre os sistemas de classificação do grau de fibrose hepática e de inflamação da SBP e a classificação METAVIR

Approximate equivalence of the most widely used classification systems for the staging and scoring of chronic hepatite s

\begin{tabular}{|c|c|c|}
\hline \multicolumn{3}{|c|}{ Architectural Alteration (Fibrosis)* } \\
\hline SBP, 2000 & METAVIR, 199 & Ishak, 1995 \\
\hline 0 & 0 & 0 \\
\hline 1 & 1 & 1 or 2 \\
\hline 2 & 2 & 3 \\
\hline 3 & 3 & 4 or 5 \\
\hline 4 & 4 & 6 \\
\hline \multicolumn{3}{|c|}{ Inflammatory Activity** } \\
\hline \multicolumn{2}{|c|}{ SBP, 2000 and Ishak, 1995} & METAVIR, 1994 \\
\hline Parenchymal activity & $\begin{array}{c}\text { Periportal activity } \\
\text { A }\end{array}$ & \\
\hline 0 or 1 & 0 & 0 \\
\hline 0 or 1 & 1 or 2 & 1 \\
\hline 2 & $0-1$ & 1 \\
\hline 2 & 2 & 2 \\
\hline 2 & $3-4$ & 3 \\
\hline 3 & $0-2$ & 2 \\
\hline 3 & $3-4$ & 3 \\
\hline 4 & $0-4$ & 3 \\
\hline
\end{tabular}

$\mathrm{SBP}=$ Sociedade Brasileira de Patologia (SBP. Brazilian Society of Pathology), "Maximum Ishak score, 6; maximum METAVIR score, 4; maximum SBP score, 4. **Corresponds to periportal and parenchymal activity, independently, for SBP and Ishak, and mixed periportal and lobular for METAVIR: in the METAVIR classification, the activity score reaches 3, whereas in Ishak and SBP it reaches 4.

Mello EV, Ferreira Alves VA. Chronic Hepatitis C: Pathological Anatomy. In Consensus of the Brazilian Society of Infectious Diseases on the Management and Treatment of Hepatitis C. Braz J Infect Dis. 2007; 11(5) Suppl. 1:32-6. 
Anexo M - Avaliações e testes realizados pelos indivíduos do grupo controle

Glicemia de jejum

Hepatite B-anti-HBS (método eletroquimioluminescência);

Hepatite B-anti-HBc total (método Abbott - Axsym - MEIA - Semi-Quantitativo Automatizado);

Hepatite B-HBSAg - Eletroquimioluminescência;

Anticorpos anti-HIV 1/2 (método Vitros - Quimioluminescência Amplificada (Imunométrica) Semi-Quantitativo Automatizado);

Sorologia para Treponema pallidum (método imunoenzimático);

VDRL (método floculação). 


\section{Referências}

Abdelkader NA, Zaky DZ, Afifi H, Saad WE, Shalaby SI, Mansour MA. Neuropathies in hepatitis C-related liver cirrhosis. Indian J Gastroenterol. 2014;33(6):554-9.

Abrantes J, Torres DS, de Mello CE. Patients with hepatitis C infection and normal liver function: an evaluation of cognitive function. Postgrad Med $\mathrm{J}$. 2013;89:433-9.

Adinolfi LE, Utili R, Attanasio V, Zampino R, Ragone E, Tripodi MF, et al. Epidemiology, clinical spectrum and prognostic value of mixed cryoglobulinaemia in hepatitis C virus patients: a prospective study [abstract]. Ital $J$ Gastroenterol.1996;28(1):1-9.

Adinolfi LE, Zampino R, Restivo L, Lonardo A, Guerrera B, Marrone A, et al. Chronic hepatitis $\mathrm{C}$ virus infection and atherosclerosis: clinical impact and mechanisms. World J Gastroenterol. 2014;20:3410-7.

Adinolfi LE, Nevola R, Lus G, Restivo L, Guerrera B, Marrone A, et al. Chronic hepatitis $C$ virus infection and neurological and psychiatric disorders: an overview. World J Gastroenterol. 2015;21:2269-80.

Agnello V, Chung RT, Kaplan LM. A role for hepatitis C virus infection in type II cryoglobulinemia. N Engl J Med. 1992; 327:1490-5.

Agnello V. The aetiology of mixed cryoglobulinaemia associated with hepatitis $\mathrm{C}$ virus infection. Scandinavian J Immunol. 1995;42(2):179-84.

Agnello V, Abél G, Elfahal M, Knight GB, Zhang QX. Hepatitis C virus and other flaviviridae viruses enter cells via low density lipoprotein receptor. Proc Natl Acad Sci USA. 1999;96:12766-71.

Aktipi KM, Ravaglia S, Ceroni M, Nemni R, Debiaggi M, Bastianello S, et al. Severe recurrent myelitis in patients with hepatitis $C$ virus infection. Neurology. 2007;68:468-9.

Alaei M, Negro F. Hepatitis $C$ virus and glucose and lipid metabolism. Diabetes Metab. 2008;34(6 Pt 2):692-700.

Allison ME, Wreghitt T, Palmer CR, Alexander GJ. Evidence for a link between hepatitis $C$ virus infection and diabetes mellitus in a cirrhotic population. $J$ Hepatol. 1994;21:1135-9.

Allison RD, Conry-Cantilena C, Kozion D, Schechterly C, Ness P, Gibble J, et al. A 25-year study of the clinical and histologic outcomes of hepatitis $C$ virus 
infection and its modes of transmission in a cohort of initially asymptomatic blood donors. J Infect Dis. 2012;206:654-61.

Al-Soud AA, ELlehleh A, El-Kapany R, El-Hagary H. Study of peripheral neuropathy in chronic hepatitis C virus infected patients. J Am Sci. 2011;7(4)2828.

Alter HJ, Seeff LB. Recovery, persistence, and sequelae in hepatitis $C$ virus infection: a perspective on long-term outcome. Semin Liver Dis. 2000;20(1):1735.

Alter MJ, Margolis HS, Krawczynski K, Judson FN, Mares A, Alexander WJ, et al. The natural history of community-acquired hepatitis $C$ in the United States. The Sentinel Counties Chronic non-A, non-B Hepatitis Study Team. N Engl J Med. 1992. 31;327(27):1899-905.

Amaku M, Burattini MN, Coutinho FAB, Lopez LF, Mesquita F, Naveira MCM, et al. Estimating the Size of the HCV Infection Prevalence: A Modeling Approach Using the Incidence of Cases Reported to an Official Notification System. Bull Math Biol. 2016;78(5):970-90.

Ammendola A, Sampaolo S, Ambrosone L, Ammendola E, Ciccone G, Migliaresi $S$, et al. Peripheral neuropathy in hepatitis-related mixed cryoglobulinemia: electrophysiologic follow-up study. Muscle Nerve. 2005; 31:382-5.

Ammendola A, Sampaolo S, Migliaresi S, Ambrosone L, Ammendola E, Ciccone $\mathrm{G}$, et al. Autonomic neuropathy in mixed cryoglobulinemia. $J$ Neurol. 2007;254(2):215-9.

Antonelli A, Ferri C, Pampana A, Fallahi P, Nesti C, Pasquini M, et al. Ferrannini E. Thyroid disorders in chronic hepatitis C. Am J Med. 2004;117:10-13.

Antonelli A, Ferri C, Fallahi P, Pampana A, Ferrari SM, Goglia F, et al. Hepatitis $C$ virus infection: evidence for an association with type 2 diabetes. Diabetes Care. 2005;28:2548-50.

Antonelli A, Ferri C, Ferrari SM, Ghiri E, Goglia F, Pampana A, et al. Serum Levels of Proinflammatory Cytokines Interleukin-1 $\beta$, Interleukin-6, and Tumor Necrosis Factor $\alpha$ in Mixed Cryoglobulinemia. Arthritis Rheum. 2009;60(12):3841-7.

Apartis E, Léger JM, Musset L, Gugenheim M, Cacoub P, Lyon-Caen O, et al. Peripheral neuropathy associated with essential mixed cryoglobulinaemia: a role for hepatitis C virus infection? J Neurol Neurosurg Psychiatry. 1996 Jun;60(6):661-6.

Aprahamian I, Martinelli JE, Yassuda MS. Doença de Alzheimer em idosos com baixa escolaridade: o teste do Desenho do Relógio pode ser útil no rastreio cognitivo? Rev Soc Bras Clin Med. 2008;6(4):130-4. 
Aprahamian I, Martinelli JE, Neri AL, Yassuda MS. The accuracy of the Clock Drawing Test compared to that of standard screening tests for Alzheimer's disease: results from a study of Brazilian elderly with heterogeneous educational backgrounds. Int Psychogeriatr. 2010;22:64-71.

Annunziata P, Marroni M, Francisci D, Stagni G. Acute transverse myelitis and hepatitis C virus. Infez. Med. 2005;13:45-47.

Arao M, Murase K, Kusakabe A, Yoshioka K, Fukuzawa Y, Ishikawa T, et al. Prevalence of diabetes mellitus in Japanese patients infected chronically with hepatitis C virus. J Gastroenterol. 2003; 38(4):355-60.

Atalaia-Silva KC, Lourenço RA. Tradução, adaptação e validação de construto do Teste do Relógio aplicado entre idosos no Brasil. Rev Saude Pública. 2008;42:930-7.

Atroshi I, Gummesson C, Johnsson R, Omstein E, Ranstam J, Rosén I. Prevalence of carpal tunnel syndrome in a general population. JAMA. 1999;282(2):153-8.

Authier FJ, Pawlotsky JM, Viard JP, Guillevin L, Degos JD, Gherardi RK. High incidence of hepatitis $C$ virus infection in patients with cryoglobulinemic neuropathy. Ann Neurol. 1993;34(5):749-50.

Authier FJ, Bassez G, Payan C, Guillevin L, Pawlotsky JM, Degos JD, et al. Detection of genomic viral RNA in nerve and muscle of patients with HCV neuropathy. Neurology. 2003;60:808-12.

Aytug S, Reich D, Sapiro LE, Bernstein D, Begum N. Impaired IRS-1/ PI3-kinase signaling in patients with HCV: a mechanism for increased prevalence of type 2 diabetes. Hepatology. 2003; 38(6):1384-92.

Baddeley A. Working memory: looking back and looking forward. Nat Rev Neurosci. 2003;4:829-39.

Badiani RG, Becker V, Perez RM, Matos CA, Lemos LB, Lanzoni VP, et al. Is autoimmune hepatitis a frequent finding among HCV patients with intense interface hepatitis? World J Gastroenterol. 2010;16:3704-8.

Baldereschi M, Inzitari M, Di Carlo A, Farchi G, Scafato E, Inzitari D. ILSA Working Group. Epidemiology of distal symmetrical neuropathies in the Italian elderly. Neurology. 2007;68(18):1460-7.

Bandi L. Renal manifestations of hepatitis C virus infection. Extrahepatic complications often are silent - and thus overlooked. Postgrad Med. 2003; 113:73-6.

Banerjee A, Mazumdar B, Meyer K, Di Bisceglie AM, Ray RB, Ray R. Transcriptional repression of $\mathrm{C} 4$ complement by hepatitis $\mathrm{C}$ virus proteins. $J$ Virol 2011;85:4157-66. 
Barbosa MED, Zaninotto AL, Mazo DFC, Pessoa MG, Oliveira CPMS, Carrilho FJ, et al. Hepatitis $C$ virus eradication improves immediate and delayed episodic memory in patients treated with interferon and ribavirin. BMC Gastroenterol. 2017;17:122.

Bartenschlager R, Penin F, Lohmann V, André P. Assembly of infectious hepatitis C virus particles. Trends Microbiol. 2011;19:95-103.

Beck AT, Ward $\mathrm{CH}$, Mendelsohn M, Mock J, Erbaugh J. An inventory for measuring depression. Arch Gen Psych. 1961;4:561-71.

Beck AT, Steer RA, Garbin MG. Psychometric properties of the Beck Depression Inventory: Twenty-five years of evaluation. Clin Psych Rev. 1988;8(1):77-100.

Beck AT, Epstein N, Brown G, Steer RA. An Inventory for Measuring Clinical Anxiety: Psychometric Properties. J Consult Clin Psychol. 1988;56:893-7.

Beck AT, Steer RA. Manual for the Beck Hopelessness Scale. San Antonio, TX: Psychological Corp, 1998.

Bedossa P, Poynard T. An algorithm for the grading of activity in chronic hepatitis C. The METAVIR Cooperative Study Group. Hepatology. 1996;24:289-93.

Bertolucci PHF, Brucki SMD, Campacci SR, Juliano Y. O mini-exame do estado mental em uma população geral: impacto da escolaridade. Arq. Neuropsiquiat.1994; 52:1-7.

Bianchi FB, Muratori P, Granito A, Pappas G, Ferri S, Muratori L. Hepatitis C and autoreactivity. Dig Liver Dis. 2007;39 Suppl 1:S22-4.

Biasiotta A, Casato M, La Cesa S, Colantuono S, Di Stefano G, Leone C, et al. Clinical, neurophysiological, and skin biopsy findings in peripheral neuropathy associated with hepatitis C virus-related cryoglobulinemia. J Neurol. 2014;261:725-31

Blank T, Detje CN, Spieß A, Hagemeyer N, Brendecke SM, Wolfart J, et al. Brainendothelial - and epithelial- specific interferon receptor chain 1 drives virusinduced sickness behavior and cognitive impairment. Immunity. 2016;44(4):90112.

Bogdanos DP, Choudhuri K, Vergani D. Molecular mimicry and autoimmune liver disease: virtuous intentions, malign consequences. Liver. 2001;21(4):225-32.

Bonetti B, Invernizzi F, Rizzuto N, Bonazzi ML, Zanusso GL, Chinaglia G, et al. T-cell-mediated epineurial vasculitis and humoral-mediated microangiopathy in cryoglobulinemic neuropathy. J Neuroimmunol. 1997;73:145-54.

Bonetti B, Scardoni M, Monaco S, Rizzuto N, Scarpa A. Hepatitis C virus infection of peripheral nerves in type II cryoglobulinaemia [abstract]. Virchows Arch. 1999;434(6):533-5. 
Bonkovsky HL, Woolley JM. Reduction of health-related quality of life in chronic hepatitis $\mathrm{C}$ and improvement with interferon therapy: the Consensus Interferon Study Group. Hepatology. 1999;29:264-70.

Borson S, Brush M, Gil E, Scanlan J, Vitaliano P, Chen P, et al. The Clock Drawing Test: utility for dementia detection in multiethnic elders. [abstract]. $J$ Geront A Biol Sci Med Sci. 1999;54(11):M534-40.

Boukhris S, Magy L, Senga-mokono U, Loustaud-ratti V, Vallat JM. Polyneuropathy with demyelinating features in mixed cryoglobulinemia with hepatitis C virus infection. Eur J Neurol. 2006;13:937-41.

Bowden DS, Berzsenyi MD. Chronic hepatitis $C$ virus infection: genotyping and its clinical role. Future Microbiol. 2006; 1(1):103-12.

Boyer A, Dumans A, Beaumont E, Etienne L, Roingeard P, Meunier JC. The association of hepatitis $C$ virus glycoproteins with apolipoproteins $E$ and $B$ early in assembly is conserved in lipoviral particles. J Biol Chem. 2014;289:18904-13.

Brasil. Ministério da Saúde. Boletim de Hepatite s Virais 2018 [Internet]. 2018. Acessado em setembro de 2018. Disponível em: http://www.aids.gov.br/ptbr/pub/2018/boletim-epidemiologico-de-hepatite s-virais-2018.

Brasil. Ministério da Saúde. Sistema de Informação de Agravos de Notificação (SINAN). Sistema de Informação de Agravos de Notificação [Internet]. 2016. Acessado em agosto de 2017. Disponível em: http://portalsinan.saude.gov.br/

Brasil. Ministério da Saúde. Sistema Nacional de Transplantes do Ministério da Saúde. Sistema de Informação de Agravos de Notificação [Internet]. 2016. Acessado em agosto de 2017. Disponível em: http://portalsinan.saude.gov.br/

Brooks-Worrell B, Palmer JP. Is diabetes mellitus a continuous spectrum? Clin Chem. 2011;57(2):158-61.

Brouet JC, Clauvel JP, Danon F, Kleim M, Seligmann M. Biologic and clinical significance of cryoglobulins. A report of 86 cases. Am J Med. 1974; 57:775-88.

Brucki SM, Malheiros SM, Okamoto IH, Bertolucci PH. Normative data on the verbal fluency test in the animal category in our milieu. Arq Neuropsychiatr. 1997;55(1):56-61.

Brucki SM, Nitrini R, Caramelli P, Bertolucci PH Okamoto IH. Suggestions for utilization of the mini-mental state examination in Brazil. Arq Neuropsiquiatr. 2003;61(3-B):777-81.

Brucki SM, Rocha MS. Category fluency test: effects of age, gender and education on total scores, clustering and switching in Brazilian Portuguesespeaking subjects. Braz J Med Biol Res. 2004;37:1771-7.

Bugianesi E, McCullough AJ, Marchesini G. Insulin resistance: a metabolic pathway to chronic liver disease. Hepatology. 2005;42:987-1000. 
Bukh J, Miller RH, Purcell RH. Genetic heterogeneity of hepatitis $\mathrm{C}$ virus: quasispecies and genotypes. Semin Liver Dis. 1995;15(1):41-63.

Burman BE, Bacchetti P, Ayala CE, Gelman N, Melgar J, Khalili M. Liver inflammation is a risk factor for prediabetes in at-risk latinos with and without hepatitis C infection. Liver Int. 2015;35(1):101-7.

Butler SM, Ashford JW, Snowdon DA. Age, education, and changes in the MiniMental State Exam scores of older women: findings from the Nun Study. J Am Geritr Soc. 1996;44(6):675-81.

Cacho J, Garcia-Garcia R, Arcaya J, Vicente JL, Lantada N. Una propuesta de aplicación y puntuación del Test del Reloj en la enfermedad de Alzheimer. Rev Neurol. 1999;28:648-55.

Cacoub P, Poynard T, Ghillani P, Charlotte F, Olivi M, Piette JC, Opolon P, for the MULTIVIRC Group. Extrahepatic manifestation of chronic hepatitis C. Arthtritis Rheum. 1999; 42(10):2204-12.

Cacoub P, Renou C, Rosenthal E, Cohen P, Loury I, Loustaud-Ratti V, et al. Extrahepatic manifestations associated with hepatitis $C$ virus infection. A prospective multicenter study of 321 patients. The GERMIVIC. Groupe d'Etude et de Recherche en Medecine Interne et Maladies Infectieuses sur le Virus de l'Hepatite C. Medicine (Baltimore). 2000;79:47-56.

Cacoub P, Maisonobe T, Thibault V, Gatel A, Servan J, Musset L, et al. Systemic vasculitis in patients with hepatitis C. J Rheumatol. 2001;28(1):109-18.

Cacoub P, Saadoun D, Limal N, Léger JM, Maisonobe T. Hepatitis C virus infection and mixed cryoglobulinaemia vasculitis: a review of neurological complications. AIDS. 2005;19(Suppl 3):S128-34.

Cacoub P, Comarmond C, Fanny Domont F, Savey L, Anne C. Desbois AC, et al. Extrahepatic manifestations of chronic hepatitis $C$ virus infection. Ther $A d v$ Infect Dis. 2016;3(1):3-14.

Cacoub P, Comarmond C, Desbois AC, Saadoun D. Rheumatologic Manifestations of Hepatitis C Virus Infection. Clin Liver Dis. 2017;21(3):455-464.

Callahan CM, Hall KS, Hui SL, Musik BS, Unverzaqt FW, Hendrie HC. Relationship of age, education, and occupation with dementia among a community-based sample of African Americans. Arch Neurol. 1996; 53(2):13440.

Campiotto S, Pinho JR, Carrilho FJ, Da Silva LC, Souto FJ, Spinelli V, et al. Geographic distribution of hepatitis C virus genotypes in Brazil. Braz J Med Biol Res. 2005;38:41-9.

Caramelli P, Carthery-Goulart MT, Porto CS, Charchat-Fichman H, Nitrini R. Category fluency as a screening test for Alzheimer disease in illiterate and literate patients. Alzheimer Dis Assoc Disord. 2007;21:65-7. 
Casato M, Saadoun D, Marchetti A, Limal N, Picq C, Pantano P, et al. Central nervous system involvement in hepatitis $C$ virus cryoglobulinemia vasculitis: a multicenter case-control study using magnetic resonance imaging and neuropsychological tests. J Rheumatol. 2005 Mar;32(3):484-8.

Cassani F, Cataleta M, Valentini P, Muratori P, Giostra F, Francesconi R, et al. Serum autoantibodies in chronic hepatitis $\mathrm{C}$ : comparison with autoimmune hepatitis and impact on the disease profile. Hepatology. 1997;26(3):561-6.

Cavalheiro NP, Barone AA, Tengan FM. HCV serotypes in brazilian patients. Int J Infect Dis. 2002;6:228-32.

Chang ML. Metabolic alterations and hepatitis C: from bench to bedside. World $J$ Gastroenterol. 2016;282(4):1461-76

Charles ED, Dustin LB. Hepatitis C virus-induced cryoglobulinemia. Kidney Int. 2009;76(8): 818-24.

Chen SL, Morgan TR. The natural history of hepatitis $\mathrm{C}$ virus HCV infection. Int $J$ Med. 2006;3:47-52.

Chin RL, Sander HW, Brannagan TH, De Sousa E, Latov N. Demyelinating neuropathy in patients with hepatitis $\mathrm{C}$ virus infection. J Clin Neuromuscul Dis. 2010;11(4):209-12.

Chiu WC, Tsan YT, Tsai SL, Chang CJ, Wang JD, Chen PC; Health Data Analysis in Taiwan (hDATa) Research Group. Hepatitis C viral infection and the risk of dementia. Eur J Neurol. 2014 Aug;21(8):1068-e59.

Chong CA, Gulamhussein A, Heathcote EJ, Lilly L, Sherman M, Naglie G, et al. Health-state utilities and quality of life in hepatitis $C$ patients. Am J Gastroenterol. 2003;98:630-8.

Choo QI, Kuo G, Weiner AJ, Overly LR, Bradley DW, Houghton M. Isolation of a cDNA clone derived from a blood-borne non-A, non-B viral hepatitis genome. Science. 1989;244:359-62.

Choo QL, Richman KH, Han JH, Berger K, Lee C, Dong C, et al. Genetic organization and diversity of the hepatitis $\mathrm{C}$ virus. Proc Natl Acad Sci USA $1991 ; 88: 451-5$.

Chrétien P, Chousterman M, Abd Alsamad I, Ozenne V, Rosa I, Barrault C, et al. Non-organ-specific autoantibodies in chronic hepatitis $C$ patients: association with histological activity and fibrosis. J Autoimmunol. 2009;32:201-5.

Clifford BD, Donahue D, Smith L, Cable E, Luttig B, Manns M, et al. High prevalence of serological markers of autoimmunity in patients with chronic hepatitis C. Hepatology. 1995;21(3):613-9.

Colpitts CC, Lupberger J, Doerig C, Baumert TF. Host cell kinases and the hepatitis C virus life cycle. Biochim Biophys Acta. 2015;1854:1657-62. 
Cordoba J, Flavia M, Jacas C, Sauleda S, Esteban JI, Vargas V, et al. Quality of life and cognitive function in hepatitis $C$ at different stages of liver disease. $J$ Hepatol. 2003; 39(2):231-8.

Corey KE, Servoss JC, Casson DR, Kim AY, Robbins GK, Franzini J, et al. A pilot study of postexposure prophylaxis for hepatitis $C$ virus in healthcare workers. Infect Control Hosp Epidemiol. 2009;30:1000-5.

Costa J, Resende C, de Carvalho M. Motor-axonal polyneuropathy associated with hepatitis C virus. Eur J Neurol. 2003;10:183-5.

Cozzi A, Zignego AL, Carpendo R, Biagiotti T, Aldinucci A, Monti M, et al. Low serum tryptophan levels, reduced macrophage IDO activity and high frequency of psychopathology in HCV patients. J Viral Hepat. 2006;13(6):402-8.

Cruz Neves A, Dickens C, Xavier M. Comorbidity between hepatitis C and depression. Epidemiological and etiopathogenic aspects. Acta Med Port. 2006; 19: 21-28.

Cunha JA. Manual da versão em português das Escalas de Beck. São Paulo: Casa do Psicólogo; 2001.

Czaja AJ, Carpenter HA. Histological findings in chronic hepatitis C with autoimmune features. Hepatology. 1997; 34:119-21.

Dale JK, Di Bisceglie AM, Hoofnagle JH, Straus SE. Chronic fatigue syndrome: lack of association with hepatitis C virus infection. J Med Virol. 1991;34:119-21.

D'Amico G. Hepatitis C virus and essential mixed cryoglobulinaemia. Nephrol Dial Transplant. 1993;8:579-8.

de Almeida SM, de Pereira AP, Pedroso MLA, Ribeiro CE, Rotta I, Tang B, et al.; HNRC Group. Neurocognitive impairment with hepatitis $\mathrm{C}$ and HIV co-infection in Southern Brazil. J Neurovirol. 2018;24(3):339-49.

De Carli DM, Pannebeker J, Pedro FL, Haygert CJP, Hertz E, Beck MO. Transverse Myelitis Associated to HCV Infection. Braz $J$ Infect Dis. 2009;13(2):147-52.

Della Rossa A, Tavoni A, D'Ascanio A, Catarsi E, Marchi F, Bencivelli W, et al. Mortality rate and outcome factors in mixed cryoglobulinaemia: the impact of hepatitis C virus. Scand J Rheumatol. 2010;39(2):167-70.

De Krom MC, Knipschild PG, Kester AD, Boekkooi PF, Spaans F. Carpal tunnel syndrome: prevalence in the general population. $J$ Clin Epidemiol. 1992;45(4):373-6.

De Rosa FG, Agnello V. Observations on cryoglobulin testing: I. The association of cryoglobulins containing rheumatoid factors with manifestation of cryoglobulinemic vasculitis. J Rheumatol. 2009;36(9):1953- 5. 
Dhiman RK, Chawla YK. Minimal hepatic encephalopathy. Indian $J$ Gastroenterol. 2009;28:5-16.

Dirks M, Haag K, Pflugrad H, Tryc AB, Schuppner R, Wedemeyer $\mathrm{H}$, et al. Neuropsychiatric symptoms in hepatitis $C$ patients resemble those of patients with autoimmune liver disease but are different from those in hepatitis B patients. Journal of Viral Hepatitis. J Viral Hepat. 2018; doi:10.1111/jvh.12979.

Dore MP, Fattovich G, Sepulveda AR, Realdi G. Cryoglobulinemia related to hepatitis C virus infection. Dig Dis Sci. 2007;52(4):897-907.

Dustin LB, Rice CM. Flying under the radar: the immunobiology of hepatitis C. Annu Rev Immunol. 2007;25:71-99.

El-Gindy EM, Ali-Elsin FA, Meguid MA. Serum leptin level and its association with fatigue in patients with chronic hepatitis $C$ virus infection. Arab $J$ Gastroenterol. 2012;13(2):54-7.

El-Serag HB, Kunik M, Richardson P, Rabeneck L. Psychiatric disorders among veterans with hepatitis C infection. Gastroenterology 2002; 123:476-82.

El-Shamy A, Branch AD, Schiano TD, Gorevic PD. The Complement System and $\mathrm{C} 1 \mathrm{q}$ in Chronic Hepatitis $\mathrm{C}$ virus infection and Mixed Cryoglobulinemia. Front. Immunol. 9:1001, 2018.

Fabiani S, Fallahi P, Ferrari SM, Miccoli M, Antonelli A. Hepatitis C virus infection and development of type 2 diabetes mellitus: Systematic review and meta-analysis of the literature. Rev Endocr Metab Disord. 2018 Jan 11. Epub ahead of print.

Farshadpour F, Taherkhani R, Ravanbod MR, Eghbali SS. Prevalence and genotype distribution of hepatitis $C$ virus infection among patients with type 2 Diabetes Mellitus. Med Princ Pract. 2018;27(4):308-16.

Felipo, V. Ordoño JF, Urios A, El Mlili N, Giménez-Garzó C, Aguado C, et al. Patients with minimal hepatic encephalopathy show impaired mismatch negativity correlating with reduced performance in attention tests. Hepatology. 2012; 55:530-9.

Ferenci P, Lockwood A, Mullen K, Tarter R, Weissenborn K, Blei AT. Hepatic encephalopathy - definition, nomenclature, diagnosis, and quantification: final report of the working party at the 11th World Congresses of Gastroenterology, Vienna, 1998. Hepatology. 2002; 35: 716-21.

Ferenci P, Staufer K. Depression in chronic hepatitis: the virus, the drug, or the ethnic background? Liver Int 2008; 28: 429-43.

Ferri C, La Civita L, Cirafisi C, Siciliano G, Longombardo G, Bombardieri S, et al. Peripheral neuropathy in mixed cryoglobulinemia: Clinical and electrophysiologic investigations. J Rheumatol. 1992;19(6):889-95. 
Ferri C, Sebastiani M, Giuggioli D, Cazzato M, Longombardo G, Antonelli A, et al. Mixed cryoglobulinemia: demographic, clinical, and serologic features and survival in 231 patients. Semin Arthitis Rheum. 2004;33(6):355-74.

Ferri C, Sebastiani M, Giuggioli D, Colaci M, Fallhi P, Piluso A, et al. Hepatitis C virus syndrome: a constellation of organ e non-organ specific immune disorders, B-cell non-Hodgkin's lymphoma, and cancer. World J Hepatol. 2015. $27 ; 7(3): 327-43$.

Figueiredo VLM, Nascimento E. Desempenhos nas duas tarefas do subteste dígitos do WISC-III e do WAIS-III. Psicol Teor Pesq. 2007;23(3):313-8.

Filippini D, Colombo F, Jann S, Cornero R, Canesi B. Central nervous system involvement in patients with HCV-related cryoglobulinemia: literature review and a case report. Reumatismo. 2002;54(2):150-5.

Fletcher NF, McKeating JA. Hepatitis C virus and the brain. J Viral Hepat. 2012;19:301-6.

Folstein MF, Folstein SE, McHugh PR. "Mini-mental state". A practical method for grading the cognitive state of patients for the clinician. $J$ Psychiatr Res. 1975;12:189-98.

Fontana RJ, Bieliauskas LA, Back-Madruga C, Lindsay KL, Kronfol Z, Lok AS, et al. Cognitive function in hepatitis $C$ patients with advanced fibrosis enrolled in the HALT-C trial. J Hepatol. 2005; 43(4):614-22.

Forton DM, Allsop JM, Main J, Foster GR, Thomas HC, Taylor-Robinson SD. Evidence for a cerebral effect of the hepatitis C virus. Lancet. 2001;358:38-9.

Forton DM, Thomas HC, Murphy CA, Allsop JM, Foster GR, Main J, et al. Hepatitis $\mathrm{C}$ and cognitive impairment in a cohort of patients with mild liver disease. Hepatology. 2002;35:433-9.

Forton DM, Karayiannis P, Mahmud N, Taylor-Robinson SD, Thomas HC. Identification of unique hepatitis $C$ virus quasispecies in the central nervous system and comparative analysis of internal translational efficiency of brain, liver, and serum variants. J Virol. 2004;78:5170-83.

Forton DM. Altered monoaminergic transporter binding in hepatitis $\mathrm{C}$ related cerebral dysfunction: a neuroimmunologial condition? [commentaries]. Gut. 2006;55:1535-7.

Forton DM, Taylor-Robinson SD, Thomas HC. Central nervous system changes in hepatitis C virus infection. Eur J Gastroenterol Hepatol. 2006;18:333-8.

Foster GR, Goldin RD, Thomas HC. Chronic hepatitis C virus infection causes a significant reduction in quality of life in the absence of cirrhosis. Hepatology.1998;27:209-12. 
Fuzikawa C, Lima-Costa MF, Uchoa E, Barreto SM, Shulman K. A population based study on the intra and inter-rater reliability of the clock drawing test in Brazil: the Bambuí Health and Ageing Study. Int $J$ Geriatr Psychiatry. 2003;18:450-6.

Gangadharan B, Antrobus R, Dwek RA, Zitzmann N. Novel serum biomarker candidates for liver fibrosis in hepatitis C patients. Clin Chem. 2007;53:1792-9.

García-García R, Cruz-Gómez AJ, Urios A, Mangas-Losada A, Forn C, Escudero-García D, et al. Learning and Memory Impairments in Patients with Minimal Hepatic Encephalopathy are Associated with Structural and Functional Connectivity Alterations in Hippocampus. Sci Rep. 2018;8(1):9664. doi:10.1038/s41598-018-27978-x.

Gatselis NK, Georgiadou SP, Tassopoulos N, Zachou K, Liaskos C, Hatzakis A, et al. Impact of parietal cell autoantibodies and non-organ-specific autoantibodies on the treatment outcome of patients with hepatitis $C$ virus infection: a pilot study. World J Gastroenterol. 2005;11:482-7.

Gemignani F, Brindani F, Alfieri S, Giuberti T, Allegri I, Ferrari C, et al. Clinical spectrum of cryoglobulinaemic neuropathy. I Neurol Neurosurg Psychiatry. 2005;76(10):1410-4.

Gemignani F, Giovanelli M, Vitetta F, Santilli D, Bellanova MF, Brindani F, et al. Non-length dependent small fiber neuropathy. a prospective case series. $J$ Peripher Nerv Syst. 2010;15:57-62.

Gilman AJ, Lee AK, Zhao C, Hoang J, Yasukawa LA, Weber SC, et al. Autoantibodies in chronic hepatitis $C$ virus infection: impact on clinical outcomes and extrahepatic manifestations. BMJ Open Gastroenterol. 2018;5(1):e000203.

Giménez-Garzó C, Garcéz JJ, Urios A, Mangas-Losada A, García-García R, Gonzáles-López O, et al. The PHES battery does not detect all cirrhotic patientes with early neurological deficits, which are different in different patients. PloS One. 2017;2(2),e0171211.

Golden J, O'Dwyer AM, Conroy RM. Depression and anxiety in patients with hepatitis C: prevalence, detection rates and risk factors. Gen Hosp Psychiatr. 2005;27:431-8.

Gomes I, Nora DB, Marquezini NC, Said G, Melo A. Peripheral neuropathy in patients with hepatitis virus $C$ infection in the Amazon region. Arq Neuropsiquiatr. 2006;64(3-A):600-2

Gomes-Oliveira MH, Gorenstein C, Lotufo Neto F, Andrade LH, Wang YP. Validation of the brazilian portuguese version of the Beck Depression InventoryII in a commnunity sample. Rev Bras Psiquiatr. 2012;34:389-94. 
Gorenstein C, Andrade L. Validation of a portuguese version of the Beck Depression Inventory and the State-Trait Anxiety Inventory in brazilian subjects. Braz J Med Biol Res. 1996;29:453-45.

Gorenstein C, Andrade L, Vieira Filho AH, Tung TC, Artes R. Psychometric properties of the portuguese version of the beck depression inventory on brazilian college students. J Clin Psychol. 1999;55:553-62.

Gorevic PD. Rheumatoid Factor, Complement, and Mixed Cryoglobulinemia. Clin Dev Immunol. 2012; 2012:439018.

Gorson KC, Herrmann DN, Thiagarajan R, Brannagan TH, Chin RL, Kinsella LJ, et al. Non-length dependent small fibre neuropathy/ganglionopathy. $J$ Neurol Neurosurg Psych. 2008; 79:163-9.

Gragnani L, Fognani E, Piluso A, Zignego AL. Hepatitis C virusrelated mixed cryoglobulinemia: is genetics to blame? World $J$ Gastroenterol. 2013;19(47):8910-5.

Grewal AK, Lopes MB, Berg CL, Bennett AK, Alves VA, Truqman JM. Recurrent demyelinating myelitis associated with hepatitis $\mathrm{C}$ virus. J Neurol Sci. 2004;15:101-6.

Grimbert S, Valensi P, Levy-Marchal C, Perret G, Richardet JP, Raffoux C, et al. High prevalence of diabetes mellitus in patients with chronic hepatitis C. A casecontrol study. Gastroenterol Clin Biol. 1996; 20:544-8.

Groeneweg M, Moerland W, Quero JC, Hop WC, Krabbe PF, Schalm SW. Screening of subclinical hepatic encephalopathy. J Hepatol. 2000;32:748-53.

Guerreiro TDT, Machado MM, Freitas THP. Association between lichen planus and hepatitis $C$ virus infection: a prospective study with 66 patients of the dermatology department of the hospital Santa Casa de Misericórdia de São Paulo. An Bras Dermatol. 2005;80(5):475-0.

Halfon P, Levy M, San Marco M, Gerolami V, Khiri H, Bourliere M, et al. Myasthenia gravis and hepatitis C virus infection. J Viral Hepat.1996;3:329-32.

Hammerstad SS, Grock SF, Lee HJ, Hasham A, Sundaram N, Tomer Y. Diabetes and hepatitis C: a two-way association. Front Endocrinol. (Lausanne) 2015;6:134.

Hanewinckel R, Ikram MA, Van Doorn PA. Peripheral neuropathies. Hand Clin Neurol. 2016;138:263-82.

Helbling B, Overbeck K, Gonvers JJ, Malinverni R, Dufour JF, Borovicka J, et al. Host-rather than virus-related factors reduce health-related quality of life in hepatitis C virus infection. Gut. 2008;57:1597-603.

Heller T, Saito S, Auerbach J, Williams T, Moreen TR, Jazwinski A, et al. An in vitro model of hepatitis $\mathrm{C}$ virion production. Proc Natl Acad Sci USA. 2005;102(7):2579-83. 
Hilsabeck RC, Perry W, Hassanein TI. Neuropsychological impairment in patients with chronic hepatitis C. Hepatology. 2002;35(2):440-6.

Hilsabeck R, Hassanein TI, Carlson M, Ziegler EA. Cognitive functioning and psychiatric symptomatology in patients with chronic hepatitis C. J Int Neuropsych Soc. $2003 ; 9(6): 847-54$.

Himoto T, Masaki T. Extrahepatic manifestations and autoantibodies in patients with hepatitis C virus infection. Clin Dev Immunol. 2012;2012:871401.

Himoto T, Yoneyama H, Kurokohchi K, et al. Clinical relevance of antibodies to cardiolipin in patients with chronic hepatitis C. Clin Lab Anal. 2012;26(5):342-8.

Hirohata S, Inoue T, Ito K. Development of rheumatoid arthritis after chronic hepatitis caused by hepatitis C virus infection. Intern Med. 1992;31(4):493-5.

Hjerrild S, Renvillard SG, Leutscher P, Sørensen LH, Østergaard L, Eskildsen SF, et al. Reduced cerebral cortical thickness in non-cirrhotic patients with hepatitis C. Metab Brain Dis. 2016;31(2):311-9.

Hoofnagle $\mathrm{JH}$. Hepatitis $\mathrm{C}$ : the clinical spectrum of disease. Hepatology. 1997;26(3 Suppl 1):15-20.

Horner SM, Gale Jr M. Regulation of hepatic innate immunity by hepatitis $\mathrm{C}$ virus. Nat Med. 2013;19(7):879-88.

Huang YW, Yang SS, Fu SC, Wang TC, Hsu CK, Chen DS, et al. Increased risk of cirrhosis and its decompensation in chronic hepatitis $C$ patients with new-onset diabetes: A nationwide cohort study. Hepatology. 2014;60(3):807-14.

Huckans M, Seelye A, Parcel T, Mull L, Woodhouse J, Bjornson D, et al. The cognitive effects of hepatitis $C$ in the presence and absence of a history of substance use disorder. J Int Neuropsychol Soc. 2009;15: 69-82.

Hughes E, Bassi S, Gilbody S, Bland M, Martin F. Prevalence of HIV, hepatitis B, and hepatitis $C$ in people with severe mental illness: a systematic review and meta-analysis. Lancet Psychiatry. 2016;3(1):40-8.

Jacqmin-Gadda H, Fabrigoule C, Commenges D, Dartigues JF. A 5-Year Longitudinal Study of the Mini-Mental State Examination in Normal Aging. Am $J$ Epidemiol. 1997; 145(6):498-506.

Johnson RJ, Gretch DR, Yamabe H, Hart J, Bacchi CE, Hartwell P, et al. Membranoproliferative glomerulonephritis associated with hepatitis $C$ virus infection. N Engl J Med. 1993;328:465-70.

Johnson ME, Fisher DG, Fenaughty A, Theno SA. Hepatitis C virus and depression in drug users. Am J Gastroenterol. 1998; 93:785-9.

Jonsson JR, Moschen AR, Hickman IJ, Richardson MM, Kaser S, Clouston AD, et al. Adiponectin and its receptors in patients with chronic hepatitis C. J Hepatol. 2005; 43:929-36. 
Juby A, Tench S, Baker V. The value of clock drawing in identifying executive cognitive dysfunction in people with a normal Mini-Mental State Examination score. CMAJ. 2002;167(8):859-64.

Kallenberg CG, Heeringa $P$, Stegeman CA. Mechanisms of disease: pathogenesis and treatment of ANCA-associated vasculitides. Nat Clin Pract Rheumatol. 2006;2:661-70.

Kanda T. Chronic hepatitis C infection and peripheral neuropathy; is mixed cryoglobulinemia really important? [editorial]. Int Med. 2003;42(5):377-8.

Karaivazoglou K, Assimakopoulos K, Thomopoulos K, Theocharis G, Messinis L, Sakellaropoulos G, et al. Neuropsychological function in Greek patients with chronic hepatitis C. Liver Int. 2007;27(6):798-805.

Kay J, McCluskey RT. Case records of the Massachusetts General Hospital. Case 31-2005. A 60-year-old man with skin lesions and renal insufficiency. $N$ Engl J Med. 2005;353(15):1605-13.

Kayali Z, Buckwold VE, Zimmerman B, Schmidt WN. Hepatitis C, cryoglobulinemia, and cirrhosis: a meta- analysis. Hepatology. 2002;36(4 Pt 1):978-85.

Khalek MAA, El-barbary AM, Elkalla FS, Essa SAM. Prevalence of peripheral neuropathy in Egyptian hepatitis $C$ virus patients: correlation to some clinical and laboratory parameters. Egyp Rheumatol. 2012;34:91-8.

Kharabian Masouleh S, Herzig S, Klose L, Roggenhofer E, Tenckhoff H, Kaiser $\mathrm{T}$, et al. Functional connectivity alterations in patients with chronic hepatitis $\mathrm{C}$ virus infection: A multimodal MRI study. J Viral Hepat. 2017;24(3):216-225

Kim H, Bose SK, Meyer K, Ray R. Hepatitis C virus impairs natural killer cellmediated augmentation of complement synthesis. J Virol. 2014,88:2564-71.

King PD, Wilkes JD, Diaz-Arias AA. Hepatitis C virus infection in non-Hodgkin's lymphoma. Clin Lab Haematol. 1998;20(2):107-10.

Kittlesen DJ, Chianese-Bullock KA, Yao ZQ, Braciale TJ, Hahn YS. Interaction between complement receptor $\mathrm{gC1qR}$ and hepatitis $\mathrm{C}$ virus core protein inhibits T-lymphocyte proliferation. J Clin Invest. 2000;106:1239-49.

Klimkeit El, Tonge B, Bradshaw JL, Melvin GA, Gould K. Neuropsychological deficits in adolescent unipolar depression. Arch Clin Neuropsychol 2011;26:66276.

Koike K. Hepatitis C as a metabolic disease: implication for the pathogenesis of NASH. Hepat Res. 2005;33:145-50.

Knobler H, Schihmanter R, Zifroni A, Fenakel G, Schattner A. Increased risk of type 2 diabetes in noncirrhotic patients with chronic hepatitis $\mathrm{C}$ virus infection. Mayo Clin Proc. 2000; 75(4):355-9. 
Köşkderelioğlu A, Ortan P, Ari A, Gedizlioğlu M. Screening for electrophysiological abnormalities in chronic hepatitis $C$ infection: peripheral neuropathy and optic neuropathy. Noro Psikiyatr Ars. 2016;53(1):23-7.

Kramer L, Bauer E, Funk G, Hofer H, Jessner W, Steindl-Munda P, et al. Subclinical impairment of brain function in chronic hepatitis $\mathrm{C}$ infection. $J$ Hepatol. 2002;37:349-54.

Kretzer IF, do Livramento A, da Cunha J, Gonçalves S, Tosin I, Spada C, et al. Hepatitis $C$ worldwide and in Brazil: silent epidemic-data on disease including incidence, transmission, prevention, and treatment. ScientificWorldJounal. 2014;2014:827-49.

Kumar A, Deep A, Gupta RK, Atam V, Mohindra S. Brain microstructural correlates of cognitive dysfunction in clinically and biochemically normal hepatitis C virus infection. J Clin Exp Hepatol. 2017; 7(3):198-204.

Lacaille $F$, Zylberberg $H$, Hagege $H$, Roualdès B, Meyrignac $C$, Chousterman M, et al. Hepatitis C associated with Guillain-Barre syndrome. Liver. 1998;18:49-51.

Lamprecht P, O. Gutzeit O, E. Csernok E, Prevalence of ANCA in mixed cryoglobulinemia and chronic hepatitis $C$ virus infection. Clin Experimental Rheumatol. 2003;21(6) suppl 32:S89-S94.

Larner AJ. Cognitive Screening Instruments. A Practical Approach. London: Springer-Verlag; 2013.

Lauer GM, Walker BD. Hepatitis C virus infection. N Engl J Med. 2001;345(1):4152.

Lauletta G, Russi S, Conteduca V, Sansonno L. Hepatitis C virus infection and mixed cryoglobulinemia. Clin Dev Immunol. 2012;2012:502156.

Lavanchy D. The global burden of hepatitis C. Liver Int. 2009;29 Suppl 1:S7478.

Lee YH, Ji JD, Yeon JE, Byun KS, Lee CH, Song GG. Cryoglobulinaemia and rheumatic manifestations in patients with hepatitis $\mathrm{C}$ virus infection. Ann Rheum Dis. 1998;57(2):728-31.

Leone N, Pellicano R, Ariata Maiocco I, Modena V, Marietti G, Rizzetto M, et al. Mixed cryoglobulinaemia and chronic hepatitis $C$ virus infection: the rheumatic manifestations. J Med Virol. 2002;66(2):200-3.

Lezak MD, Howieson DB, Loring DW. Neuropsychological assessment. 4th ed. New York: Oxford University Press; 2004.

Lidar M, Lipschitz N, Agmon-Levin N, Langevitz P, Barziani O, Ram M, et al. Infectious serologies and autoantibodies in hepatitis $\mathrm{C}$ and autoimmune diseaseassociated mixed cryoglobulinemia. Clin Rev Allergy Immunol. 2012;42:238-46. 
Lindahl G, Sjöbring U, Johnsson E. Human complement regulators: a major target for pathogenic microorganisms. Curr Op Immunol. 2000;12(1):4451.

Liu M, Guo S, Hibbert JM, Jain V, Singh N. CXCL 10/IP-10 in infectious diseases pathogenesis and potential therapeutic implications. Cytokine Growth Factor Rev. 2011;22(3):121-30.

Lonardo A, Adinolfi LE, Petta S, Craxi A, Loria P. Hepatitis C and diabetes: the inevitable coincidence? Expert Rev Anti Infect Ther. 2009; 7(3):293-308.

Lourenço RA, Veras R. Mini-Exame do Estado Mental: características psicométricas em idosos ambulatoriais. Rev Saúde Pública. 2006;40(4):712-9.

Lourenço RA, Ribeiro-Filho ST, de Freitas Henriques, Moreira I, Paradela EMP, Miranda AS. The Clock Drawing Test performance among elderly with low educational level. Rev Bras Psiquiatr. 2008;30:309-315.

Lowry D, Coughlan B, McCarthy O, Crowe J. Investigating health-related quality of life, mood and neuropsychological test performance in homogeneous cohort of Irish female hepatitis C patients. J Viral Hepat. 2010;17:352-9.

Lowry D, Burke T, Galvin Z, Ryan JD, Russel A, Hegarty J, et al. Is psychosocial and cognitive dysfunction misattributed to the virus in hepatitis $C$ infection? Select psychosocial contributors. J Viral Hepat. 2016;23:584-95.

Lunel F, Musset L, Cacoub P, Frangeul L, Cresta P, Perrin M, et al. Cryoglobulinemia in chronic liver diseases: role of hepatitis $C$ virus and liver damage. Gastroenterology. 1994;106:1291-300.

Luo JC, Hwang SJ, Li CP, Lu RH, Chan CY, Wu JC, et al. Clinical significance of serum auto-antibodies in Chinese patients with chronic hepatitis $\mathrm{C}$ : negative role of serum viral titre and genotype. J Gastroenterol. 1998;13(5):475-9.

Maasoumy B, Wedemeyer $\mathrm{H}$. Natural history of acute and chronic hepatitis $\mathrm{C}$. Best Pract Res Clin Gastroenterol. 2012;26:401-12.cc

Maisonobe T, Leger JM, Musset L, Cacoub P. Neurological manifestations in cryoglobulinemia. Rev Neurol. 2002;158:920-4.

Mangia A, Schiavone G, Lezzi G, Marmo R, Bruno F, Villani MR, et al. HCV and diabetes mellitus: evidence for a negative association. Am J Gastroenterol. 1998;93(12):2363-7.

Manos PJ, Wu R. The ten point clock test: a quick screen and grading method for cognitive impairment in medical and surgical patients. Int J Psych Med 1994; 24: 229-44.

Mapoure NY, Budzi MN, Eloumou SAFB, Malongue A, Okalla C, Luma HN. Neurological manifestations in chronic hepatitis $C$ patients receiving care in a reference hospital in sub-Saharan Africa: a cross-sectional study. PLoS One. 2018; 7;13(3):e0192406. 
Marconcini ML, Fayad L, Shiozawa MB, Dantas-Correa EB, Lucca Schiavon L, Narciso-Schiavon JL. Autoantibody profile in individuals with chronic hepatitis C. Rev Soc Bras Med Trop. 2013;46:147-53.

Marie I, Levesque H, Courtois H, Francois A, Riachi G. Polymyositis, cranial neuropathy, autoimmune hepatitis, and hepatitis C. Ann Rheum Dis. 2000;59(10):839-40.

Mariotto S, Ferrari S, Monaco S. HCV-Related Central and Peripheral Nervous System Demyelinating Disorders. Inflamm Allergy Drug Targets. 2014;13(5):299304.

Martyn CN, Hughes RA. Epidemiology of peripheral neuropathy. J Neurol Neurosurg Psych. 1997;62:310-8.

Masaki T, Suzuki R, Murakami K, Aizaki H, Ishii K, Murayama A, et al. Interaction of hepatitis $C$ virus nonstructural protein $5 \mathrm{~A}$ with core protein is critical for the production of infectious virus particles. J Virol. 2008;82:7964-76.

Mason AL, Lau JY, Hoang N, Qian K, Alexander GJ, Xu L, et al. Association of diabetes mellitus and chronic hepatitis $\mathrm{C}$ virus infection. Hepatology. 1999;29(2):328-33.

Masini M, Campani D, Boggi U, Menicagli M, Funel N, Pollera M, et al. Hepatitis $\mathrm{C}$ virus infection and human pancreatic beta-cell dysfunction. Diabetes Care. 2005;28(4):940-1.

Mastroianni A, Allegrini F, Nardi S, Donatucci D, Girelli F, Guidi C. Carpal tunnel syndrome in HIV-positive patients coinfected with HCV. Reumatismo. 2017;21;69(4):164-9.

Matsumoto N, Arase Y, Seko Y, Imai N, Kawamura Y, Sezaki H, et al. Prevalence and predictive factors of diabetes in hepatitis virus positive liver cirrhosis with fasting plasma glucose level of <126 mg/dl. Hepatol Res. 2012;42:558-63.

Matarozzi K, Stracciari A, Vignatelli L, D’Alessandro R. Minimal hepatic encephalopathy: longitudinal effects of liver transplantation. Arch Neurol. 2004;61(2):242-7.

McAndrews MP, Farcnik K, Carlen P, Damyanovich A, Mrjonjic M, Jones S, et al. Prevalence and significance of neurocognitive dysfunction in hepatitis $C$ In the absence of correlated risk factors. Hepatology. 2005;41:801-8.

McCready H, Kohno M, Kolessar M, Dennis L, Kriz D, Luber H, et al. Functional $\mathrm{MRI}$ and delay discounting in patients infected with hepatitis C. $J$ Neurovirol. 2018;24(6):738-51.

McDermott LM, Ebmeir KP. A meta-analysis of depression severity and cognitive function. J Affect Disord. 2009;119:1-8. 
McDonald J, Jayasuriya J, Bindley P, Gonsalvez C, Gluseska S. Fatigue and psychological disorders in chronic hepatitis C. J Gastroenterol Hepatol. 2002; 17:171-6.

McFarlane IG. Immunological abnormalities and hepatotropic viral infections. Clin Exp Immunol. 1992;87:337-9.

Mello EV; Ferreira Alves VA. Chronic Hepatitis C: pathological anatomy. In Consensus of the Brazilian Society of Infectious Diseases on the management and treatment of hepatitis C. Braz J Infect Dis. 2007;11(Suppl 1):32-6Melo, DM, Barbosa, AJ Gonçalves. O uso do Mini-Exame do Estado Mental em pesquisas com idosos no Brasil: uma revisão sistemática. Ciênc. Saúde Coletiva. 2015;20(12):3865-76. https://dx.doi.org/10.1590/1413-812320152012.06032015

Mendez MF, Ala T, Underwood KL. Development of scoring criteria for the clock drawing task in Alzheimer's disease. J Am Geriatr Soc. 1992;40:1095-9.

Messina JP, Humphreys I, Flaxman A, Brown A, Cooke GS, Pybus OG, et al. Global distribution and prevalence of hepatitis $C$ virus genotypes. Hepatology. 2015;61(1):77-87.

Meyerhoff DJ, Bloomer C, Cardenas V, Norman D, Weiner MW, Fei G. Elevated subcortical choline metabolites in cognitively and clinically asymptomatic HIV+ patients. Neurology. 1999;52:995-1003.

Micallef JM, Kaldor JM, Dore GJ. Spontaneous viral clearance following acute hepatitis $C$ infection: a systematic review of longitudinal studies. J Viral Hepat. 2006;13(1):34-41.

Middleton SD, Anakwe RE. Carpal tunnel syndrome. BMJ. 2014;349:g6437.

Mihm S. Hepatitis $\mathrm{C}$ virus, diabetes and steatosis: clinical evidence in favor of a linkage and role of genotypes. Dig Dis. 2010;28:280-4.

Missiha SB, Ostrowski M, Heathcote EJ. Disease progression in chronic hepatitis C: modifiable and nonmodifiable factors. Gastroenterology. 2008; 134(6):1699714.

Monaco S, Ferrari S, Gajofatto A, Zanusso G, Mariotto S. HCV-related nervous system disorders. Clin Dev Immunol. 2012;2012:236148.

Monaco S, Mariotto S, Ferrari S, Calabrese M, Zanusso G, Gajofatto A, et al. Hepatitis $C$ virus-associated neurocognitive and neuropsychiatric disorders: Advances in 2015. World J Gastroenterol. 2015;21(42):11974-83.

Montiel JM, Cecato JF, Bartholomeu D, Martinelli, JE. Testes do desenho do relógio e de fluência verbal: contribuição diagnóstica para o Alzheimer. Psicol Teor Prat. 2014;16(1):169-80. 
Montoliu C, Piedrafita B, Serra MA, del Olmo JÁ, Urios A, Rodrigo JM, et al. IL-6 and IL-8 in blood may discriminate cirrhotic patients with and without minimal hepatic encephalopathy. J Clin Gastroenterol. 2009;43(3):272-9.

Moraes C, Pinto JÁ Jr, Lopes MA, Litvoc J, Bottino CMC. Impact of sociodemographic and health variables on mini-mental state examination in a community-based sample of older people. Eur Arch Psychiatry Clin Neurosci 2010;260:535-42.

Moucari R, Asselah T, Cazals-Hatem D, Voitot H, Boyer N, Ripault MP, et al. Insulin resistance in chronic hepatitis $C$ : association with genotypes 1 and 4, serum HCV RNA level, and liver fibrosis. Gastroenterology. 2008;134:416-23.

Muratori P, Muratori L, Guidi M, Granito A, Susca M, Lenzi M, et al. Clinical impact of non-organ-specific autoantibodies on response to combined antiviral treatment in patients with hepatitis C. Clin Infect Dis. 2005;40(4):501-7.

Nagao Y, Sata M. Hepatitis C virus and lichen planus. J Gastroenterol Hepatol. 2004;19:1101-13.

Nagasaka A, Takahashi T, Sasaki T, Takimoto K, Miyashita K, Nakamura M, et al. Cryoglobulinemia in japanese patients with chronic hepatitis $C$ virus infection: host genetic and virological study. J Med Virol. 2001;65:52-7.

Naing C, Mak JW, Ahmed SI, Maung M. Relationship between hepatitis C virus infection and type 2 diabetes mellitus: meta-analysis. World $J$ Gastroenterol. 2012;14(18):1642-51.

Narciso-Schiavon JL, Freire FC, Suarez MM, Ferrari MV, Scanhola GQ, Schiavon $\mathrm{L}$ de $\mathrm{L}$, et al. Antinuclear antibody positivity in patients with chronic hepatitis $\mathrm{C}$ : clinically relevant or an epiphenomenon? Eur $J$ Gastroenterol Hepatol. 2009;21:440-6.

Narciso-Schiavon JL, Schiavon L de L. Autoantibodies in chronic hepatitis C: A clinical perspective. World J Hepatol. 2015;7(8):1074-85.

Nascimento E, Figueiredo VLM. WISC-III e WAIS-III: alterações nas versões originais americanas decorrentes das adaptações para uso no Brasil. Psicol Refl Crit. 2002;15(3):603-12.

Nemni R, Corbo M, Fazio R, Quattrini A, Comi G, Canal N. Cryoglobulinaemic neuropathy. A clinical, morphological and immunocytochemical study of 8 cases. Brain. 1988;111 (Pt 3):541-52.

Nemni R, Sanvito L, Quattrini A, Santuccio G, Camerlingo M, Canal N. Peripheral neuropathy in hepatitis $C$ virus infection with and without cryoglobulinaemia. $J$ Neurol Neurosurg Psychiatr. 2003;74:1267-71.

Neumann AU, Lam NP, Dahari H, Gretch DR, Wiley TE, Layden TJ, et al. Hepatitis $C$ viral dynamics in vivo and the antiviral efficacy of interferon-alpha therapy. Science. 1998;282(5386):103-7. 
Nishitsuji H, Funami K, Shimizu Y, Ujino S, Sugiyama K, Seya T, Takaku H, Shimotohno K. HCV infection induces inflammatory cytokines and chemokines mediated by the cross-talk between hepatocytes and stellate cells. $J$ Virol. 2013;87:8169-8178

Nitrini R, Lefèvre BH, Mathias SC, Caramelli P, Carilho PHM, Sauaia N, et al. Testes neuropsicológicos de aplicação simples para o diagnóstico de demência. Arq Neuropsiquiatr. 1994;52:457-65.

Nolte $\mathrm{CH}$, Endres AS, Meisel $\mathrm{H}$. Sensory ataxia in myelopathy with chronic hepatitis C viral infection. Neurology. 2002;59:958.

Okamoto H, Kurai K, Okada S, Yamamoto K, Lizuka H, Tanaka T, et al. Fulllength sequence of a hepatitis $\mathrm{C}$ virus genome having poor homology to reported isolates: comparative study of four distinct genotypes. Virology. 1992;188:33141.

Okuse C, Yotsuyanagi H, Okazaki T, Yasuda K, Fujioka T, Tomoe M, et al. Detection, using a novel method, of a high prevalence of cryoglobulinemia in persistent hepatitis C virus infection. Hepatol Res. 2003; 27: 18-22.

Omagari K, Ohba K, Kadokawa Y, Hayashida K, Isomoto H, Takeshima F, et al. Antiextractable nuclear antigens (ENA) antibodies in patients with chronic hepatitis $\mathrm{C}$ before and after treatment with interferon. Autoimmunity 2003;36:269-73.

Organização Mundial da Saúde. Global health sector strategy on viral hepatitis, 2016-2021: towards ending viral hepatitis. [Internet]. 2016. [acessado em 11 de setembro de 2018]. Disponível em: http://apps.who.int/iris/bitstream/10665/246177/1/WHO-HIV2016.06-eng.pdf.

Origgi L, Vanoli M, Carbone A, Grasso M, Scorza R. Central nervous system involvement in patients with HCV-related cryoglobulinemia. Am J Med Sci. 1998;315:208-10.

Palazzi C, Buskila D, D'Angelo S, D'Amico E, Olivieri I. Autoantibodies in patients with chronic hepatitis $C$ virus infection: pitfalls for the diagnosis of rheumatic diseases. Autoimmun Rev. 2012;11:659-63.

Palin K, Bluthé RM, McCusker RH, Moos F, Dantzer R, Kelley KW. TNF alphainduced sickness behavior in mice with functional $55 \mathrm{kD}$ TNF receptors is blocked by central IGF-I. J Neuroimmunol. 2007;187:55-60

Papatheodoridis GV, Chrysanthos N, Savvas S, Sevastianos V, Kafiri G, Petraki $\mathrm{K}$, et al. Diabetes mellitus in chronic hepatitis $\mathrm{B}$ and $\mathrm{C}$ : prevalence and potential association with the extent of liver fibrosis. J Viral Hepat. 2006;13(5):303-10.

Parise ER, Oliveira AC, Ferraz ML, Pereira AB, Leite KR. Cryoglobulinemia in chronic hepatitis $\mathrm{C}$ : clinical aspects and response to treatment with interferon alpha and ribavirin. Rev Inst Med Trop S. Paulo. 2007;49(2):67-72. 
Parise ER, Oliveira AC. Importância da resistência insulínica na hepatite C crônica. Arq Gastroenterol. 2007;44(2):178-84.

Parvaiz F, Manzoor S, Tariq H, Javed F, Fatima K, Qadri I. Hepatitis C Virus Infection: Molecular Pathways to Insulin resistance. Virol J. 2011; 8:474.

Pazhanivel M, Jayanthi V. Diabetes mellitus and cirrhosis liver. Minerva Gastroenterol Dietol. 2010;56(1):7-11.

Pattullo V, McAndrews MP, Damyanovich A, Heathcote EJ. Influence of hepatitis $C$ virus on neurocognitive function in patients free from other risk factors: validation from therapeutic outcomes. Liver Int. 2011;31(7):1028-38.

Pawlotsky JM, Roudot-Thoraval F, Simmonds P, Mellor J, Ben Yahia MB, André $\mathrm{C}$, et al. Extrahepatic immunologic manifestations in chronic hepatitis $\mathrm{C}$ and hepatitis C virus serotypes. Ann Intern Med. 1995;122:169-73.

Peng YC, Hsieh SC, Yang DY, Tung CF, Hu WH, Huang WN, et al. Expression and clinical significance of antinuclear antibody in hepatitis $C$ virus infection. $J$ Clin Gastroenterol. 2001;33:402-6.

Pereira LM, Martelli CM, Moreira RC, Merchan-Hamman E, Stein AT, Cardoso MR, et al. Prevalence and risk factors of Hepatitis $C$ virus infection in Brazil, 2005 through 2009: a cross-sectional study. BMC Infect Dis. 2013;13:60.

Perniola R, De Rinaldis C, Accogli E, Lobreglio G. Prevalence and clinical features of cryoglobulinaemia in multitransfused betathalassaemia patients. Ann Rheum Dis. 1999;58:698-702.

Perry W, Hilsabeck RC, Hassanein TI. Cognitive dysfunction in chronic hepatitis C: a review. Dig Dis Sci. 2008;53:307-21.

Persico M, De Marino FA, Di Giacomo RG, Persico E, Morante A, Palmentieri B, et al. Prevalence and incidence of cryoglobulins in hepatitis $C$ virus-related chronic hepatitis patients: a prospective study. Am J Gastroenterol. 2003;98(4):884-8.

Peters R, Pinto EM. Predictive value of the Clock Drawing Test. A review of the literature. Dement Geriatr Cogn Disord. 2008;26(4):351-5.

Petta S, Torres D, Fazio G, Cammà C, Cabibi D, Di Marco V, et al. Carotid atherosclerosis and chronic hepatitis $\mathrm{C}$ : a prospective study of risk associations. Hepatology. 2012;55(5):1317-23.

Petty GW, Duffy J, HoustonJ 3rd. Cerebral ischemia in patients with hepatitis C virus infection and mixed cryoglobulinemia. Mayo Clin Proc. 1996;71:671-8.

Pflugrad H, Meyer GJ, Sirks M, Raab P, Tryc AB, Goldbecker A, et al. Cerebral microglia activation in hepatitis $C$ virus infection correlates to cognitive dysfunction. J Viral Hepat. 2016;23:348-57. 
Piñeiro D, Martinez-Salas E. RNA structural elements of hepatitis C virus controlling viral RNA translation and the implications for viral pathogenesis. Viruses. 2012;4:2233-50.

Poynard T, Cacoub P, Ratziu V, Myers RP, Dezailles MH, Mercadier A, et al. Multivirc group. Fatigue in patients with chronic hepatitis $\mathrm{C}$. J Viral Hepat. 2002;9(4):295-303.

Quarantini LC, Miranda-Scippa A, Batista-Neves S, Powell VB, Abreu N, Abreu $\mathrm{KC}$, et al. A neuropsychological study comparing patients infected with $\mathrm{HCV}$ and HBV without psychiatric comorbidities. J Med Virol. 2009;81:1184-8.

Radanovic M, Diniz BS, Mirandez RM, Novaretti TM, Flacks MK, Yassuda MS, et al. Verbal fluency in the detection of mild cognitive impairment and Alzheimer's disease among Brazilian Portuguese speakers: the influence of education. Int Psychogeriatr. 2009;21(6):1081-7.

Radkowski M, Wilkinson J, Nowicki M, Adair D, Vargas H, Ingui C, et al. Search for hepatitis $C$ virus negative-strand RNA sequences and analysis of viral sequences in the central nervous system: evidence of replication. $J$ Virol. 2002;76:600-8.

Ragab G, Hussein MA. Vasculitic syndromes in hepatitis $C$ virus: A review. $J A d v$ Res. 2017; 8(2):99-111.

Raichle ME, MacLeod AM, Snyder AZ, Powers WJ, Gusnard DA, Shulman GL. A default mode of brain function. Proc Natl Acad Sci USA. 2001;98(2)676-82.

Ramos-Casals M, Loustaud-Ratti V, De Vita S; Zeher M; Bosch JA; Toussirot E; et al. Sjögren syndrome associated with hepatitis $C$ virus: a multicenter analysis of 137 cases. Medicine (Baltimore) 2005; 84:81-9.

Ramos-Casals M, Robles A, Brito-Zerón P, Nardi N, Nicolás JM, Forns X, et al. Lifethreatening cryoglobulinaemia: clinical and immunological characterization of 29 cases. Sem Arthritis Rheum. 2006;36:189-96.

Ramos-Casals M, Muñoz S, Medina F, Jara LJ, Rosas J, Calvo-Alen J, et al. Systemic autoimmune diseases in patients with hepatitis $C$ virus infection: characterization of 1020 cases (The HISPAMEC Registry). $J$ Rheumatol. 2009;36(7):1442-8.

Revie D, Salahuddin SZ. Human cell types important for hepatitis C virus replication in vivo and in vitro: old assertions and current evidence. Virol $J$. $2011 ; 8: 346-70$.

Ridola L, Cardinale V, Riggio O. The burden of minimal hepatic encephalopathy: from diagnosis to therapeutic strategies. Ann Gastroenterol. 2018;31(2):151-64.

Ripault MP, Borderie C, Dumas P, Vallat JM, Goujon JM, Brecheteau P, et al. Peripheral neuropathies and chronic hepatitis $\mathrm{C}$ : a frequent association? Gastroeenterol Clin Biol. 1998; 22(11):891-6. 
Roccatello D, Fornasieri A, Giachino O, Rossi D, Beltrame A, Banfi G, et al. Multicenter study on hepatitis $C$ virus-related cryoglobulinemic glomerulonephritis. Am J Kidney Dis. 2007;49:69-82.

Rodger AJ, Jolley D, Thompson SC, Lanigan A, Crofts N. The impact of diagnosis of hepatitis C virus on quality of life. Hepatology. 1999;30:1299-301.

Rosenberg S. Recent advances in the molecular biology of Hepatitis $C$ virus. $J$ Mol Biol. 2001; 313(3):451-64.

Rosenbloom MJ, O'Reilly A, Sassoon SA, Sullivan EV, Pfefferbaum A. Persistent cognitive deficits in community treated alcoholic men and women volunteering for research: limited contribution from psychiatric comorbidity. J Stud Alcohol. 2005;66:254-65.

Rosenthal E, Cacoub P. Extrahepatic manifestations in chronic hepatitis $C$ virus carriers. Lupus. 2015;24:469-82.

Royall DR, Cordes JA, Polk M. CLOX: an executive clock drawing task. J Neurol Neurosurg Psychiatry. 1998;64(5):588-94.

Russi S, Sansonno D, Monaco S, Mariotto S, Ferrari S, Pavone F, et al. Genomic sequences and HCV-E2 glycoprotein in sural nerve biopsies from HCV-infected patients with peripheral neuropathy. Neuropathol Appl Neurobiol. 2018;44(4):427-38.

Ryan EL, Morgello S, Isaacs K, Naseer M, Gerits P. Neuropsychiatric impact of hepatitis C on advanced HIV. Neurology. 2004;62:957-62.

Saadoun D, Terrier B, Semoun O, Sene D, Maisonobe T, Musset L, et al. Hepatitis C virus-associated polyarteritis nodosa. Arthritis Care Res. 2011;63(3):427-35.

Sacconi S, Salviati L, Merelli E. Acute disseminated encephalomyelitis associated with hepatitis C virus infection. Arch Neurol. 2001;58:1679-81.

Sansonno D, Lauletta G, Nisi L, Gatti P, Pesola F, Pansini N, et al. Nonenveloped HCV core protein as constitutive antigen of cold-precipitable immune complexes in type II mixed cryoglobulinaemia. Clin Exp Immunol. 2003;133(2):275-82.

Sansonno D, Dammacco F. Hepatitis C virus, cryoglobulinemia, and vasculitis: immune complex relations. Lancet Infect Dis. 2005;5:227-36.

Sansonno D, Carbone A, De Re V, Dammacco F. Hepatitis C virus infection, cryoglobulinaemia, and beyond. Rheumatology (Oxford). 2007;46:572-8.

Sansonno L, Tucci FA, Sansonno S, Lauletta G, Troiani L, Sansonno D. B cells and HCV: an infection model of autoimmunity. Autoimmun Rev. 2009;9(2):93-4.

Santoro L, Manganelli F, Briani C, Giannini F, Benedetti L, Vitelli E, et al. HCV Peripheral Nerve Study Group. Prevalence and characteristics of peripheral 
neuropathy in hepatitis C virus population. J Neurol Neurosurg Psychiatry. 2006;77(5):626-9.

Sawada T, Horohata S, Inoue T, Ito K. Development of rheumatoid arthritis after hepatitis C virus infection. Arthritis. 1991;34:1620-1.

Schindler BA, Ramchandani D, Matthews MK, Podell K. Competency and the frontal lobe. The impact of executive dysfunction on decisional capacity. Psychosomatics. 1995;36:400-4.

Seaman K, Paterson BL, Vallis M, Hirsch G, Peltekian KM. Future directions for investigation of fatigue in chronic hepatitis C viral infection. Chronic IIIn. 2009 5(2):115-28.

Sène D, Limal N, Ghillani-Dalbin P, Saadoun D, Piette JC, Cacoub P. Hepatitis $C$ virus-associated $B$-cell proliferation-the role of serum $B$ lymphocyte stimulator (BLyS/BAFF). Rheumatology. 2007;46(1):65-9.

Senzolo M, Schiff S, D'Aloiso CM, Crivellin C, Cholongitas E, Burra P, et al. Neuropsychological alterations in hepatitis $C$ infection: the role of inflammation. World J Gastroenterol. 2011;17:3369-74.

Sersté T, Nkuize M, Moucari R, Van Gossum M, Reynders M, Scheen R, et al. Metabolic disorders associated with chronic hepatitis $\mathrm{C}$ : impact of genotype and ethnicity. Liver Int. 2010;30: 1131-6.

Sestiere C, Corbetta M, Romani GL, Shulman GL. Episodic memory retrieval, parietal cortex, and the default mode network: functional and topographic analyses. J Neurosci. 2011; 23;31(12):4407-20.

Shepard CW, Finelli L, Alter MJ. Global epidemiology of hepatitis C virus infection. Lancet Infect Dis. 2005;5:558-67.

Shulman KI, Gold DP, Cohen CA, Zucchero CA. Clock-drawing and dementia in the community: A longitudinal study. Intern J Geriatr Psychiatry. 1993;8:487-96.

Shulman KI. Clock-drawing: is it the ideal cognitive screening test? Int J Geriatr Psychiatry. 2000;15(6):548-61.

Siagris D, Christofidou M, Tsamandas A, Lekkou A, Thomopoulos K, Labropoulou-Karatza C. Cryoglobulinemia and progression of fibrosis in chronic HCV infection: cause or effect? J Infect. 2004;49(3):236-41.

Simmonds P, Holmes EC, Cha TA, Chan SW, McOmish, Irvine B, et al. Classification of hepatitis $\mathrm{C}$ virus into six major genotypes and a series of subtypes by phylogenetic analysis of the NS-5 region. J Gen Virol. 1993; 74(Pt 11):2391-9.

Simmonds P. Genetic diversity and evolution of hepatitis $C$ virus -15 years on. $J$ Gen Virol. 2004; 85(Pt 11):3173-88. 
Snyder HR. Major depressive disorder is associated with broad impairments on neuropsychological measures of executive function: A meta-analysis and review. Psychol Bull. 2012;28:1-52.

Soogoor M, Lynn HS, Donfield SM, Gomperts E, Bell TS, Daar ES. Hemophilia Growth and Development Study. Hepatitis $C$ virus infection and neurocognitive function. Neurology. 2006;67:1482-5.

Spiegel BMR, Younossi ZM, Hays RD, Revicki D, Robbins S, Kanwal F. Impact of hepatitis $\mathrm{C}$ on health related quality of life: a systematic review and quantitative assessment. Hepatology. 2005;41:790-800.

Sridharan D, Levitin DJ, e Menon V. A critical role for the right fronto-insular cortex in switching between central-executive and default-mode networks. Proc Natl Acad Sci USA. 2008; 26;105(34):12569-74.

Stefanova-Petrova DV, Tzvetanska AH, Naumova EJ, Mihailova AP, Hadjiev EA, Dikova RP, et al. Chronic hepatitis $C$ virus infection: prevalence of extrahepatic manifestations and association with cryoglobulinemia in Bulgarian patients. World J Gastroenterol. 2007;13(48):6518-28.

Stinton LM, Jayakumar S. Minimal hepatic encephalopathy. Can J Gastroenterol. 2013;27:572-4.

Stübgen JP. Immune-mediated myelitis associated with hepatitis virus infection. J Neuroimmunol. 2011;239:21-7.

Sunderland T, Hill JL, Lellow AM, Lawlor BA, Gundersheimer J, Newhouse PA, et al. Clock drawing in Alzheimer's disease. A novel measure of dementia severity. J Am Geritr Soc. 1989;37(8):725-9.

Sureka B, Bansal K, Patidar Y, Rajesh S, Mukund A, Arora A. Neurologic Manifestations of Chronic Liver Disease and Liver Cirrhosis. Curr Probl Diagn Radiol. 2015;44(5):449-61.

Taieb G, Maisonobe T, Musset L, Cacoub P, Léger JM, Bouche P. Cryoglobulinemic peripheral neuropathy in hepatitis $C$ virus infection: clinical and anatomical correlations of 22 cases. Rev Neurol. (Paris). 2010;166(5):509-14.

Téllez-Zenteno JF, Calva-Mercado J, Weder-Cisneros N, Estanõl B, Montes J, Rosales $\mathrm{M}$, et al. Prevalence and risk factors associated with the presence of peripheral neuropathy in patients with hepatitis $C$ virus infection [abstract]. J Clin Neuromuscul Dis. 2003;4(3):109-14.

Tembl JI, Ferrer JM, Sevilla MT, Lago A, Mayordomo F, Vilchez JJ. Neurologic complications associated with hepatitis $\mathrm{C}$ virus infection. Neurology. 1999;11;53(4):861-4.

Terrier B, Saadoun D, Sène D, Scerra S, Musset L, Cacoub P. Presentation and outcome of gastrointestinal involvement in hepatitis $C$ virus-related systemic 
vasculitis: a case-control study from a single-centre cohort of 163 patients. Gut. 2010;59:1709-15.

Thein HH, Maruff P, Krahn MD, Kaldor JM, Koorey DJ, Brew BJ, et al. Improved cognitive function as a consequence of hepatitis $\mathrm{C}$ virus treatment. HIV Med. 2007;8:520-8.

Tohme RA, Holmberg SD. Is sexual contact a major mode of hepatitis $\mathrm{C}$ virus transmission? Hepatology. 2010;52(4):1497-505.

Tombaugh TN, Mclntyre NT. The Mini-Mental State Examination: a comprehensive review. J Am Geriatr Soc. 1992;40:922-35.

Uddin LQ, Supekar KS, Ryali S, Menon V. Dynamic reconfiguration of structural and functional connectivity across core neurocognitive brain networks with development. J. Neurosci. 2011;31:18578-89.

Uhlmann RF, Larson EB. Effect of education on the Mini-Mental State Examination as a screening test for dementia. J Am Geriatr Soc. 1991;39:87680.

Universidade de Pernambuco, Núcleo de Pós-Graduação. Estudo de Prevalência de Base Populacional das Infecções Pelos Vírus das Hepatite s A, B e C nas Capitais do Brasil; 2010.

Vallat JM, Desproges-Gotteron R, Leboutet MJ, Loubet A, Gualde N, Treves R. Cryoglobulinemic neuropathy: a pathological study. Ann Neurol. 1980;8(2):179_ 85.

van den Heuvel MP, Hulshoff Pol HE. Exploring the brain network: A review on resting-state $\mathrm{fMRI}$ functional connectivity. Eur Neuropsychopharmacol. 2010;20(8):519-34.

Venneti S, Lopresti BJ, Wiley CA. Molecular imaging of microglia/ macrophages in the brain. Glia. 2013;61(1):10-23.

Vermeersch P, Gijbels K, Mariën G, Lunn R, Egner W, White P, Bossuyt V. A critical appraisal of current practice in the detection, analysis, and reporting of cryoglobulins. Clin Chem. 2008;54(1):39-43.

Vigani AG, Macedo-de-Oliveira A, Pavan MH, Pedro MN, Gonçales Jr FL. Hepatitis $C$ virus infection, cryoglobulinemia, and peripheral neuropathy: a case report. Braz J Med Biol Res. 2005;38(12):1729-34.

Visser NA, Notermans NC, Linssen RS, van den Berg LH, Vrancken AF. Incidence of polyneuropathy in Utrecht, the Netherlands. Neurology. 2015;84:259-64.

Voma CB, Levinson SS. Analysis detection and quantitation of mixed cryoglobulins in HCV infection: brief review and case examples. Clin Chem Lab Med. 2016;54(12):1853-9. 
von Giesen HJ, Heintges T, Abbasi-Boroudjeni N, Kucukkoylu S, Koller H, Haslinger BA, et al. Psychomotor slowing in hepatitis $\mathrm{C}$ and HIV infection. $J$ Acquir Immune Defic Syndr. 2004; 35:131-137.

Weinman SA, Belalcazar LM. Hepatitis C: a metabolic liver disease. Gastroenterology. 2004;126(3):917-919.

Weissenborn K, Heidenreich S, Giewekemeyer K, Ruckert N, Hecker H. Memory function in early hepatic encephalopathy. J Hepatol. 2003;39:320-5.

Weissenborn K, Krause J, Bokemeyer M, Hecker H, Schuler A, Ennen JC, et al. Hepatitis $C$ virus infection affects the brain - evidence from psychometric studies and magnetic resonance spectroscopy. J Hepatol. 2004;41(5):845-51.

Weissenborn K, Ennen JC, Bockmeyer M, Ahl B, Wurter U, Tillmann H, et al. Monoaminergic neurotransmission is altered in hepatitis $C$ virus infected patients with chronic fatigue and cognitive impairment. Gut. 2006;55:1624-30.

Weissenborn K, Tryc AB, Heeren M, Worthmann H, Pflugrad H, Berding G, et al. Hepatitis C virus infection and the brain. Metab Brain Dis. 2009;24:197-210.

Wessely S, Pariante C. Fatigue, depression and chronic hepatitis C infection. Psychol Med. 2002;32:1-10.

White DL, Ratziu V, El-Serag HB. Hepatitis C infection and risk of diabetes: a systematic review and meta-analysis. J Hepatol. 2008;49:831-44.

Wilkinson J, Radkowski M, Eschbacher JE, Laskus T. Activation of brain macrophages/microglia cells in hepatitis C patients. Gut. 2010; 59(10);1394-400.

Williams MJ, Lawson A, Neal KR, Ryder SD, Irving WL; Trent HCV Group. Autoantibodies in chronic hepatitis $\mathrm{C}$ virus infection and their association with disease profile. J Viral Hepat. 2009;16(5):325-31.

Wong VS, Egner W, Elsey T, Brown D, Alexander GJM. Incidence, character and clinical relevance of mixed cryoglobulinaemia in patients with chronic hepatitis $C$ virus infection. Clin Exper Immunol. 1996;104:25-31.

Wu YY, Hsu TC, Chen TY, Liu TC, Liu GY, Lee YJ, et al. Proteínase 3 and dihydrolipoamide dehydrogenase (E3) are major autoantigens in hepatitis $C$ virus (HCV) infection. Clin Exp Immunol. 2002;128:347-52.

Yang W, Qiu C, Biswas N, Jin J, Watkins SC, Montelaro RC, et al. Correlation of the tight junction-like distribution of Claudin-1 to the cellular tropism of hepatitis C virus. J Biol Chem. 2008;283:8643-53.

Yang L, Yan J, Jin X, Jin Y, Yu W, Xu S, et al. Screening for Dementia in Older Adults: Comparison of Mini-Mental State Examination, Mini-Cog, Clock Drawing Test and AD8. PLoS One. 2016;11(12):1-5.

Yarlott L, Heald E, Forton D. Hepatitis C virus infection, and neurological and psychiatric disorders - A review. J Adv Res. 2017;8(2):139-148. 
Yoon MS, Obermann M, Dockweiler C, Assert R, Canbay A, Haag S, et al. Sensory neuropathy in patients with cryoglobulin negative hepatitis- $C$ infection. $J$ Neurol. 2011; 258: 80-8.

Younossi Z, Park H, Henry L, Adeyemy A, Stepanova M. Extra-hepatic manifestations of hepatitis $\mathrm{C}-\mathrm{a}$ meta-analysis of prevalence, quality of life, and economic burden. Gastroenterology. 2016;150(7):1599-608.

Yuki N, Yoshioka A, Yasuda R, Ohmichi T, Oka N. Hepatitis C virusassociated neuropathy accompanied by eosinophilic vasculitis and granuloma formation. Intern Med. 2014;53(11):1187-90.

Zaltron S, Puoti M, Liberini P, Antonini L, Quinzanini M, Manni M, et al. High prevalence of peripheral neuropathy in hepatitis $C$ virus infected patients with symptomatic and asymptomatic cryoglobulinaemia [abstract]. Ital $J$ Gastroenterol. 1998;30(4):391-5.

Zampino R, Marrone A, Restivo L, Guerrera B, Sellitto A, Rinaldi L, et al. Chronic $\mathrm{HCV}$ infection and inflammation: Clinical impact on hepatic and extra-hepatic manifestations. World J Hepatol. 2013; 5:528-40.

Zandman-Goddard G, Levy Y, Weiss P, Shoenfeld Y, Langevitz P. Transverse myelitis associated with chronic hepatitis C. Clin Exp Rheumatol. 2003;21:1113.

Zein NN. Clinical significance of hepatitis C virus genotypes. Clin Microbiol Rev. 2000; 13(2):223-35.

Zein NN, Abdulkarim AS, Wiesner RH, Egan KS, Persing DH. Prevalence of diabetes mellitus in patients with end-stage liver cirrhosis due to hepatitis $\mathrm{C}$, alcohol, or cholestatic disease. J Hepatol. 2000;32(2):209-17.

Zignego AL, Ferri C, Pileri SA, Caini P, Bianchi FB. Extrahepatic manifestations of Hepatitis C Virus infection: a general overview and guidelines for a clinical approach. Dig Liver Dis. 2007;39:2-17.

Zignego AL, Craxì A. Extrahepatic manifestations of hepatitis $\mathrm{C}$ virus infection. Clin Liver Dis. 2008;12:611-36.

Zignego AL, Wojcik GL, Cacoub P, Visentini M, Casato M, Mangia A, et al. Genome-wide association study of hepatitis $C$ virus- and cryoglobulin-related vasculitis. Genes Immun. 2014; 15:500-5. 